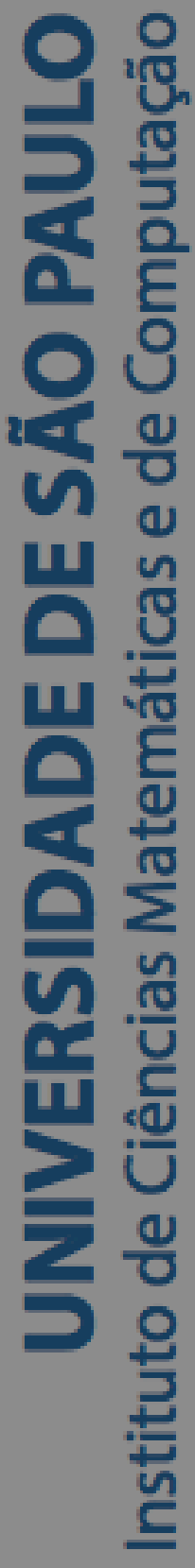

Uma contribuição à automatização da atividade de teste para sistemas de realidade virtual

\title{
Alinne Cristinne Corrêa Souza
}

Tese de Doutorado do Programa de Pós-Graduação em Ciências de Computação e Matemática Computacional (PPG-CCMC) 

Data de Depósito:

Assinatura:

\section{Alinne Cristinne Corrêa Souza}

\section{Uma contribuição à automatização da atividade de teste para sistemas de realidade virtual}

Tese apresentada ao Instituto de Ciências Matemáticas e de Computação - ICMC-USP, como parte dos requisitos para obtenção do título de Doutora em Ciências - Ciências de Computação e Matemática Computacional. VERSÃO REVISADA

Área de Concentração: Ciências de Computação e Matemática Computacional

Orientador: Prof. Dr. Marcio Eduardo Delamaro Coorientadora: Profa. Dra. Fátima de Lourdes dos Santos Nunes Marques 
Ficha catalográfica elaborada pela Biblioteca Prof. Achille Bassi e Seção Técnica de Informática, ICMC/USP, com os dados fornecidos pelo(a) autor(a)

Souza, Alinne Cristinne Corrêa
Uma contribuição à automatização da atividade
de teste para sistemas de realidade virtual /
Alinne Cristinne Corrêa Souza; orientador Marcio
Eduardo Delamaro; coorientadora Fátima de Lourdes dos
Santos Nunes Marques. - São Carlos - SP, 2017.
182 p.
Tese (Doutorado - Programa de Pós-Graduação em
Ciências de Computação e Matemática Computacional)
- Instituto de Ciências Matemáticas e de Computação,
Universidade de São Paulo, 2017.
1. Teste de Software. 2. Critérios de Teste.
3. Engenharia de Requisitos. 4. Realidade Virtual.
5. Grafo de Cena. I. Delamaro, Marcio Eduardo,
orient. II. Marques, Fátima de Lourdes dos Santos
Nunes, coorient. III. Título.




\section{Alinne Cristinne Corrêa Souza}

\section{A contribution to the automation of test activity for virtual reality systems}

Doctoral dissertation submitted to the Instituto de Ciências Matemáticas e de Computação - ICMCUSP, in partial fulfillment of the requirements for the degree of the Doctorate Program in Computer Science and Computational Mathematics. FINAL VERSION

Concentration Area: Computer Science and Computational Mathematics

Advisor: Prof. Dr. Marcio Eduardo Delamaro

Co-advisor: Profa. Dra. Fátima de Lourdes dos Santos Nunes Marques 

Dedico este trabalho a todos que contribuíram direta ou indiretamente para o seu desenvolvimento, pois sem o incentivo e o apoio não seria possível a concretização do mesmo. 

Agradeço a Deus, primeiramente, pois sem sua orientação nada seria possível. Por conceder-me sabedoria e força para nunca desistir dos meus ideais e por ter me guiado para aprender com cada dificuldade enfrentada, pois tudo o que eu sou e tudo o que eu tenho é graças a Ele.

Ao meu grande amigo, eterno namorado, noivo e futuro esposo, pelo seu apoio, incentivo, ideias, por sempre ter estado ao meu lado e com o ar da sua graça ter tornado cada momento difícil em dias melhores. "Filho", sem você este trabalho não teria sido concretizado, obrigada por todo o seu amor, dedicação, paciência e carinho $\varnothing$.

Aos meus queridos pais Jorge e Eliane, por sempre acreditarem em mim, por nunca terem medido esforços para me ajudar e que mesmo longe sempre estiveram ao meu lado concedendo amor e carinho. A vocês meu amor e minha gratidão serão eternos. Aos meus familiares, em especial minha irmã e minha avó, pelas palavras de incentivo, apoio e torcida.

Ao meu orientador, Prof. Dr. Márcio Eduardo Delamaro, pela sua dedicação, postura e ética no desenvolvimento desse trabalho. Obrigada também pela a amizade construída ao longo desses cinco anos, bem como todos os ensinamentos os quais foram fundamentais para o meu crescimento profissional e pessoal. A minha coorientadora Prof ${ }^{\mathrm{a}}$. Dra. Fátima Lourdes pela sua orientação, apoio, incentivo e pela compreensão em todos os momentos de dificuldades. Obrigada por tudo, a sua contribuição foi fundamental para a conclusão deste trabalho.

À todos os amigos que tive o privilégio de conhecer, conviver e compartilhar grandes momentos em São Carlos. Aos amigos do LabES por tornarem os cafés de todas as tardes mais saborosos e por tantas risadas compartilhadas. Aos amigos dos demais laboratórios, pelas conversas, pelo apoio e pela companhia durante essa caminhada. Aos professores do LabES pela amizade, pelos ensinamentos e pelas colaborações durante todos esses anos. Vocês foram muito mais que mestres e sim grandes amigos. Aos alunos do LApIS, em especial ao Rafael Torres, pelo apoio durante a realização do estudo de caso.

Aos funcionários da pós-graduação, em especial à Carol Murata e ao Leo Miyake, pela atenção, disposição e por nunca terem medido esforços no esclarecimento de dúvidas e por terem ajudado nos momentos de dificuldades.

À Fundação de Amparo à Pesquisa do Estado de São Paulo (FAPESP) (processo N. 2012/05168-4 e processo N. 2013/14682-6) por apoiar financeiramente este projeto de doutorado no Brasil e pelo financiamento do estágio no exterior, respectivamente. 

"A vida é uma peça de teatro que não permite ensaios. Por isso, cante, chore, dance, ria e viva intensamente, antes que a cortina se feche e a peça termine sem aplausos."

(Charles Chaplin) 



\section{RESUMO}

SOUZA, A. C. C. Uma contribuição à automatização da atividade de teste para sistemas de realidade virtual. 2017. 182 p. Tese (Doutorado em Ciências - Ciências de Computação e Matemática Computacional) - Instituto de Ciências Matemáticas e de Computação, Universidade de São Paulo, São Carlos - SP, 2017.

O teste de software é considerado uma atividade importante para a revelação de falhas. Apesar desta vantagem, tem sido pouco explorado no âmbito de aplicações de Realidade Virtual (RV). Dentre as lacunas existentes, a definição e automatização de critérios de teste de software para esse domínio foi identificada, uma vez que esses sistemas possuem características próprias que requerem definição ou adaptação de técnicas de teste, fazendo com que aplicações nesse domínio constituam sistemas de alta complexidade. Diante disso, o objetivo desta tese é apresentar uma abordagem denominada Virtual Reality-Requirements Specification and Testing (VR-ReST) que visa apoiar a especificação de requisitos de aplicações de RV com base na descrição de casos de uso e conceitos do domínio de RV e Grafo de Cena (GC), derivar requisitos de teste e gerar dados de teste a partir dos requisitos especificados. Além disso, é apresentado um apoio ferramental chamado de Virtual Requirements Specification and Testing (ViReST), que permite automatizá-las. A abordagem é composta por três módulos: (i) especificação dos requisitos por meio do auxílio de um modelo denominado Virtual Requirements Specification (ViReS); (ii) mapeamento dos requisitos por meio de uma linguagem semi-formal chamada Behavior Language Requirement Specification (BeLaRS) para garantir uma especificação padronizada; e (iii) geração automática dos requisitos de teste e dos dados de teste. Foi realizado um estudo de caso para avaliar a conformidade e a usabilidade da BeLaRS em auxiliar a especificação de requisitos de uma aplicação de RV. Além disso, também foi realizado um experimento para avaliar a eficácia da abordagem VR-ReST por meio da ferramenta ViReST. Usando teste de mutação neste último experimento, a abordagem VR-ReST alcançou um escore de mutação médio de 15,49\% maior que o teste aleatório. Portanto, os resultados mostraram que a abordagem, bem como o apoio ferramental, podem auxiliar o projetista durante a atividade de especificação de requisitos e o testador na geração dos testes para aplicações de RV.

Palavras-chave: Teste de Software, Critérios de Teste, Engenharia de Requisitos, Realidade Virtual, Grafo de Cena. 



\section{ABSTRACT}

SOUZA, A. C. C. A contribution to the automation of test activity for virtual reality systems. 2017. 182 p. Tese (Doutorado em Ciências - Ciências de Computação eMatemática Computacional) - Instituto de Ciências Matemáticas e de Computação, Universidade de São Paulo, São Carlos - SP, 2017.

Software testing is considered an important activity towards fault revealing. Despite this advantage, it has been few explored within the scope of Virtual Reality (VR) applications. Among the existing gaps, the definition and automation of software testing criteria for this domain were identified, since these systems have their own characteristics that require definition or adaptation of testing techniques, making applications in this domain constitute highly complex systems. Therefore, a Virtual Reality-Requirements Specification and Testing (VR-ReST) approach is presented to perform the functional test of VR applications using Scene Graph (SG) concepts and a support tool called Virtual Requirements Specification And Testing (ViReST), which allows you to automate them. The approach is composed of three modules: ( $i$ ) the first consists in specifying the requirements by means of a model called Virtual Requirements Specification (ViReS); (ii) the second involves mapping the requirements through a semi-formal language called Behavior Language Requirement Specification (BeLaRS) to ensure a standardized specification; and (iii) the third is the automatic generation of test requirements and test data. A case study was conducted to evaluate the compliance and usability of BeLaRS in assisting the requirements specification of an RV application. Also, an experiment was also carried out to evaluate the effectiveness of the VR-ReST approach using the ViReST tool. Using mutation testing in this latter experiment, the VR-ResT approach achieved a mean mutation score of $15.49 \%$ higher than the random testing. Therefore, the results showed that the approach, as well as tooling support, can assist the designer during the requirement specification activity and the tester in generating the tests for RV applications.

Keywords: Software Testing, Test Criteria, Requirement Engineering, Virtual Reality, Scene Graph. 



\section{LISTA DE ILUSTRAÇÕES}

Figura 1 - Visão geral do processo metodológico . . . . . . . . . . . . . 36

Figura 2 - Processo de ER utilizado para a especificação de requisitos . . . . . . . . 43

Figura 3 - Processo de condução do teste em um programa durante o desenvolvimento de software . . . . . . . . . . . . . . . . . . . 4 47

Figura 4 - Exemplo de um programa sem defeitos (programas original) e um com defeitos (mutante) . . . . . . . . . . . . . . . . 51

Figura 5 - Exemplo de mutante equivalente em relação ao programa original . . . . . . 51

Figura 6 - Exemplo de um ambiente de RV não imersivo e imersivo . . . . . . . . . . 54

Figura 7 - Etapas de renderização de um objeto 3D . . . . . . . . . . . . . 56

Figura 8 - Exemplo da renderização de um objeto 3D . . . . . . . . . . . 58

Figura 9 - Strings de busca definidas . . . . . . . . . . . . . 65

Figura 10 - Criação das categorias . . . . . . . . . . . . . . . . . . 66

Figura 11 - Processo de seleção dos estudos primários das questões $\mathrm{QP}_{1}, \mathrm{QP}_{2}$ e $\mathrm{QP}_{3} \ldots 67$

Figura 12 - Visão geral dos estudos primários categorizados por ano . . . . . . . . . . 68

Figura 13 - Visão geral dos estudos primários categorizados por QP . . . . . . . . . . . 69

Figura 14 - Processo da abordagem VR-ReST . . . . . . . . . . . . . . . . . 80

Figura 15 - Processo do modelo ViReS . . . . . . . . . . . . . . . . . . . 81

Figura 16 - Fases da linguagem BeLaRS . . . . . . . . . . . . . . . . 85

Figura 17 - BeLaRS - uma gramática para especificação de requisitos . . . . . . . . . 88

Figura 18 - Exemplo de uma especificação de requisitos usando a BeLaRS . . . . . . . 89

Figura 19 - Exemplo da geração do GFR a partir da especificação de requisitos . . . . . 92

Figura 20 - Exemplo de requisitos de teste e dados de teste gerados a partir dos GFR . . 93

Figura 21 - Exemplo de uma especificação de requisitos usando a ferramenta ViReST . . 94

Figura 22 - Exemplo de execução dos testes usando a ferramenta ViReST . . . . . . . . 96

Figura 23 - Exemplo de requisitos de teste e dados de teste gerados usando a abordagem VR-ReST . . . . . . . . . . . . . . . . . . 108

Figura 24 - Exemplo da execução de $T_{1}$ para o programa Alternate Appearance usando a ferramenta Sikuli . . . . . . . . . . . . . . . . . . . 110

Figura 25 - Exemplo de uma especificação de requisitos usando a BeLaRS . . . . . . . 112

Figura 26 - Resultados referentes à simplicidade, ortogonalidade e escalabilidade da BeLaRS . . . . . . . . . . . . . . . . . . 113

Figura 27 - Resultados referentes à aceitação e ao uso da BeLaRS . . . . . . . . . . . 114

Figura 28 - Tempo gasto pelos alunos para esecificar os requisitos usando a BeLaRS . . 116 
Figura 29 - Definição e interação de objetos do mesmo tipo . . . . . . . . . . . . . . 117

Figura 30 - Exemplo de um comportamento correto no programa original (a) e de uma falha detectada no programa mutado (b) . . . . . . . . . . . . . . 119

Figura 31 - Comparação entre as especificações dos requisitos . . . . . . . . . . . . . . 121

Figura 32 - Comparação entre as especificações dos requisitos . . . . . . . . . . . . . . 122

Figura 33 - Comparação do número de dados de teste gerados entre a abordagem VRReST e o teste aleatório . . . . . . . . . . . . . . . . . 125

Figura 34 - Comparação do escore de mutação obtido pela ferramenta ViReST e Teste Aleatório . . . . . . . . . . . . . . . . . . 126

Figura 35 - Fases do MS . . . . . . . . . . . . . . . . . . 155

Figura 36 - Strings de busca definidas . . . . . . . . . . . . . . 158

Figura 37 - Criação das categorias . . . . . . . . . . . . . . . . . . . . 161

Figura 38 - Processo de seleção dos estudos primários da $\mathrm{QP}_{1} \ldots \ldots$. . . . . . . . 163

Figura 39 - Processo de seleção dos estudos primários da $\mathrm{QP}_{2}$. . . . . . . . . . . . 164

Figura 40 - Processo de seleção dos estudos da questão $\mathrm{QP}_{3}$. . . . . . . . . . . . . 165

Figura 41 - Estudos incluídos por base utilizando busca automática . . . . . . . . . . 167

Figura 42 - Relação entre as áreas de ES e RV . . . . . . . . . . . . . . . 168

Figura 43 - Tipos de publicação de acordo com cada QP . . . . . . . . . . . . . 168

Figura 44 - Estudos primários publicados por ano de acordo com as QPs . . . . . . . . 169

Figura 45 - Estudos primários por país de acordo com as QPs . . . . . . . . . . . . . . 169 
Quadro 1 - Cenário para especificar os requisitos utilizando a linguagem BeLaRS . . 103

Quadro 2 - Lista de Controle . . . . . . . . . . . . . . . . 159 



\section{LISTA DE ALGORITMOS}

Algoritmo 1 - Algoritmo para Geração de Dados de Teste (GDT) . . . . . . . . . . . 92 

Tabela 1 - Fontes de busca automática . . . . . . . . . . . . . . . . . 65

Tabela 2 - Técnicas de ER utilizadas em sistemas de RV e tecnologias de RV utilizadas na área de $\mathrm{ER}\left(\mathrm{QP}_{1}\right) \ldots \ldots \ldots$. . . . . . . . . . . . . . . . . . 69

Tabela 3 - Utilização do projeto de software em sistemas de RV e aplicabilidade de tecnologias de $\mathrm{RV}$ na área de projeto de software $\left(\mathrm{QP}_{2}\right) \ldots \ldots . \ldots 72$

Tabela 4 - Tipos de teste de software utilizados em sistemas de RV e a utilização tecnologias de $\mathrm{RV}$ na atividade de teste de software $\left(\mathrm{QP}_{3}\right) \ldots \ldots$. . . . . 74

Tabela 5 - Fases e atividades do modelo ViReS com base em diferentes métodos e conceitos .......................... 84

Tabela 6 - Entradas e Palavras-chaves da BeLaRS . . . . . . . . . . . . . . . 87

Tabela 7 - Trs específicas . . . . . . . . . . . . . . . . 90

Tabela 8 - Regras e exemplos para explicar o significado de cada $\operatorname{Tr}$. . . . . . . . . . 91

Tabela 9 - Conformidade: Questões de Pesquisa e suas respectivas hipóteses . . . . . . 101

Tabela 10 - Aceitação e Uso: Questões de Pesquisa e suas respectivas hipóteses . . . . . 102

Tabela 11 - Escala Likert usada para avaliar a linguagem BeLaRS . . . . . . . . . . . . 104

Tabela 12 - Definições de teste de mutação adaptadas para RV . . . . . . . . . . . . . . 105

Tabela 13 - Sujeitos do experimento . . . . . . . . . . . . . . . . . . . . . . . 108

Tabela 14 - Operadores de mutação oferecidos pela ferramenta MuJava . . . . . . . . . 109

Tabela 15 - Exemplo de um conjunto de dados de teste gerados usando a função aleatória 111

Tabela 16 - Resultados da eficácia da abordagem VR-ReST . . . . . . . . . . . . 118

Tabela 17 - Relação entre a qualidade dos requisitos especificados e a qualidade dos dados de testes gerados pela abordagem VR-ReST . . . . . . . . . . . . 120

Tabela 18 - Relação entre a qualidade dos requisitos especificados e a qualidade dos dados de testes gerados a partir das especificações modificadas . . . . . . . 121

Tabela 19 - Estatística descritiva sumarizando o EM alcançado por cada programa de RV a partir da especificação $(\mathrm{O})$ e especificação $(\mathrm{M})$. . . . . . . . . . . . . . . 122

Tabela 20 - Comparação entre o EM obtido pela abordagem VR-ReST e pelo teste aleatório com o mesmo tamanho do conjunto de dados de teste . . . . . . . 124

Tabela 21 - Fontes de busca automática . . . . . . . . . . . . . . . . . . 158

Tabela 22 - Fontes de busca manual . . . . . . . . . . . . . . . . . . . . . . 159

Tabela 23 - Critérios de qualidade . . . . . . . . . . . . . . . . . . . . 160

Tabela 24 - Anos consultados nas fontes de busca manual . . . . . . . . . . . . . . . 162

Tabela 25 - Visão geral dos estudos incluídos de acordo com as suas respectivas categorias 166 



\section{LISTA DE ABREVIATURAS E SIGLAS}

$3 \mathrm{D}$

tridimensionais

ANTLR Another Tool for Language Recognition

API Application Programming Interface

BeLaRS Behavior Language Requirements Specification

CIM Computer Integrated Manufacturing

CNL Control Natural Language

CRTC Complete Round Trip Coverage

DFS Depth-First Search

DSL Domain Language Specific

EC Edge Coverage

EPC Edge-Pair Coverage

FAB ATM First Australian Bank Automatic Teller Machines

GQM Goal/Question/Metric

GUI Graphical User Interface

HMD Head-Mounted Display

IND Interaction Description

MGUT $\quad$ Modified Group Usability Testing

MOs $\quad$ Mutation Operators

MS Mutation Score

NC Node Coverage

OpenGL Open Graphics Library

PDF Portable Document Format

POS Parts Of Speech

PPC Prime Path Coverage

PUT Program Under Test

RUP Rational Unified Process

SM Systematic Mapping Study

SRTC Simple Round Trip Coverage

TAM Technology Acceptance Model

Trs Thematic roles

UCs Use Cases 


$\begin{array}{ll}\text { UML } & \text { Unified Modeling Language } \\ \text { VED } & \text { Virtual Environment Description } \\ \text { ViMeT } & \text { Virtual Medical Training } \\ \text { ViReS } & \text { Virtual Requirement Specification } \\ \text { VIRSEE } & \text { Virtual Software Engineering Environment } \\ \text { VRID } & \text { Virtual Reality Interface Design } \\ \text { VS } & \text { Virtual Scrum } \\ \text { XP } & \text { Extreme Programming } \\ \text { AV } & \text { Ambiente Virtual } \\ \text { AVs } & \text { Ambientes Virtuais } \\ \text { CE } & \text { Critérios de Exclusão } \\ \text { CF } & \text { Case Frame } \\ \text { CI } & \text { Critérios de Inclusão } \\ \text { CLEVR } & \text { Concurrent and Level by Level Development of VR Systems }\end{array}$

EACH-USP Escola de Artes, Ciências e Humanidades da Universidade de São Paulo

EM Escore de Mutação

ER Engenharia de Requisitos

ES Engenharia de Software

ESm Engenharia Semiótica

FH Fatores Humanos

GC Grafo de Cena

GFC Grafo de Fluxo de Controle

GFR Grafo de Fluxo de Requisitos

GP Grafo de Programa

ICMC Instituto de Ciências Matemáticas e de Computação

IMSOVISION IMmersive SOftware VISualizatION

ISRE Immersive Scenario-based Requirements Engineering

LabES Laboratório de Engenharia de Software

LApIS Laboratório de Aplicações de Informática em Saúde

LDE Linguagem de Domínio Específico

LIGHTVIEWS Visual Interactive Environments for Learning OO Testing

LNC Linguagem Natural Controlada

MS Mapeamento Sistemático

OO Orientados a Objetos

PICO Population, Intervention, Comparison e Outcomes

QPs Questões de Pesquisa

RS Revisão Sistemática 
RT Requisito de Teste

RTs Requisitos de Teste

RV Realidade Virtual

SAVAnT $\quad$ Software Attribute Visual Analysis Tool

SnT Interdisciplinary Centre for Security, Reliability and Trust

TA Teste Aleatório

TREG The Training in Requirements Engineering Game

ViReST Virtual Requirements Specification and Testing

VR-RA Virtual-Reality based information Requirement Analysis

VR-ReST Virtual Reality-Requirements Specification and Testing (VR-ReST)

VTSS VR-based test and simulation system

VV\& T Verificação, Validação e Teste 

INTRODUÇÃO $\ldots \ldots \ldots \ldots \ldots \ldots \ldots \ldots \ldots$

FUNDAMENTOS DE ENGENHARIA DE REQUISITOS E TESTE DE SOFTWARE

2.3.1 Terminologia e Conceitos Básicos . . . . . . . . . . . . . 46

2.3.2 Técnicas e Critérios de Teste . . . . . . . . . . . . . . . . 47

2.3.2.1 Técnica Funcional . . . . . . . . . . . . . . . . . . . . 48

2.3.2.2 Técnica Estrutural . . . . . . . . . . . . . . . . . . . . . . . 48

2.3.2.3 Técnica baseada em Defeitos . . . . . . . . . . . . . . . . . . 50

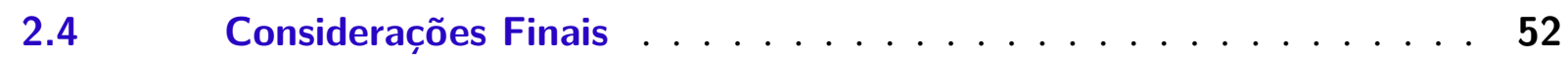

3 FUNDAMENTOS DE REALIDADE VIRTUAL . . . . . . . 53

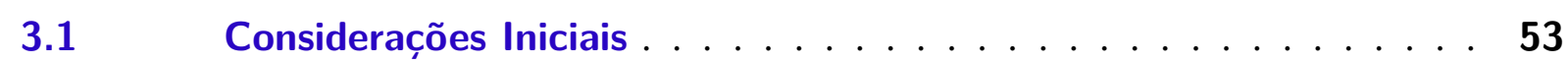

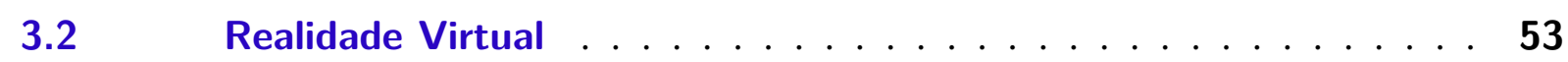

$3.3 \quad$ Bibliotecas Gráficas . . . . . . . . . . . . . . . . 56

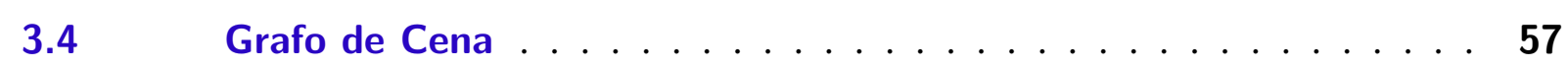

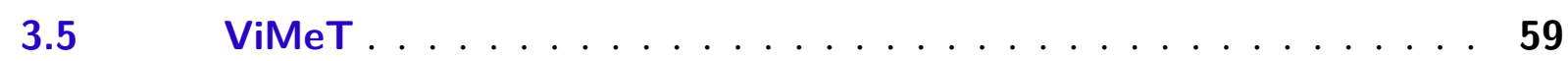

3.6 Engenharia de Requisitos para sistemas de Realidade Virtual . . . 60

$3.7 \quad$ Considerações Finais $\ldots \ldots \ldots \ldots \ldots \ldots$

4 MAPEAMENTO SISTEMÁTICO SOBRE A RELAÇÃO ENTRE ES

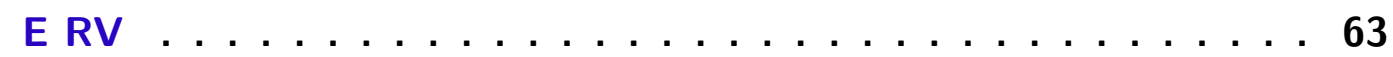

$4.1 \quad$ Considerações Iniciais . . . . . . . . . . . . 63

$4.2 \quad$ Planejamento do Mapeamento Sistemático . . . . . . . . . . 64 
4.2.1 Estratégia de Busca . . . . . . . . . . . . . . . . . . . 64

4.2.2 Critérios para Seleção dos Estudos . . . . . . . . . . . . . . 65

4.2.3 Extração dos Dados . . . . . . . . . . . . . . . . . . . 66

4.3 Condução do Mapeamento Sistemático . . . . . . . . . . . . 67

$4.4 \quad$ Síntese e Análise dos Dados . . . . . . . . . . . . . . . . . 68

$4.5 \quad$ Ameaças à Validade . . . . . . . . . . . . . . . . . . 77

$4.6 \quad$ Considerações Finais $\ldots \ldots \ldots \ldots \ldots$

5 VR-REST: UMA ABORDAGEM PARA ESPECIFICAÇÃO DE REQUISITOS E TESTE FUNCIONAL DE APLICAÇÕES DE RV . . 79

$5.1 \quad$ Considerações Iniciais . . . . . . . . . . . . . . . 79

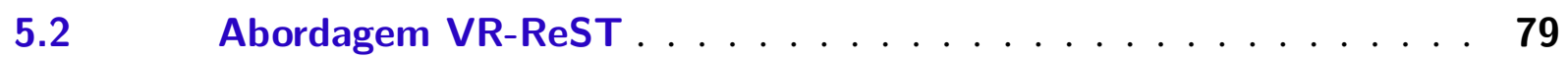

5.2.1 Módulo 1: Especificação dos Requisitos . . . . . . . . . . . 81

5.2.2 Módulo 2: Mapeamento dos Requisitos . . . . . . . . . . . . 83

5.2.3 Módulo 3: Geração dos Testes . . . . . . . . . . . . . . . 91

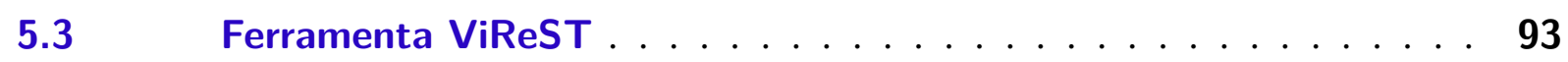

5.3.1 Componente de Requisitos . . . . . . . . . . . . . . . 94

5.3.2 Componente de Teste . . . . . . . . . . . . . . . . 95

$5.4 \quad$ Considerações Finais $\ldots \ldots \ldots \ldots$. . . . . . . . . 97

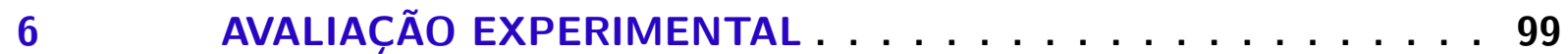

6.1 Considerações Iniciais . . . . . . . . . . . . . . . . . . 99

6.2 Estudo de Caso: Eficácia da BeLaRS para auxiliar na especificação

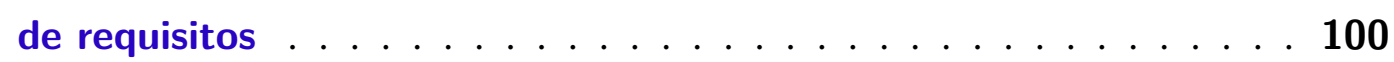

6.2.1 Planejamento . . . . . . . . . . . . . . . . . . 100

6.2.1.1 Conformidade (C) . . . . . . . . . . . . . . . . . . . 100

6.2.1.2 Aceitação e Uso $(U)$. . . . . . . . . . . . . . . . . . . . . . . . 101

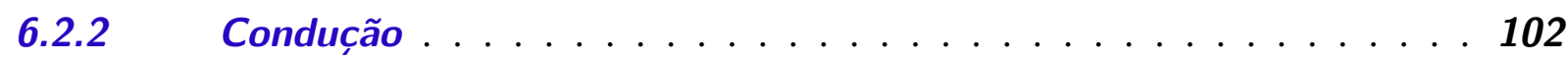

6.2.2.1 Etapa 1: Especificação de Requisitos . . . . . . . . . . . . . . . . . 102

6.2.2.2 Etapa 2: Análise da conformidade e aceitação e uso da BeLaRS . . . . . 103

6.3 Experimento: Eficácia da abordagem VR-ReST para auxiliar a geração automática dos testes . . . . . . . . . . . . . . . . . . 104

6.3.1 Design do Experimento . . . . . . . . . . . . . . . . . . . . . . . . . 104

6.3.2 Definição dos Objetivos . . . . . . . . . . . . . . . . . . . . 106

6.3.3 Definição das variáveis . . . . . . . . . . . . . . . . . . . 107

$6.3 .4 \quad$ Sujeitos do Experimento . . . . . . . . . . . . . . . . . 107

6.3.5 Configuração do Experimento . . . . . . . . . . . . . . . . . . 108

6.3.6 Coleta e Análise dos Dados . . . . . . . . . . . . . . . . . 111

$6.4 \quad$ Análise e Discussão dos Resultados . . . . . . . . . . . . 111

6.4.1 Eficácia da BeLaRS para auxiliar na especificação de requisitos . . 112 
6.4.1.1 Conformidade ........................ . . 112

6.4.1.2 Aceitação e Uso . . . . . . . . . . . . . . . . . . . . 114

6.4.2 Eficácia da abordagem VR-ReST para auxiliar a geração automática dos testes . . . . . . . . . . . . . . . . . 117

6.4.2.1 Eficácia da abordagem VR-ReST na detecção de falhas $\left(Q P_{1}\right)$. . . . . . 117

6.4.2.2 Relação entre a qualidade dos requisitos especificados e a qualidade dos dados de teste gerados $\left(Q P_{2}\right) \ldots$. . . . . . . . . . . . . . 119

6.4.2.3 Eficácia da abordagem VR-ReST comparada com o teste aleatório . . . . . 123

$6.5 \quad$ Ameaças à Validade . . . . . . . . . . . . . . . 127

$6.6 \quad$ Considerações Finais . . . . . . . . . . . . . . 127

7 CONSIDERAÇÕES FINAIS . . . . . . . . . . . . . 129

$7.1 \quad$ Contribuições . . . . . . . . . . . . . . . 130

$7.2 \quad$ Limitações . . . . . . . . . . . . . . . . 132

7.3 Sugestões de Trabalhos Futuros . . . . . . . . . . . 133

REFERÊNCIAS . . . . . . . . . . . . . . . . . . 135

APÊNDICE A GUIA PARA ESPECIFICAÇÃO DE REQUISITOS DE APLICAÇÕES DE RV . . . . . . . . . . . . . 147

APÊNDICE B MAPEAMENTO SISTEMÁTICO . . . . . . . 155

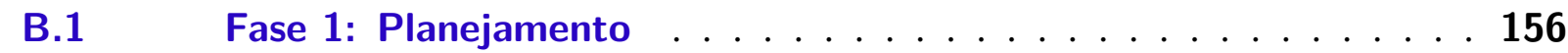

B.1.1 Questões de Pesquisa . . . . . . . . . . . . 156

B.1.2 Estratégia de Busca . . . . . . . . . . . . . . 157

B.1.3 Critério de Seleção dos Estudos . . . . . . . . . . . . . 159

B.1.4 Avaliação da Qualidade . . . . . . . . . . . . . . . . . 160

B.1.5 Extração e Síntese dos Resultados . . . . . . . . . . . . . . . . 160

B.2 Fase 2: Condução . . . . . . . . . . . . . . 162

B.3 Fase 3: Síntese e Análise dos Resultados . . . . . . . . . . 166

APÊNDICE C QUESTIONÁRIO APLICADO PARA AVALIAÇÃO DA

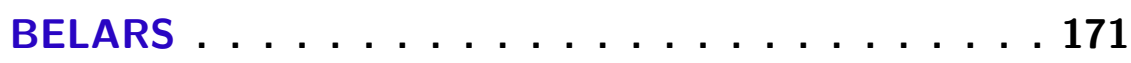

APÊNDICE D EXPLICAÇÕES E EXEMPLOS DAS REGRAS DA BELARS DISPONIBILIZADAS AOS ESTUDANTES . . . 177 

Com os avanços tecnológicos, o uso de sistemas baseados em computação está cada vez mais presente nas atividades da sociedade, aumentando a busca por produtos de software de qualidade, confiáveis e com custo reduzido. No entanto, durante o desenvolvimento de um software, apesar das técnicas, métodos e ferramentas empregados, erros podem estar presentes nos produtos. Esses erros podem ser oriundos de diversas questões técnicas como, por exemplo, uma elicitação inadequada, uma modelagem incoerente, uma programação incorreta e a falta de comunicação entre os envolvidos no projeto e os usuários (COSTA, 2004).

Considerando a importância dos softwares no mundo contemporâneo, a confiança e a qualidade desses softwares são fatores fundamentais para a sua utilização. Para garantir um nível de confiança e qualidade, é necessário que sejam introduzidas atividades ao longo de todo o processo de desenvolvimento. Dentre essas atividades estão as de Verificação, Validação e Teste (VV\& T), que visam reduzir a ocorrência de erros e riscos associados durante o ciclo de desenvolvimento, consequentemente aumentando a confiabilidade do software desenvolvido. Dentre as técnicas de VV\& T, a atividade de teste é considerada fundamental no contexto da Engenharia de Software (ES) (BERTOLINO, 2007).

Teste de software visa fornecer evidências da confiabilidade do software em complemento a outras atividades, como por exemplo o uso de revisões e de técnicas formais e rigorosas de especificação e de verificação (MALDONADO, 1991). A atividade de teste consiste em uma análise dinâmica do produto, sendo fundamental para a identificação e eliminação de erros que persistem.

Ressalta-se que, apesar dos avanços e pesquisas na área como desenvolvimento de técnicas e critérios de teste (MARCOZZI et al., 2017), (DELAMARO et al., 2001), (BARDIN et al., 2015a) automatização da atividade (BARDIN et al., 2015b), (KINTIS; MALEVRIS, 2015) aplicações de domínios específicos como sistemas WEB (BOUKHRIS et al., 2016), (ANDREWS; BOUKHRIS; ELAKEILI, 2014), (ALSHAHWAN N.AND HARMAN, 2011), 
aplicações de banco de dados (PAN; WU; XIE, 2014), (ROGSTAD; BRIAND, 2016) e para interface gráfica do usuário (ZELKOWITZ, 2010), (KOWALCZYK; MEMON, 2015), em alguns domínios ainda há a carência de técnicas que tratem de características específicas.

Por outro lado, existe a percepção de que o teste é uma atividade indispensável independentemente do domínio (JINO; MALDONADO; DELAMARO, 2016). Pesquisas em busca de técnicas e critérios de teste têm sido intensificadas, pois a aplicação dessas técnicas e critérios é necessária para que a atividade de teste possa ser conduzida de forma sistemática, e consiga atingir um nível de confiança e de qualidade com os testes realizados.

Dentre as técnicas utilizadas, destacam-se as técnicas funcional, estrutural e baseada em defeitos. A técnica funcional baseia-se na especificação do sistema, portanto as funções do software são identificadas a partir da especificação dos requisitos do sistema, sem preocupação com detalhes de implementação. Em contrapartida, a técnica estrutural utiliza a estrutura interna do programa, na qual os detalhes do código são analisados. A técnica baseada em defeitos utiliza informações sobre os tipos específicos de defeitos que se deseja revelar e os erros mais frequentes cometidos no processo de desenvolvimento de software (JINO; MALDONADO; DELAMARO, 2016).

É importante ressaltar que as técnicas de teste devem ser vistas como complementares, visto que nenhuma delas é suficiente para garantir a qualidade da atividade de teste. Essas técnicas devem ser aplicadas em conjunto, de forma que as vantagens de cada uma possam ser melhor exploradas, a fim de levar a uma atividade de teste de boa qualidade, ou seja, eficaz e de baixo custo (JINO; MALDONADO; DELAMARO, 2016).

Apesar da pesquisa nessa área ser diversificada em várias linhas, ainda existem lacunas, principalmente relacionadas a problemas específicos de alguns domínios de aplicação como, por exemplo, ambientes de Realidade Virtual (RV).

RV pode ser definida como uma tecnologia que permite a criação de ambientes sintéticos tridimensionais (3D), gerados por computador, e a utilização de canais multissensoriais, oferecendo ao usuário a possibilidade de navegar, de interagir e de estar imerso no Ambiente Virtual (AV) (KIRNER; SISCOUTTO, 2007), (TREVISAN et al., 2014). Essas operações são realizadas por meio de dispositivos convencionais, como mouse, teclado e tela de vídeo, mas também utilizam dispositivos não convencionais como capacetes, óculos estereoscópicos, luvas de dados e dispositivos hápticos. Diversas aplicações de RV têm sido desenvolvidas e utilizadas em uma gama de domínios, com o intuito de realizar simulações (RUTHENBECK; CARNEY; REYNOLDS, 2013), (MOAZZEN; AHMADI, 2017), (PINTO et al., 2017); análises (SCAIFE; ROGERS, 2017), (KIM., 2017) e visualizações (GREINER et al., 2016), (GAONA et al., 2016).

Na sua essência, a RV pode ser vista como "espelho" da realidade física, no qual o indivíduo existe em três dimensões, podendo ter a sensação de estar imerso no ambiente e ter a capacidade de interagir com o mundo ao seu redor. Os dispositivos de RV simulam essas 
condições, chegando ao ponto em que o usuário pode tocar virtualmente os objetos de um mundo virtual e fazer com que eles respondam, ou mudem, de acordo com suas ações (KIRNER; SISCOUTTO, 2007).

De um modo geral, uma grande diversidade de características e funcionalidades associadas aos programas de RV podem ser observadas. Um fator que intensifica o desafio de desenvolver programas de RV é o fato desses programas possuírem requisitos peculiares, pois apresentam alta complexidade, necessitando de uma especificação de requisitos mais rigorosa. Assim, com a finalidade de organizar os objetos e as suas características no AV, como comportamentos e aparências, boa parte das bibliotecas gráficas de apoio à construção de ambientes de RV usam o conceito de Grafo de Cena (GC).

GC é uma estrutura de dados organizada em classes capaz de especificar cenas complexas por meio de uma hierarquia de objetos e atributos (WOO et al., 1999). Um GC pode ser visto como um modelo e uma abstração de um programa de RV e, assim, pode ser empregado para derivar requisitos de teste. Além disso, é importante ressaltar que é possível utilizar GC analogamente aos critérios estruturais para selecionar estruturas a serem exercitadas durante a atividade de teste.

\subsection{Motivações}

A crescente evolução do hardware e o aumento do poder de processamento faz com que cenas de RV cada vez mais complexas e mais realistas possam ser geradas e visualizadas em tempo real com o uso de computadores comuns. Nesse cenário, é imperativo que o usuário de aplicações de RV obtenha respostas corretas às suas interações, considerando os requisitos do sistema desenvolvido. Assim, durante uma interação para atingir um grau elevado de realismo, múltiplos recursos podem ser utilizados na implementação de Ambientes Virtuais (AVs), como imagens 3D exibidas em tempo real, dispositivos especiais de entrada e saída, tais como capacetes, óculos estereoscópicos, luvas de dados e equipamentos hápticos.

Diversos benefícios são propiciados pela RV, principalmente no que diz respeito ao desenvolvimento de interfaces avançadas, permitindo que o usuário se sinta dentro de um ambiente, podendo explorar o local, selecionar e manipular objetos. Além dessas aplicações, também existem aquelas nas quais o usuário não está totalmente imerso, isto é, não são usados dispositivos específicos para propiciar a sensação de "estar dentro do AV".

$\mathrm{O}$ fato de tratar-se inerentemente de AVs 3D, em contraposição aos tradicionais ambientes bidimensionais considerados ao longo dos anos em aplicações computacionais; a exigência de disponibilizar interação no ambiente 3D, acrescentando um nível a mais (profundidade) para ser interpretado durante as entradas fornecidas pelo sistema; e a importância do uso de dispositivos convencionais e não convencionais durante a interação, tornam os programas de RV altamente complexos e acrescentam muitas dificuldade às atividades de especificação de requisitos e de 
teste de software.

A especificação de requisitos de aplicações de RV é um processo complexo, uma vez que compreende os sentidos humanos (tato, visão, audição e percepção) e comportamentos complexos dos objetos virtuais. Estes comportamentos podem envolver a adaptação de algoritmos complexos para a simulação de características físicas de objetos, tais como respostas adequadas para detecção de colisões, deformação, além de características de interação do usuário com o ambiente virtual, como transformação, escala e rotação. Essas especificações dependem de uma combinação de diferentes requisitos decorrentes de vários cenários com características heterogêneas e uma ampla gama de interações. Algumas metodologias (KIM et al., 1999), (SEO; KIM, 2002), (PELLENS; TROYER; KLEINERMANN, 2008); modelos (KIRNER; MARTIN, 1999), (TANRIVERDI; JACOB, 2001); abordagens (SCAIFE; ROGERS, 2001); e avaliação de multi-critérios de usabilidade (STANNEY et al., 2003) foram propostas para melhorar o processo de desenvolvimento de aplicações RV. No entanto, a maioria destas abordagens são utilizadas no processo de desenvolvimento ou somente em uma das fases do processo de Engenharia de Requisitos (ER).

É importante destacar que, em geral, os testes em aplicações de RV são realizados manualmente e somente após o processo de desenvolvimento destas aplicações. Uma maneira de assegurar o funcionamento apropriado de aplicações RV, isto é, alcançar um nível de confiança e qualidade, é por meio da utilização de técnicas e critérios de teste. Estas técnicas auxiliam na geração de Requisitos de Teste (RTs) que devem ser cobertos durante o teste. Alguns estudos exploram diferentes aspectos do teste de software, como o suporte a testes de interfaces de RV (BIERBAUM; HARTLING; CRUZ-NEIRA, 2003), testes de usabilidade de ambientes de aprendizagem baseados em RV (CHEN et al., 2013), testes e validação de componentes para automação (ZOFKA et al., 2008), ambiente de RV para a realização de testes em progrmas complexos (MARZANO et al., 2015). No entanto, o uso prático de critérios de teste foi apenas abordado no trabalho de Bezerra, Delamaro e Nunes (2011), que propôs quatro critérios de teste (All-Nodes-Leaves, All-Nodes-Intermediary, All-Paths-Ascendants e All-Paths-Descendants), com base em critérios de testes estruturais, para serem utilizados em aplicações de RV. Portanto, ainda não existe uma abordagem para auxiliar testes funcionais no domínio de RV.

Adicionalmente, métodos formais auxiliam na análise e na geração dos testes a partir das especificações de requisitos, fornecendo um feedback inicial sobre o comportamento de um sistema. Nesse contexto, métodos formais (SOMÉ; CHENG, 2008), (SOUZA, 2009), (CHEN; LI, 2010) e ferramentas (CHATTERJEE; JOHARI, 2010), (CHEN; LI, 2010), (MATOS, 2012) têm sido desenvolvidas para analisar os softwares a partir de suas especificações a fim de evitar comportamentos inesperados e gerar dados de teste com a finalidade de garantir a adequação da implementação às especificações. Apesar dos benefícios da geração de dados de teste, nenhum estudo aborda a utilização de métodos formais para a geração de dados de teste no domínio de RV. 


\subsection{Objetivos e Hipótese}

A partir dessas perspectivas, evidencia-se a relevância em definir e automatizar critérios de teste no escopo de aplicações de RV, uma vez que tem-se um domínio pouco explorado e com possibilidade de contribuições inéditas tanto para a área de teste de software quanto para a área de RV. Acrescenta-se a esses fatores, a introdução cada vez mais frequente de aplicações de RV no dia-a-dia da sociedade, com a finalidade de permitir interações mais naturais e realistas do que as fornecidas pelos softwares com interfaces bidimensionais. Portanto, a hipótese a ser validade nesta pesquisa é apresentada a seguir.

- É possível gerar dados de teste automatizados, de qualidade, a partir de uma especificação de requisitos semi-formal para realizar o teste funcional em aplicações de Realidade Virtual que utilizam conceitos de Grafo de Cena.

A partir da motivação e da hipótese descritas, o objetivo deste trabalho é apresentar uma abordagem denominada Virtual Reality-Requirements Specification and Testing (VR-ReST) que visa: $(i)$ semi formalizar a especificação de requisitos de aplicações de RV, que abordam aspectos visuais e iterativos, com base na descrição de casos de uso e conceitos do domínio de RV (terminologias e conceitos de GC); e (ii) derivar requisitos de teste e gerar dados de teste a partir dessa especificação semi-formalizada com a finalidade de auxiliar o teste funcional de aplicações de RV.

É importante destacar que a padronização da especificação de requisitos é fundamental para a automatização do teste funcional, uma vez que para conduzir esse teste é necessário que os requisitos especificados sejam coerentes, completos e livres de ambiguidades. Além disso, a qualidade dos dados de teste está diretamente relacionada a sua capacidade em revelar defeitos.

O objetivo geral pode ser subdividido nos seguintes objetivos específicos:

- adaptar a técnica incremental de ER para padronizar a especificação de requisitos de aplicações de RV;

- selecionar critérios de teste estruturais baseados em cobertura para testar aplicações de RV que utilizam conceitos de GC;

- definir uma abordagem para especificação de requisitos e geração dos dados de teste;

- automatizar a especificação de requisitos e a geração de dados de teste por meio da implementação de uma ferramenta de apoio; e

- avaliar por meio de estudo de caso e avaliação controlada a especificação de requisitos e a geração de dados de teste utilizando a ferramenta. 


\subsection{Processo Metodológico}

Na Figura 1 é apresentada uma visão geral do processo metodológico seguido para atingir os objetivos definidos.

Figura 1 - Visão geral do processo metodológico

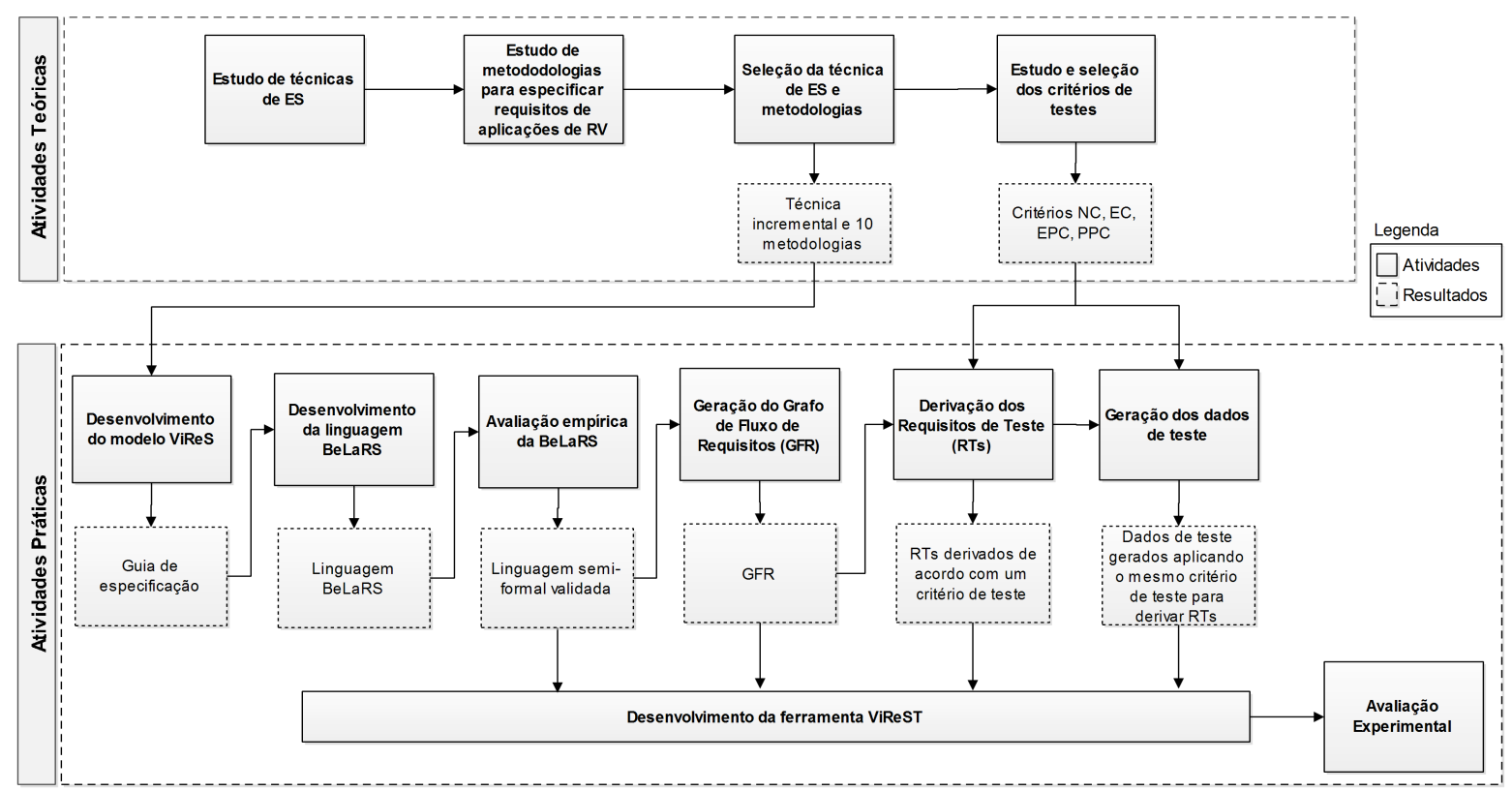

Fonte: Elaborada pelo autor.

1. Estudo de técnicas de Engenharia de Software (ES): esta atividade consistiu na investigação e estudo das principais características das técnicas de ES para especificação de requisitos tais como: incremental, prototipação, espiral, cascata entre outros, a fim de verificar quais poderiam ser adaptadas para a especificação de requisitos de aplicações de RV.

2. Estudo de metodologias para especificação de requisitos de aplicações de RV: esta atividade consistiu na identificação de metodologias diferentes que auxiliam na especificação de requisitos de aplicações de RV por meio de um mapeamento sistemático que é apresentado no Capítulo 4.

3. Seleção da técnica de ES e metodologias: durante essa fase foram selecionadas uma técnica de ES e metodologias a serem utilizadas, extraindo suas principais características, a fim de contribuir para especificação de requisitos de aplicações de RV.

4. Estudo e seleção dos critérios de testes: durante esta fase foram selecionados os critérios utilizados para auxiliar o teste funcional: (i) Node Coverage (NC); (ii) Edge Coverage (EC); (iii) Edge-Pair Coverage (EPC); e (iv) Prime Path Coverage (PPC). Esses critérios 
são selecionados para garantir a qualidade dos dados de testes gerados e a cobertura dos Requisitos de Teste (RTs) produzidos e são apresentados na na Seção 2.3 do Capítulo 2.

5. Desenvolvimento de um modelo: nesta atividade foi criado um modelo chamado Virtual Requirement Specification (ViReS) para auxiliar o processo de levantamento, especificação e validação de requisitos de aplicações de RV que utilizam o conceito de GC que é apresentado na Seção 5.2 do Capítulo 5. Esse modelo é incremental e as atividades que compõem as suas quatro fases (descrição geral, elicitação, especificação e validação) são baseadas nas principais características extraídas de cada metodologia a ser selecionada. O modelo fornece um Guia de Especificação de Requisitos com todas as informações e requisitos necessários para o desenvolvimento de aplicações de RV. Esse Guia é apresentado no Apêndice A.

6. Desenvolvimento de uma linguagem: durante essa fase foi desenvolvida uma linguagem semi-formal chamada Behavior Language Requirement Specification (BeLaRS) para obter uma especificação semi-formal dos requisitos do software a fim de auxiliar o teste funcional no domínio RV. A versão inicial da BeLaRS foi baseada na especificação de casos de uso proposta por Cockburn (COCKBURN, 2001), nas práticas de desenvolvimento dirigido ao comportamento (do inglês, Behavior-Driven Development - BDD) (CHELIMSKY et al., 2010) e em um padrão para especificação de casos de uso proposto por Diaz (DÍAZ et al., 2004).

7. Avaliação empírica da BeLaRS: nesta atividade a BeLaRS foi avaliada por meio de um estudo de caso com a finalidade de verificar a conformidade e aceitação e uso da linguagem proposta que é apresentado na Seção 6.2 do Capítulo 6. Para alcançar tal objetivo foi fornecido um cenário de uma aplicação que simula exame de biópsia, gerada pelo framework Virtual Medical Training (ViMeT) (OLIVEIRA; NUNES, 2010), para 31 estudantes voluntários de pós-graduação que realizaram a especificação de requisitos de acordo com a gramática definida na linguagem. A partir dos resultados obtidos, uma nova gramática da BeLaRS foi desenvolvida conforme pode ser vista na Subseção 5.2.2 do Capítulo 5. Nessa nova gramática foi adicionada a teoria da estrutura de constituintes, originalmente introduzida por Noam Chomsky (CHOMSKY, 1956), e a especificação de casos de uso proposta por Cockburn (COCKBURN, 2001) foi mantida. Chomsky (CHOMSKY, 1956) discute estruturas sintáticas e a análise do constituinte para o desenvolvimento de gramáticas que devem ser vistas como "máquinas" para produzir sentenças de uma determinada linguagem que podem ser analisadas e utilizadas independente do domínio do problema.

8. Geração do Grafo de Fluxo de Requisitos (GFR): esta atividade ocorreu a partir dos requisitos especificados e validados usando a BeLaRS. O processo de geração do GFR é 
composto de três etapas: (i) especificação dos requisitos; (ii) associação dos requisitos aos nós; e (iii) geração do GFR. O processo de geração do GFR é apresentado no Capítulo 5.

9. Derivação dos requisitos de teste: nesta atividade os RTs são derivados de acordo com os critérios de teste (NC, EC, EPC e PPC) usando o algoritmo de busca em profundidade. Um típico RT é coberto por meio de uma visita a um nó, aresta ou percorrendo um caminho particular. O processo de derivação dos RTs é apresentado na Subseção 5.2.3 do Capítulo 5.

10. Geração dos dados de teste: nesta fase os dados de teste são gerados de acordo com os critérios de teste (NC, EC, EPC e PPC) e aplicados nos RTs derivados para verificar quais destes foram ou não cobertos. $O$ processo de geração dos dados de teste é apresentado na Subseção 5.2.3 do Capítulo 5.

11. Desenvolvimento da ferramenta ViReST: essa fase consistiu no desenvolvimento da ferramenta que é composta por dois componentes: (i) Requirements e (ii) Testing. O componente Requirements foi desenvolvido para especificar de forma padronizada os requisitos relativos às interações do sistema e do usuário e às características dos objetos fim de utilizar essas o teste funcional. O componente Testing foi desenvolvido para executar os testes funcionais. Esse componente utiliza como entrada o Grafo de Fluxo de Requisitos (GFR) que representa os requisitos especificados por meio da BeLaRS. A partir desse grafo, os RTs são derivados de acordo com um dos quatro critérios apresentados anteriormente. Além disso, esse componente permite também, gerar dados de teste para verificar a cobertura dos RTs. A ferramenta ViReST é apresentada na Seção 5.3 do Capítulo 5

12. Avaliação experimental: esta atividade foi responsável pela condução de experimentos para avaliar a eficiência da geração dos dados de teste utilizando a abordagem VR-ReST. Os detalhes da avaliação experimental são apresentados na Seção 6.3 do Capítulo 6.

\subsection{Grupos de Pesquisa}

Este trabalho é uma contribuição para a ciência originado no grupo de pesquisa do Laboratório de Engenharia de Software (LabES) do Instituto de Ciências Matemáticas e de Computação (ICMC) da Universidade de São Paulo (campus São Carlos/SP). Além disso, a presente pesquisa também foi conduzida em parceria com o grupo de pesquisa do Laboratório de Aplicações de Informática em Saúde (LApIS) da Escola de Artes, Ciências e Humanidades da Universidade de São Paulo (EACH-USP). Este grupo tem colaboração com o Prof. Márcio Delamaro, no sentido de definir técnicas e ferramentas para avaliar e testar aplicações no domínio de processamento gráfico. Assim, já foram definidas ferramentas para seleção de casos de teste para aplicações de auxílio ao diagnóstico (GONCALVES et al., 2011), oráculos gráficos 
(DELAMARO; NUNES; ANDRADE, 2006) e o trabalho citado anteriormente para definir critérios estruturais no domínio de RV (BEZERRA; DELAMARO; NUNES, 2011).

Outra colaboração importante ocorreu durante o doutorado sanduíche com o grupo de Engenharia de Software do Interdisciplinary Centre for Security, Reliability and Trust (SnT) na Universidade de Luxemburgo devido a excelência e a singularidade em validação, verificação e automatização de testes. Acredita-se, que além do fortalecimento desta colaboração entre ambos grupos de pesquisa, a junção dos pesquisadores das duas áreas da Computação (ES e RV) contribuirá com novas linhas de pesquisa e inovação para ambas as áreas no país.

\subsection{Estrutura da Tese}

Esta tese está organizada em sete capítulos. No primeiro capítulo, estão apresentados a contextualização, a motivação, a abordagem desenvolvida em resumo, os objetivos e o grupo de pesquisa do trabalho.

No Capítulo 2 são apresentados os conceitos e o processo de ER, bem como os conceitos envolvendo teste de software, técnicas e critérios de teste com o objetivo de facilitar a compreensão com relação à tese. E, no Capítulo 3 são apresentados os conceitos de RV, destacando as particularidades e as características dos GCs.

No Capítulo 4, é apresentado um mapeamento sistemático que foi realizado com o objetivo de identificar metodologias/modelos utilizadas para especificação de requisitos e utilização de teste de software no domínio de RV. Além disso, nesse mapeamento também são demonstradas as principais constatações e questões em aberto que nortearam a tese.

No Capítulo 5 é apresentada uma abordagem conceitual para especificação de requisitos e geração dos testes de aplicações de RV. Nesse capítulo também é apresentada a ferramenta que foi desenvolvida e utilizada como apoio para automatizar essas atividades.

No Capítulo 6, são detalhados o planejamento, a execução e a análise dos dados do estudo de caso e do experimento que visam validar o processo de especificação de requisitos e a geração de testes, respectivamente, e são discutidos os resultados obtidos para ambas avaliações experimentais. E, por fim, no Capítulo 7, são descritas as conclusões do trabalho com as principais contribuições, limitações, lições apreendidas, publicações e trabalhos futuros que poderão ser conduzidos como continuação da presente pesquisa. 



\section{FUNDAMENTOS DE ENGENHARIA DE REQUISITOS E TESTE DE SOFTWARE}

\subsection{Considerações Iniciais}

Neste capítulo, são apresentados e discutidos os conceitos fundamentais de ES para o entendimento desta tese. Está organizado da seguinte forma: na Seção 2.2, são descritos os aspectos conceituais de ER, o seu processo e as suas respectivas atividades; na Subseção 2.2.2 é apresentada a descrição dos casos de uso; na Seção 2.3, os conceitos e terminologias sobre de teste de software, técnicas de teste e seus respectivos critérios de teste são detalhados; por fim, na Seção 2.4, as considerações finais deste capítulo são destacadas. A compreensão e a realização de um processo de ER eficaz é fundamental para obter uma especificação de requisitos completa, coerente e livre de ambiguidades.

\subsection{Engenharia de Requisitos}

A ER consiste em um processo para descobrir qual o propósito do sistema por meio da identificação dos stakeholders $^{1}$ e de suas necessidades, e documentar essas informações de forma que sejam concisas para análise, comunicação, e posterior implementação (NUSEIBEH; EASTERBOOK, 2000). A ER auxilia na compreensão do problema que será trabalhado, com a finalidade de facilitar a elaboração de sistemas de software que atendam às reais necessidades dos clientes. Ela permite a definição e o estudo do contexto em que o software estará envolvido, as necessidades específicas que deverão ser satisfeitas, as prioridades em relação à ordem em que as partes do software serão implementadas, as informações, funções e os comportamentos que deverão compor o software (PRESSMAN, 2016).

1 Stakeholders são os interessados em identificar os serviços que o sistema deve fornecer e as restrições operacionais (PRESSMAN, 2016). 
Apesar dos problemas identificados em ER, como requisitos incompletos, ambíguos, incoerentes, a sua importância não é limitada em relação ao processo de desenvolvimento de um novo produto. De acordo com Pressman (2016), a importância da ER está em fornecer os mecanismos apropriados para entender o que o cliente quer, analisar necessidades, o que é possível fazer, negociar uma solução razoável, especificar uma solução não ambígua, validar a especificação e gerenciar os requisitos na medida em que estes se concretizam em um produto.

Em um sistema de software os requisitos consistem nas descrições dos serviços ofertados pelo sistema e por suas restrições operacionais (SOMMERVILLE, 2016). Sendo assim, os requisitos de software representam as necessidades apresentadas pelos usuários ou clientes, que por sua vez devem ser contempladas pelo sistema a ser desenvolvido. Sommerville (2016) classifica os requisitos de software da seguinte maneira:

- requisitos funcionais: correspondem às funcionalidades que o sistema de software deve satisfazer, ou seja, descrevem o que o sistema deve fazer. Esses requisitos dependem do tipo de software a ser desenvolvido, de quem são seus possíveis usuários e da abordagem geral adotada pela organização ao definir os requisitos. Quando expressos como requisitos de usuário, os requisitos funcionais são normalmente descritos de forma abstrata, para serem compreendidos pelos usuários do sistema. No entanto, requisitos funcionais expressos como requisitos do sistema descrevem em detalhes as funções do sistema, suas entradas, saídas e exceções.

- requisitos não-funcionais: estão associados às restrições e aos atributos de qualidade, tais como: desempenho, segurança, usabilidade e segurança, ou seja, definem restrições sobre como os requisitos funcionais deverão ser implementados. Os requisitos não-funcionais podem ser provenientes das características requeridas do software (requisitos do produto), da organização que desenvolve o software (requisitos organizacionais) ou de fontes externas.

\subsubsection{Processo de Engenharia de Requisitos}

É importante salientar que no desenvolvimento de um sistema uma das tarefas mais desafiadoras para os engenheiros de software é a correta compreensão dos requisitos do software, pois, os requisitos são afetados por fatores dos mais variados tipos, tais como preconceitos dos usuários ou mesmo por causa da influência de políticas organizacionais.

A ER provê um conjunto de técnicas que são utilizadas para levantar, detalhar, documentar e validar os requisitos de um produto (FILHO, 2003) e que são executadas ao longo das suas atividades. Segundo Sommerville (2016) existem quatro atividades do processo de ER (i) Estudo da Viabilidade; (ii) Elicitação e Análise dos Requisitos; (iii) Especificação dos Requisitos; e (iv) Validação dos Requisitos (Figura 2). Esse conjunto de atividades que caracteriza a ER não deve ser entendido simplesmente como um processo técnico, pois os requisitos do sistema são, muitas 
vezes, influenciados por preferências, recusas e até preconceitos dos usuários, além de questões políticas e organizacionais.

Figura 2 - Processo de ER utilizado para a especificação de requisitos

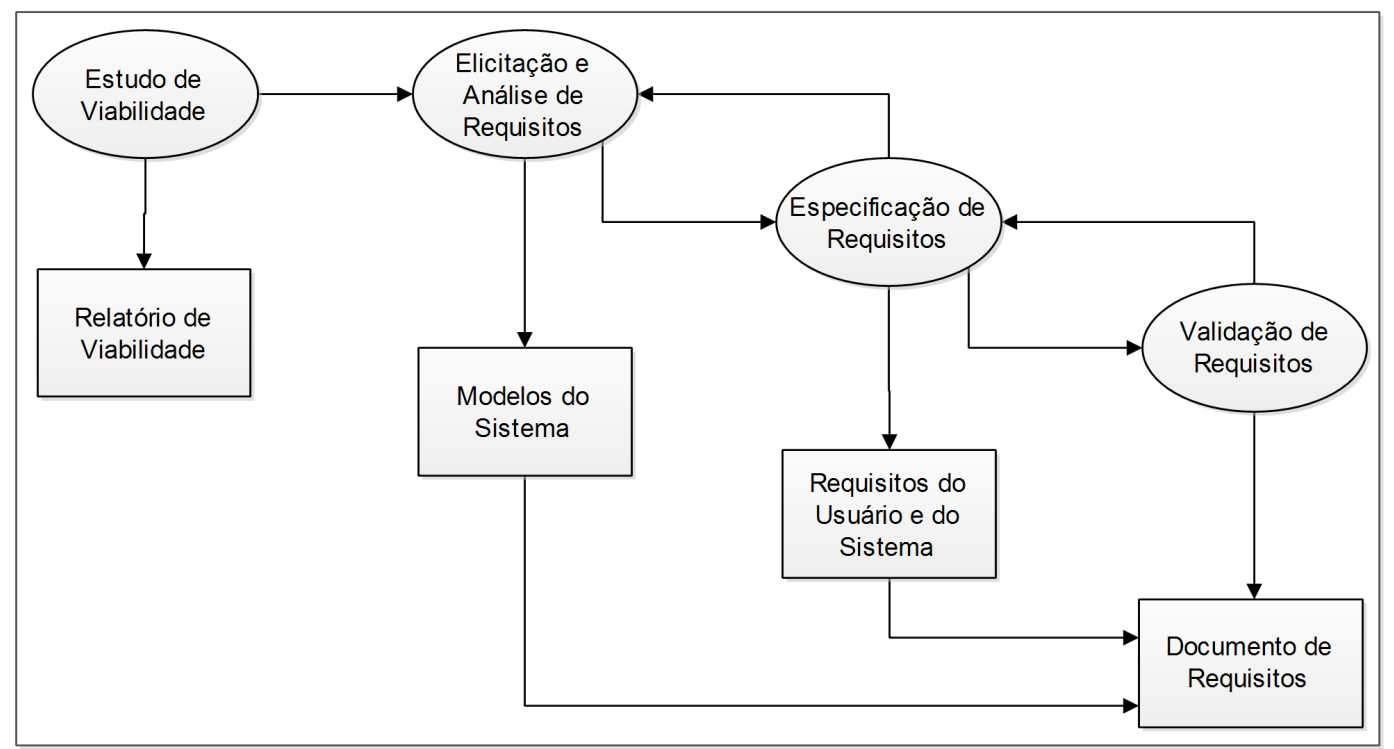

Fonte: Adaptada de Sommerville (2016).

Em todos os sistemas o processo de ER deve começar com o estudo da viabilidade. A entrada para o estudo de viabilidade é um conjunto preliminar de requisitos de negócios, um esboço da descrição do sistema e uma noção de como o sistema pretende apoiar os processos de negócios. Os resultados do estudo de viabilidade retratam se é recomendável ou não prosseguir com o processo de ER e o desenvolvimento do sistema.

$\mathrm{Na}$ atividade de elicitação de requisitos, os engenheiros de software trabalham com os clientes e usuários finais do sistema para elicitar e analisar os requisitos para compreender o domínio da aplicação, quais serviços o sistema deve fornecer, o desempenho esperado do sistema, restrições de hardware, entre outros. Para a realização da etapa de levantamento de requisitos, há a necessidade da aplicação de uma ou mais técnicas tais como entrevistas, etnografia, questionários, brainstorms, entre outros. Estas técnicas têm por objetivo auxiliar o engenheiro de software na extração das necessidades dos interessados no software

$\mathrm{Na}$ atividade de especificação de requisitos, os requisitos funcionais e não funcionais são detalhados e padronizados para facilitar a compreensão de todos os envolvidos no projeto. É importante destacar que é a partir desta atividade que os requisitos são registrados em documento técnico de requisitos. Machado (2014) frisa que o documento de requisitos deve ser escrito com um nível apropriado de detalhamento, utilizando-se de uma linguagem clara o suficiente para que todos os stakeholders possam compreendê-lo sem dificuldades. Esse documento deve apresentar os seguintes conteúdos:

- serviços e funções que o sistema deve prover; 
- restrições sobre as quais o sistema deve operar;

- definições de outros sistemas com os quais o sistema deve interagir;

- informações sobre o domínio da aplicação do sistema;

- limitações nos processos utilizados para desenvolver o sistema;

- descrição do hardware que o sistema irá ser executado

Ao final, ocorre a validação dos requisitos para evidenciar se os requisitos realmente definem o sistema que o usuário deseja. A validação se sobrepõe à análise e está relacionada à descoberta de problemas com os requisitos. Durante este processo, os requisitos são validados para confirmar a consistência, o realismo e a viabilidade. Tem por objetivo identificar quaisquer problemas antes que a próxima fase de desenvolvimento sejam iniciadas.

Os documentos de requisitos podem ser validados visando garantir que a compreensão feita pelo engenheiro de software está de acordo com as necessidades reais do cliente. O processo de validação, deve verificar se o documento é compreensível, consistente, completo e está em conformidade com as normas da organização. A revisão dos documentos, geralmente é feita pelos stakeholders, incluindo representantes do cliente e do desenvolvedor.

Em paralelo ocorre o gerenciamento dos requisitos para manter um registro das modificações e assegurar que as mesmas ocorram de forma controlada no documento de requisitos. Portanto, independentemente do domínio, a satisfação dos requisitos especificados pelos usuários é a pré-condição básica para o sucesso de um software.

Contudo, a medida que os requisitos são levantados, começa-se a ter uma visão geral das funções e características do software, porém é difícil especificar esses requisitos sem a compreensão de como estas funções e características serão utilizadas pelos diferentes tipos usuários do software. Nesse contexto, um conjunto de cenários sao criados com a finalidade de identificar um roteiro de uso das funcionalidades. Estes cenários são também conhecidos como “casos de uso" (PRESSMAN, 2016).

\subsubsection{Casos de Uso}

A técnica de casos de uso (do inglês, Use Cases (UCs)) teve sua origem com Jacobson (1987). Casos de uso são úteis para realizar a adição de detalhes a uma descrição geral de requisitos, ou seja, oferecer diversos tipos de informação sob diferentes níveis de detalhamento do sistema. Essas ações são descritas por meio de informações adicionais que podem serem feitas de forma textual ou utilizando outros modelos gráficos, como diagramas (SOMMERVILLE, 2016). Além disso, um caso de uso é definido como um conjunto de ações que ocorrem entre o sistema e agentes externos a ele, conhecidos como atores. 
Atores são papéis desempenhados pelos usuários e outros sistemas que interagem com o sistema em questão (aquele ao qual se aplica ao caso de uso). Cada caso de uso especifica uma parte da funcionalidade que o sistema fornece a seus usuários.

Sabe-se que casos de uso são formas padronizadas já estabelecidas para representação de uma ou mais funcionalidades de um sistema. No entanto, um caso de uso criado é composto pelo fluxo principal e fluxo alternativo. O fluxo principal descreve as funcionalidades que devem ser realizadas com sucesso sem considerar a ocorrência de desvios ou problemas durante a mesma. Por outro lado, os fluxos alternativos indicam extensões que podem ser realizadas a partir das funcionalidades descritas no fluxo principal (LARMAN, 2007). Portanto, de uma forma geral, a descrição dos casos de uso deve ser composta pelos seguintes itens:

- descrição geral do sistema e dos usuários;

- listagem dos requisitos funcionais e não-funcionais;

- descrição do fluxo normal de eventos;

- descrição do que pode dar errado e como isto deve ser tratado;

- informações sobre outras atividades que podem acontecer ao mesmo tempo.

Nesse contexto, uma estratégia que está sendo utilizada como uma possibilidade de formalizar as ideias apresentadas na descrição de casos de uso é conhecida como Linguagem de Domínio Específico (LDE) (do inglês Domain Language Specific (DSL)). Uma LDE é criada dentro de um contexto para resolver um conjunto específico de problemas (FOWLER, 2009), e tendem a ser mais naturais e próximas da linguagem humana, facilitando a manutenção de seus códigos (PARR, 2007).

Vale ressaltar que a LDE permite especificar software e/ou outros sistemas, modelando e exprimindo de um modo formal os conceitos chaves de um determinado domínio. Nesse cenário, essas linguagens estão sendo utilizadas em diversas áreas como especificação de requisitos para domínios de orientação a aspecto (OLIVEIRA, 2010), para descobrir e estruturar requisitos a um nível organizacional (NUNES, 2009) e modelagem de jogos (LIMA, 2012).

\subsection{Teste de Software}

O processo de desenvolvimento de software envolve uma série de atividades para produzir software de alta qualidade; no entanto, erros no produto ainda podem ocorrer. Para minimizar tais erros e riscos associados, atividades conhecidas como VV\&T têm sido introduzidas no processo de desenvolvimento. Dentre as técnicas de VV\&T, a atividade de teste é uma das mais utilizadas, constituindo-se em um dos elementos para fornecer evidências da confiabilidade do software (MALDONADO, 1991). 
A atividade de teste de software consiste em uma análise dinâmica com a intenção de executar um programa ou um modelo e verificar se o seu comportamento está em conformidade com o esperado. Segundo Myers, Sandler e Badgett (2004), teste de software tem como função executar um sistema com a finalidade de encontrar possíveis erros.

\subsubsection{Terminologia e Conceitos Básicos}

Apesar da importância da atividade de teste no processo de desenvolvimento de software, esta tem sido indicada como uma das mais onerosas no desenvolvimento de software. Além disso, diversos problemas podem emergir durante o desenvolvimento de software, pois um ser humano está sujeito a cometer enganos (mistake) que produzem defeitos (faults) durante a realização de um processo, atividade ou método. Esses defeitos, durante a execução do programa, podem ocasionar erros (error) que se caracterizam por um estado inconsistente ou inesperado. Assim, tal estado pode ocasionar falhas (failure), fazendo com que o resultado produzido seja diferente do resultado esperado (DELAMARO et al., 2007).

Em teste de software, considera-se que os programas são compostos por domínios de entrada e de saída. O domínio de entrada de um programa $\mathbf{P}$, denotado por $\mathbf{D}(\mathbf{P})$, é o conjunto de todos os possíveis valores que podem ser utilizados para executar $\underline{\mathbf{P}}$ (AMMANN; OFFUTT, 2008). O domínio de saída de um programa, denotado por $\underline{\mathbf{S}(\mathbf{P})}$ é um conjunto de todos os possíveis resultados produzidos por $\underline{\mathbf{P}}$ (DELAMARO et al., 2007).

Define-se "dado de teste", um elemento do domínio de entrada de P. Um par formado por um dado de teste e o resultado esperado para a execução do programa é denominado "caso de teste" (DELAMARO et al., 2007).

Um cenário típico da atividade de teste é ilustrado na Figura 3. Nesse cenário, um conjunto de casos de teste $\underline{\mathbf{T}}$ é definido, em seguida o programa em teste é executado com $\underline{\mathbf{T}}$ e o resultado obtido é verificado. Caso o resultado produzido pela execução de $\underline{\mathbf{P}}$ esteja em conformidade com o esperado, nenhum erro foi identificado. No entanto, caso o resultado seja diferente do esperado, então um defeito foi revelado.

Conforme apresentado na Figura 3, o testador muitas vezes assume o papel conhecido como "oráculo", pois é ele quem decide se a saída obtida de uma determinada execução está em conformidade com a saída esperada. Parte do desafio de automatização da atividade de teste consiste na criação de oráculos automatizados.

O teste de software é composto por quatro etapas: (i) planejamento de testes; ( $i i)$ projeto de casos de testes; (iii) execução; (iv) avaliação dos resultados de teste. Ao longo do processo de desenvolvimento, essas atividades devem ser desenvolvidas e se consolidam em três fases de teste: de unidade, de integração e de sistema (MYERS; SANDLER; BADGETT, 2011).

O teste de unidade visa verificar as menores unidades de um programa, podendo ser funções, procedimentos, classes ou métodos, a fim de identificar erros de lógica e de implementação. 
Figura 3 - Processo de condução do teste em um programa durante o desenvolvimento de software

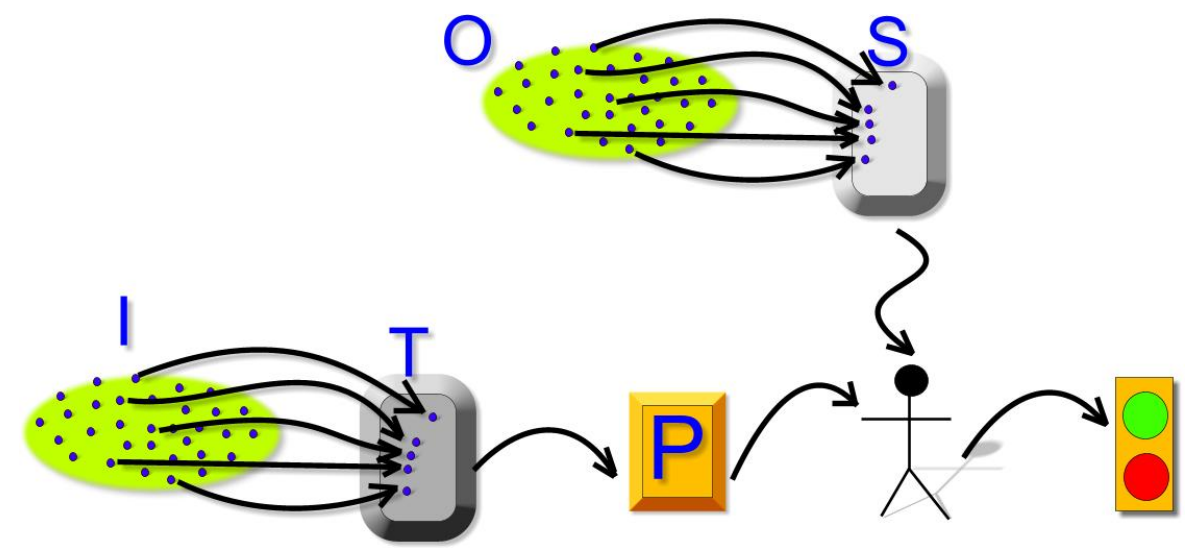

Fonte: Delamaro (2012).

O teste de integração é realizado após as unidades serem testadas individualmente. A preocupação desta fase do teste é com a construção do sistema, ou seja, verificar se a junção das diversas partes funciona adequadamente e não levam a erros.

O teste de sistema é realizado quando o sistema está completo, com as suas partes integradas, visando identificar defeitos por meio de suas características e funções baseadas nas especificações. $\mathrm{O}$ objetivo é verificar se os requisitos funcionais e não funcionais foram implementados corretamente de acordo com as suas especificações.

Com base nas etapas do teste de software mencionadas anteriormente, é importante destacar que a geração de casos de testes é considerada um dos pontos críticos da atividade de teste. O programa $\underline{\mathbf{P}}$ deve ser testado com todos os elementos de $\underline{\mathbf{D}(\mathbf{P})}$, a fim de garantir que nenhum defeito esteja presente. Isso, em geral, é impossível por razões de custo e tempo. Dessa forma, o objetivo é utilizar casos de teste que possuam alta probabilidade em revelar a maioria dos defeitos com tempo e esforço reduzido (DELAMARO et al., 2007).

Dentro dessa perspectiva, para auxiliar a criação ou avaliação de casos de teste, a aplicação de técnicas e critérios é necessária para que a atividade de teste possa ser conduzida de forma sistemática e consiga atingir um nível de confiança e de qualidade com os testes realizados (DEMILLO, 1980).

\subsubsection{Técnicas e Critérios de Teste}

Os critérios de teste podem ser usados tanto para a geração de um conjunto de casos de teste quanto na avaliação da adequação desse conjunto, evidenciando a eficiência do teste (FRANKL; WEYUKER, 2000). Nesse contexto, a qualidade dos testes está associada ao critério de teste utilizado, uma vez que ele define quais requisitos deverão ser validados na avaliação dos testes (ZHU, 1996).

Técnicas de teste são empregadas para conduzir e avaliar a qualidade da atividade de 
teste e diferenciam-se pela origem da informação utilizada na avaliação e na construção dos conjuntos de casos de teste (MALDONADO, 1991).

Em geral, os critérios de teste de software são estabelecidos a partir de três técnicas: (i) funcional, que baseia-se na especificação do produto de software; (ii) estrutural, que utiliza a estrutura interna do programa; e (iii) baseada em defeitos, que utiliza os defeitos típicos cometidos pelos programadores durante o desenvolvimento de software.

A utilização de técnicas e critérios de teste são fundamentais na seleção de casos de teste, pois conseguem minimizar a quantidade de casos de teste e a identificação de defeitos a um baixo custo. Dada a importância para este projeto, as três técnicas são descritas detalhadamente.

\subsubsection{Técnica Funcional}

A técnica de teste funcional, também conhecida como teste de caixa preta, verifica funções do sistema sem se preocupar com os detalhes de implementação, sendo visível e disponível somente os dados de entrada fornecidos e as saídas produzidas. O teste funcional envolve dois passos: (1) identificar as funções que o software deve realizar e (2) projetar casos de teste capazes de verificar se essas funções estão sendo realizadas pelo software (MYERS; SANDLER; BADGETT, 2011). As funções que o software deve possuir são identificadas a partir de sua especificação. Assim, uma especificação bem elaborada e de acordo com os requisitos do usuário é essencial para esse tipo de técnica.

Apesar das vantagens da técnica funcional, um dos seus problemas é que, muitas vezes, a especificação do programa é realizada de modo descritivo e não formal. Dessa maneira, os RTs derivados de tais especificações podem ser também imprecisos e informais. Como consequência, tem-se dificuldade em automatizar a aplicação de tais critérios que ficam, em geral, restritos à aplicação manual. Por outro lado, para a aplicação desses critérios é essencial que se identifiquem as entradas, a função a ser computada e a saída do programa. Os principais critérios do teste funcional são "Particionamento em Classes de Equivalência", "Análise do Valor Limite", "Grafo de Causa-Efeito" e "Error-Guessing" (FABBRI; VINCENZI; MALDONADO, 2007).

Conforme foi descrito, os critérios da técnica funcional necessitam somente da especificação do produto para derivar os RTs, podendo, dessa forma, serem aplicados em programas distintos, uma vez que o código fonte não é fundamental. No entanto, como os critérios funcionais são baseados na especificação, logo eles não podem assegurar que parte críticas e essenciais do código tenham sido cobertas sendo esta uma característica do teste estrutural (ROPER, 1994).

\subsubsection{Técnica Estrutural}

O teste estrutural, também conhecido como caixa branca, estabelece os RTs com base em um determinado código fonte, requerendo a execução de partes ou componentes do programa em teste (MYERS; SANDLER; BADGETT, 2011). Essa técnica está diretamente relacionada ao co- 
nhecimento da estrutura interna do programa, sendo os aspectos de implementação fundamentais para geração/seleção dos casos de teste (BARBOSA et al., 2007).

Geralmente, a maioria dos critérios dessa técnica utilizam uma representação de programa conhecida como Grafo de Fluxo de Controle (GFC)ou Grafo de Programa (GP). Um programa $\mathbf{P}$ pode ser representado como um $\operatorname{GFC}(G=(N, E, s))$ por meio da correspondência entre vértices (nós) e blocos de comando e a indicação de possíveis fluxos de controle entre esses blocos por meio das arestas (arcos) (MYERS; SANDLER; BADGETT, 2011). Em um GFC $(G=(N, E, s))$, $N$ representa um conjunto de nós, $E$ constitui um conjunto de arcos e $s$ retrata o nó de entrada. Um "caminho" é uma sequência finita de nós $(n 1, n 2, \ldots, n k), k \geq 2$, tal que existe uma aresta de $n_{i}$ para $n_{i}+1$ para $i=1,2, \ldots, k-1$.

GFC é um grafo orientado, com um único nó de entrada $s \in N$, sendo que cada nó constitui um bloco indivisível de comando e cada aresta constitui um possível desvio de um bloco para outro. Portanto, o teste estrutural pode ser caracterizado a partir da seleção dos elementos do GFC que devem ser executados.

Os critérios de teste estrutural baseiam-se em diferentes tipos de conceitos e elementos de programas para determinar os RTs. Os critérios estruturais são classificados em: $(i)$ critérios baseados na complexidade; (ii) critérios baseados em fluxo de controle; (iii) critérios baseados em fluxo de dados e (iv) critérios baseados na cobertura. Somente o segundo e o último critérios serão detalhados devido a serem utilizados na presente pesquisa.

1. Critérios baseados em fluxo de controle: utilizam apenas características de controle da execução do programa (comandos ou desvios), com o objetivo de determinar quais estruturas são necessárias. Os critérios mais conhecidos são (MYERS; SANDLER; BADGETT, 2004): (i) Todos-Nós: exige que cada comando do programa seja executado (passe em cada nó do GFC) pelo menos uma vez; (ii) Todas-Arestas: exige que cada aresta do grafo seja exercitada pelo menos uma vez; e (iii) Todos-Caminhos: requer que todos os caminhos possíveis do programa sejam executados.

2. Critérios baseados na cobertura: consiste em dois critérios proposto por Ammann e Offutt (2008): (i) Edge-Pair Coverage (EPC); e (ii) Prime Path Coverage (PPC). Além desses critérios, Ammann e Offutt (2008) também cita os critérios Todos-Nós (Node Coverage $(N C)$ ) e Todas-Arestas (Edge Coverage $(E C)$ ).

a) Node Coverage (NC): o critério NC exige que cada nó $n$ presente no GFC seja executado pelo menos uma vez, ou seja, um teste $T$ satisfaz a cobertura do nó em um grafo $G$ se e somente se para cada nó $n$ sintaticamente alcançável, existe um caminho $p$ presente em $T$, em que $p$ visita $n$.

b) Edge Coverage (EC): o critério EC exige que cada aresta $e$ presente no GFC seja executada pelo menos uma vez, ou seja, um teste $T$ satisfaz a cobertura da aresta 
em um grafo $G$ se e somente se para cada aresta $e$ sintaticamente alcançável, existe um caminho $p$ presente em $T$, em que $p$ visita $e$. Os RTs derivados por meio do EC possuem cada caminho alcançável de comprimento até 1 , ou seja, cada caminho deve conter pelo menos uma aresta.

c) Edge-Pair Coverage (EPC): o critério EPC exige a cobertura de pares de arestas ou caminhos alcançáveis de comprimento até 2 , ou seja, grafos que possuem pelo menos duas arestas.

d) Prime Path Coverage (PPC): no critério PPC um caminho de $\mathrm{n}_{i}$ até $\mathrm{n}_{j}$ é dito um caminho primo se ele é um caminho simples e não aparecer como um subcaminho adequado de qualquer outro caminho simples. O PPC envolve dois casos especiais com o tratamento de loops com caminhos de "ida e volta" (do inglês, round trip), ou seja, caminhos que começam e terminam no mesmo nó. O primeiro caso é o Simple Round Trip Coverage (SRTC), no qual o RT contém pelo menos um caminho de ida e volta para cada nó alcançável em $G$ que começa e termina um caminho de ida e volta. O último caso é o Complete Round Trip Coverage (CRTC), no qual o RT possui todos os caminhos de ida e volta para cada nó alcançável em $G$.

\subsubsection{Técnica baseada em Defeitos}

O teste baseado em defeitos utiliza informações sobre os tipos específicos de defeitos que se deseja revelar e os erros mais frequentes cometidos no processo de desenvolvimento de software. Dentre os critérios baseados em defeitos, é importante destacar Semeadura de Erros (BUDD, 1981) e Teste de Mutação (DEMILLO; LIPTON; SAYWARD, 1978). Neste texto dá-se ênfase ao último critério, pois foi utilizado para durante a avaliação empírica que será apresentada no Capítulo 6.

No teste de mutação pequenas modificações sintáticas são realizadas no programa em teste (do inglês, Program Under Test (PUT)). Esse programas alterados, ou seja, com diferentes tipos de defeitos são chamados de mutantes. Este critério visa gerar um conjunto de casos de teste $T$ que, a partir da mesma entrada, os resultados gerados pelo programa original $P$ sejam diferentes dos gerados pelos programas mutantes $P^{\prime}$.

Para modelar as modificações sintáticas nos programas mutantes são utilizados os operadores de mutação (do inglês, Mutation Operators $(M O s)$ ). Um operador de mutação é aplicado a um programa original $P$, transformando-o em programas mutantes de $P$ (DELAMARO; MALDONADO; JINO, 2007). Os operadores de mutação consistem em regras que determinam as modificações que devem ser realizadas no programa original $P$. Os operadores de mutação são criados com a finalidade de satisfazer um entre dois propósitos: (i) induzir mudanças sintáticas simples com base nos erros comuns cometidos durante o processo de desenvolvimento, por exemplo, modificar o nome de uma variável; ou (ii)forçar objetivos comuns de teste, por exemplo, executar cada arco do programa. 
Em seguida o conjunto de casos de teste $T$ gerado é aplicado em $P$ e no conjunto de mutantes $P^{\prime}$ a fim de evidenciar se os casos de teste são capazes de revelar defeitos, ou seja, distinguir as saídas dos programas $P^{\prime}$ do programa $P$. Se um mutante $P^{\prime}$ gerar uma saída diferente do programa $P$ para um determinado caso de teste, então, o mutante $P^{\prime}$ está "morto", caso contrário, está “vivo". Na Figura 4 é exibido um exemplo de uma mutação gerada com a mudança do operador relacional ">" do programa $P$ para o operador " $<$ ".

Figura 4 - Exemplo de um programa sem defeitos (programas original) e um com defeitos (mutante)

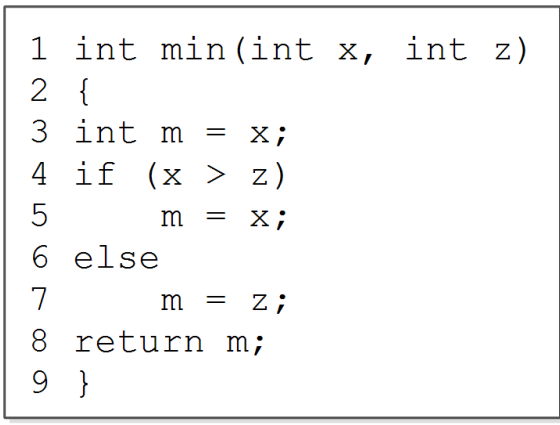

Original

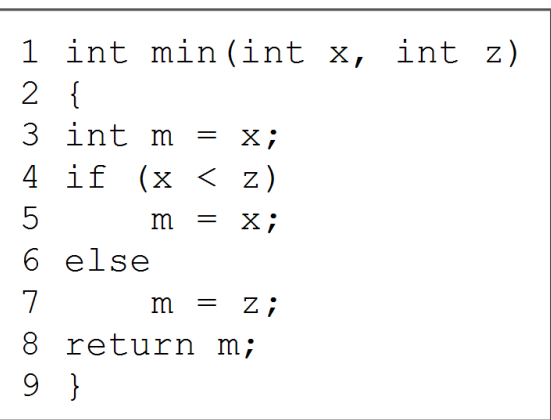

Mutante

Fonte: Elaborada pelo autor.

Caso o mutante $P^{\prime}$ apresente sempre a mesma saída do programa $P$ para qualquer valor de entrada, então $P^{\prime}$ é classificado como equivalente, ou seja, os casos de teste não são adequados o suficiente para matar esse mutante. É importante destacar que, em geral, a equivalência entre programas é uma questão indecidível e requer a intervenção do testador. Na Figura 5 é ilustrado um exemplo de mutante equivalente gerado com com a mudança do operador "==" do programa P para o operador " $<=$ ".

Figura 5 - Exemplo de mutante equivalente em relação ao programa original

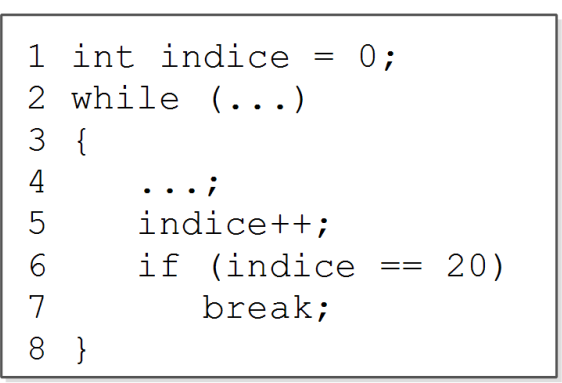

Original

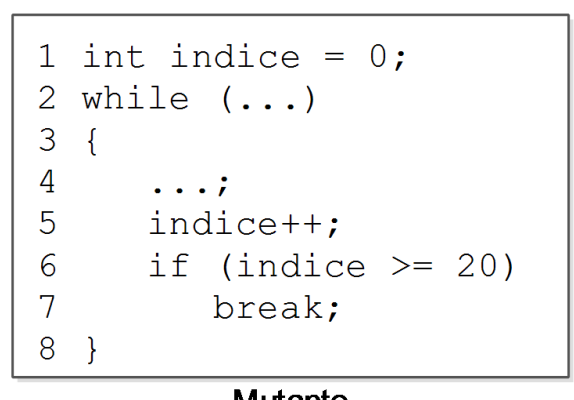

Mutante

Fonte: Elaborada pelo autor.

Para analisar o nível de confiança da adequação dos casos de teste gerados, o teste de mutação fornece uma medida objetiva denominada de Escore de Mutação (EM) (do inglês, Mutation Score (MS)) (DEMILLO, 1980). O escore de mutação relaciona o número de mutantes mortos com o número de mutantes gerados e varia entre $0 \%$ e $100 \%$. O escore de mutação é calculado por meio da seguinte formula (2.1): 


$$
E M(P, T)=\frac{M(P, T)}{M M(P)-M E(P)}
$$

em que:

$\mathrm{MM}(\mathrm{P}, \mathrm{T})$ : número de mutantes mortos pelo conjunto de teste $\mathrm{T}$;

$\mathrm{M}(\mathrm{P})$ : número total de mutantes gerados;

$\mathrm{ME}(\mathrm{P})$ : número de mutantes gerados equivalentes a $\mathrm{P}$.

Quando o valor do escore de mutação alcançar $100 \%$, significa que o conjunto de teste $T$ é adequado para testar o programa $P^{\prime}$, logo, a confiança é consideravelmente alta uma vez que o programa em teste está praticamente livre de defeitos.

Portanto, a partir das técnicas e seus respectivos critérios descritos e exemplificados, tais técnicas podem ser consideradas como complementares, uma vez que cobrem classes distintas de defeitos. Nesse contexto, o estabelecimento de estratégias de testes incrementais com a finalidade de explorar as diversas características dos critérios de teste favorece a obtenção de casos de teste mais eficazes e de qualidade.

\subsection{Considerações Finais}

Neste capítulo foram reunidos os principais aspectos conceituais de ER e da atividade de teste de software relacionados ao contexto que este trabalho se insere. Vale ressaltar que também foram apresentados os conceitos relacionados ao processo de ER, uma vez que, independente do domínio, é necessário que qualquer sistema computacional tenha seus requisitos definidos de forma adequada, considerando as especificidades tecnológicas adotadas no projeto do sistema. Visando contribuir para definição de requisitos e automatização da atividade de teste, especificamente neste trabalho, o interesse está relacionado ao domínio de RV que será apresentado no capítulo seguinte.

Observou-se também que as técnicas de teste são diferenciadas pelas informações utilizadas na construção e avaliação de casos de teste. Essas técnicas visam a avaliar a qualidade da atividade de teste que, por sua vez, está associada ao critério de teste utilizado, uma vez que ele define quais requisitos deverão ser utilizados na avaliação dos testes. Assim, a utilização de técnicas e critérios de teste é fundamental na seleção de casos de teste, pois consegue minimizar a quantidade de casos de teste e a identificação de defeitos a um baixo custo. 


\section{3}

\section{FUNDAMENTOS DE REALIDADE VIRTUAL}

\subsection{Considerações Iniciais}

Neste capítulo são descritos conceitos fundamentais de RV na Seção 3.2. Conceitos sobre bibliotecas gráficas são fundamentadas na Seção 3.3. Conceitos e a construção de um Grafo de Cena são descritos na Seção 3.4. A importância da ER para sistemas de RV é descrito na Seção 3.6. Por fim, o framework ViMeT é apresentado na Seção 3.5, pontualizando uma das motivações para o desenvolvimento deste projeto e, por fim, na Seção 3.7 são discutidas as considerações finais do capítulo.

\subsection{Realidade Virtual}

Representações da realidade ou da imaginação sempre fizeram parte do cotidiano do ser humano, permitindo-o se expressar ao longo tempo. Essas expressões foram convergidas e potencializadas por meio da utilização do computador, viabilizando sons, vídeos, imagens, animações e interações. Com a utilização dessas tecnologias, ambientes 3D interativos são gerados por meio de técnicas de RV. O conceito mais citado na literatura sobre RV a define como a forma mais avançada de interação entre o usuário e o computador em tempo real, a partir de um ambiente 3D sintético, utilizando dispositivos multissensoriais (KIRNER; SISCOUTTO, 2007).

O AV de aplicações de RV permite que ao usuário interagir usando uma variedade de dispositivos, desde os mais simples, tais como teclado, mouse e monitor de vídeo até dispositivos mais complexos de interação e imersão como luva de dados, um capacete Head-Mounted Display (HMD) e dispositivos tácteis (TREVISAN et al., 2014), (KIRNER; SISCOUTTO, 2007).

A RV permite ao usuário modificar e interagir com cenas 3D envolvendo objetos virtuais para representar situações reais ou imaginárias. As aplicações de RV podem fornecer diferentes graus de imersão, com diferentes sentidos envolvidos, tais como visão, tato e audição, dependendo 
dos recursos computacionais e do equipamento utilizado (KIRNER; SISCOUTTO, 2007).

De acordo com Vince (2004), o usuário pode explorar e até mesmo modificar o AV, o que lhe é possível por meio de técnicas de navegação, interação e imersão. A navegação refere-se à movimentação do usuário no AV, envolvendo a "viagem" e a "definição do trajeto". A "viagem" consiste na movimentação mecânica no ambiente e é utilizada para explorar, buscar e manobrar, envolvendo seleção de direção, objetivo, velocidade, aceleração e ações como: iniciar o movimento, indicação de posição e orientação e parar o movimento. A "definição do trajeto" é a componente cognitiva da navegação que permite o estabelecimento do caminho a ser seguido, do conhecimento e do comportamento espacial do usuário (TORI; KIRNER; SISCOUTTO, 2006).

A interação oferece a oportunidade de interagir com objetos virtuais e manipulá-los como se fossem objetos reais. Monteiro e Zanchet (2003) afirmam que imersão pode ser mental ou física. A imersão mental ocorre quando os objetos virtuais 3D são visualizados somente em um dispositivo de saída sem que o usuário tenha a sensação de estar dentro do AV. A imersão física ocorre quando o usuário utiliza dispositivos como HMD ou outros aparatos estereoscópicos para ter a sensação de estar dentro do AV.A navegação dentro de um AV é um exemplo de interação.

Nesse contexto, a RV pode ser classificada, em função da sensação de estar dentro do $\mathrm{AV}$, em vários graus de imersão, desde RV não imersiva até RV totalmente imersiva. A RV é imersiva quando o usuário tem a sensação de estar presente dentro do mundo virtual por meio da utilização de dispositivos sensoriais (capacetes e caverna, por exemplo) que captam seus movimentos e comportamento. Já a RV é considerada como não imersiva, quando o usuário é transportado parcialmente ao mundo virtual por meio de uma janela (monitor ou projeção, por exemplo) (TORI; KIRNER; SISCOUTTO, 2006). Na Figura 6 é apresentado um exemplo de sistema de RV não imersivo utilizando monitor e um exemplo de sistema de RV imersivo utilizando um capacete HMD.

Figura 6 - Exemplo de um ambiente de RV não imersivo e imersivo

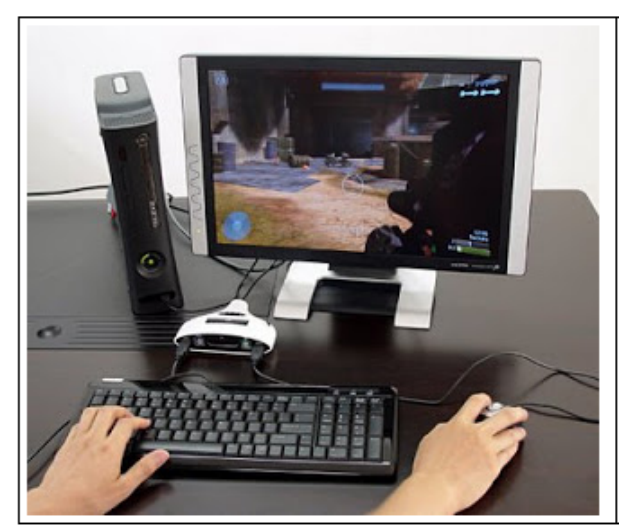

(a) Não existe imersão

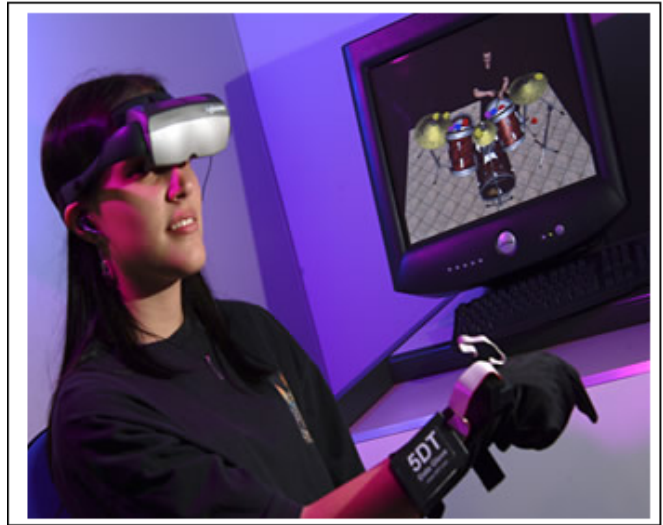

(b) Existe imersão

Fonte: MariLili (2011), Alipio (2010). 
Com a evolução tecnológica, novos dispositivos de entrada e saída foram surgindo ao longo do tempo, porém a classificação da RV de acordo com os diferentes graus de imersão ainda permanece. A imersão envolve principalmente o sentido da visão, mas os demais sentidos também contribuem para prover ao usuário a sensação de estar dentro do AV. Vários dispositivos visam a disponibilizar modos mais intuitivos de interação. Para ocorrer essa interação com o mundo virtual, o usuário pode utilizar dispositivos convencionais, como mouse ou teclado, ou dispositivos não convencionais, como luva de dados (MARCO, 2012) e dispositivos hápticos (INITION, 2013).

É importante destacar que usando esses dispositivos os usuários podem interagir por meio da seleção, manipulação e controle do sistema (KIRNER; SISCOUTTO, 2007). A seleção consiste na definição de um objeto virtual para ser manipulado, envolvendo três passos: indicação do objeto, confirmação e realimentação. A indicação normalmente é realizada por meio dos dedos ou das mãos, empregando algum dispositivo de entrada, podendo ocorrer por oclusão, toque no objeto, apontamento ou de maneira indireta. $\mathrm{O}$ sistema deve apresentar a seleção, usando elementos visuais, auditivos ou hápticos, como mudar cor, piscar, emitir som, emitir reação, etc. Para que a seleção tenha efeito, ela deve ser confirmada, o que pode ser feito, por meio de eventos tais como: clique do mouse, acionamento da tecla, gesto, comando de voz ou outra ação. Novamente, deverá haver uma realimentação, indicando que a ação ocorreu.

A manipulação de um objeto selecionado consiste na alteração de sua posição, por meio de translação, rotação ou escala; ou de suas características, como cor, transparência e textura. O objeto selecionado pode ser também: apagado, copiado, duplicado, deformado ou alterado por outras ações. O controle do sistema consiste na emissão de comandos do usuário para serem executados pelo sistema. Os comandos podem ser emitidos por meio de menus gráficos, comandos de voz, comandos gestuais ou por meio de dispositivos de comandos específicos (BOWMAN et al., 2004).

Para melhorar a interação com o usuário, um sistema de RV deve possuir alguns requisitos, tais como: $(i)$ interface de alta qualidade, para se aproximar ao máximo do mundo real e permitir uma interação mais intuitiva; (ii) alta interatividade, permitindo ao ambiente reagir de forma adequada de acordo com as ações dos usuários; (iii) imersão, consistindo na sensação oferecida ao participante de uma simulação de estar dentro do AV; (iv) envolvimento e uso da intuição, que consiste em oferecer condições para que o usuário se concentre e realize atividades como no mundo real; e $(v)$ analogia e ampliação do mundo real, permitindo que o AV seja definido como o mundo real, com acréscimo de aspectos que não são encontrados neste último (MONTEIRO; ZANCHET, 2003).

Portanto, para facilitar o desenvolvimento de aplicações com todos os requisitos necessários utilizando diversos dispositivos, surgiram algumas bibliotecas gráficas de RV que agem como uma camada de abstração, uma vez que são capazes de fornecer informações a repeito da posição do dispositivo ou de sua orientação, sem que a aplicação saiba de qual dispositivo esta 
informação está sendo encaminhada.

\subsection{Bibliotecas Gráficas}

A construção de AVs consiste em representar o mundo real utilizando primitivas (esfera, cone, cilindro, caixa, curvas e superfícies) ou elementos mais complexos que têm o poder de representar objetos reais com maior fidelidade. Existem diversas técnicas disponíveis para essa representação sendo a mais comum a representação por malhas de triângulos ou outros polígonos (BIRTHELMER; SOETEBIER; SAHM, 2003).

No ambiente computacional, as bibliotecas gráficas são responsáveis por fazer a ligação entre a aplicação e a placa gráfica, facilitando a construção de AVs e a manipulação dos objetos $3 \mathrm{D}$, favorecendo a interação em tempo real. A aplicação envia a malha, juntamente com seus atributos (cor, material, texturas, etc.), para a biblioteca gráfica e esta, por sua vez, envia os vértices para a placa gráfica que fará os cálculos necessários para transformar a coordenada 3D dos vértices dos polígonos em pixels na tela do computador (SHREINER, 2009). Na Figura 7 são ilustradas as etapas referentes à renderização de um objeto 3D.

Figura 7 - Etapas de renderização de um objeto 3D

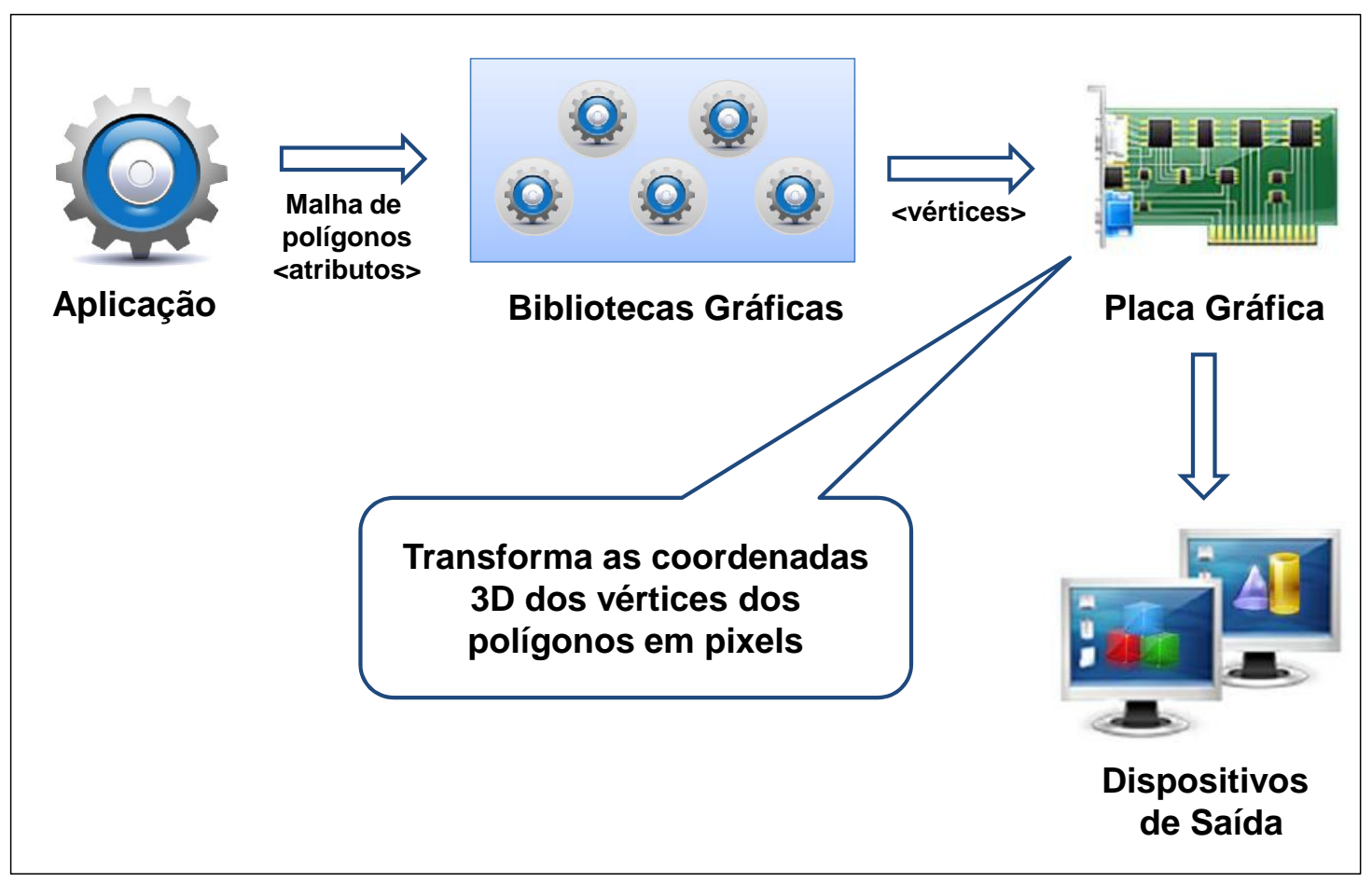

Fonte: Adaptada de Shreiner (2009).

Segundo Walsh (2002), as bibliotecas gráficas podem ser denominadas de Application Programming Interface (API) gráficas, sendo as mais utilizadas a Open Graphics Library 
$(\text { OpenGL })^{1}$ e a DirectX ${ }^{2}$. A OpenGL é uma API livre utilizada na computação gráfica, para desenvolvimento de aplicativos gráficos, ambientes 3D, jogos, entre outros. A DirectX é uma interface de desenvolvimento capaz de facilitar a comunicação entre software e hardware quando o assunto é um jogo eletrônico para o sistema operacional Microsoft Windows (MICROSOFT, 2017).

Com o avanço da tecnologia das placas gráficas, as aplicações de computação gráfica e, consequentemente, de RV, estão sendo capazes de produzir efeitos visuais que não podem ser percebidos em aplicações $2 \mathrm{D}$. No entanto, essa tecnologia traz consigo um alto grau de complexidade. A alta complexidade das cenas em ambientes virtuais levou à necessidade de definir-se estruturas adequadas para representá-las. Uma dessas estruturas, utilizada por uma parte significativa das bibliotecas gráficas é o GC, descrito na próxima seção.

\subsection{Grafo de Cena}

Grafo de Cena é uma estrutura de dados hierárquica capaz de especificar cenas complexas. É composto por nós que representam objetos, suas características (geometria, cor, textura) e comportamentos (WOO et al., 1999). Cada uma dessas características desempenha um papel importante no AV, que deve ser incorporado no GC. As principais propriedades que podem ser representadas na estrutura do GC são descritas a seguir (FERREIRA, 1999).

- Descrição geométrica: trata-se em representar a forma do objeto a ser processado. Quanto maior a complexidade da descrição geométrica, melhor a qualidade visual e menor a velocidade com que a imagem é gerada (Figura 8). Além disso, Ferreira (1999) destaca que a descrição geométrica pode ser classificada no tempo como estática ou dinâmica. A descrição geométrica estática não varia a forma de um objeto no tempo, enquanto que na descrição dinâmica sua forma pode ser modificada;

- Aparência: influencia na qualidade da imagem final. A aparência pode ser dada de diversas maneiras. Entre elas, aquelas que geralmente estão presentes nas aplicações de RV são: ausência de aparência, cores, material, textura, brilho, sombra e reflexão. Além disso, é possível que haja uma combinação balanceada entre as aparências mencionadas;

- Transformação: qualquer objeto posicionado no mundo virtual pode sofrer uma transformação geométrica (rotação, translação ou escala). As transformações estão diretamente relacionadas à hierarquia dos objetos, pois se um nó pai for transformado, seus nós filhos herdarão sua transformação (BAR-ZEEV, 2007);

- Comportamento: pode ser classificado em duas categorias: determinístico e não determinístico. O comportamento determinístico é aquele que pode ser definido em função

2 http://www.microsoft.com/windows/directx 
Figura 8 - Exemplo da renderização de um objeto 3D

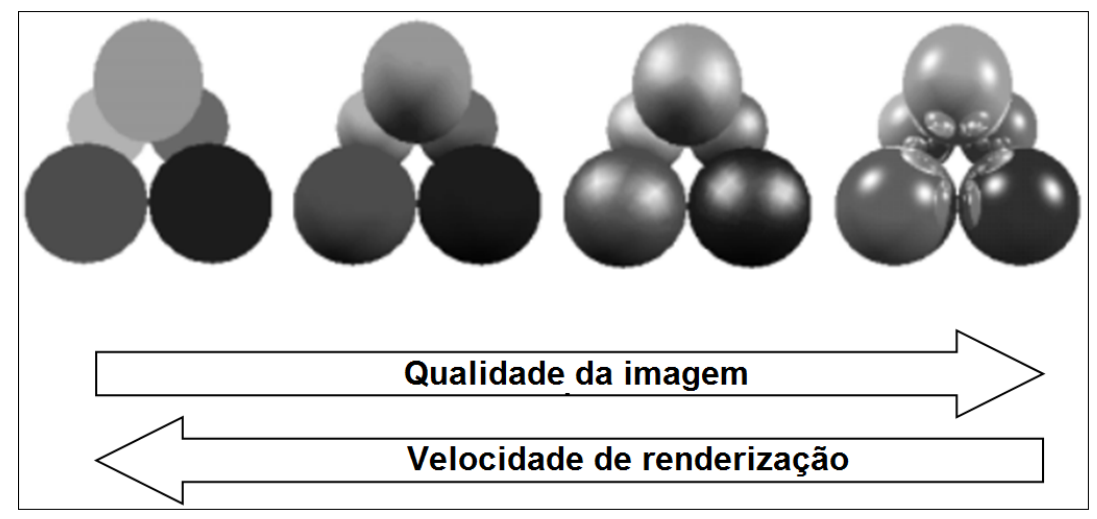

Fonte: Adaptada de Ferreira (1999).

do tempo, enquanto que o comportamento não determinístico é imprevisível, uma vez que trata-se do reflexo de ações do usuário que não seguem um padrão definido (ROEHL, 1995);

- Câmera: é a visão do mundo virtual. Geralmente é uma câmera de projeção perspectiva; e

- Iluminação: várias fontes de luz podem ser adicionadas à cena, logo nenhum tipo de impedimento referente à quantidade de luz pode ser empregado. Existem vários tipos de modelos de iluminação, dentre os quais podem ser destacados o de Gouraud (1971), pois o seu cálculo é realizado nas placas gráficas atuais; o de Phong (1975); e o de Poulin e Fournier (1990) que aborda a anisotropia ${ }^{3}$.

É importante destacar que cada uma dessas propriedades deve ser inserida no GC, a fim de representar os objetos no AV. Esses objetos são representados por nós (vértices) e são conectados por meio das arestas (arcos) (MANSSOUR, 2003). Os nós de um GC podem ser divididos em três categorias: nó raiz, nó interno e nó folha. O nó raiz é o primeiro nó do grafo de cena, logo todos os demais nós são ligados direta ou indiretamente a ele. Os nós internos, também conhecidos como nós de agrupamento, podem ter uma variedade de propriedades, dentre as mais comuns destacam-se as transformações 3D (rotação, translação e escala) e descrevem a posição, orientação, ou estado do mundo 3D. Por fim, o nó folha contem dados geométricos. Deste modo, um GC é uma coleção de nós em uma estrutura de grafo ou árvore.

Baseado nos conceitos mencionados anteriormente, a utilização de um GC em uma aplicação ocorre basicamente por meio de três passos (VALENTE, 2004):

1. construção: consiste em criar instâncias dos nós, determinar os valores que os nós representam e determinar as hierarquias entre os nós. Um dos nós é escolhido para ser o nó raiz, que é o ponto de entrada no GC;

\footnotetext{
3 Ansitropia utiliza cilindros para calcular a direção da iluminação.
} 
2. travessia: é um passo importante e está diretamente relacionado ao desempenho da aplicação. A travessia do GC começa pela raiz e termina em nós folhas. Essa travessia é dita completa se percorrer todos os caminhos possíveis do nó raiz até os nós folhas. Ao final da travessia do GC uma imagem renderizada é obtida; e

3. otimização: a compilação do GC pode realizar duas tarefas: reordenação dos nós e otimização do grafo. A reordenação dos nós visa reagrupar os nós de modo a minimizar o número de alterações de estados do hardware gráfico realizadas durante a travessia, sem alterar os resultados finais da renderização. Já a otimização do grafo visa gerar um grafo de funcionalidade equivalente com um menor número de nós. A compilação do grafo é executada, geralmente, uma única vez, no início da aplicação. No entanto, se durante a execução alguma parte do grafo for alterada, pode ser necessário realizar uma nova compilação, o que pode prejudicar o desempenho.

A partir da utilização do $\mathrm{GC}$ foram identificadas algumas vantagens na liteaturas em relação: ao desempenho, por explorarem técnicas de eliminação de objetos que não contribuem para o resultado final da imagem; à produtividade, pois além de implementarem grande parte dos requisitos necessários para se desenvolver uma aplicação, possibilitam a aplicação de paradigmas como orientação a objetos, permitindo a reutilização de projetos; à portabilidade, pois traduções da aplicação para execução em outros ambientes de hardware podem necessitar apenas de recompilação de código fonte; à escalabilidade, que consiste no poder oferecido pelos GCs para aumentar a complexidade da simulação de maneira controlada.

\section{$3.5 \quad$ ViMeT}

Muitas áreas têm se beneficiado com o desenvolvimento de ferramentas de RV para simular procedimentos para o treinamento de profissionais. Dentre essas áreas, a medicina é a que tem mais se destacado. Nessa área simuladores de RV podem proporcionar uma experiência de aprendizagem aos estudantes, diminuindo a probabilidade de ocorrer imprevistos quando o profissional for realizar os procedimentos médicos em um paciente real (LIU et al., 2003).

Nesse contexto, está em desenvolvimento no LApIS da EACH-USP, um framework denominado Virtual Medical Training (ViMeT) (OLIVEIRA; NUNES, 2010), construído utilizando as tecnologias Java e a API Java 3D, com a finalidade de possibilitar a geração de ferramentas de RV para treinamento médico.

O ViMeT permite construir com facilidade um AV dinâmico com objetos virtuais que representam um órgão humano e um instrumento médico. Ele disponibiliza funcionalidades importantes para o treinamento virtual, como a detecção de colisões com precisão, a deformação de objetos flexíveis na região de contato com o objeto rígido, estereoscopia, além de interação com equipamentos convencionais (mouse e teclado) e não convencionais (luva de dados e dispositivo 
háptico). Paralelamente ao desenvolvimento do ViMeT foi desenvolvida uma ferramenta de instanciação denominada ViMeTWizard para auxiliar na geração de aplicações e manutenção dos dados de cada aplicação gerada (NUNES et al., 2007).

Como já mencionado anteriormente, a necessidade de se explorar técnicas de teste surgiu em função dos trabalhos realizados em conjunto com os pesquisadores do LApIS, para que os sistemas desenvolvidos utilizando o ViMeT ou outros arcabouços pudessem ser avaliados de forma sistemática e fundamentada. Portanto, espera-se que a proposta desse projeto seja aplicável a qualquer sistema de RV que implemente suas funcionalidades por meio de GCs. É importante ressaltar que aplicações geradas pelo ViMeT podem ser estudos de caso para a validação deste projeto, porém não existem dependências entre ambos, podendo ser aplicado a outros sistemas de RV.

\subsection{Engenharia de Requisitos para sistemas de Realidade Virtual}

Assim como em qualquer sistema de software, é necessário que um sistema de RV tenha seus requisitos definidos adequadamente, em conformidade com as peculiaridades desses sistemas, a fim de que a aplicação desenvolvida esteja em conformidade com as necessidades do usuário.

Projetos de sistemas de RV começam com uma lista de requisitos que devem ser analisados cuidadosamente, a fim de verificar a necessidade da RV. Os requisitos devem ser centrados em torno das expectativas do usuário. Com base nos requisitos, o cenário geral pode ser construído usando storyboards ${ }^{4}$. Os objetos que compõem a cena são identificados e as especificações básicas em relação a sua forma, função e comportamento devem ser realizadas. Além disso, outros aspectos do sistema, como restrições de dispositivo, interação, efeitos e sinais de presença são também observados nesta fase inicial de desenvolvimento do sistema.

Dessa forma, o uso de metodologias de desenvolvimento de sistemas que priorizem o papel do usuário no projeto se constitui em um requisito essencial no que se refere ao atendimento de padrões de usabilidade esperados em sistemas de RV. Apesar dessa importância, estudos que priorizem e detalhem o processo de desenvolvimento desses sistemas de modo que os reais benefícios do uso da tecnologia da RV em sistemas interativos sejam efetivamente explorados por meio de abordagens com enfoque no usuário, dificilmente são identificados na literatura.

Portanto, o desenvolvimento desses sistemas, além de apresentar maior grau de complexidade, caracteriza-se como um desafio, principalmente no que diz respeito ao projeto de sua

4 É uma técnica utilizada principalmente para trabalhar nos detalhes dos ambientes, no qual são descritos como o usuário irá interagir com o artefato que está sendo desenvolvido (??). Essa descrição é realizada por meio de quadros com imagens que ilustram os eventos do domínio. Cada quadro deve representar uma cena que descreve os eventos, os atores e as ações que cada um deve desempenhar. 
interface, à conformidade de suas funcionalidades e aos requisitos dos usuários.

\subsection{Considerações Finais}

Neste capítulo foram reunidos os principais aspectos conceituais sobre RV, bibliotecas gráficas, GC, o framework ViMeT, bem como a importância da ER para sistemas de RV. No próximo capítulo é apresentado um Mapeamento Sistemático (MS), com a finalidade de enriquecer as motivações da proposta desse trabalho, apresentando o estado da arte referente a utilização das áreas de ES como ER, Projeto de Software e Teste de Software para sistemas de RV e as contribuições de RV para essas áreas. 

CAPÍTULO

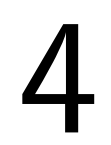

\section{MAPEAMENTO SISTEMÁTICO SOBRE A RELAÇÃO ENTRE ES E RV}

\subsection{Considerações Iniciais}

Conforme a área de pesquisa vai evoluindo, existe uma tendência referente ao aumento do número de resultados divulgados, tornando-se importante uma síntese para o fornecimento de uma visão geral em uma determinada área. Nesse contexto, Engenharia de Software baseada em Evidência (do inglês, Evidence-Based Software Engineering-EBSE) propõe a utilização de determinadas técnicas para a identificação, avaliação, interpretação e sintetização das informações relacionadas aos estudos relevantes sobre uma determinada área de pesquisa (KITCHENHAM; BUDGEN; BRERETON, 2015).

Dentre tais técnicas é importante destacar o Mapeamento Sistemático (MS) (do inglês, Systematic Mapping Study (SM)). Nesse contexto, foi realizado um MS sobre a relação entre ER e RV (SANTOS; DELAMARO; NUNES, 2013), projeto de software e teste de software e RV. A motivação para realizar esse MS é identificar as principais técnicas de ER que são utilizadas no contexto de RV, bem como as estratégias de projeto de software e os tipos de testes que são realizados em aplicações de RV. Esse MS foi conduzido em 2013 e atualizado em 2016. Além disso, para a realização do MS foi utilizado o processo proposto por Kitchenham et al. (2010) que é composto por três fases: ( i) Planejamento, (ii) Condução e (iii) Análise.

Este capítulo está organizado da seguinte forma: a Seção 4.2 descreve o processo de planejamento do MS, definindo as questões de pesquisa; a Subseção 4.2.1 apresenta a estratégia de busca, bem como as fontes de estudos utilizadas no MS; na Subseção 4.2.2 são descritos os critérios utilizados para apoiar a seleção dos estudos; na Subseção 4.2.3, o esquema de classificação e o processo de extração dos dados é discutido; na Seção 4.3 o processo de seleção dos estudos para cada Questão de Pesquisa (QP) é apresentado; na Seção 4.4, a síntese e a análise 
dos estudos primários são apresentadas; a Seção 4.5 apresenta as ameaças à validade do MS; por fim, a Seção 4.6 descreve as considerações finais deste capítulo.

\subsection{Planejamento do Mapeamento Sistemático}

O protocolo é um artefato fundamental no MS que descreve o processo e os métodos que serão adotados. Nesse protocolo são especificadas as Questões de Pesquisa (QPs), as bases de dados consultadas, as strings de busca, os critérios de inclusão e exclusão, bem como a forma que será realizada a extração dos dados. Segundo Kitchenham et al. (2010), as QPs devem ser estruturadas e analisadas utilizando a técnica Population, Intervention, Comparison e Outcomes (PICO). Esses termos podem ser vistos em detalhes no Apêndice B. A partir desses termos, as seguintes QPs foram definidas:

- $\mathbf{Q P}_{1}$ :Quais são as evidências existentes da relação entre ER e RV?

$\mathrm{Na} \mathrm{QP}_{1}$ busca-se investigar quais e como as técnicas e/ou metodologias de ER são utilizadas no processo de desenvolvimento de sistemas de RV. Além disso, pretende-se identificar também como as tecnologias de RV são utilizadas no processo de ER.

- $\mathbf{Q P}_{2}$ :Quais são as evidências existentes da relação entre projeto de software e RV?

Nesta QP busca-se revelar quais metodologias, abordagens e/ou estratégias de projeto de software estão sendo utilizadas no desenvolvimento de sistemas de RV. Além disso, pretende-se detectar como as tecnologias de RV são utilizadas na área de projeto de software.

- $\mathbf{Q P}_{3}$ : Quais são as evidências existentes da relação entre Teste de Software e RV?

$\mathrm{Na} \mathrm{QP}_{3}$ busca-se pesquisar quais tipos de teste e como têm sido utilizados no desenvolvimento de sistemas de RV. Além disso, pretende-se identificar como as tecnologias de RV são utilizadas na atividade de teste de software.

\subsubsection{Estratégia de Busca}

Com a criação das QPs, a string de busca foi definida. Na Figura 9, são apresentadas as strings de busca utilizadas para cada $Q P$.

Após a criação da string, o próximo passo consistiu em definir em quais fontes de busca a string criada deve ser aplicada. A seleção das fontes foi realizada em conjunto com um especialista da área de ES e RV, a fim de garantir uma maior cobertura de estudos relevantes. Para assegurar a inclusão de todos os estudos relevantes foram realizadas pesquisas automática, manual e por meio de referências. Na Tabela 1 são apresentadas as fontes de buscas automáticas utilizadas neste MS com base na seleção realizada por Brereton et al. (2007). 
Figura 9 - Strings de busca definidas

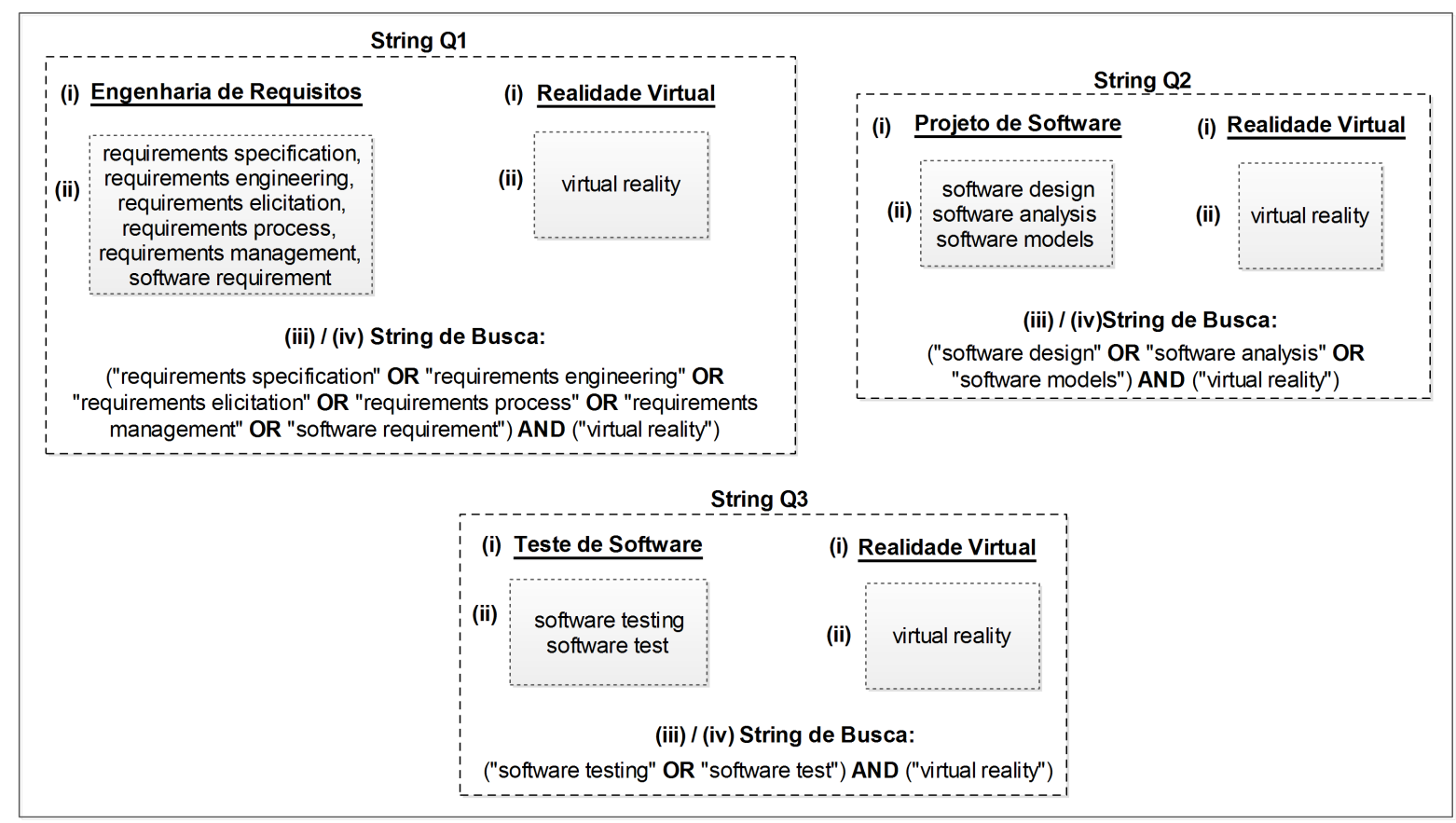

Fonte: Elaborada pelo autor.

Tabela 1 - Fontes de busca automática

\begin{tabular}{c|c}
\hline Fontes de Busca & Endereço Eletrônico \\
\hline \hline IEEE Xplore & www.ieeexplore.com.br \\
ACM Digital Library & www.portal.acm.org \\
Compendex & www.engineeringvillage.com \\
Science Direct & www.sciencedirect.com \\
Scopus & www.scopus.com \\
Springer & www.springerlink.com \\
\hline
\end{tabular}

Fonte: Elaborada pelo autor.

A busca manual foi realizada em cinco eventos relevantes das áreas de ER, Projeto de Software, Teste de Software e RV, sendo analisado o título de todos os artigos publicados e em caso de dúvidas, foi realizada a leitura do resumo, cujos artigos não foram incluídos nas bases mencionadas.

\subsubsection{Critérios para Seleção dos Estudos}

Os critérios de inclusão e exclusão apoiam a seleção de estudos relevantes e que apropriadamente auxiliam no esclarecimento das questões de pesquisa propostas. A inclusão de um estudo foi determinada pela relevância, análise do título, resumo, introdução e conclusão. Para cada questão de pesquisa foram identificados Critérios de Inclusão (CI) diferentes e os mesmos Critérios de Exclusão (CE) se mantiveram para todas as questões. No contexto desse MS, os 
estudos primários foram examinados de acordo com os seguintes critérios:

\section{- Critérios de Inclusão:}

- $\mathrm{CI}_{1}$ : estudos primários que apresentam a utilização de técnicas de ER e a utilização de um tipo de teste de software para o domínio de RV;

- $\mathrm{CI}_{2}$ : estudos primários que apresentam evidências das contribuições de RV para o processo de ER e a atividade teste de software.

\section{- Critérios de Exclusão:}

- $\mathrm{CE}_{1}$ : estudos primários que mencionam as técnicas de ER e o tipo de teste de software apenas no abstract;

- $\mathrm{CE}_{2}$ : estudos primários introdutórios para livros;

- $\mathrm{CE}_{3}$ : estudos primários com texto e conteúdo incompletos;

- $\mathrm{CE}_{4}$ : estudos primários que não sejam full paper ou short paper (pôsteres, tutoriais, relatório técnicos, teses e dissertações).

- $\mathrm{CE}_{5}$ : estudos primários que não estejam escritos em inglês ou português.

\subsubsection{Extração dos Dados}

Conforme os dados dos estudos foram extraídos e sintetizados, foi realizada uma análise detalhada dos trabalhos, classificando-os em quatro categorias: $\mathrm{C}_{1}-$ Metodologia; $\mathrm{C}_{2}-$ Ferramentas; $\mathrm{C}_{3}$-Educação e; $\mathrm{C}_{4}$-Contribuições para ES ou RV. As categorias foram definidas baseadas nos objetivos de cada estudo incluído para facilitar a compreensão dos resultados. $\mathrm{Na}$ Figura 37 é ilustrada a criação da categoria " $C_{2}-$ Ferramentas", por exemplo, sendo associados sinônimos baseados nos objetivos identificados nos estudos.

Figura 10 - Criação das categorias

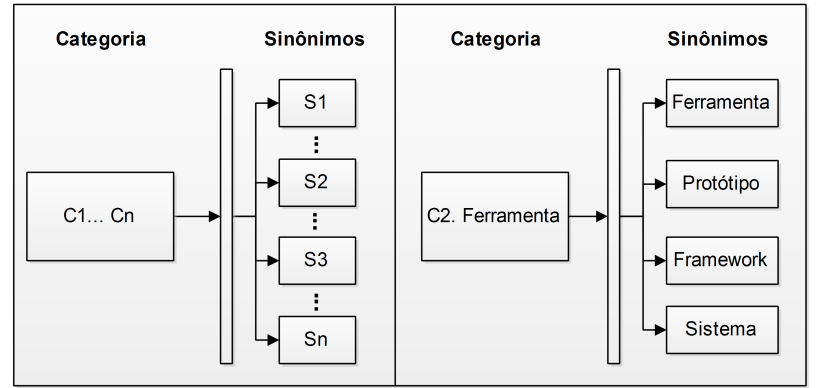

Fonte: Elaborada pelo autor. 


\subsection{Condução do Mapeamento Sistemático}

Uma visão geral do processo de seleção dos estudos primários das três QPs é apresentada na Figura 11. É importante destacar que a primeira execução deste MS foi realizada em 2013; posteriormente foi conduzido novamente em novembro de 2016 com o objetivo de atualizá-lo. No total foram incluídos 32 estudos, sendo 25 estudos por meio da busca automática, 5 estudos por meio da busca manual e 2 estudos por meio de referência.

Figura 11 - Processo de seleção dos estudos primários das questões $\mathrm{QP}_{1}, \mathrm{QP}_{2}$ e $\mathrm{QP}_{3}$

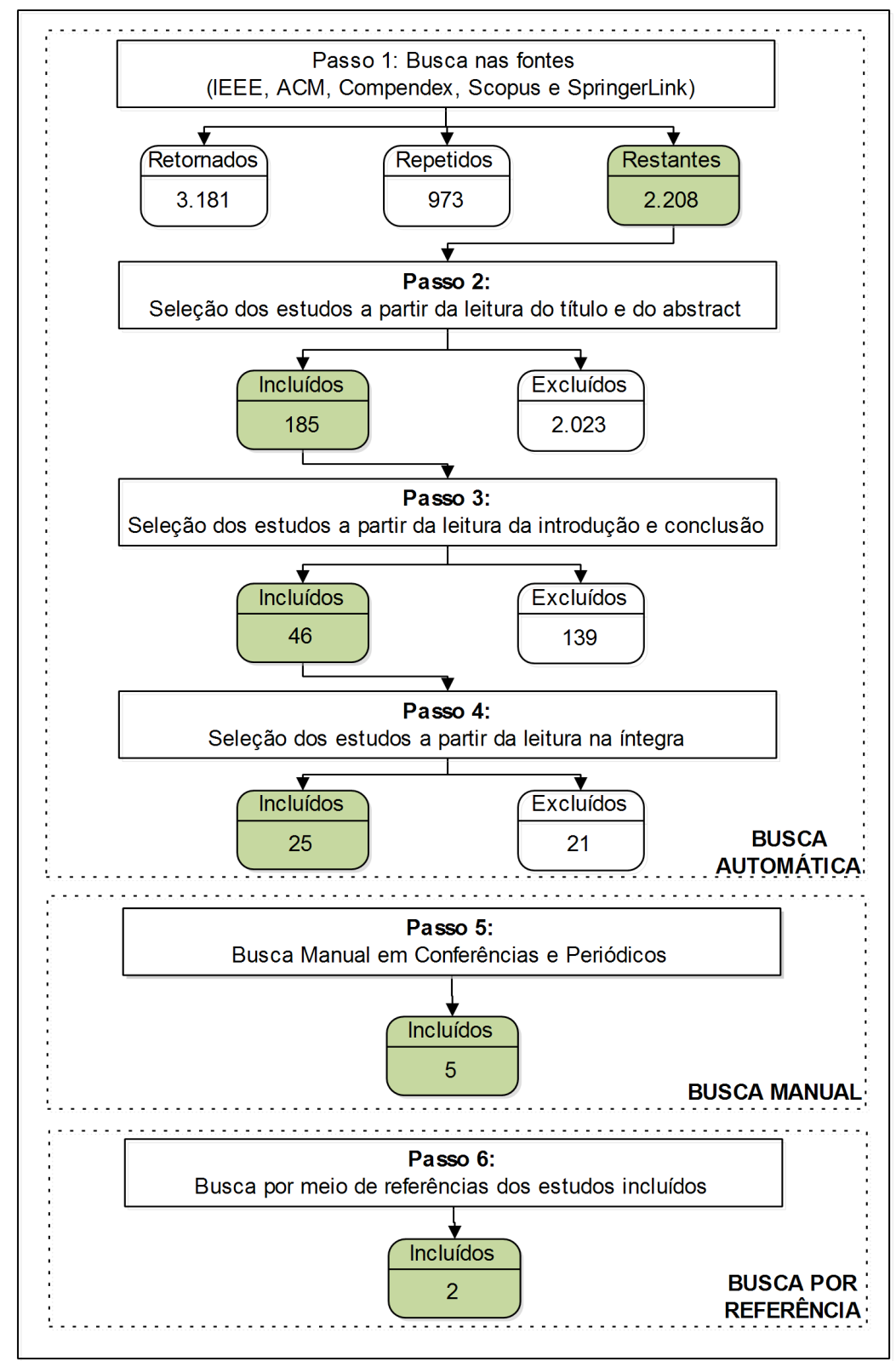

Fonte: Elaborada pelo autor.

Para $\mathrm{QP}_{1}$ foram incluídos 8 estudos por meio da busca automática e 4 estudos por meio da busca manual, totalizando 12 estudos previamente selecionados. Para $\mathrm{QP}_{2}$ foram selecionados um total de 9 estudos, sendo 6 por meio de busca automática, 1 estudo por meio da busca manual 
e 2 estudos por meio da busca por referências realizada nos 7 estudos selecionados por meio da busca automática e manual. Por fim, para $\mathrm{QP}_{3}$ todos os 11 estudos incluídos foram por meio da busca automática. Os resultados do processo de seleção para cada QP pode ser visto no Apêndice B.

\subsection{Síntese e Análise dos Dados}

Após efetuar as buscas e a análise, foi possível constatar que somente 11 estudos apresentam a relação entre ES e RV, ou seja, a utilização de ES no domínio de RV. Por outro lado, 21 estudos apresentam a utilização de RV para auxiliar alguma atividade em ES.

Para reportar a frequência e distribuição dos estudos primários selecionados de acordo com suas categorias e data de publicação foi produzido um gráfico conforme pode ser visto na Figura 12. É válido destacar que o tamanho de cada bolha representa o número de estudos primários que foram classificados em uma determinada categoria de acordo com o seu ano de publicação. Esse gráfico fornece uma visão panorâmica que permite identificar quais são as categorias que foram salientadas em pesquisas anteriores.

Figura 12 - Visão geral dos estudos primários categorizados por ano

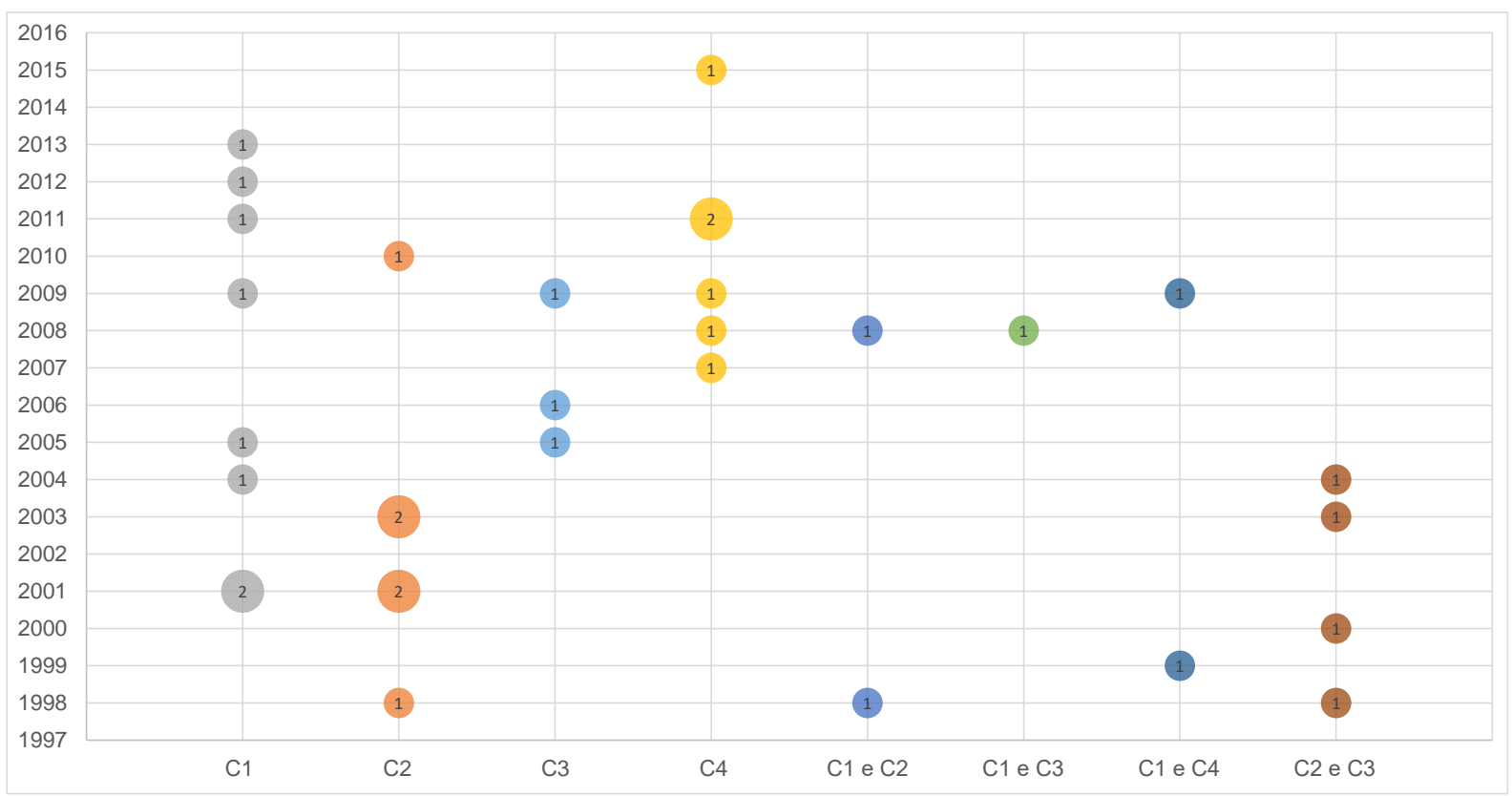

Fonte: Elaborada pelo autor.

Além disso, na Figura 13 são apresentados os estudos primários classificados de acordo com cada categoria por QP. Conforme pode ser visto, nenhum estudo primário selecionado para responder $\mathrm{QP}_{2}$ foi classificado nas categorias $\mathrm{C}_{3}$ e $\mathrm{C}_{4}$. 
Figura 13 - Visão geral dos estudos primários categorizados por QP

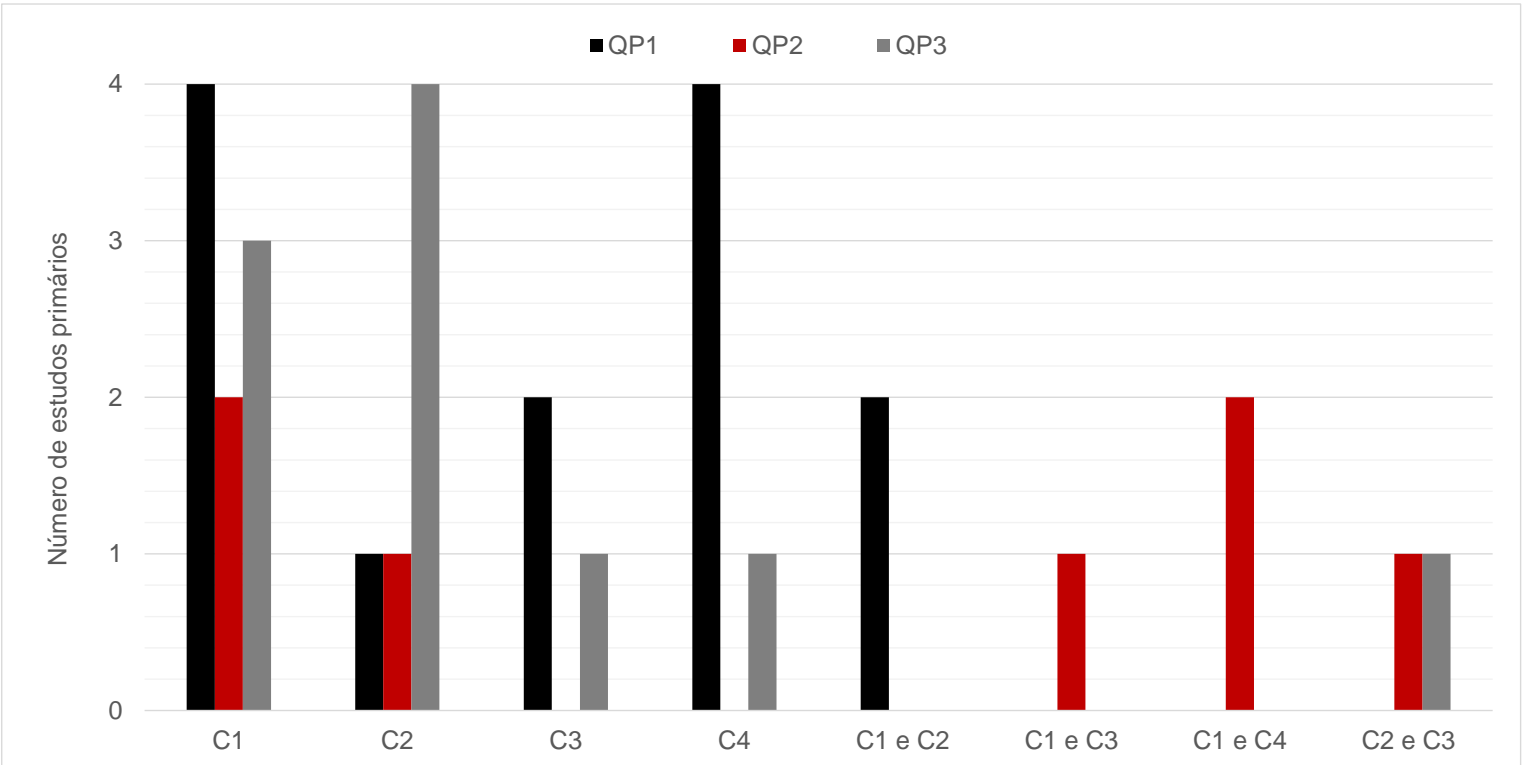

Fonte: Elaborada pelo autor.

O objetivo desta questão de pesquisa está dividido nas duas subquestões que visam a identificar: $\left(Q P 1_{1}\right)$ técnicas e/ou metodologias de ER são utilizados no processo de desenvolvimento de sistemas de RV e $\left(Q P 1_{2}\right)$ utilização de tecnologias de RV são utilizadas no processo de ER. Na Tabela 2 é presentada uma visão geral dos estudos identificados.

Tabela 2 - Técnicas de ER utilizadas em sistemas de RV e tecnologias de RV utilizadas na área de ER $\left(\mathrm{QP}_{1}\right)$

\begin{tabular}{|c|c|c|}
\hline \multicolumn{3}{|c|}{ ER - RV } \\
\hline Tipos de Técnicas & Técnicas & Estudos \\
\hline \multirow{3}{*}{ Baseadas nos conceitos de ER } & Incremental & (KIM et al., 1999) \\
\hline & ER tradicional & (KIRNER; MARTIN, 2007) \\
\hline & $\begin{array}{l}\text { Espiral e Rational Unified Process } \\
(R U P)\end{array}$ & (DAMASCENO; JR; LOPES, 2009) \\
\hline \multirow{3}{*}{ Específicas } & Fatores Humanos $(\mathrm{FH})$ & (SALEM, 2008) \\
\hline & Engenharia Semiótica (ESm) & (DAMASCENO; OLIVEIRA, 2009) \\
\hline & $\begin{array}{l}\text { Mapas conceituais, heurísticas e técni- } \\
\text { cas de mapeamento comportamental }\end{array}$ & (DAMASCENO; JR; LOPES, 2009) \\
\hline \multicolumn{3}{|c|}{ RV - ER } \\
\hline Utilização de RV & Abordagens & Estudos \\
\hline \multirow{2}{*}{ Análise e validação de requisitos } & Modelos Visuais & (WINTER; DESOVSKI; CUKIC, 2001) \\
\hline & Cenários & (SUTCLIFFE; GAULT, 2004) \\
\hline Melhorias na confiança do software & $\begin{array}{l}\text { Ferramenta Virtual-Reality based infor- } \\
\text { mation Requirement Analysis (VR-RA) } \\
\text { Ferramenta Software Attribute Visual } \\
\text { Analysis Tool (SAVAnT) }\end{array}$ & $\begin{array}{c}\text { (BAL; MANESH; HASHEMIPOUR, 2008) } \\
\text { (POLLOCK, 1998) }\end{array}$ \\
\hline Aprendizagem das práticas de ER & $\begin{array}{l}\text { Jogo multiusuário tridimensional } \\
\text { Plataforma que simula um jogo } \\
\text { Ambiente denominado de FAB ATM } \\
\text { First Australian Bank Automatic Teller } \\
\text { Machines }\end{array}$ & $\begin{array}{c}\text { (VEGA; FUKS; CARVALHO, 2009) } \\
\text { (RUSSELL; CREIGHTON, 2011) } \\
\text { (CYBULSKI; PARKER; SEGRAVE, 2006) }\end{array}$ \\
\hline
\end{tabular}

Fonte: Elaborada pelo autor.

De acordo com a análise realizada, foi possível observar que os estudos não seguem um 
padrão para a elicitação de requisitos, uma vez que as possíveis abordagens adotadas por estes são adequadas para um determinado contexto ou aplicação de RV. Alguns estudos como (KIM et al., 1999), (KIRNER; MARTIN, 2007) e (DAMASCENO; OLIVEIRA, 2009) apresentam técnicas baseadas nos conceitos de ER. Kim et al. (1999), por exemplo, apresentaram uma técnica de especificação de requisitos baseada no paradigma de desenvolvimento incremental, ou seja, os requisitos são especificados, implementados e validados a cada incremento.

Kirner e Martin (2007) apresentam uma metodologia baseada no processo de elicitação, especificação e validação dos requisitos utilizado no desenvolvimento de softwares. Essa metodologia é adaptada para o contexto de RV a partir de experiências de desenvolvimento de $\mathrm{AVs}$, ou seja, nessas etapas são definidos os usuários do sistema; os objetos, suas propriedades e comportamentos; e as tarefas a serem realizadas. Por fim, dentre as metodologias levantadas por Damasceno e Oliveira (2009), somente duas são baseadas em ER tais como: Concurrent and Level by Level Development of VR Systems (CLEVR) baseada na modelagem espiral (SEO; KIM, 2002) e RUP adaptado para o contexto de RV (SCHERP, 2002).

Os estudos (SALEM, 2008), (DAMASCENO; JR; LOPES, 2009) e (DAMASCENO; OLIVEIRA, 2009) utilizam metodologias específicas para a elicitação de requisitos de sistemas de RV. Salem (2008) utiliza uma metodologia chamada Fatores Humanos que é baseada na definição de cenários e mapeamento de requisitos do usuário para apoiar a análise de risco em ambientes de RV (CACCIABUE, 2004).

Damasceno, Jr e Lopes (2009) descrevem uma técnica baseada na Engenharia Semiótica que tem como foco o usuário do sistema. Por fim, as demais metodologias apresentadas por Damasceno e Oliveira (2009) são baseadas em alguma técnica específica, não utilizando conceitos de ES, como mapas conceituais, heurísticas e técnicas de mapeamento comportamental.

Outra análise realizada foi referente à utilização de tecnologias de RV para contribuir para o processo de ER. Os estudos de (WINTER; DESOVSKI; CUKIC, 2001) e Sutcliffe e Gault (2004) descrevem métodos utilizando RV, a fim de fornecer orientações para análise e validação de requisitos. Winter, Desovski e Cukic (2001) descrevem o desenvolvimento de um modelo visual para avaliar a aplicabilidade de RV para a validação de requisitos por meio de modelos formais. Sutcliffe e Gault (2004) apresentam um método denominado Immersive Scenario-based Requirements Engineering (ISRE) para a análise de requisitos por meio de cenários.

Os estudos (BAL; MANESH; HASHEMIPOUR, 2008) e (POLLOCK, 1998) apresentam ferramentas desenvolvidas com a finalidade de melhorar a garantia da confiança do software. Bal, Manesh e Hashemipour (2008) descrevem uma metodologia e uma ferramenta de RV baseada nas informações de análise de requisitos denominada $V R-R A$, que modela e analisa a relação entre os fluxos de objetos e as informações para identificar incoerências, incompletudes e erros na análise de requisitos. Pollock (1998) apresenta uma ferramenta de análise visual de atributo de software chamada SAVAnT que utiliza técnicas de visualização e RV para melhorar a garantia da confiança do software por meio de um ambiente que permite a visualização de objetos abstratos 
e a animação do comportamento do programa, incorporando restrições de requisitos.

Os estudos (VEGA; FUKS; CARVALHO, 2009), (RUSSELL; CREIGHTON, 2011) e (CYBULSKI; PARKER; SEGRAVE, 2006), classificados na categoria $\mathrm{C}_{3}$ da relação RV-ER, apresentam abordagens e jogos que utilizam tecnologias de RV para ensinar as práticas de ER aso estudante $\left(\left(\mathrm{QP}_{2}\right)\right)$. Vega, Fuks e Carvalho (2009) apresentam um jogo multiusuário tridimensional online denominado The Training in Requirements Engineering Game (TREG), que visa ensinar ER usando simulação e colaboração. Russell e Creighton (2011) oferecem uma plataforma de teste similar a um jogo para descrição e avaliação dos requisitos, no qual existem atores, atividades, motivações, conflitos, e resultados. Por fim, Cybulski, Parker e Segrave (2006) relatam um ambiente de aprendizagem chamado First Australian Bank Automatic Teller Machines (FAB ATM), concebido especificamente para treinar estudantes e profissionais para desenvolverem habilidades em ER por meio da simulação em computador.

Em termos de validação, a maioria dos estudos realizou experimentos a fim de avaliar as estratégias propostas. No entanto, esses estudos realizaram experimentos em contextos específicos de RV, como protótipo de jogos, simulação de sala de aula, processos industriais (químico e nuclear), sistemas de Computer Integrated Manufacturing (CIM) e etc, dificultando a possibilidade de reutilização de estratégias para outros contextos ou aplicações de RV. Para que as estratégias propostas sejam realmente validadas, o ideal é que para uma mesma aplicação de RV a utilização de tais estratégias fossem comparadas, por exemplo, por equipes ou usuários diferentes, a fim de verificar a contribuição e possíveis melhorias na elicitação de requisitos de sistemas de RV.

Conforme ressaltado pelos estudos identificados, os sistemas de RV mencionados possuem características interativas de manipulação, navegação e seleção associadas à atuação do usuário (comportamento, interações e reflexões) no AV em que está imerso. Portanto, com o auxílio do processo de ER é possível identificar e descrever os requisitos dos sistemas de RV incluindo: ( $i$ ) análise das ações do usuário nas tarefas definidas e sua interação com o ambiente virtual; (ii) definição dos requisitos básicos do ambiente virtual e; (iii) definição do funcionamento da aplicação. Assim, alguns erros podem ser corrigidos, diminuindo o custo e aumentando a qualidade final desses sistemas.

É válido ressaltar que apesar das contribuições apresentadas pelos estudos ((WINTER; DESOVSKI; CUKIC, 2001), (POLLOCK, 1998), (SALEM, 2008), (VEGA; FUKS; CARVALHO, 2009), (RUSSELL; CREIGHTON, 2011), (BAL; MANESH; HASHEMIPOUR, 2008), (SUTCLIFFE; GAULT, 2004),(KIM et al., 1999), (KIRNER; MARTIN, 2007), (CYBULSKI; PARKER; SEGRAVE, 2006), (DAMASCENO; JR; LOPES, 2009) e (DAMASCENO; OLIVEIRA, 2009)), esses não detalharam se os requisitos funcionais e não funcionais foram abordados. Outras informações relevantes que devem ser destacadas são referentes à relação entre as áreas de teste de software e RV. Como pode ser observado nenhum estudo apresenta a definição de critérios funcionais para sistemas de RV, ratificando a relevância da proposta da presente 
tese. Mais detalhes referentes aos estudos que respondem a $\mathrm{QP}_{1}$ podem ser vistos em Santos, Delamaro e Nunes (2013).

\section{- $\mathbf{Q P}_{2}$. Quais são as evidências existentes da relação entre Projeto de Software e RV?}

O objetivo desta questão de pesquisa está dividido nas duas subquestões apresentadas no Apêndice B que visa identificar: $\left(Q P 2_{1}\right)$ metodologias, abordagens e/ou estratégias de projeto de software que estão sendo utilizadas para o desenvolvimento de sistemas de RV e $\left(Q P 2_{2}\right)$ a utilização de tecnologias de RV na área de projeto de software. Na Tabela 3 é apresentada uma visão geral dos estudos identificados.

Tabela 3 - Utilização do projeto de software em sistemas de RV e aplicabilidade de tecnologias de RV na área de projeto de software $\left(\mathrm{QP}_{2}\right)$

\begin{tabular}{|c|c|c|}
\hline Relação & Estratégias & Estudos \\
\hline \multirow[t]{3}{*}{ Projeto - RV } & $\begin{array}{l}\text { Abordagem iterativa de desenvolvimento de } \\
\text { software baseada em conceitos de ES. }\end{array}$ & (KIRNER; MARTIN, 1999) \\
\hline & $\begin{array}{l}\text { Metodologias para apoiar os designers de in- } \\
\text { terface. }\end{array}$ & $\begin{array}{l}\text { (BENNES; BAZZARO; SAGOT, 2012) } \\
\text { (TANRIVERDI; JACOB, 2001) }\end{array}$ \\
\hline & $\begin{array}{l}\text { Utilização de metodologia ágil para o desen- } \\
\text { volvimento de sistemas de RV. }\end{array}$ & (MATTIOLI et al., 2009) \\
\hline \multirow[t]{3}{*}{ RV - Projeto } & $\begin{array}{l}\text { AV para auxiliar a execução de um projeto de } \\
\text { software com base no Scrum. }\end{array}$ & (RODRIGUÉZ; SORIA; CAMPO, 2004) \\
\hline & $\begin{array}{l}\text { Aprendizagem e desenvolvimento de softwa- } \\
\text { res Orientados a Objetos (OO). }\end{array}$ & $\begin{array}{l}\text { (JIMÉNEZ-DÍAZ; GóMEZ-ALBARRáN; } \\
\text { GONZáLEZ-CALERO, 2008), (MALETIC et } \\
\text { al., 2001) e (MATTIOLI et al., 2009) }\end{array}$ \\
\hline & $\begin{array}{l}\text { Ferramenta para ensinar conceitos de ES e } \\
\text { modelagem de software. }\end{array}$ & (NEUBAUER; HARRIS, 2003) \\
\hline
\end{tabular}

Fonte: Elaborada pelo autor.

Como pode ser observado, os quatro estudos ((KIRNER; MARTIN, 1999), (BENNES; BAZZARO; SAGOT, 2012), (TANRIVERDI; JACOB, 2001) e (MATTIOLI et al., 2009)) que respondem a QP2 1 apresentam uma metodologia ou uma abordagem para a condução de projetos de software de sistemas de RV. Kirner e Martin (1999) seguem uma abordagem iterativa de desenvolvimento de software baseada em conceitos de ES (especificação de requisitos, projeto, implementação, validação) para atender as peculiaridades dos sistemas de RV.

Os estudos (BENNES; BAZZARO; SAGOT, 2012) e (TANRIVERDI; JACOB, 2001) propõem metodologias que visam a ajudar os designers (projetistas) de interfaces de RV. Bennes, Bazzaro e Sagot (2012) relatam uma metodologia chamada As Soon As Possible (ASAP) com o objetivo de ajudar os designers de aplicações de RV imersivas de acordo com as restrições impostas pelo ambiente industrial. ASAP é dedicada especificamente à criação de revisões de projeto usando a RV como ferramenta de apoio para convergência multidisciplinar.

Tanriverdi e Jacob (2001) apresenta um modelo chamado Virtual Reality Interface Design (VRID), baseado em uma arquitetura de multi-componentes, com o objetivo de ajudar os projetistas a verificarem quais e por que determinadas questões e decisões estão envolvidas 
no design de interfaces de RV. A arquitetura usada no modelo VRID é composta por cinco componentes, sendo que os quatro primeiros são responsáveis em distinguir conceitualmente e abordar as características distintas das interfaces de RV. Os cinco componentes chaves do modelo VRID são: ( $i$ ) gráficos; (ii) comportamento; (iii) interação; (iv) comunicador; e (v) mediador. Assim, o modelo VRID permite que os designers pensem de forma abrangente sobre vários tipos de interações humano-computador, objetos, comportamentos e comunicação que precisam ser suportados por interfaces de RV.

Uma estratégia identificada tem como foco metodologias ágeis. Mattioli et al. (2009) propõem uma metodologia para o desenvolvimento de software de sistemas de RV baseado na metodologia Extreme Programming (XP).

Outra análise realizada está relacionada às contribuições de RV para projetos de software apresentadas nos estudos (NEUBAUER; HARRIS, 2003), (JIMÉNEZ-DÍAZ; GóMEZALBARRáN; GONZáLEZ-CALERO, 2008), (RODRIGUÉZ; SORIA; CAMPO, 2004), (MALETIC et al., 2001) e (CALLAGHAN; HIRSCHMüLLER, 1998) ( $Q P 2_{2}: R V$ - Projeto). No estudo de Rodriguéz, Soria e Campo (2004) é apresentado um ambiente de RV denominado Virtual Scrum (VS) que auxilia os alunos na execução de um projeto de software seguindo o framework Scrum.

Os estudos (NEUBAUER; HARRIS, 2003), (JIMÉNEZ-DÍAZ; GóMEZ-ALBARRáN; GONZáLEZ-CALERO, 2008), (MALETIC et al., 2001) e (CALLAGHAN; HIRSCHMüLLER, 1998) apresentam a aplicabilidade de tecnologias de RV para o ensino e desenvolvimento de softwares OO. Neubauer e Harris (2003) propõem uma ferramenta de ensino chamado Virtual Software Engineering Environment (VIRSEE) que é usada para ensinar conceitos de ES que são utilizados na Unified Modeling Language (UML) (classe, objeto, método e propriedades) e outros conceitos de $\mathrm{OO}$ (generalização, polimorfismo, encapsulamento e ocultação de informações), bem como instruir a modelagem de software. Jiménez-Díaz, Gómez-Albarrán e González-Calero (2008) apresentam uma metodologia de aprendizagem ativa, utilizando técnicas de Cartões CRC e sessões Role-Play para ensinar projeto OO em um AV Wirfs-Brock e McKean (2002). Maletic et al. (2001) descrevem um sistema denominado de IMmersive SOftware VISualizatION (IMSOVISION) para a visualização de desenvolvimento de software OO em um ambiente de RV. Callaghan e Hirschmüller (1998) abordam uma nova forma de visualização de software com o objetivo de criar um ambiente para aprendizagem e exploração de padrões para desenvolvimento orientado a objetos e programação Java.

É importante destacar que todos os estudos, com exceção dos estudos (NEUBAUER; HARRIS, 2003), (JIMÉNEZ-DÍAZ; GóMEZ-ALBARRáN; GONZáLEZ-CALERO, 2008), (MALETIC et al., 2001), (CALLAGHAN; HIRSCHMüLLER, 1998) e (MATTIOLI et al., 2009), foram validados por meio de estratégias empíricas, como estudo de caso e experimento. Bennes, Bazzaro e Sagot (2012), por exemplo, realizou um estudo de caso baseado em um projeto industrial, sendo possível notar a dificuldade da integração de RV ao processo de design, uma 
vez que essa integração implica na modificação de hábitos dos designers, podendo ocasionar uma rejeição das tecnologias de RV se proporcionarem mais inconvenientes do que vantagens. Os outros estudos foram validados por meio de um estudo de caso em um museu histórico e durante uma disciplina de ES e, um experimento em um sistema virtual de cirurgia para treinamento de cirurgiões.

\section{- $\mathbf{Q P}_{3} \cdot$ Quais são as evidências existentes da relação entre Teste de Software e RV?}

O objetivo desta questão de pesquisa está dividido nas duas subquestões apresentadas no Apêndice B que visa identificar: $\left(Q P 3_{1}\right)$ Evidências de quais tipos de teste de software têm sido utilizados no desenvolvimento de sistemas de RV e $\left(Q P 3_{2}\right)$ Contribuições dos sistemas de RV para teste de software. Na Tabela 4 é apresentada uma visão geral dos estudos identificados.

Tabela 4 - Tipos de teste de software utilizados em sistemas de RV e a utilização tecnologias de RV na atividade de teste de software $\left(\mathrm{QP}_{3}\right)$

\begin{tabular}{c|l|l}
\hline \multicolumn{1}{c|}{ Relação } & \multicolumn{1}{|c}{ Estratégias } & Estudos \\
\hline \multirow{4}{*}{ Teste - RV } & Critérios de teste estruturais baseados em GC. & (BEZERRA; DELAMARO; NUNES, 2011) \\
\cline { 2 - 3 } RV - Teste & $\begin{array}{l}\text { Automatização da geração de casos de teste baseado em } \\
\text { diagrama de estado. }\end{array}$ & (KIM; KIM, 2011) \\
\cline { 2 - 3 } & $\begin{array}{l}\text { Definição de um método paramétrico para testes funcio- } \\
\text { nais de instrumentos virtuais. }\end{array}$ & (FLORCZYK; WINIECKI, 2005) \\
\hline & $\begin{array}{l}\text { Framework para o planejamento dos testes. } \\
\text { Framework para realização de testes de usabilidade nas } \\
\text { áreas telecomunicações móveis. }\end{array}$ & $\begin{array}{l}\text { (KUUTTI } \text { et al., 2001) } \\
\text { EBRECHT, 2010) }\end{array}$ \\
\cline { 2 - 3 } & $\begin{array}{l}\text { Framework de aprendizagem ativa para teste funcional } \\
\text { desenvolvido no contexto de jogos comerciais. }\end{array}$ & (XIAO et al., 2005) \\
\cline { 2 - 3 } & $\begin{array}{l}\text { Curso interativo em comunidades virtuais para a aprendi- } \\
\text { zagem de processos de teste OO. }\end{array}$ & (RAMAKRISHNAN, 2000) \\
\cline { 2 - 3 } & $\begin{array}{l}\text { Abordagem para a realização de testes de usabilidade em } \\
\text { ambientes de aprendizagem baseado em RV. }\end{array}$ & (CHEN et al., 2013) \\
\cline { 2 - 3 } & $\begin{array}{l}\text { Framework para automatizar o teste de interfaces de apli- } \\
\text { cações de RV. }\end{array}$ & $\begin{array}{l}\text { (BIERBAUM; HARTLING; CRUZ-NEIRA, } \\
\text { 2003) }\end{array}$ \\
\cline { 2 - 3 } & $\begin{array}{l}\text { Método para realizar teste de software embarcado de } \\
\text { forma automática e manual, utilizando laboratório de RV. }\end{array}$ & Patil (2015) \\
\hline
\end{tabular}

Fonte: Elaborada pelo autor.

Florczyk e Winiecki (2005) apresenta um método paramétrico, baseado em Fluxo de Dados, para testes funcionais de instrumentos virtuais, que permite a realização de testes do instrumento virtual na fase do desenvolvimento da interface do usuário e na fase que o instrumento ainda não tiver sido produzido.

O trabalho de Bezerra, Delamaro e Nunes (2011) merece um detalhamento, em função de ser utilizado para o contexto desse projeto. Esse estudo apresenta critérios de teste estruturais para sistemas de RV baseados em GC. Apresentam-se, também, aspectos da automatização da aplicação desses critérios por meio de uma ferramenta de teste. Foram definidos cinco critérios de teste estrutural com base em GCs: 
- Todos-Nós-Internos: determina que, por meio de um ou mais casos de teste, todos os nós intermediários do GC que contemplem algum tipo de transformação (rotação, translação ou escala) sejam exercitados pelo menos uma vez;

- Todos-Nós-Folhas: exige que todos os nós folhas do GC que contemplem modificações de aparência (cores, sombreamento, iluminação) sejam exercitados ao menos uma vez;

- Todos-Caminhos-Ascendentes: requer que, por meio de um caso de teste, todos os nós dos possíveis caminhos identificados de um nó folha até um nó raiz, sejam exercitados;

- Todos-Caminhos-Descentes: determina que, por meio de um caso de teste, todos os nós dos possíveis caminhos identificados de um nó raiz até um nó folha, sejam exercitados;

- Todas-Transformações: exige que, por meio de um ou mais casos de teste, todas as transformações requeridas para cada nó interno do GC sejam exercitados pelo menos uma vez.

Para a realização dos testes foram selecionadas duas aplicações geradas pelo framework ViMeT (OLIVEIRA; NUNES, 2010). A aplicação A possui dois objetos virtuais, representados por uma mama e uma seringa e outra aplicação B possui dezoito objetos virtuais, representados por uma mama, uma seringa e dezesseis objetos que compõem uma mão virtual. Por meio da ferramenta é possível verificar os nós que representam os objetos virtuais na cena e se satisfazem seus requisitos conforme foram especificados. De acordo com os autores, a ferramenta é capaz de apontar se, durante a realização de um teste, não forem executadas transformações definidas por meio das especificações de determinados objetos (representados por nós).

Kim e Kim (2011) propõem um método de geração de casos de teste automaticamente com base no diagrama de estado e executa-os no simulador virtual, utilizando um agente denominado no estudo como "robô". Chen et al. (2013) propõem uma abordagem chamada Modified Group Usability Testing (MGUT), que é utilizada para a realização de testes de usabilidade em ambientes de aprendizagem baseado em RV. Ao utilizar essa abordagem, os participantes do MGUT são convidados a anotar brevemente problemas de usabilidade que eles encontram durante a sessão de testes e são alertados pelos observadores para verbalizar ativamente os problemas de usabilidade. Isso ajuda os participantes a relembrar sua interação com o sistema e mais uma vez visa minimizar a possibilidade de perder quaisquer problemas de usabilidade. A abordagem pode ser aplicada para testar outros sistemas e não se limitar a ambientes de aprendizagem baseados em RV.

Patil (2015) apresenta um método de teste de software embarcado, podendo ser realizado de forma automática e manual, utilizando laboratório de realidade virtual. No ambiente de teste manual o aplicativo interage com o computador em tempo real com a finalidade de obter os valores do sistema. Para o ambiente automatizado, a plataforma da National Instruments TestStand é utilizada. Essa plataforma pode realizar execução dos testes de forma sequencial e 
paralela. Nesse método, o usuário pode definir os casos de teste que foram chamados de Edit time e Runtime concept. No Edit time o usuário precisa definir os parâmetros para testar, criar os cenários de ambiente de teste e no Runtime os testes são executados os parâmetros indicados pelo usuário.

Os estudos (GUO; ZHOU; ZHU, 2003), (TORENS; EBRECHT, 2010), (KUUTTI et al., 2001), (XIAO et al., 2005) e (BIERBAUM; HARTLING; CRUZ-NEIRA, 2003) apresentam frameworks utilizando tecnologias de RV para contribuir para a atividade de teste $\left(Q P 3_{2}\right)$. Guo, Zhou e Zhu (2003) desenvolveram um sistema de teste baseado em simulação e RV chamado $V R$-based test and simulation system (VTSS), no qual os processos de teste são planejados de forma interativa, otimizada e simulada para a realização de testes em AVs. Torens e Ebrecht (2010) apresentam o framework denominado RemoteTest que é utilizado para testes de sistemas distribuídos e seus componentes. Os componentes individuais de um sistema distribuído podem ser isolados por meio da emulação de um AV. Kuutti et al. (2001) descrevem um protótipo virtual 3D de telefone celular destinado a testes de usabilidade centrado nas áreas telecomunicações móveis.

Bierbaum, Hartling e Cruz-Neira (2003) apresenta um framework para automatizar a realização do teste de interfaces de aplicação de RV. Esse framework mantém uma lista de testes que é gerenciado pelo design. Cada um desses testes monitora o estado da aplicação de RV que é controlada por dados de entrada pré-gravados. Quando a aplicação de RV atingir um estado que necessita ser testado, o teste é executado a fim de verificar se aplicação alcançou ou não um estado correto.

Xiao et al. (2005) apresentam um framework de aprendizagem ativa para testes de software funcionais que combina aspectos de testes de software estatístico e técnicas de aprendizagem de máquina. Nesse framework, as entradas e as saídas são obtidas por meio de amostras do sistema inicial e de ações do usuário e, em seguida, o teste funcional é executado para obter os rótulos dessas amostras. Este conjunto de amostras é então usado para obter um modelo referente ao comportamento do sistema. Uma vez que um modelo foi aprendido, então ele é usado para selecionar novas entradas para amostragem aumentando o conjunto de treinamento para a próxima iteração do modelo de aprendizagem. Esse framework foi desenvolvido para o contexto de videogames comerciais, mundos virtuais complexos com grandes espaço dimensionais.

Ramakrishnan (2000) descreve um curso interativo em comunidades virtuais chamado Visual Interactive Environments for Learning OO Testing (LIGHTVIEWS) para a aprendizagem de processos de teste OO. Os estudos (GUO; ZHOU; ZHU, 2003) e (FLORCZYK; WINIECKI, 2005) não foram validados. No entanto, os estudos (TORENS; EBRECHT, 2010), (KUUTTI et al., 2001), (KIM; KIM, 2011), Xiao et al. (2005) e (RAMAKRISHNAN, 2000) foram validados e descreveram estratégias para contextos específicos. A estratégia do estudo (TORENS; EBRECHT, 2010) foi utilizada principalmente para validar a nível funcional, o controle de tráfego e sistemas de segurança chamado RailSiTe. No estudo de Kuutti et al. (2001) a estratégia 
foi utilizada para testes de usabilidade centrada na área de telecomunicações. No estudo de Kim e Kim (2011) a estratégia é validada por meio do agente "robô", não sendo especificado se a estratégia pode ser validada por meio da utilização de outros agentes. Xiao et al. (2005) relataram um estudo de caso realizado em um jogo chamado Electronic Arts FIFA Soccer, no qual foi analisado o cenário "batedor-goleiro".

\subsection{Ameaças à Validade}

Em relação às ameaças da validade do MS conduzido, uma das limitações mais comuns é o possível viés introduzido no processo de seleção e imprecisões na extração dos dados. As principais ameaças à validade identificadas nesse MS são:

- validade de conclusão: refere-se à relação estatisticamente significativa entre o tratamento e os resultados (WOHLIN et al., 2012). Para minimizar a ameaça da seleção dos estudos ter sido realizada por somente um pesquisador, $10 \%$ dos estudos incluídos e excluídos foram verificados por outro pesquisador, sem comprometer a qualidade do MS. Quanto à extração dos dados, em vários estudos, dados importantes não foram explicitamente apresentados, forçando aos pesquisadores buscarem outros artigos relacionados para facilitar a interpretação dessas informações, sendo possível a ocorrência de alguma imprecisão nos dados extraídos. No entanto, para garantir a validade dos estudos, no caso de discordâncias entre os dois pesquisadores, um terceiro pesquisador foi consultado para garantir a confiabilidade do MS;

- validade interna: refere-se à uma relação causal entre o tratamento e os resultados (WOHLIN et al., 2012). Uma das ameaças à validade interna surge, pelo fato de alguns estudos não estarem disponíveis nas bases de dados eletrônicas. É difícil ter acesso a esses estudos, no entanto, é de conhecimento que a inclusão de tal literatura teria contribuído para aumentar a validade interna;

- validade de construção: está preocupada com a relação entre a teoria e aplicação (WOHLIN et al., 2012). Uma possível ameaça à validade de construção é a exclusão de estudos relevantes. Para minimizar essa ameaça, foi definida uma estratégia de busca rigorosa, que incluiu os três tipos de busca (automática, manual e por meio de referências), a fim de melhorar a cobertura do processo de seleção e minimizar as ameaças à validade de construção. Além disso, com o objetivo de assegurar um processo de seleção imparcial e evitar vieses foi desenvolvido um protocolo de pesquisa sobre as orientações estabelecidas por Kitchenham et al. (2010);

- validade externa: está preocupada com a generalização de resultados fora do âmbito do estudo (WOHLIN et al., 2012). Pode relacioná-la com o grau em que os estudos são 
representativos em relação ao objetivo deste MS. Com o protocolo desenvolvido, foi possível obter um conjunto representativo de estudos em maior escala.

\subsection{Considerações Finais}

No decorrer deste capítulo foi apresentado o MS conduzido, a fim de identificar as principais evidências disponíveis na literatura referentes à utilização das áreas de ES (ER, Projeto de Software e Teste de Software) para sistemas de RV e às contribuições de RV para essas áreas. De acordo com os resultados extraídos dos 32 estudos, foi possível identificar que RV é utilizada com mais frequência para auxiliar as áreas de ES em relação às estratégias de ES empregadas para o desenvolvimento de sistemas de RV.

Diversos estudos identificados apresentam abordagens e metodologias que serviram como base para definir e sistematizar a especificação de requisitos para sistemas de RV que é um dos focos deste projeto. Apesar das contribuições dessas metodologias, o processo de ER para sistemas de RV ainda precisa ser amadurecido, pois a criação desses sistemas compreende os sentidos do ser humano, permitindo que os requisitos sejam possivelmente definidos com imprecisões, incompletudes e/ou ambiguidades. É importante destacar que uma das principais diferenças da presente proposta em relação aos estudos identificados na literatura é a utilização de uma linguagem semi-formal para padronizar a especificação de requisitos e um guia para documentar a especificação de requisitos que podem contribuir com a economia de tempo e recursos no desenvolvimento de aplicações de RV, bem como melhorar a comunicação entre os usuários e os desenvolvedores.

Quanto à área de teste, somente o trabalho de Bezerra, Delamaro e Nunes (2011) propõe a automatização de critérios de teste no domínio de RV; o trabalho proposto por Xiao et al. (2005) apresenta um framework de aprendizagem ativa para testes de software funcionais que combina aspectos de testes de software estatístico e técnicas de aprendizagem de máquinas; e o estudo de Chen et al. (2013) aborda testes de usabilidade em ambientes de aprendizagem baseado em RV. Os demais estudos selecionados utilizam o domínio de RV para realizar testes em sistemas embarcados e distribuídos, para ensinar teste de software e para realizar teste de usabilidade.

Portanto, a partir dessas perspectivas, evidencia-se a relevância em automatizar critérios de teste no escopo de aplicações de RV, uma vez que tem-se um domínio pouco explorado e com possibilidade de contribuições inéditas tanto para a área de teste de software quanto para a área de RV. 


\section{VR-REST: UMA ABORDAGEM PARA ESPECIFICAÇÃO DE REQUISITOS E TESTE FUNCIONAL DE APLICAÇÕES DE RV}

\subsection{Considerações Iniciais}

Este capítulo detalha a abordagem conceitual para padronizar a especificação dos requisitos, a derivação dos Requisitos de Teste (RTs) e a geração dos dados testes para aplicações de RV com base em GC. O capítulo está organizado da seguinte forma: na Seção 5.2 são detalhadas as fases da abordagem; na Subseção 5.2.1 é apresentada a primeira etapa da abordagem referente à especificação de requisitos; na Subseção 5.2.2 o mapeamento dos requisitos especificados para uma linguagem especificamente desenvolvida para esta finalidade é apresentado; na Subseção 5.2.3 é descrita a geração dos RTs e dos dados de teste a partir dos requisitos padronizados por meio da linguagem criada; na Seção 5.3 é apresentada a ferramenta de apoio e seus componentes para automatizar as atividades de especificação dos requisitos e realização do teste funcional e, por fim, na Seção 5.4 são discutidas as considerações finais do capítulo.

\subsection{Abordagem VR-ReST}

A abordagem conceitual proposta neste trabalho, denominada Virtual Reality-Requirements Specification and Testing (VR-ReST), visa apoiar a especificação de requisitos de aplicações de RV, que abordem aspectos visuais e interativos, com base na descrição de casos de uso e conceitos do domínio de RV (terminologia e conceitos de GC). A VR-ReST também utiliza quatro critérios de teste $(N C, E C, E P C, P P C)$, apresentados na Subseção 2.3.2.2, para derivar os RTs e gerar dados de teste a partir dos requisitos especificados, com a finalidade de auxiliar o teste funcional de aplicações de RV. 
Capítulo 5. VR-ReST: Uma abordagem para especificação de requisitos e teste funcional de aplicações 80 de $R V$

É importante destacar que, apesar dos critérios de teste utilizados na abordagem serem classificados como estruturais, esta visa apoiar a realização do teste funcional, uma vez que se baseia na especificação de requisitos sem se preocupar com os detalhes de implementação, sendo visível e disponível somente os dados de entrada fornecidos (requisitos especificados) e as saídas produzidas (comportamentos da aplicação de RV). Para facilitar a geração dos requisitos de teste e dados de teste a partir da especificação foi utilizado o Grafo de Fluxo de Requisitos (GFR) que foi definido e adaptado com base no GFC.

O processo da abordagem $V R-R e S T$ consiste em três módulos sequenciais: (1) Especificação dos Requisitos, (2) Mapeamento dos Requisitos e (3) Geração dos Testes (Figura 14).

Figura 14 - Processo da abordagem VR-ReST

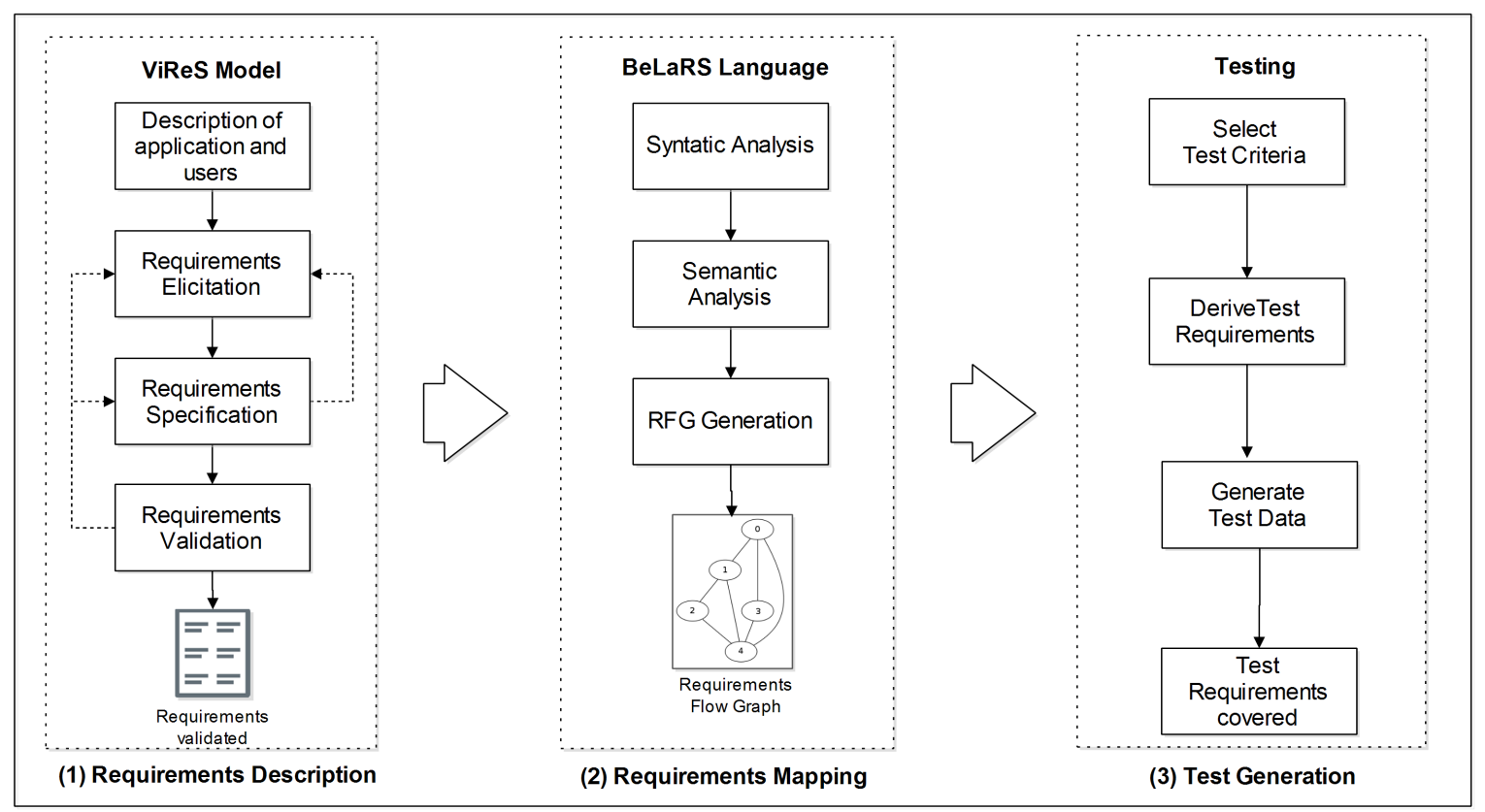

Fonte: Elaborada pelo autor.

No primeiro módulo as informações gerais sobre aplicação, usuário, incluindo os requisitos, são especificadas por meio do modelo desenvolvido chamado de Virtual Requirement Specification (ViReS). No segundo módulo os requisitos especificados são utilizados como entrada na linguagem chamada Behavior Language Requirements Specification (BeLaRS) para obter uma especificação semi-formal. Por fim, no terceiro módulo, a partir do GFR gerado no segundo módulo, os RTs são derivados e os dados de teste são gerados com base em um critério de teste selecionado. Assim, esses dados de teste são aplicados aos requisitos de teste para verificar sua cobertura. 


\subsubsection{Módulo 1: Especificação dos Requisitos}

ER é um processo importante dentro do ciclo de vida do software. Para garantir a qualidade dos sistemas durante esse processo foi desenvolvido o modelo ViReS. Este modelo visa orientar a especificação de requisitos de aplicações de RV e obter informações essenciais sobre o $\mathrm{AV}$, as quais serão mapeadas no próximo módulo da abordagem (Subseção 5.2.2). O modelo ViReS fornece meios para apoiar a especificação de requisitos sobre as características e as interações no AV.

O modelo ViReS foi desenvolvido com base na mineração das melhores características de cada método proposto em vários estudos ((KIRNER; MARTIN, 1999), (SCAIFE; ROGERS, 2001), (TANRIVERDI; JACOB, 2001), (SEO; KIM, 2002), (STANNEY et al., 2003), (PELLENS; TROYER; KLEINERMANN, 2008)); estratégias de especificação de requisitos para sistemas de realidade aumentada proposto por Nakamoto (2011); definição de comportamentos (BOWMAN et al., 2004); elementos e tecnologias (TORI; KIRNER; SISCOUTTO, 2006); e as fases do processo tradicional de ER empregados em ES (SOMMERVILLE, 2016). Essas características foram analisadas minunciosamente, verificando quais delas eram comuns entre os estudos e quais delas seriam essenciais para obter um modelo completo e possível de ser utilizado em diferentes domínios de aplicações de RV. O modelo ViReS consiste em quatro fases inter relacionadas, conforme pode ser visto na Figura 15.

Figura 15 - Processo do modelo ViReS

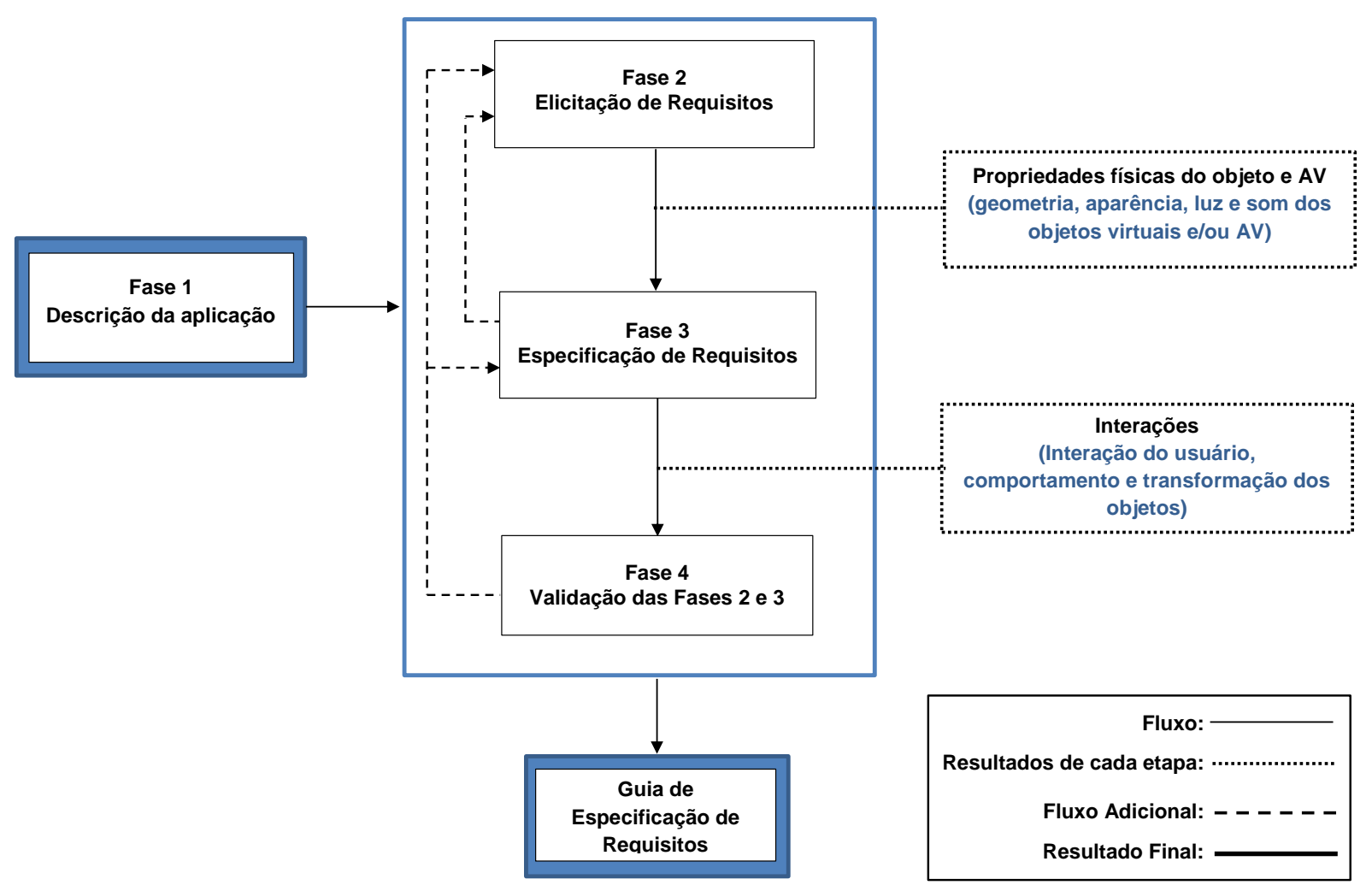

Fonte: Elaborada pelo autor. 
Capítulo 5. VR-ReST: Uma abordagem para especificação de requisitos e teste funcional de aplicações 82 de $R V$

A primeira fase consiste na descrição da aplicação, definição do problema e identificação dos usuários. Na segunda fase, os requisitos elicitados estão relacionados com as propriedades dos objetos e do AV. Na terceira fase, os requisitos que envolvem a interação entre o usuário e o sistema são especificados. Por fim, na fase 4 , os requisitos especificados são validados a fim de verificar se estão em conformidade com as necessidades da aplicação pretendida. Ao final, um Guia de Especificação de Requisitos com todas as informações e requisitos necessários para o desenvolvimento de aplicações de RV é apresentado. Esse Guia é apresentado no Apêndice A. As fases do modelo ViReS são detalhadas a seguir.

\section{- Fase 1: Descrição da aplicação}

Esta fase refere-se à descrição geral da aplicação e inclui a definição do domínio do problema, dos objetos e uma visão dos stakeholders e do público alvo. Além disso, a identificação dos perfis de usuário, juntamente com o nível de conhecimento e/ou experiência do usuário com a tecnologia de RV são necessários para avaliar as habilidades e dificuldades dos usuários no domínio do problema. Os resultados desta fase irão compor a documentação relativa à aplicação a ser desenvolvida.

\section{- Fase 2: Elicitação de requisitos}

Elicitação de requisitos é a principal atividade envolvida na identificação dos requisitos de um software. Nesta atividade, os analistas determinam os problemas, as oportunidades e as necessidades dos clientes, de modo que o desenvolvedor possa implementar softwares capazes de solucionar tais problemas, alavancar oportunidades e atender às necessidades dos clientes (SOMMERVILLE, 2016).

Esta fase tem como objetivo determinar as propriedades físicas dos objetos e as características do AV, bem como todos os tipos de dispositivos que são utilizados e a quantidade de cenas. Os principais elementos da elicitação estão relacionados com as características e propriedades do AV (tais como objetos, geometria e aparência dos objetos no AV) e as interações no AV (tais como transformações e comportamentos dos objetos). Estes elementos são mapeados pela linguagem BeLaRS para descrever as características de AV e as interações no AV.

\section{- Fase 3: Especificação de requisitos}

Especificação de requisitos é uma descrição das funcionalidades essenciais e pretendidas a serem desempenhadas pelo software em desenvolvimento. Esta fase descreve adequadamente o que o software deve fazer e como deve ser executado. Além disso, nesta fase todos os requisitos que retratam as informações sobre as características, as propriedades e as interações no AV descritas na fase anterior devem ser especificadas. Estes requisitos também são mapeados pela 
linguagem BeLaRS, que será apresentada na Subseção 5.2.2, com a finalidade de descrever as interações do usuário com o AV.

\section{- Fase 4: Validação de requisitos}

A validação de requisitos procura garantir que os requisitos do sistema sejam concisos, não ambíguos, consistentes e claros. O principal objetivo desta fase é atestar que os requisitos especificados estão em conformidade com as necessidades da aplicação pretendida. Nesta fase são estabelecidas diretrizes para permitir que os projetistas e desenvolvedores possam conferir se as especificações foram realizadas corretamente e registrar quaisquer alterações imprevistas que possam ocorrer durante o desenvolvimento da aplicação. Portanto, ao final, todos os requisitos validados são mapeados pela linguagem BeLaRS.

$\mathrm{Na}$ Tabela 5 é apresentada uma descrição das atividades de cada fase do modelo ViReS. Essas atividades foram definidas com base nos métodos e conceitos mencionados anteriormente para obter uma especificação de requisitos mais completa e concisa. Nesta Tabela são apresentadas as fases do modelo ViReS (primeira coluna), as atividades que são realizadas em cada fase (segunda coluna), as abordagens/conceitos usados para definir as atividades (terceira coluna) e, por fim, as referências subjacentes às abordagens e aos conceitos utilizados (quarta coluna).

As atividades que compõem as fases acima mencionadas consideram características das cenas comumente usadas em GCs, como a descrição do AV e a descrição das interações, sendo ambas nomeadas na abordagem como Virtual Environment Description (VED) e Interaction Description (IND), respectivamente. A partir da especificação de requisitos da aplicação de RV utilizando o modelo ViReS, os requisitos devem ser formalizados para garantir uma especificação concisa e não ambígua para a realização do teste funcional.

\subsubsection{Módulo 2: Mapeamento dos Requisitos}

Para auxiliar o mapeamento dos requisitos especificados pelo modelo ViReS foi desenvolvida a linguagem BeLaRS. A BeLaRS é uma linguagem semi-formal que permite uma especificação padronizada dos requisitos para auxiliar o teste funcional no domínio de RV. A BeLaRS foi desenvolvida com base em uma Linguagem Natural Controlada (LNC) (do inglês, Control Natural Language (CNL)) (HEITMEYER; BHARADWAJ, 2000), descrições de casos de uso (COCKBURN, 2001) e conceitos de GC. Esses conceitos foram utilizados para permitir uma especificação mais formal dos requisitos e isenta de qualquer imprecisão, ambiguidade e mais próximo do nível de compreensão do usuário. A BeLaRS é considerada uma liguagem semi-formal por não ter sido desenvolvida com base em métodos formais.

Em geral, as LNCs são baseadas em um vocabulário predefinido e um conjunto restrito de regras gramaticais. Este vocabulário e estas regras são usadas para identificar a estrutura sintática das sentenças, as quais podem ser mapeadas em alguma representação formal (HEITMEYER; 
Tabela 5 - Fases e atividades do modelo ViReS com base em diferentes métodos e conceitos

\begin{tabular}{|c|c|c|c|}
\hline $\begin{array}{l}\text { Fases do mo- } \\
\text { delo ViReS }\end{array}$ & Atividades & Abordagens / Conceitos & Referencias \\
\hline \multirow{7}{*}{ Fase 1} & Delimitação e definição do problema & \multirow[b]{2}{*}{ Informações do design do AV } & \multirow[b]{2}{*}{ (SCAIFE; ROGERS, 2001) } \\
\hline & $\begin{array}{l}\text { Identificação dos benefícios da utilização } \\
\text { da tecnologia de RV }\end{array}$ & & \\
\hline & Definição do público alvo & $\begin{array}{l}\text { Estratégia de especificação de re- } \\
\text { quisitos }\end{array}$ & (NAKAMOTO, 2011) \\
\hline & $\begin{array}{l}\text { Identificação dos perfis dos usuários, suas } \\
\text { capacidades e dificuldades no espaço do } \\
\text { problema }\end{array}$ & Informações do design do AV & (SCAIFE; ROGERS, 2001) \\
\hline & $\begin{array}{l}\text { Identificação do grau de conhecimento } \\
\text { e/ou experiência do usuário com a tecno- } \\
\text { logia de RV }\end{array}$ & $\begin{array}{l}\text { Estratégia de especificação de re- } \\
\text { quisitos }\end{array}$ & (NAKAMOTO, 2011) \\
\hline & \multirow[t]{2}{*}{$\begin{array}{l}\text { Descrição geral do sistema, identificando a } \\
\text { visão dos envolvidos }\end{array}$} & Informações do design do AV & (SCAIFE; ROGERS, 2001) \\
\hline & & Processo de ER & (SOMMERVILLE, 2016) \\
\hline \multirow{16}{*}{ Fase 2} & \multirow[t]{2}{*}{ Identificação dos objetos } & CLEVR & (SEO; KIM, 2002) \\
\hline & & VRID & (TANRIVERDI; JACOB, 2001) \\
\hline & Identificação das cenas & WR-WISE & $\begin{array}{l}\text { (PELLENS; TROYER; KLEI- } \\
\text { NERMANN, 2008) }\end{array}$ \\
\hline & Identificação da geometria dos objetos & CLEVR & (SEO; KIM, 2002) \\
\hline & & VRID & (TANRIVERDI; JACOB, 2001) \\
\hline & Identificação da aparência dos objetos & CLEVR & (SEO; KIM, 2002) \\
\hline & Identificação da transformação dos objetos & VRID & (TANRIVERDI; JACOB, 2001) \\
\hline & & WR-WISE & $\begin{array}{l}\text { (PELLENS; TROYER; } \quad \text { KLEI- } \\
\text { NERMANN, 2008) }\end{array}$ \\
\hline & Definição dos usuários & Design do AV & (STUART, 1996) \\
\hline & & $\begin{array}{l}\text { Modelo para desenvolvimento do } \\
\text { AV }\end{array}$ & (KIRNER; MARTIN, 1999) \\
\hline & & VRID & (TANRIVERDI; JACOB, 2001) \\
\hline & & Processo de ER para AV & (KIRNER; MARTIN, 2007) \\
\hline & Definição do tipo de AV (Immersivo/Não & Design do AV & (SEO; KIM, 2002) \\
\hline & & Processo de ER para AV & (KIRNER; MARTIN, 2007) \\
\hline & Definição das tecnologias de entrada e & VRID & (TANRIVERDI; JACOB, 2001) \\
\hline & & $\begin{array}{l}\text { Modelo para o desenvolvimento } \\
\text { do AV }\end{array}$ & (KIRNER; MARTIN, 1999) \\
\hline & Seleção & & \\
\hline & Manipulação & Definição do Comportamento & (BOWMAN et al., 2004) \\
\hline & Navegação & & \\
\hline & Controle do sistema & & \\
\hline Fase 3 & Deformação & Elementos e tecnologia & (BOWMAN et al., 2004) \\
\hline rase & Detecção de colisão & WR-WISE & $\begin{array}{l}\text { (PELLENS; TROYER; KLEI- } \\
\text { NERMANN, 2008) }\end{array}$ \\
\hline & & Elementos e tecnologia & (BOWMAN et al., 2004) \\
\hline & $\begin{array}{l}\text { Definição das restrições referentes aos dis- } \\
\text { positivos }\end{array}$ & $\begin{array}{l}\text { Estratégia de especificação de re- } \\
\text { quisitos }\end{array}$ & (NAKAMOTO, 2011) \\
\hline & $\begin{array}{l}\text { Restrições relacionada à renderização de } \\
\text { imagens }\end{array}$ & Elementos e tecnologia & (BOWMAN et al., 2004) \\
\hline & $\begin{array}{l}\text { Restrições relacionadas à resposta do sis- } \\
\text { tema aos comandos do usuário }\end{array}$ & & \\
\hline Fase 4 & $\begin{array}{l}\text { Revisão dos requisitos, verificando a exis- } \\
\text { tência de incompletudes, ambiguidades }\end{array}$ & Processo de ER & (SOMMERVILLE, 2016) \\
\hline & $\begin{array}{l}\text { Validação dos requisitos de acordo com os } \\
\text { critérios de usabilidade. }\end{array}$ & Processo de ER & (SOMMERVILLE, 2016) \\
\hline & & Abordagem MAUVE & (STANNEY et al., 2003) \\
\hline
\end{tabular}

Fonte: Elaborada pelo autor. 
BHARADWAJ, 2000). Nesse contexto, a linguagem BeLaRS foi desenvolvida como uma LNC, uma vez que restringe a expressividade da linguagem natural para permitir que os requisitos sejam processados automaticamente e ainda compreensíveis para todos os envolvidos.

A descrição de casos de uso foi utilizada pelo fato de ser considerada como uma especificação de ações interconectadas que um sistema pode executar por meio da interação entre os atores e o sistema. As terminologias e conceitos de $\mathrm{GC}$ empregados visam descrever as características do $\mathrm{AV}$, bem como as interações entre os usuários e as aplicações. A linguagem BeLaRS é composta por três fases (ver Figura 16): (1) análise sintática; (2) análise semântica; e (3) geração do GFR.

Figura 16 - Fases da linguagem BeLaRS

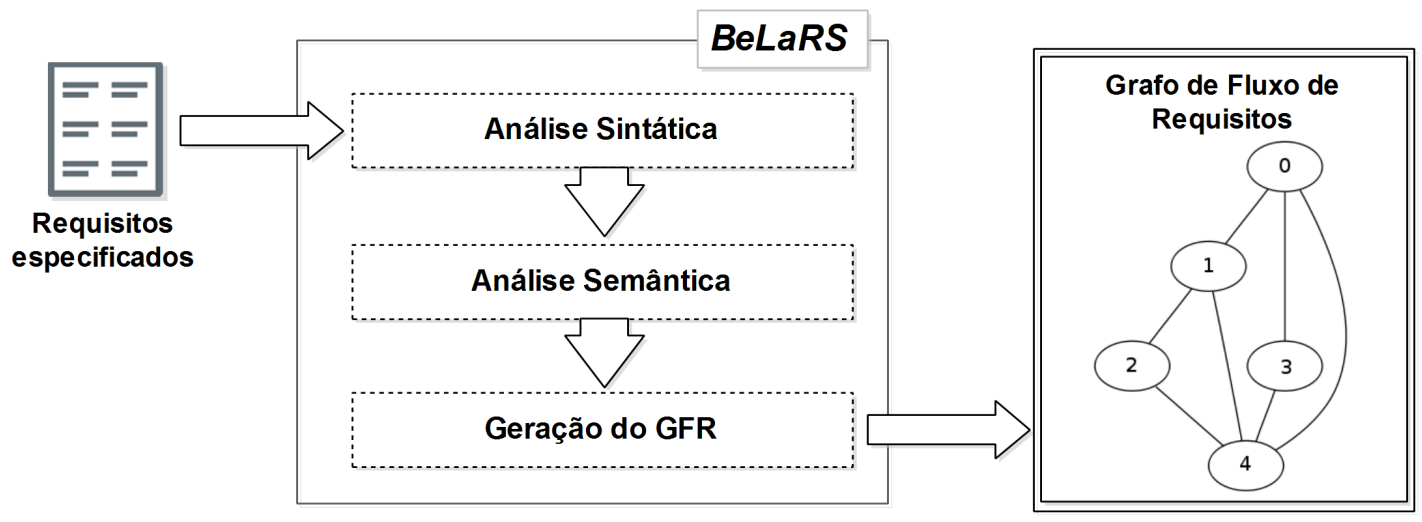

Fonte: Elaborada pelo autor.

Na primeira fase, a BeLaRS realiza a análise sintática dos requisitos validados por meio do modelo ViReS. Na segunda fase é realizado o mapeamento das árvores sintáticas em uma representação semântica com base na gramática dos casos proposta por Fillmore (1968). Por fim, na última fase, a representação semântica é convertida no GFR que será utilizado para produzir os RTs e os dados de teste. Estas fases são detalhadas a seguir.

\section{- Fase 1: Análise Sintática}

A primeira fase tem como objetivo verificar se os requisitos do sistema são especificados de acordo com as regras da BeLaRS. O componente BeLaRS-Parser é implementado nesta fase. Para cada requisito válido (entrada), o BeLaRS-Parser gera a árvore sintática correspondente que é usada como entrada para a fase de análise semântica. A linguagem é definida por uma gramática livre de contexto e a parte léxica é composta por um vocabulário que envolve os conceitos de GC.

Na parte léxica da BeLaRS, suas entradas são classificadas em categorias, também conhecidas como Parts Of Speech (POS) (ALLEN, 1995). Para essa linguagem foram consideradas as seguintes categorias: 
Capítulo 5. VR-ReST: Uma abordagem para especificação de requisitos e teste funcional de aplicações 86 de $R V$

- Determiners (DETER): palavras que determinam o significado de um nome (por exemplo, um número, um artigo ou um pronome pessoal) (CRYSTAL, 2008);

- Nouns: representam os objetos, por exemplo ball, cars, que são especificados podendo ser no singular (NSING) ou no plural(NPLU) e, os atores ou as entidades;

- Verbs: verbos com flexões, por exemplo VTOBEPRE - verbo no presente; VAUXPRE verbo auxiliar no presente; VAUXPP - verbo auxiliar no pretérito perfeito;

- Prepositions (PREP): representam as preposições, por exemplo in, into, by, for, until, to, up to, in the, on, between.

Com a finalidade de simplificar as regras da gramática da BeLaRS, foram definidas três categorias especiais:

- NUMBER para dígitos: $1,2,3,4,5,6,7,8,9$;

• SYMBOL para símbolo: por exemplo, “:”, “,”, “,”, “(”, “")”, “+”, “.”;

- PARAMETER para a combinação de SYMBOL com DIGIT: por exemplo, (3.1), 3.1.1;

- CONTROL para estruturas de controle: if, else, while, for e case.

Além disso, algumas palavras-chaves foram definidas com base no domínio de GC e caso de uso. Na Tabela 6 são apresentadas as palavras-chaves utilizadas na definição da gramática da linguagem BeLaRS. A gramática, as palavras-chaves e as entradas estão em inglês uma vez que a abordagem de padronização utilizada na linguagem são propostas para o idioma inglês.

Adicionalmente, a teoria da estrutura de constituintes, proposta por Chomsky (CHOMSKY, 1956), foi adicionada no desenvolvimento da BeLaRS. Esta teoria assume que as sentenças podem ser divididas em Noun Phrase (NP) e em Verb Phrase (VP). As frases podem ser divididas em constituintes que podem ser uma palavra ou uma sentença (grupo de palavras).

Portanto, a gramática de BeLaRS consiste de frases que são estruturadas de acordo com algumas regras, as quais definem as estruturas sintáticas aceitas pelo analisador sintático. A gramática da BeLaRS foi definida como uma Gramática Livre de Contexto (do inglês, Context Free Grammar-CFG), representada na notação de Extended Backus-Naur Form (EBNF), conforme pode ser visto na Figura 17. As palavras em maiúsculo denotam símbolos terminais que correspondem às categorias léxicas.

Para facilitar a compreensão da estrutura da gramática, os símbolos terminais, em maiúsculo, estão em negrito e os não terminais estão em itálico. O símbolo inicial da gramática é o SCENARIO. O SCENARIO é composto pelos EnvironmentReq e InteractionReq que representam a descrição do AV e as interações entre o usuário e o sistema, respectivamente. 
Tabela 6 - Entradas e Palavras-chaves da BeLaRS

\begin{tabular}{|c|c|c|}
\hline Domínio & Entrada & Palavras-chaves \\
\hline Caso de Uso & $\begin{array}{c}\text { Main Path } \\
\text { Alternative Path } \\
\text { ACTOR } \\
\text { ENTITY }\end{array}$ & $\begin{array}{l}\text { Main Path } \\
\text { Alternative Path } \\
\text { User, user } \\
\text { system, application, virtual environment }\end{array}$ \\
\hline Grafo de Cena & $\begin{array}{c} \\
\text { APPEARANCE } \\
\text { COLOR } \\
\\
\text { LIGHT } \\
\text { SOUND } \\
\text { VTRANSFORMATION } \\
\text { VBEHAVIOR }\end{array}$ & $\begin{array}{l}\text { point, line, vector, vertex, polygon, triangle, } \\
\text { sphere, cone, cube, cylinder, box, curves, surfa- } \\
\text { ces } \\
\text { upper right corner, upper left corner, lower right } \\
\text { corner, lower left corner, inside left, inside right, } \\
\text { centre, right side, left side, underside, upper, } \\
\text { top center, bottom center } \\
\text { COLOR, transparency, texture, brightness } \\
\text { white, black, red, blue, yellow, green, orange, } \\
\text { purple, pink, gray, silver, brown, gold, lime, vio- } \\
\text { let, magenta } \\
\text { ambient, directional, reflective, punctual } \\
\text { background, point, cone, soundscape } \\
\text { rotates, translates, scales } \\
\text { selects, clicks, inserts, moves, moves up, mo- } \\
\text { ves down, moves right, moves left, moves out, } \\
\text { moves into, moves into, deforms, detects colli- } \\
\text { sion, navigates, manipulates, releases, opens, } \\
\text { closes, shows, presents, changes, makes, does, } \\
\text { goes, picks, drops } \\
\text { gloves, Head Mounted Displays (HMD), joys- } \\
\text { ticks, haptics, mouse, keyboard }\end{array}$ \\
\hline
\end{tabular}

Fonte: Elaborada pelo autor.

O EnvironmentReq compreende um NounPhrase (um ou mais substantivos eventualmente precedidos por um opcional DETER ou número) e um VerbPhraseDesc. A VerbPhraseDesc começa com um verbo (o verbo "to be" e "aux verb" no presente ou no passado). O verbo é seguido por um Adj (adjetivo), um ou mais NounPhrase ou ambos. GEOMETRY é seguido por um parâmetro opcional que determina as dimensões dos objetos.

A InteractionReq começa com um MainPath seguido por um opcional AlternatPath. O MainPath determina os requisitos que "normalmente" ocorrem quando o cenário é criado. AlternatPath é um desvio do MainPath e abrange um comportamento opcional ou excepcional em relação ao comportamento do fluxo principal, bem como variações de comportamento no fluxo principal. O MainPath pode ter um ou mais AlternatPath.

MainPath compreende um NounPhrase seguido por um VerbPhraseAction, que é sucedido por um VerbComplement e um PARAMETER opcional. Se o PARAMETER for usado, então é necessário adicionar um AlternatPath. O VerbPhraseAction pode representar um VBEHA- 
Capítulo 5. VR-ReST: Uma abordagem para especificação de requisitos e teste funcional de aplicações 88 de $R V$

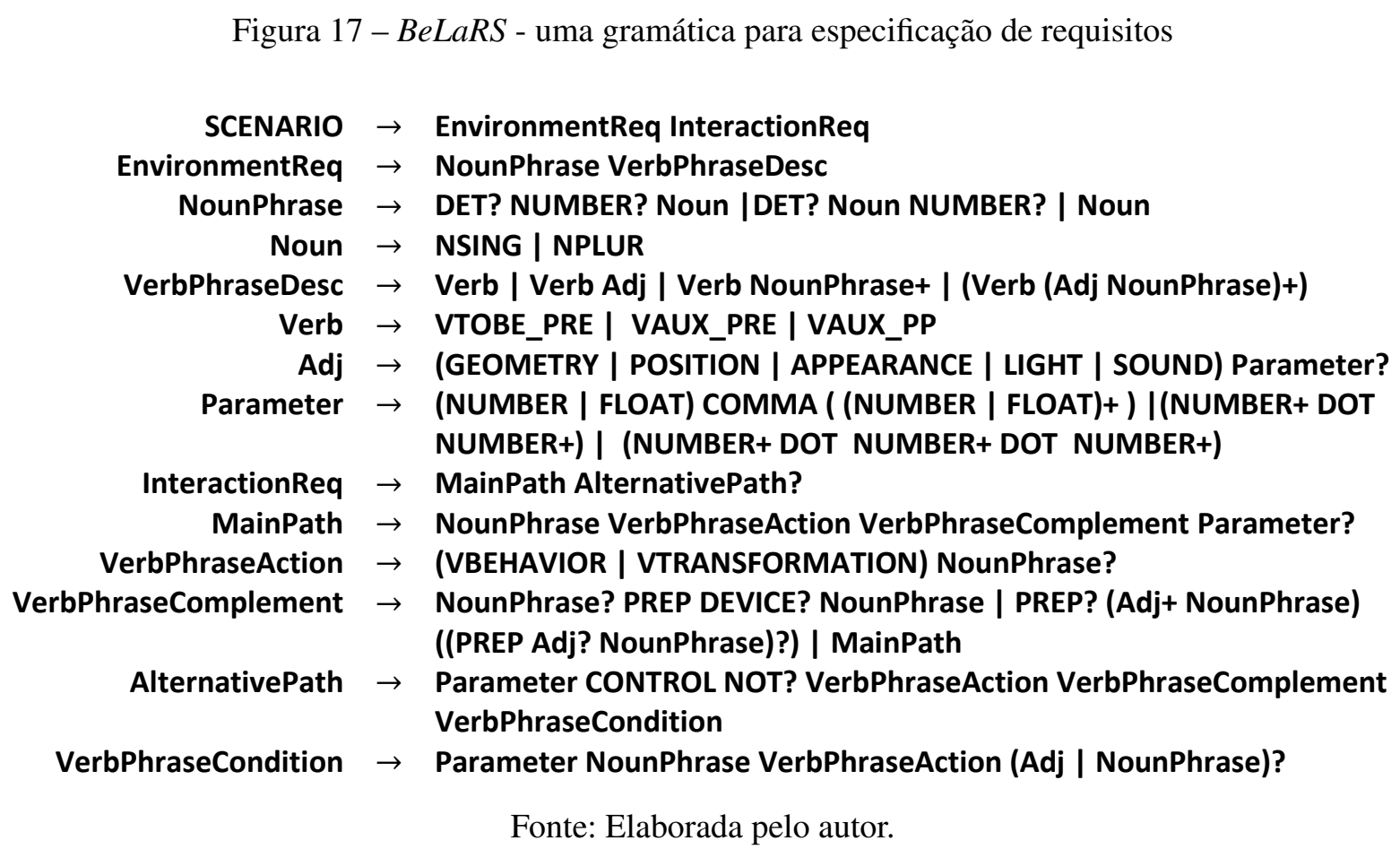

VIOR ou VTRANSFORMATIONS (ver Tabela 6). O VerbComplement é seguido por um opcional NounPhrase que é sucedido por uma PREP e um NounPhrase; ou uma opcional PREP seguido por um ou mais Adj e NounPhrase; ou a estrutura do MainPath.

O AlternatPath inicia com um PARAMETER, que representa o número do AlternatPath, seguido por CONTROL, um opcional NOT, que nega o significado do termo seguinte (VerbPhraseAction), um VerbPhraseComplement e uma VerbPhraseCondition. CONTROL consiste em estruturas que estabelecem as condições da declaração relativas aos requisitos especificados no MainPath, que podem ser de natureza iterativa ou repetitiva. Essas estruturas de controle são usadas apenas no AlternatPath para direcionar os possíveis caminhos que podem ser seguidos e, assim, permitir que os teste sejam executados. As mesmas regras estabelecidas nas definições anteriormente mencionadas são empregadas nas frases usando essas estruturas de controle. A VerbPhraseCondition compreende um PARAMETER seguido de um NounPhrase, um VerbPhraseAction e um opcional Adj ou um NounPhrase.

Portanto, a gramática da BeLaRS consiste em frases estruturadas de acordo com algumas regras que definem as estruturas sintáticas aceitas pelo analisador. A gramática permite especificar os requisitos por meio da formação de diferentes sentenças para aplicações de RV baseadas em conceitos de GC. No entanto, esta gramática pode auxiliar as necessidades de diferentes áreas de aplicação tais como treinamento médico e jogos, que foram considerados neste trabalho.

A Figura 25 apresenta um exemplo de uma especificação de requisitos usando a BeLaRS, a qual é dividida em duas partes: a primeira (VED) consiste na descrição dos objetos e das características do AV, e a segunda (IND) é responsável por especificar as interações entre o usuário e o sistema, destacando as transformações e os comportamentos dos objetos. 
Figura 18 - Exemplo de uma especificação de requisitos usando a BeLaRS

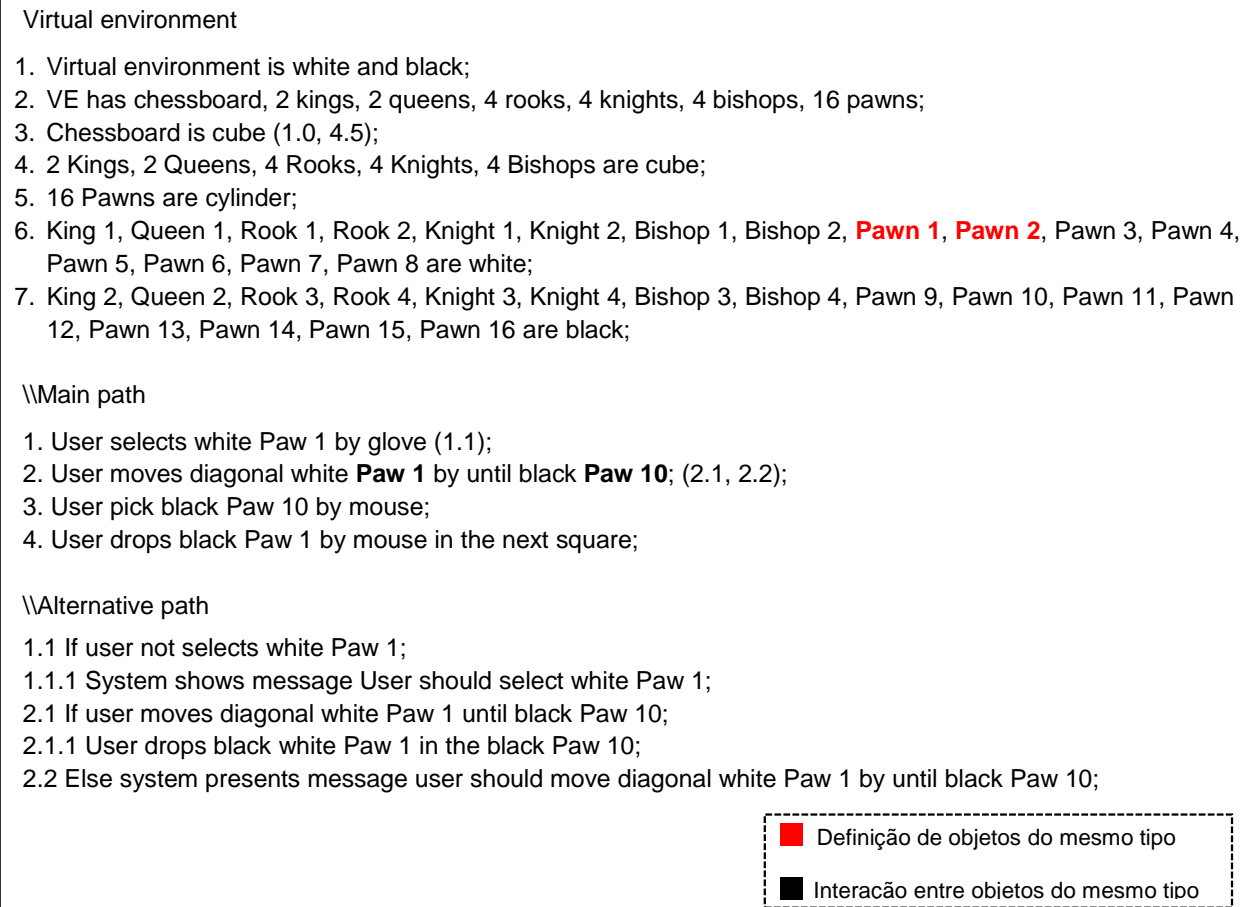

Fonte: Elaborada pelo autor.

\section{- Fase 2: Análise Semântica}

A segunda fase recebe como entrada a árvore de sintaxe gerada na análise sintática e fornece, como saída, a representação semântica das sentenças. Neste estudo, adota-se a gramática dos casos (FILLMORE, 1968) para representar o significado das sentenças. Nesta teoria, uma sentença é analisada a respeito da semântica (do inglês, Thematic roles (Trs)) de cada palavra/grupo de palavras na sentença (por exemplo, agente, paciente, localização, objeto e instrumento). Um exemplo simples de Trs é: "User (agente) moves (ação) the ball (paciente) with the mouse (instrumento)". O papel temático (Tr) é organizado em Case Frame (CF), isto é, uma estrutura que representa o significado semântico da sentença.

Na gramática dos casos, o verbo é o elemento principal da sentença, e determina suas possíveis relações semânticas com outras palavras na sentença. No exemplo acima, as possíveis relações com o verbo "moves" são representadas pelo agente, paciente e instrumento na Tr. As Trs associadas ao verbo são agregadas em um $C F$. Um $C F$ pode ser visto como uma estrutura, na qual cada um representa a $\operatorname{Tr}$ de um verbo a ser preenchido por elementos da sentença. Isto significa que as Trs em um $C F$ especificam o contexto estrutural do verbo.

O presente estudo definiu nove Trs baseadas na nomenclatura desenvolvida por Allen (1995), apresentadas na Tabela 7. Os requisitos assumem a forma de "declarações de ação" (do inglês, Action Statement) que devem estar em conformidade com as condições descritas 
Capítulo 5. VR-ReST: Uma abordagem para especificação de requisitos e teste funcional de aplicações 90 de $R V$

na gramática. A semântica determina que quando uma condição particular é verdadeira, a ação correspondente deve ser realizada. Deve-se notar que alguns verbos usados nas cláusulas condicionais (do inglês, Condition Clause) são diferentes daqueles usados nas declarações de ação, dado que definimos Trs específicas para cláusulas condicionais e outras Trs para as instruções de ação (Tabela 7).

Tabela 7 - Trs específicas

\begin{tabular}{|c|c|c|}
\hline \multicolumn{2}{|r|}{ Trs } & Descrição \\
\hline $\begin{array}{l}\text { Declarações } \\
\text { de ação }\end{array}$ & $\begin{array}{l}\text { Ação (ACT) } \\
\text { Agente (AGT) } \\
\text { Paciente (PAT) } \\
\text { Instrumento (INST) } \\
\text { Localização (LOC) } \\
\text { Objetivo (GL) }\end{array}$ & $\begin{array}{l}\text { ação realizada se as condições forem } \\
\text { satisfeitas e descrevem as característi- } \\
\text { cas sobre a entidade } \\
\text { entidade que realiza a ação } \\
\text { entidade que é afetada pela ação } \\
\text { dispositivo que permite a ação ser exe- } \\
\text { cutada } \\
\text { localização da entidade ou objeto } \\
\text { objetivo da entidade }\end{array}$ \\
\hline $\begin{array}{l}\text { Cláusula } \\
\text { Condicional }\end{array}$ & $\begin{array}{l}\text { Condição Ação (CACT) } \\
\text { Condição Paciente (CPAT) } \\
\text { Condição Modificador (CMOD) }\end{array}$ & $\begin{array}{l}\text { ação que diz respeito a cada condição } \\
\text { entidade relacionada a cada condição } \\
\text { um modificador relacionado à condi- } \\
\text { ção }\end{array}$ \\
\hline
\end{tabular}

Fonte: Adaptada de Allen (1995).

A partir das nove $T r s$ definidas, foi possível explicar como os conteúdos de cada $T r$ podem ser inferidos a partir das árvores sintática obtidas na análise sintática (Fase 1 da BeLaRS). A Tabela 8 apresenta as dez regras $\left(R_{n}\right)$, sendo que $n$ representa o número da regra para as $\operatorname{Tr} s$. Na primeira coluna são apresentadas as regras definidas, na segunda é realizada uma descrição de cada regra e, na terceira coluna é apresentado um exemplo para cada regra. Esse exemplo é realizado em inglês, uma vez que a linguagem BeLaRS é estruturada na língua inglesa.

\section{- Fase 3: Geração do GFR}

O gerador do GFR recebe como entrada os requisitos validados na fase de análise semântica e gera o GFR correspondente. Este grafo é usado para derivar os RTs e gerar os dados de teste. Para a geração automática do GFR a partir dos requisitos especificados foi utilizada a biblioteca Prefuse (CHI, 2007), pois permite a modelagem, a visualização e a interação de grafos.

O processo de geração do GFR é composto por dois estágios: (a) associação de cada requisito aos nós do GFR e (b) geração do GFR. A Figura 19 apresenta um exemplo da geração do GFR.

No primeiro estágio (a) cada requisito especificado é associado a um nó que irá compor o GFR. Cada requisito especificado no caminho principal é associado a um nó (estágio $(a)$ na 
Tabela 8 - Regras e exemplos para explicar o significado de cada $T r$

\begin{tabular}{|c|c|c|}
\hline Trs & Descrição & Exemplo \\
\hline$R_{1} . \mathrm{ACT}$ & $\begin{array}{l}\text { compreende os seguintes terminais: } \\
\text { (i) Em relação à descrição das características do AV: os ver- } \\
\text { bos são VTOBE_PRE, VAUX_PRE, VAUX_PP e devem } \\
\text { ser utilizados somente no VerbPhraseDesc } \\
\text { (ii) Em relação às interações entre o usuário e osistema: os } \\
\text { verbos são VTRANSFORMATION e VBEHAVIOR e de- } \\
\text { vem ser usados no VerbPhraseAction, VerbPhraseComple- } \\
\text { mente e VerbPhraseCondition. }\end{array}$ & $\begin{array}{l}\text { (i) Virtual environment has } \\
\text { Sun, Moon. } \\
\text { (ii) User selects Sun by } \\
\text { mouse. }\end{array}$ \\
\hline$R_{2}$. AGT & $\begin{array}{l}\text { compreende os terminais do NounPhrase que pode ser um } \\
\text { ator, uma entidade ou um substantivo. }\end{array}$ & User scales Sun. \\
\hline$R_{3}$. PAT & $\begin{array}{l}\text { compreende os terminais do NounPhrase que está presente } \\
\text { no VerbPhraseCondition. }\end{array}$ & $\begin{array}{l}\text { If user not moves Sun until } \\
\text { Moon. } \\
\text { System presents error mes- } \\
\text { sage. }\end{array}$ \\
\hline$R_{4} . \mathrm{INS}$ & $\begin{array}{l}\text { compreende os terminais do DEVICE que está presente no } \\
\text { VerbPhraseComplement. }\end{array}$ & User rotates Sun by mouse. \\
\hline$R_{5} . \mathrm{LOC}$ & $\begin{array}{l}\text { compreende os terminais do POSITION que está presente } \\
\text { no VerbPhraseDesc, VerbPhraseComplement e VerbPhrase- } \\
\text { Condition. }\end{array}$ & Sun is upper right corner. \\
\hline$R_{6} \cdot \mathrm{GL}$ & $\begin{array}{l}\text { está relacionada aos verbos moves, moves up, moves down, } \\
\text { moves right, moves left, moves out, moves into. A estrutura } \\
\text { é "moves X to Y" ou "moves X until Y" }\end{array}$ & User moves up Sun to Moon. \\
\hline$R_{7} . \mathrm{CACT}$ & compreende os terminais do VerbPhraseCondition. & If user not selects Sun. \\
\hline$R_{8} \cdot$ CPAT & $\begin{array}{l}\text { compreende os terminais do NounPhrase que está presente } \\
\text { no VerbPhraseCondition. }\end{array}$ & While user not moves Syringe \\
\hline$R_{9}$. & $\begin{array}{l}\text { relacionada ao verbo changes. A estrutura é "changes } X \text { to } \\
Y \text { ”. }\end{array}$ & $\begin{array}{l}\text { System changes Moon color } \\
\text { to white. }\end{array}$ \\
\hline$R_{10} \cdot \mathrm{CMOD}$ & compreende os terminais do VerbPhraseCondition. & $\begin{array}{l}\text { If user rotates Sun. } \\
\text { System deforms Sun. }\end{array}$ \\
\hline
\end{tabular}

Figura 19). No caminho alternativo (do inglês, Alternative Path), todos os requisitos que fazem parte de uma condição (por exemplo, 1.1.1, 2.1.1) são associados a um único nó, ou seja, são associados ao nó que aquela condição foi especificada. Por exemplo o requisito 1.1 tem uma condição e, portanto, seu requisito descendente (1.1.1) está relacionado ao nó que representa o requisito 1.1. Por fim, no último estágio (b) o GFR é gerado de acordo com a sequência em que os requisitos foram especificados.

\subsubsection{Módulo 3: Geração dos Testes}

Neste módulo, os testes são gerados a partir do GFR. Primeiramente, os RTs foram derivados de acordo com cada critério de teste (NC, EC, EPC e PPC), apresentados na Subseção 2.3.2.2 e, em seguida, um conjunto de dados de teste foi gerado percorrendo o GFR a partir do vértice inicial até o vértice final.

Para percorrer o GFR foi utilizado o algoritmo de Busca em Profundidade (do inglês, Depth-First Search (DFS)) (COREMAN et al., 2009). No DFS as arestas $\mathrm{A}=\left\{a_{1}, a_{2}, a_{3}, \ldots, a_{n}\right\}$ são exploradas a partir do vértice $v_{x}$ mais recentemente visitado que ainda possui arestas não exploradas saindo dele. Este processo continua até que todos os vértices que são acessíveis a 
Capítulo 5. VR-ReST: Uma abordagem para especificação de requisitos e teste funcional de aplicações 92 de $R V$

Figura 19 - Exemplo da geração do GFR a partir da especificação de requisitos

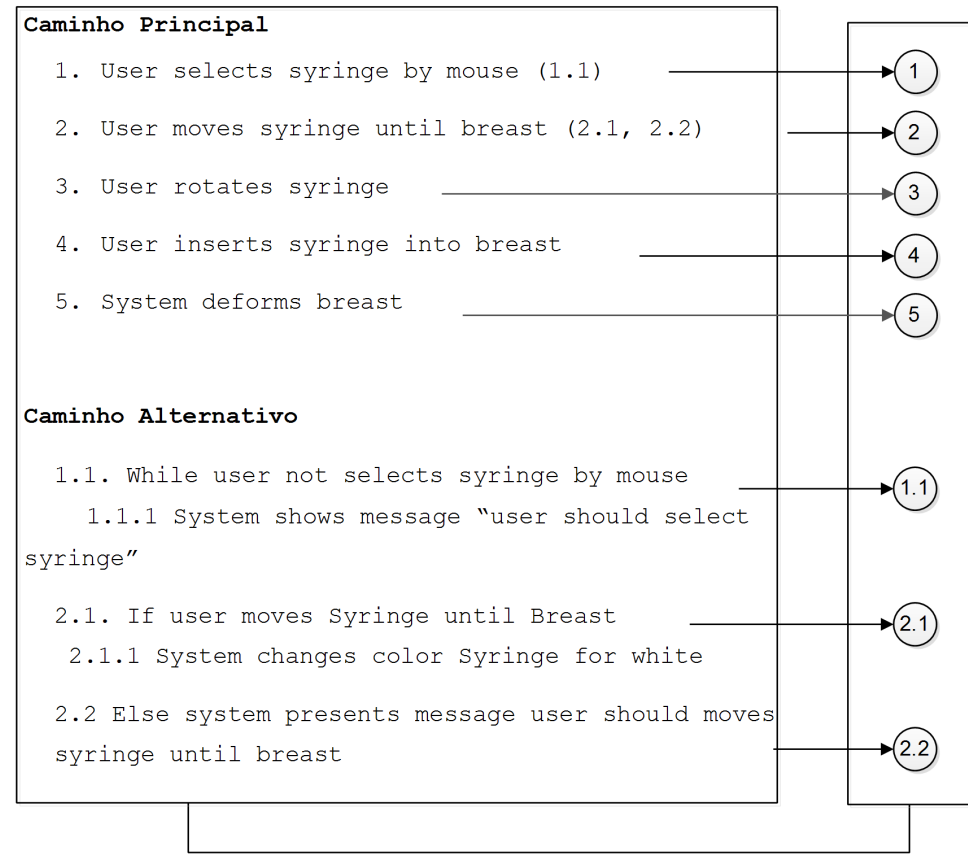

(a)

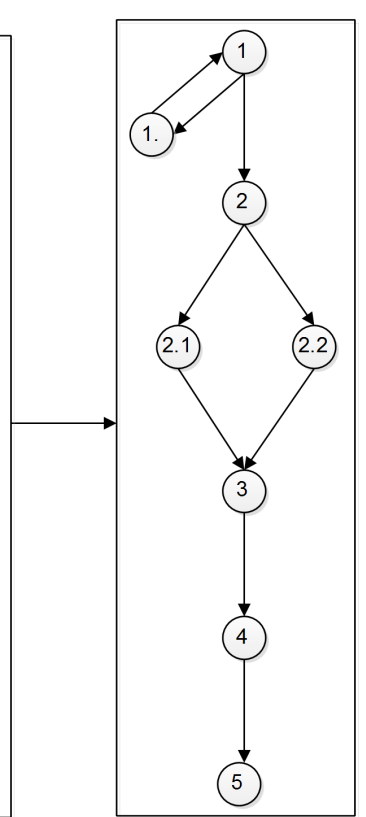

(b)

Fonte: Elaborada pelo autor.

partir do vértice inicial sejam explorados. Quando todas as arestas adjacentes a $v_{x}$ tiverem sido exploradas, a busca retorna para explorar novos vértices a partir do vértice do qual $v_{x}$ foi visitado. A estratégia adotada para a geração de dados de teste é descrita no Algoritmo 1.

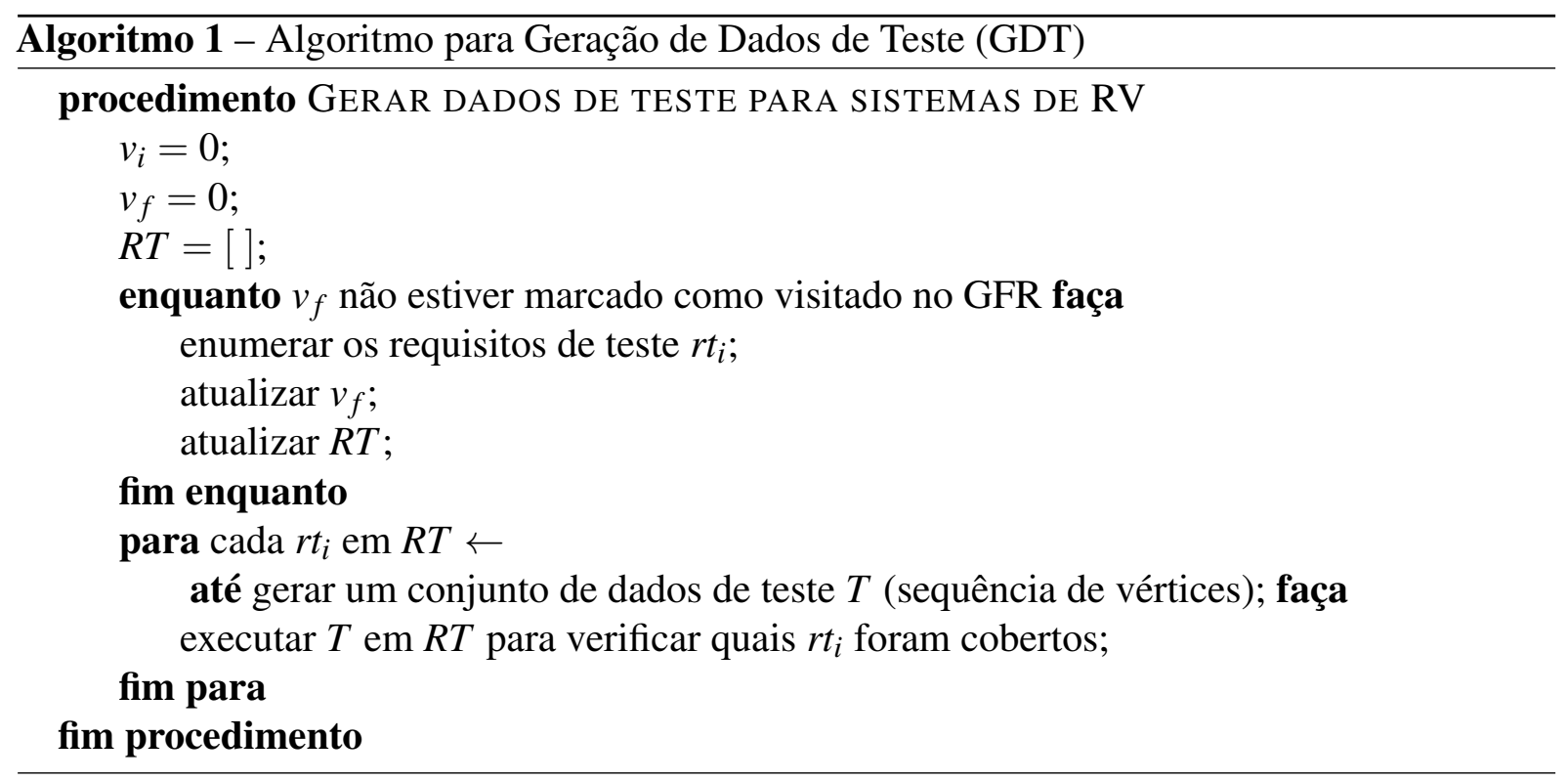

No Algoritmo 1, $v_{i}$ o vértice inicial, $v_{f}$ o vértice final e $R T$ é o conjunto de requisitos de teste $r t_{i}$. As linhas 7 e 8 somente devem ser repetidas se os requisitos de teste não forem totalmente cobertos. A Figura 20 apresenta um exemplo dos requisitos de teste e dos dados de teste gerados a partir da especificação de requisitos e do GFR. 
Figura 20 - Exemplo de requisitos de teste e dados de teste gerados a partir dos GFR

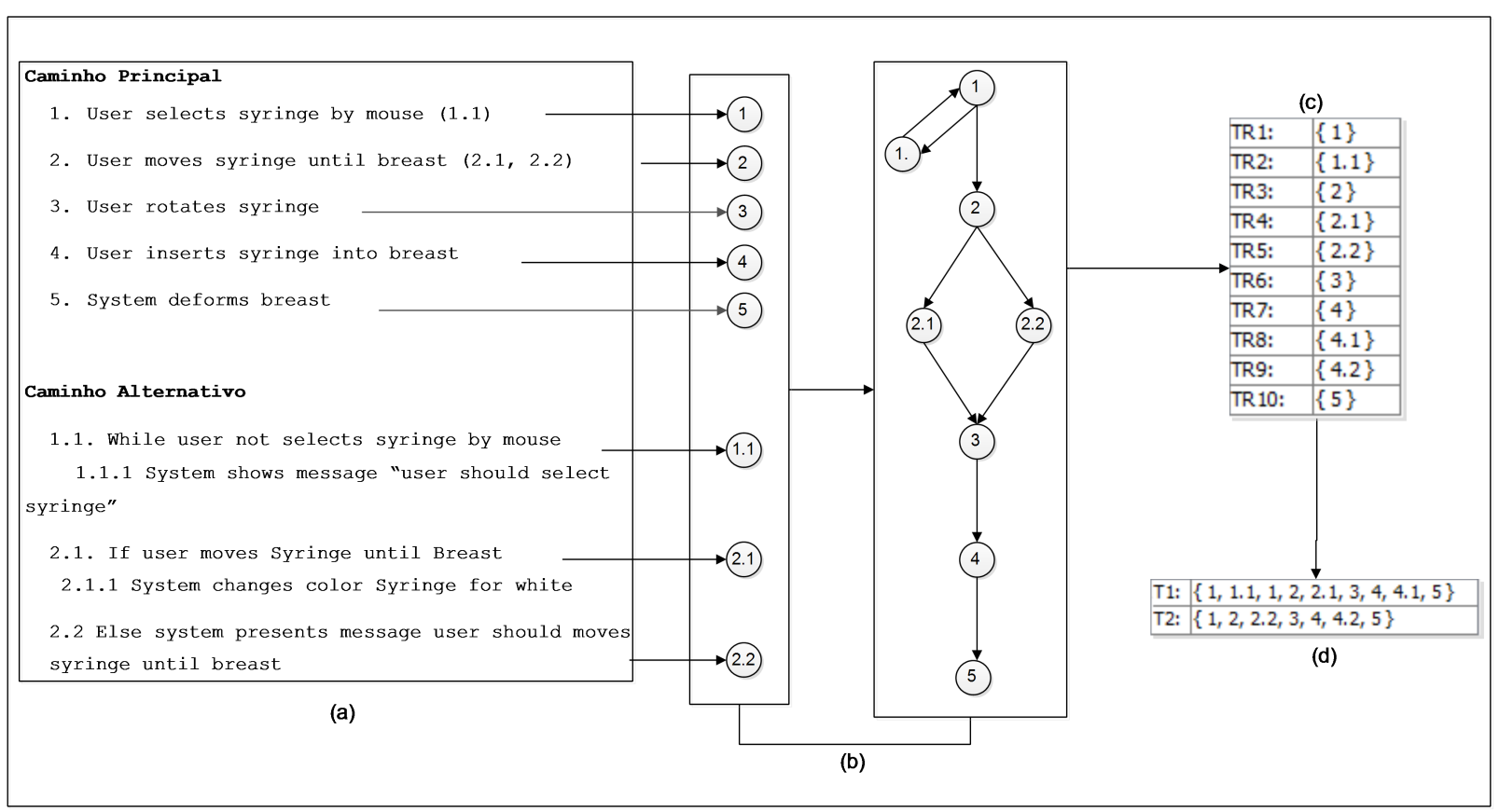

Fonte: Elaborada pelo autor.

No estágio (a) os requisitos são especificados e validados de acordo com as regras estabelecidas na linguagem BeLaRS. No estágio (b) cada requisito especificado no caminho principal, no estágio (a), é associado a um nó que irá compor o GFR. No estágio (c) os RTs são derivados de acordo com um dos critérios de teste definidos. A partir das especificações de requisitos convertidas no GFR, é possível selecionar qual critério de teste será utilizado. De acordo com o critério, a cobertura do grafo é realizada a partir da derivação de um conjunto de RTs, em termos de propriedades de caminhos de teste em um grafo (G). Um típico RT é coberto por meio de uma visita a um nó, aresta ou percorrendo um caminho particular. Portanto, os RTs derivados a partir do GFR podem ter tanto o valor verdadeiro (o RT foi coberto) ou falso (o RT não foi coberto). No estágio (d), a partir da derivação dos RTs, os dados de teste são gerados com a finalidade de cobrí-los. Com a geração dos dados de teste, é possível executar os testes e verificar a cobertura dos RTs.

Para automatizar a especificação de requisitos utilizando a linguagem BeLaRS e a geração dos testes foi desenvolvida uma ferramenta de apoio chamada Virtual Requirements Specification and Testing (ViReST).

\subsection{Ferramenta ViReST}

Com o objetivo de viabilizar o uso da abordagem VR-ReST, foi implementada a ferramenta ViReST. Esta ferramenta permite que os requisitos sejam especificados de forma padronizada; permite, ainda, derivar os RTs e, gerar e executar automaticamente os dados de teste 
Capítulo 5. VR-ReST: Uma abordagem para especificação de requisitos e teste funcional de aplicações 94 de $R V$

empregando os conceitos descritos nas seções anteriores. A ViReST foi desenvolvida usando a linguagem de programação Java e é composta por dois componentes: (i) requisitos e (ii) teste, os quais serão detalhados nas próximas seções.

\subsubsection{Componente de Requisitos}

O componente de requisitos abrange as especificações dos requisitos referentes à descrição do AV e dos objetos, bem como as interações entre o usuário e o sistema, necessárias para realizar o teste funcional. A ViReST visa cobrir as atividades relacionadas aos módulos de Especificação de Requisitos, Mapeamento de Requisitos e Geração de Teste descritos nas Subseções 5.2.1, 5.2.2, 5.2.3, respectivamente.

Para o desenvolvimento desse componente foi utilizada a ferramenta Another Tool for Language Recognition (ANTLR). Essa ferramenta consiste em um gerador de parser usado para ler, processar, executar ou traduzir o texto estruturado ou arquivos binários (PARR, 2007). Um exemplo de uma especificação de requisitos usando a linguagem BeLaRS na ferramenta ViReST é apresentado na Figura 21.

Figura 21 - Exemplo de uma especificação de requisitos usando a ferramenta ViReST

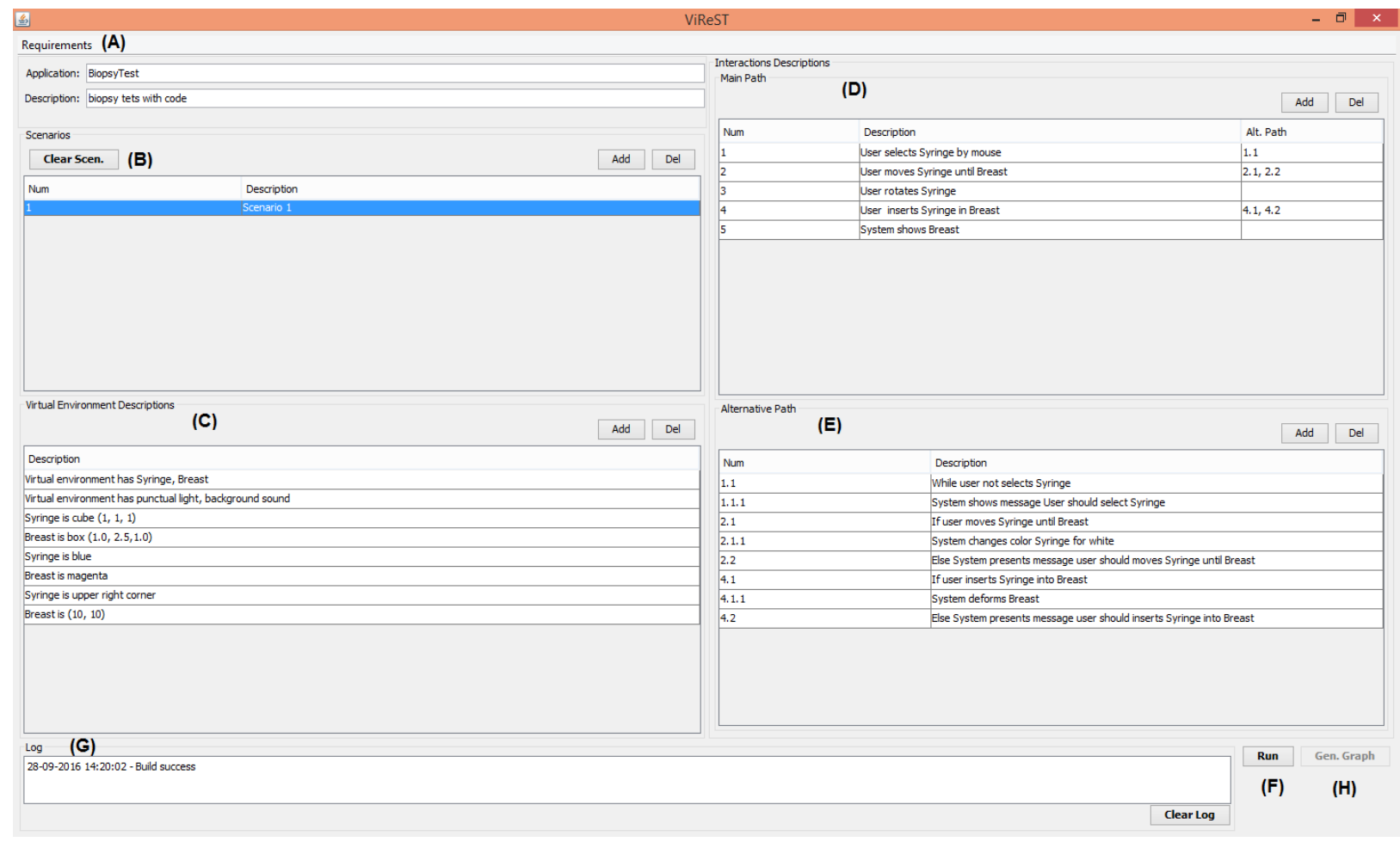

Fonte: Elaborada pelo autor.

A especificação no componente de requisitos inclui o nome, juntamente com uma breve descrição da aplicação e descrição geral do cenário, VED e IND.

No menu Requirements (parte (A) da Figura 21), os requisitos especificados podem ser salvos por meio da opção save e importados por meio da opção load. As especificações são 
armazenadas em um arquivo no formato $x \mathrm{ml}$ e podem ser alteradas de duas maneiras: $(i)$ na ViReST ou (ii) diretamente no arquivo. Além disso, o usuário pode obter a especificação realizada como uma forma textual por meio da opção show as text.

Cada cenário de uma determinada aplicação e seus respectivos requisitos podem ser adicionados por meio do botão $A d d$ ou excluídos por meio do botão $\operatorname{Del}$ (parte (B) da Figura 21).

Os requisitos relacionados com as características do AV são especificadas no VED (parte (C) da Figura 21) e os requisitos sobre as interações entre o usuário e o sistema são especificados no IND (partes (D) e (E) da Figura 21).

No IND, mais especificamente no Caminho Principal (parte (D) da Figura 21), o usuário pode indicar a existência de um ou mais Caminhos Alternativos por meio do Alt. Flow (parte (E) da Figura 21). Com os requisitos especificados no VED e no IND, o usuário deve executar a especificação por meio do botão Run (parte (F) da Figura 21) para verificar se esses requisitos estão ou não em conformidade com as regras da linguagem BeLaRS. Se a especificação não estiver correta, os possíveis erros que precisam ser corrigidos são mostrados no campo log (parte (G) da Figura 21). Caso os requisitos estejam em conformidade com as regras da BeLaRS, o botão Gen. Graph é habilitado para a geração do GFR (parte (H) da Figura 21).

É importante ressaltar que, neste componente, o usuário pode realizar a especificação de requisitos referente às características do $\mathrm{AV}$, comportamentos e transformações dos objetos. $\mathrm{A}$ partir da especificação usando a linguagem BeLaRs, o usuário pode validar a especificação e executá-la. Em seguida, os possíveis erros detectados em relação à especificação são apresentados no espaço log por meio do número da linha em que se encontra o erro e o tipo de erro. Por exemplo, 'Parser error: line 27:5: extraneous input 'user' expecting 'Else', 'Case', 'While', 'If', 'For', DIGIT'. Portanto, como uma saída, este componente fornece uma especificação de requisitos completa, concisa e sem ambiguidade que é utilizada para realizar os testes no componente de teste.

\subsubsection{Componente de Teste}

O componente de teste é um meio de executar os testes funcionais. Esse componente utiliza os requisitos especificados (Subseção 5.2.1) por meio da linguagem BeLaRS como entrada e os converte em um GFR apresentado na Subseção 5.2.2. Os RTs podem ser derivados a partir do GFR usando o algoritmo DFS apresentado na Subseção 5.2.3. Além disso, os dados de teste são gerados utilizando os quatro critérios previamente definidos (NC, EC, EPC e PPC) para verificar a cobertura dos RTs. O objetivo deste componente é fornecer um método sistemático de empregar critérios de teste para maximizar a detecção de falhas.

A partir do requisitos especificados na Figura 21, os RTs, os dados de teste gerados e os resultados do teste correspondentes são ilustrados na Figura 22.

A partir do GFR (parte (A) da Figura 22), o usuário pode selecionar qual critério de 
Capítulo 5. VR-ReST: Uma abordagem para especificação de requisitos e teste funcional de aplicações 96

Figura 22 - Exemplo de execução dos testes usando a ferramenta ViReST

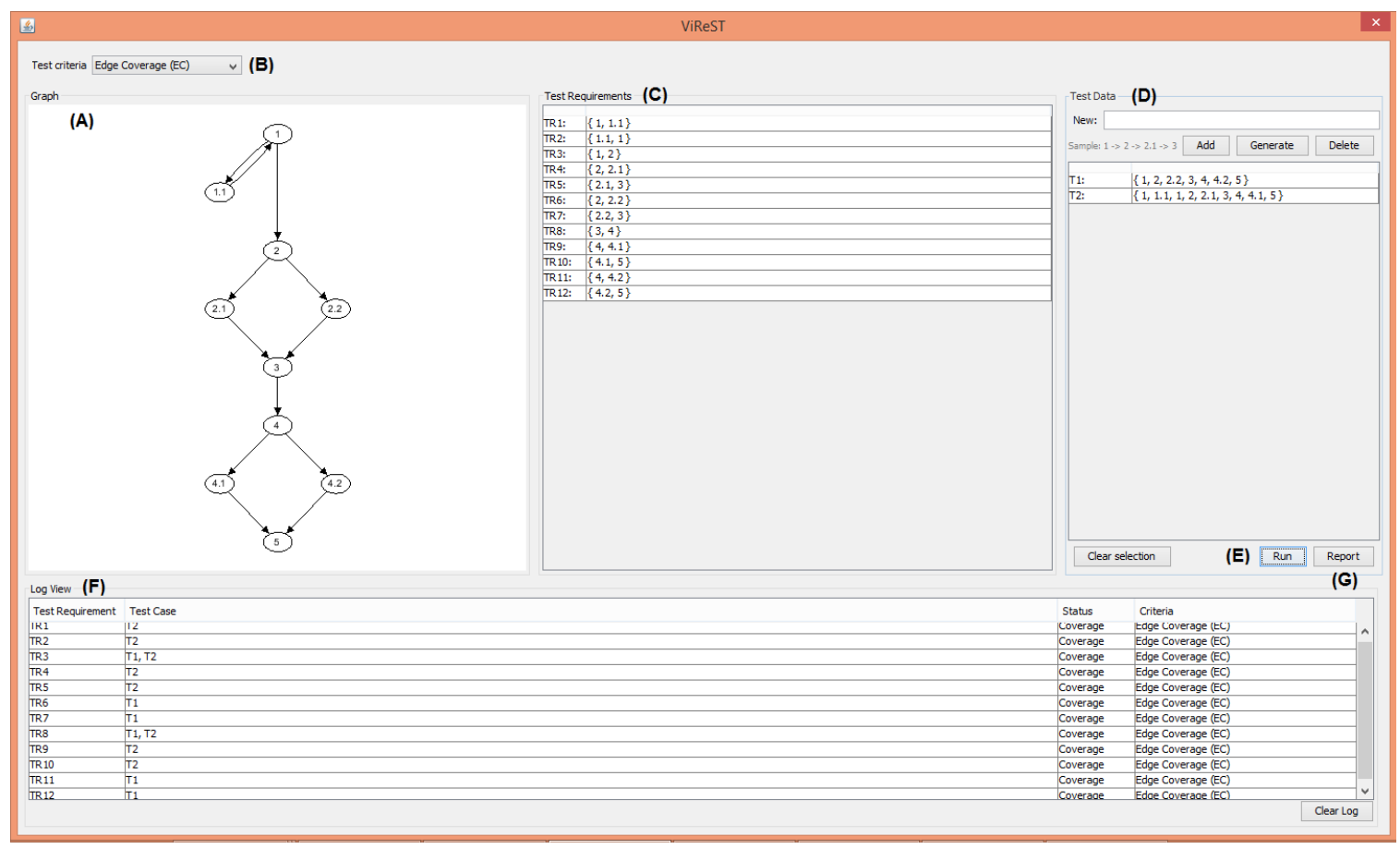

Fonte: Elaborada pelo autor.

teste será utilizado para derivar os RTs e gerar os dados de teste utilizando a opção Test Criteria (parte (B) da Figura 22). Uma vez que o critério de teste foi selecionado, os RTs são derivados automaticamente e são apresentados na opção Test Requirements (parte (C) da Figura 22).

Com os RTs derivados os dados de teste são gerados na opção Test Data (parte (d) na Figura 22). Os dados de teste podem ser gerados de duas formas: automaticamente por meio do botão Generate ou manualmente utilizando o botão Add. Além disso, o usuário pode excluir qualquer dado de teste por meio do botão Delete. Em seguida, o usuário deve executar o conjunto de dados de teste gerado usando o botão Run (parte (E) na Figura 22).

Os resultados deste teste, ou seja, os RTs cobertos ou não cobertos por cada um dos dados de teste são detalhados na opção Log View (parte (F) na Figura 22). Esses resultados podem ser armazenados no formato Portable Document Format (PDF) usando a opção Report (parte (G) na Figura 22).

Neste componente, o usuário pode executar o teste funcional automaticamente a partir da especificação de requisitos realizada no primeiro componente. A partir da especificação, o GFR é produzido, e o usuário pode selecionar o critério de teste que será aplicado para gerar os RTs. Em seguida, os RTs são gerados automaticamente e apresentados ao usuário. O usuário também pode definir se os dados de teste serão gerados automaticamente ou manualmente. Após a execução desses dados de teste, o usuário pode observar a cobertura dos RTS e os dados de teste utilizados no Log View (por exemplo, "TR1 was covered by T1 and T2 using Node Coverage"). Assim, como saída, este componente fornece a cobertura dos RTs a partir da aplicação dos dados de 
teste que foram gerados de acordo com um determinado critério de teste.

Portanto, o componente de teste visa prover um método sistemático utilizando critérios de teste para maximizar a detecção de falhas, uma vez que permite localizar erros que o testador dificilmente seria capaz de identificar utilizando testes $a d-h o c$ ou que somente poderiam ser detectados na fase final do desenvolvimento.

\subsection{Considerações Finais}

O presente capítulo foca na abordagem $V R-R e S T$, a qual foi proposta de modo a ser utilizada para auxiliar a especificação de requisitos e a realização de teste funcional de aplicações de RV, descrevendo seus três módulos: (1) Especificação dos Requisitos, (2) Mapeamento dos Requisitos e (3) Geração dos Testes.

O primeiro módulo é responsável por apoiar a especificação de requisitos sobre as características e as interações no AV. Nesse módulo as informações gerais sobre aplicação e o usuário, incluindo os requisitos, são especificadas por meio do modelo ViReS. Durante o processo de especificação, o projetista pode documentar no Guia de Especificação de Requisitos (apresentado no Apêndice A) os requisitos necessários para o desenvolvimento de aplicações de RV. Ao final, todos os requisitos validados são utilizados como entrada para o segundo módulo.

O segundo módulo é responsável por disponibilizar uma linguagem específica (BeLaRS) para mapear os requisitos definidos no primeiro módulo, com a finalidade de obter uma especificação semi-formal. Além disso, esse módulo converte a semântica da BeLaRS no GFR de acordo com a sequência em que os requisitos foram especificados. Cada nó no GFR representa um requisito especificado. O GFR é utilizado como entrada para a realização dos testes.

Finalmente, o terceiro módulo é responsável por derivar os RTs e gerar os dados de teste, a partir do GFR, com base em um critério de teste selecionado. Esse módulo visa fornecer a cobertura dos RTs por meio da aplicação do dados de teste.

Com o objetivo de viabilizar o uso da abordagem VR-ReST, a ferramenta ViReST foi implementada como apoio ferramental. Portanto a abordagem e a ferramenta apresentadas visam auxiliar o projetista na especificação de requisitos e o testador na criação ou na avaliação de conjuntos de dados de teste. Assim, com a utilização da abordagem e da ferramenta os requisitos podem ser especificados de uma forma padronizada e o teste funcional ser executado automaticamente, independentemente da aplicação. No próximo Capítulo é apresentada a validação da abordagem proposta nesta tese. 



\subsection{Considerações Iniciais}

Conforme apresentado nos capítulos anteriores, dois grandes desafios identificados no desenvolvimento de aplicações de RV são a especificação de requisitos de forma padronizada e a automatização dos testes. Nessa direção, este Capítulo apresenta dois estudos experimentais conduzidos para investigar a viabilidade da abordagem VR-ReST, mais especificamente a eficácia da linguagem BeLaRS, bem como a eficácia da abordagem VR-ReST por meio da ferramenta ViReST. O primeiro estudo empírico consistiu em um estudo de caso exploratório para verificar a conformidade e a aceitação de uso da linguagem BeLaRS; e o segundo foi um experimento controlado para investigar se a abordagem proposta é eficaz na realização do teste funcional em aplicações de RV. Ambos estudos foram planejados e executados seguindo a abordagem definida por Wohlin et al. (2012).

Na Seção 6.2 é descrito o estudo de caso que avalia a linguagem BeLaRS; na Subseção 6.2.1 é descrito o planejamento do estudo de caso, além das questões de pesquisa; na Subseção 6.2.2 é apresentado o procedimento para condução do estudo de caso.

Na Seção 6.3 é descrito o experimento que verifica a eficácia da abordagem VR-ReST; na Subseção 6.3.1, é apresentado o design do experimento; na Subseção 6.2.2 é apresentada a forma como foi realizado o experimento; na Subseção 6.3.6 é descrito o procedimento da coleta dos dados.

Na Seção 6.4 é descrita como foi realizada a análise dos dados e a discussão acerca dos resultados. Na Seção 6.5 são descritas as ameaças à validade das avaliações empíricas conduzidas e, por fim, na Seção 6.6 são apresentadas as considerações finais do capítulo. 


\subsection{Estudo de Caso: Eficácia da BeLaRS para auxiliar na especificação de requisitos}

Este estudo de caso teve como objetivo avaliar se a primeira versão da linguagem BeLaRS era eficaz para a especificação de requisitos de aplicações de RV. É importante enfatizar que o estudo foi conduzido para revelar possíveis problemas relacionados à conformidade e à aceitação e o uso da primeira versão da BeLaRS. Nesse contexto, a partir do estudo de caso foi possível melhorar a linguagem.

\subsubsection{Planejamento}

Esta seção descreve a configuração do estudo de caso. Este estudo foi realizado com 31 estudantes de pós-graduação em Ciência da Computação de três universidades diferentes (duas no Brasil e uma em Luxemburgo). Três dos 31 estudantes eram especialistas em RV, 17 tinham experiência intermediária com RV, 8 tinham pouca experiência e 3 não tinham nenhuma experiência. Todos os estudantes tem uma experiência intermediária com especificação de requisitos. $\mathrm{O}$ grupo dos estudantes foi constituído por seis mulheres e 25 homens com idade entre 24 e 30 anos.

Neste estudo, foram utilizadas duas métricas,: (i) Conformidade e (ii) Aceitação e Uso, para avaliar a precisão e utilidade da linguagem BeLaRS.

\subsubsection{Conformidade (C)}

A conformidade envolve a avaliação da precisão das palavras-chaves usadas na BeLaRS por meio de conceitos do domínio de RV. No presente estudo, são analisadas a simplicidade, a ortogonalidade e a escalabilidade da BeLaRS. Estas são as três principais métricas utilizadas para o desenvolvimento de uma LDE. A simplicidade representa uma linguagem desejável que expressa os conceitos de RV e apoia os usuários e os stakeholders na realização de seu trabalho. A ortogonalidade garante que cada palavra-chave utilizada na BeLaRS represente exatamente um conceito distinto no domínio RV. Finalmente, a escalabilidade mostra como a BeLaRS pode auxiliar a especificação de requisitos de aplicações de diferentes tipos e tamanhos com base nos conceitos de GC.

De acordo com as métricas apresentadas anteriormente, foram definidas três questões de pesquisa $\left(\mathrm{C}-\mathrm{QP}_{1}, \mathrm{C}-\mathrm{QP}_{2}\right.$ e $\left.\mathrm{C}-\mathrm{QP}_{3}\right)$, e suas respectivas hipóteses nula $\left(\mathrm{C}-\mathrm{Hx}_{0}\right)$ e alternativa $\left(\mathrm{C}-\mathrm{Hx}_{1}\right)$, em que $x$ representa o número da QP. As QPs e as hipóteses são apresentadas na Tabela 9 . 
Tabela 9 - Conformidade: Questões de Pesquisa e suas respectivas hipóteses

\begin{tabular}{|c|c|}
\hline Questão de Pesquisa & Hipóteses \\
\hline $\begin{array}{l}\text { C-QP } \\
\text { LaRS O quão simples é a Be- } \\
\text { RV? }\end{array}$ & $\begin{array}{l}\text { C-H1 } \\
\text { ceitos } \text { A suficientes de RV e não auxilia os usuários na } \\
\text { realização de seu trabalho. } \\
\text { C-H1 } \\
\text { ceitos de R BeLaRS é simples pois utiliza diversos con- } \\
\text { trabalho. }\end{array}$ \\
\hline \multirow[t]{2}{*}{$\begin{array}{l}\text { C-QP } \\
\text { LaRS } \text { : O quão ortogonal é a Be- } \\
\text { tos de RV? }\end{array}$} & $\begin{array}{l}\text { C-H2 } 0 \text { : A BeLaRS não é ortogonal devido às palavras- } \\
\text { chaves não representarem conceitos distintos de RV. }\end{array}$ \\
\hline & $\begin{array}{l}\text { C-H2 } 1 \text { : A BeLaRS é ortogonal devido a cada palavra- } \\
\text { chave representar um conceito específico de RV. }\end{array}$ \\
\hline $\begin{array}{l}\text { C-QP } \mathbf{P}_{3} \text { : O quão escalável é a Be- } \\
\text { LaRS para realizar especificações } \\
\text { de requisitos em larga escala? }\end{array}$ & $\begin{array}{l}\text { C-H3 } 0 \text { : A BeLaRS não é escalável devido a não pos- } \\
\text { suir palavras-chaves suficientes para especificar requi- } \\
\text { sitos em larga escala. } \\
\text { C-H3 } 1 \text { : A BeLaRS é escalável devido a conter } \\
\text { palavras-chaves suficientes para especificar requisitos } \\
\text { em larga escala. }\end{array}$ \\
\hline
\end{tabular}

Fonte: Elaborada pelo autor.

\subsubsection{Aceitação e Uso (U)}

Com esta métrica, o objetivo é avaliar a aceitação e o uso da linguagem BeLaRS com base no Modelo de Aceitação de Tecnologia (do inglês, Technology Acceptance Model (TAM) (DAVIS; BAGOZZI; WARSHAW, 1989). A TAM baseia-se no pressuposto de que o valor da tecnologia é determinado pela vontade dos sujeitos de usá-la, isto é, a intenção de utilizar um dispositivo tecnológico é determinada pela percepção do usuário sobre sua utilidade e sua facilidade de uso. Neste contexto, as variáveis de TAM são baseadas nos seguintes critérios:

- a facilidade do uso refere-se ao grau em que o usuário espera que o sistema a ser utilizado não exija muito esforço;

- a intenção em usar a tecnologia é determinada pela visão do usuário em utilizá-la ou não no futuro;

- a utilidade é definida baseada nos sentimentos do usuário sobre a probabilidade de que, utilizando um sistema específico, seu desempenho no trabalho pode aumentar.

Para avaliar a aceitação e o uso, as QPs foram baseadas na variável "facilidade de uso" da TAM. Quatro QPs (U-QP, U- $\mathrm{QP}_{2}, \mathrm{U}_{-} \mathrm{QP}_{3}, \mathrm{U}_{-} \mathrm{QP}_{4}$ e U-QP $)$ e suas respectivas hipóteses nula $\left(\mathrm{U}-\mathrm{Hx}_{0}\right)$ e alternativa $\left(\mathrm{U}-\mathrm{Hx}_{1}\right)$ foram definidas, como pode ser visto na Tabela 10. 
Tabela 10 - Aceitação e Uso: Questões de Pesquisa e suas respectivas hipóteses

\begin{tabular}{|c|c|}
\hline Questões de Pesquisa & Hipóteses \\
\hline \multirow[t]{2}{*}{$\begin{array}{l}\mathbf{U}-\mathbf{Q P} \mathbf{P}_{1} \text { : O quão próximo é a espe- } \\
\text { cificação de requisitos usando a } \\
\text { BeLaRS da especificação usando } \\
\text { a linguagem natural? }\end{array}$} & $\begin{array}{l}\text { U-H1 }{ }_{0} \text { : A especificação de requisitos usando a Be- } \\
\text { LaRS não é próxima da especificação usando a lingua- } \\
\text { gem natural. }\end{array}$ \\
\hline & $\begin{array}{l}\text { U-H1 } 1_{1} \text { A especificação de requisitos usando a BeLaRS } \\
\text { é próxima da especificação usando a linguagem natu- } \\
\text { ral. }\end{array}$ \\
\hline \multirow{2}{*}{$\begin{array}{l}\mathbf{U}-\mathbf{Q P} \mathbf{P}_{2}: \text { O quão fácil são as re- } \\
\text { gras da BeLaRS de serem com- } \\
\text { preendidas? }\end{array}$} & $\begin{array}{l}\text { U-H2 }{ }_{0} \text { : As regras da BeLaRS não são fáceis de serem } \\
\text { compreendidas. }\end{array}$ \\
\hline & $\begin{array}{l}\text { U-H2 } 1 \text { : As regras da BeLaRS são fácies de serem } \\
\text { compreendidas. }\end{array}$ \\
\hline \multirow{2}{*}{$\begin{array}{l}\text { U-QP } \\
\text { lita }: \text { O quão a BeLecificação de requisitos } \\
\text { de aplicações de RV? }\end{array}$} & $\begin{array}{l}\text { U-H3 } \\
\text { quisitos. }\end{array}$ \\
\hline & $\begin{array}{l}\text { U-H3 } \\
\text { tos. A BeLaRS facilita a especificação de requisi- }\end{array}$ \\
\hline \multirow{2}{*}{$\begin{array}{l}\text { U-QP } \\
\text { na especificaçãa de requisitos de } \\
\text { aplicações de RV? }\end{array}$} & $\begin{array}{l}\text { U-H4 } 4_{0} \text { : A BeLaRS não é útil na especificação de re- } \\
\text { quisitos de aplicações de RV. }\end{array}$ \\
\hline & $\begin{array}{l}\text { U-H4 } 1 \text { : A BeLaRS é útil na especificação de requisitos } \\
\text { de aplicações de RV. }\end{array}$ \\
\hline \multirow{2}{*}{$\begin{array}{l}\text { U-QP } \\
\text { c: O quão rápida é a espe- } \\
\text { cificação de requisitos usando a } \\
\text { BeLaRS? }\end{array}$} & $\begin{array}{l}\text { U-H5 } \\
\text { requisitos de aplicações de RV. }\end{array}$ \\
\hline & $\begin{array}{l}\text { U-H5 } 1 \text { : A BeLaRS é rápida para especificar os requi- } \\
\text { sitos de aplicações de RV. }\end{array}$ \\
\hline
\end{tabular}

Fonte: Elaborada pelo autor.

\subsubsection{Condução}

Depois de definir e planejar o estudo de caso, sua fase de condução foi realizada em duas etapas: (1) especificação de requisitos de uma aplicação usando a BeLaRS e (2) análise da conformidade e aceitação e uso da BeLaRS a partir dos requisitos especificados na primeira etapa.

\subsubsection{Etapa 1: Especificação de Requisitos}

Esta etapa visa especificar os requisitos de uma aplicação de RV. A saída desta fase consiste em um conjunto de requisitos que devem estar em conformidade com as regras previamente estabelecidas na BeLaRS (apresentadas na Subseção 5.2.2). Esta etapa foi precedida por duas atividades. Na primeira atividade, foi disponibilizado em um repositório online um formulário detalhado (ver Apêndice C) para os estudantes com explicações e exemplos das regras 
da BeLaRS (ver Apêndice D).

Na segunda atividade, a descrição geral de uma aplicação de RV que simula um exame de biópsia, gerada pelo framework ViMeT (OLIVEIRA; NUNES, 2010), foi disponibilizada aos estudantes. A descrição geral disponibilizada aos estudantes é apresentado no Quadro 1 e encontra-se na língua inglesa uma vez que as regras da BeLaRS foram criadas nessa língua. Finalmente, os voluntários tiveram acesso ao documento no qual deveriam realizar a especificação de requisitos remotamente. Em ambas as atividades, os voluntários não tiveram contato com o pesquisador responsável durante a realização deste experimento. Além disso, é importante ressaltar que foi computado o tempo total que cada estudante levou para especificar os requisitos.

Quadro 1 - Cenário para especificar os requisitos utilizando a linguagem BeLaRS

Nome da aplicação: Simulação de um exame de biópsia.

Cenário: Inserção da seringa na mama.

The virtual environment is composed of black color and directional light. The virtual environment is composed of two objects: syringe and breast. The syringe is represented by a cylinder. The breast is represented by a cube. The breast has the pink color. The syringe has the blue color. The syringe is on the right side, and the breast is located on the left side of the virtual environment.The user should select the syringe using the mouse. While the user doesn't to select the syringe, the system should show a message that user should select the syringe. Then, the syringe should be moved until breast by the user. If the syringe has not been moved until breast by the user, the system should display a message that user should move the syringe until breast. Else, if syringe has been moved until breast, thus the syringe color should be changed to red, and the user goes to next step. Next, the user should rotate the syringe. Then, the user should insert the syringe on the breast and finally the breast should be deformed by the system.

Fonte: Elaborada pelo autor.

\subsubsection{Etapa 2: Análise da conformidade e aceitação e uso da BeLaRS}

Esta etapa está relacionada com a análise das respostas obtidas por meio do questionário sobre a conformidade e a aceitação e o uso da BeLaRS. O questionário foi composto por perguntas estruturadas e três perguntas abertas, cujo objetivo foi obter um feedback individual dos estudantes (ver Apêndice C). Os estudantes avaliaram cada questão usando a escala Likert que consiste em cinco níveis, sendo o nível mais alto representado por "Extremely" e o nível mais baixo "Not a bit" (LIKERT, 1932), conforme pode ser visto na Tabela 11. Para as hipóteses serem confirmadas ou rejeitadas foram definidas duas premissas: (i) Se 70\% dos estudantes avaliarem a BeLaRS com uma nota igual ou acima de 4 na escala Likert, as hipóteses podem ser confirmadas; (ii) caso contrário, as hipóteses devem ser rejeitadas.

Além dos resultados obtidos por meio do questionário, foi realizada uma inspeção manual dos requisitos, produzidos na Etapa 6.2.2.1, para determinar quais estavam ou não em conformidade com a BeLaRS. 
Tabela 11 - Escala Likert usada para avaliar a linguagem BeLaRS

\begin{tabular}{cc}
\hline Escala Likert & Descrição \\
\hline \hline 5 & Extremely \\
4 & Very \\
3 & Moderately \\
2 & Slightly \\
1 & Not a bit \\
\hline
\end{tabular}

Fonte: Elaborada pelo autor.

\subsection{Experimento: Eficácia da abordagem VR-ReST para auxiliar a geração automática dos testes}

Nessa seção será detalhado o experimento conduzido para verificar a eficácia e a aplicabilidade da abordagem VR-ReST, utilizando a ferramenta ViReST, na realização de testes funcionais em aplicações de RV. Além disso, será apresentado um estudo comparativo entre a abordagem ViReST e o Teste Aleatório (TA).

\subsubsection{Design do Experimento}

A abordagem VR-ReST foi avaliada por meio do critério de teste de mutação proposto por Hamlet (1977) e DeMillo, Lipton e Sayward (1978). A partir do teste de mutação, algumas de suas definições foram adaptadas ao contexto deste experimento. Na Tabela 12 são apresentadas essas definições.

De acordo com as informações apresentadas na Tabela 12, os dados de teste gerados pela abordagem VR-ReST visam revelar falhas, isto é, distinguir os comportamentos visuais dos programas mutados do programa original de RV. Finalmente, a qualidade do conjunto de dados de teste foi computado pelo EM. Especificamente, pretende-se investigar as seguintes questões de pesquisa:

- QP 1 : Qual a eficácia da abordagem VR-ReST usando a ferramenta ViReST para identificar falhas em aplicações de RV?

Para responder à $\mathrm{QP}_{1}$ foram coletados dados de teste gerados para cada critério $(\mathrm{NC}, \mathrm{EC}$, EPC e PPC) implementados na ferramenta ViReST. Em seguida, a eficácia da abordagem foi avaliada por meio do número de falhas detectadas que, no teste de mutação, são representadas pelo número de mutantes mortos.

- $\mathbf{Q P}_{2}$ : Existe relação entre a qualidade dos requisitos especificados e a qualidade dos dados de teste gerados para aplicações de RV? 
Tabela 12 - Definições de teste de mutação adaptadas para RV

\begin{tabular}{|c|c|c|}
\hline Definição & Teste de Mutação & $\begin{array}{l}\text { Teste de Mutação adaptado } \\
\text { para RV }\end{array}$ \\
\hline $\begin{array}{l}\text { Programa Original } \\
(P)\end{array}$ & Teste & Programa de RV em Teste $(P)$ \\
\hline Mutante $(M)$ & $\begin{array}{l}\text { Versões defeituosas do pro- } \\
\text { grama }\end{array}$ & $\begin{array}{l}\text { Versões defeituosas do pro- } \\
\text { grama }\end{array}$ \\
\hline $\begin{array}{l}\text { Mutante } \\
(M M)\end{array}$ & $\begin{array}{l}\text { Mutante que produz diferen- } \\
\text { tes saídas a partir do Programa } \\
\text { Original para um determinado } \\
\text { teste. }\end{array}$ & $\begin{array}{l}\text { Mutante que produz diferentes } \\
\text { comportamentos visuais a par- } \\
\text { tir do programa original para } \\
\text { um determinado teste }\end{array}$ \\
\hline $\begin{array}{l}\text { Mutante } \\
(M V)\end{array}$ & $\begin{array}{l}\text { Mutante que não foi morto pe- } \\
\text { los dados de teste }\end{array}$ & $\begin{array}{l}\text { Mutante que não foi morto pe- } \\
\text { los dados de teste }\end{array}$ \\
\hline $\begin{array}{l}\text { Mutante Equiva- } \\
\text { lente }(M E)\end{array}$ & $\begin{array}{l}\text { Mutante que não pode ser } \\
\text { morto por qualquer dado de } \\
\text { teste devido produzir a mesma } \\
\text { saída do Programa Original. }\end{array}$ & $\begin{array}{l}\text { Mutante que não pode ser } \\
\text { morto por qualquer dado de } \\
\text { teste devido produzir o mesmo } \\
\text { comportamento visual do pro- } \\
\text { grama original de RV }\end{array}$ \\
\hline $\begin{array}{l}\text { Operadores de Mu- } \\
\text { tação }\end{array}$ & $\begin{array}{l}\text { Definem alterações } \\
\text { que geram os mutan }\end{array}$ & $\begin{array}{l}\text { Definem alterações sintáticas } \\
\text { que geram os mutantes }\end{array}$ \\
\hline $\begin{array}{l}\text { Escore de Mutação } \\
(E M)\end{array}$ & $E M=\frac{M M(P)}{M(P)-M E(P)}$ & $E M=\frac{M M(P)}{M(P)-M E(P)}$ \\
\hline
\end{tabular}

Fonte: Elaborada pelo autor.

O teste funcional depende da qualidade da especificação dos requisitos. A qualidade dos requisitos está diretamente relacionada com a integridade e consistência com que eles são especificados. Neste caso, a qualidade dos requisitos especificados pode interferir na qualidade dos dados de teste, pois os dados de teste são gerados a partir desses requisitos.

Para responder a $\mathrm{QP}_{2}$ foi analisada se a ausência de determinadas características e/ou requisitos específicos está relacionada à qualidade dos dados de teste gerados e, consequentemente, à quantidade de mutantes que permanecem vivos. As seguintes hipóteses foram definidas para esta QP:

$H 2_{0}$ : Não existe relação entre a qualidade dos requisitos especificados $(\mu R e q)$ e a qualidade dos dados de teste gerados $(\mu D T)$, assim:

$$
H 2_{0}: \mu R e q \neg \Rightarrow \mu D T
$$

$H 2_{1}$ : Existe relação entre a qualidade dos requisitos especificados $(\mu R e q)$ e a qualidade dos dados de teste gerados $(\mu D T)$, assim:

$$
H 2_{1}: \mu R e q \Rightarrow \mu D T
$$


- $\mathbf{Q P}_{3}$ : Quão eficaz é a abordagem VR-ViReST na geração dos dados de teste para detectar falhas comparada com o teste aleatório?

A abordagem VR-ReST, por meio da ferramenta ViReST, foi comparada com o TA para verificar a eficácia na detecção de falhas em programas de RV. O número de dados de teste gerados e o EM obtidos foram comparados. Um conjunto de dados, de acordo com cada critério, foi gerado pela ferramenta ViReST e obtido o EM. Por outro lado, utilizando o TA, o experimento foi executado 10 vezes e, ao final, a média do número de dados de teste gerados e a média do EM foram computadas. As seguintes hipóteses foram definidas para esta questão de pesquisa:

$H 3_{0}$ : Não existe diferença entre a abordagem VR-ReST $(\mu V R-R e S T)$ e o teste aleatório ( $\mu$ T.A.) na detecção de falhas a partir dos dados de teste gerados teste, assim:

$$
H 3_{0}: \mu V R-\operatorname{ReST}=\mu T . A .
$$

$H 3_{1}$ : Existe diferença entre a abordagem VR-ReST $(\mu V R-R e S T)$ e o teste aleatório $(\mu T A)$ na detecção de falhas a partir dos dados de teste gerados, assim:

$$
H 3_{1}: \mu V R-\operatorname{ReST} \neq \mu T A
$$

\subsubsection{Definição dos Objetivos}

O modelo Goal/Question/Metric (GQM) proposto por Basili e Weiss (1986) foi utilizado para definir os objetivos desse experimento. Esse modelo apresenta o experimento dividido em cinco partes: objeto de estudo, propósito, perspectiva, foco qualitativo e contexto.

- Objeto de estudo: o objeto do estudo é a abordagem VR-ReST.

- Propósito: o propósito deste experimento é avaliar a eficácia da abordagem VR-ReST para executar testes funcionais em programas de RV.

- Perspectiva: este experimento é executado do ponto de vista de um pesquisador.

- Foco Qualitativo: o principal efeito sob investigação é a eficácia da abordagem VR-ReST que é medido pelo número de dados de teste gerados e pelo escore de mutação.

- Contexto: Este experimento foi realizado utilizando três programas de RV.

O experimento pode ser resumido utilizando o seguinte modelo proposto por Wohlin et al. (2012): Analisar abordagem VR-ReST; com o propósito de avaliar a execução dos testes funcionais; com respeito à "eficácia"; do ponto de vista de um pesquisador; no contexto de três programas de RV. 


\subsubsection{Definição das variáveis}

Para este experimento foram analisadas: (i) uma variável independente - geração dos dados de teste e; (ii) três variáveis dependentes - eficácia da detecção de falhas, tamanho do conjunto de testes e escore de mutação.

- Dados de teste: representa o número de dados de teste em um conjunto de teste. Os conjuntos de dados de teste são gerados por meio do algoritmo DFS, apresentado na Subseção 5.2.3, para satisfazer cada um dos critérios de teste (NC, EC, EPC, PPC), conforme explicado na Subseção 2.3.2.2.

- Detecção de falhas: é medida por meio da eficácia de um conjunto de testes que pode obter "sucesso", ou seja, quando a falha é detectada por pelo menos um dado de teste, ou "fracasso" quando a falha não é detectada por nenhum dado de teste.

- Escore de mutação: é representado pela cobertura dos $R T s$ que são satisfeitos por um conjunto de dados de teste $T$.

\subsubsection{Sujeitos do Experimento}

Para realizar a avaliação da abordagem proposta foram utilizados três programas diferentes $\left(\mathrm{P}=\left\{\mathrm{p}_{1}, \mathrm{p}_{2}, \mathrm{p}_{3}\right\}\right)$. Os três programas selecionados (Bouncing Ball, Alternate Appearance e ViMeT Game) foram desenvolvidas em Java. Os dois primeiros programas são amplamente utilizados (SELMAN, 2002) e o último é um jogo baseado na aplicação gerada pelo ViMeT apresentado na Seção 3.5.

Bouncing Ball é uma aplicação que tem como objetivo movimentar um objeto (bola) para baixo, para cima, para direita ou para esquerda na cena. O movimento do objeto ocorre por meio do uso das teclas A e S ou selecionando um botão chamado "OK”.

Alternate Appearance é uma aplicação que visa alterar a aparência (cor) de nove objetos (bolas) na cena. Esta aparência pode ser alterada por quatro novas cores (preto, vermelho, verde e azul), de acordo com o tamanho dos objetos que pode ser: minúsculo, pequeno e grande.

ViMeT Game é uma aplicação baseada em conceitos de serious game e RV, cuja finalidade é usar elementos lúdicos de jogos para favorecer o treinamento virtual de biópsia mamária (TORRES et al., 2012). É importante ressaltar que o ViMeT Game foi desenvolvido no LApIS da EACH da Universidade de São Paulo.

A lista detalhada com o nome das aplicações, linhas de código (LOC), número de classes e número de funções são apresentadas na Tabela 13. 
Tabela 13 - Sujeitos do experimento

\begin{tabular}{cccc}
\hline Aplicações & LOC & Classes & Funções \\
\hline \hline BouncingBall & 211 & 1 & 7 \\
AlternateAppearance & 660 & 3 & 12 \\
ViMeTGame & 11.420 & 41 & 455 \\
\hline
\end{tabular}

Fonte: Elaborada pelo autor.

\subsubsection{Configuração do Experimento}

O procedimento realizado durante a execução do experimento consiste nas seguintes etapas:

1. especificação dos requisitos: as especificações dos requisitos $R=\left(r_{1} ; r_{2} ; \ldots ; r_{m}\right)$ para cada programa de RV $\left(p_{i}\right)$ foram realizadas usando inicialmente o modelo ViReS e foram adicionadas na ferramenta ViReST.

2. geração do GFR: a partir dos requisitos especificados e validados utilizando a linguagem BeLaRS na ferramenta ViReST foi gerado o GFR correspondente.

3. geração dos requisitos de teste: a partir do GFR, os requisitos de teste $R T=\left\{r t_{1} ; r t_{2} ; \ldots\right.$; $\left.r t_{n}\right\}$ foram derivados de acordo com cada critério de teste $C=\{\mathrm{NC}, \mathrm{EC}, \mathrm{EPC}, \mathrm{PPC}\}$ por meio da ferramenta ViReST.

4. geração do conjunto de dados de teste: a ferramenta ViReST foi utilizada para gerar e executar os dados de teste $T=\left\{t_{1} ; t_{2} ; \ldots ; t_{r}\right\}$, a fim de verificar quais $R T s$ foram cobertos. Esse conjunto de dados de teste gerados e os $R T s$ cobertos são armazenados.Na Figura 23 é apresentado um exemplo de requisitos de teste e seus respectivos dados de teste gerados usando o a abordagem VR-ReST.

Figura 23 - Exemplo de requisitos de teste e dados de teste gerados usando a abordagem VR-ReST
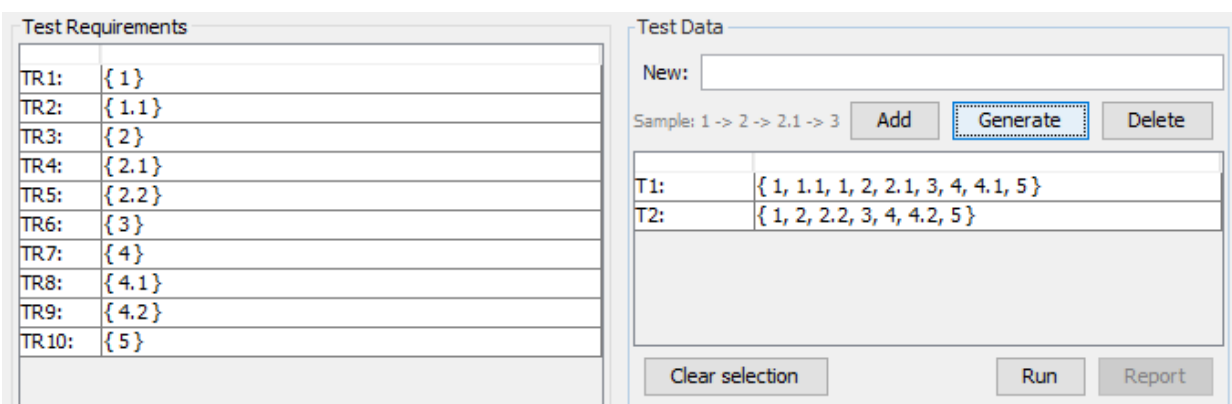

Fonte: Elaborada pelo autor. 
5. geração dos mutantes para cada programa: a ferramenta MuJava ${ }^{1}$ (MA; OFFUTT; KWON, 2005) foi utilizada para gerar os mutantes $M=\left\{m_{1}, m_{2}, m_{3}\right\}$, onde $M$ é o conjunto de mutantes por programa de RV $\left(p_{i}\right)$. Para gerar os mutantes foram utilizados operadores que modificam as expressões, substituindo, excluindo e inserindo operadores primitivos. A ferramenta MuJava oferece seis tipos de operadores primitivos: (i) Aritimético, (ii) Relacional, (iii) Condicional, (iv) Lógico, (v) Deslocamento e (vi) Atribuição. Além disso, alguns dos operadores são separados em duas ou três subdivisões, por exemplo, o operador AOR é subdividido em: $A O R_{B}$ (binary), $A O R_{S}$ (short-cut) and $A O R_{U}$ (unary). Na Tabela 14 são descritos esses operadores.

Tabela 14 - Operadores de mutação oferecidos pela ferramenta MuJava

\begin{tabular}{c|l}
\hline Operadores & Descrição \\
\hline \hline$A O R_{B}$ & \\
$A O R_{U}$ & Arithmetic Operator Replacement \\
$A O R_{S}$ & \\
\hline$A O I_{U}$ & Arithmetic Operator Insertion \\
$A O I_{S}$ & \\
\hline$A O D_{U}$ & Arithmetic Operator Deletion \\
$A O D_{S}$ & \\
\hline $\mathrm{ROR}$ & Relational Operator Replacement \\
\hline $\mathrm{COR}$ & Conditional Operator Replacement \\
\hline $\mathrm{COI}$ & Conditional Operator Insertion \\
\hline $\mathrm{COD}$ & Conditional Operator Deletion \\
\hline SOR & Shift Operator Replacement \\
\hline LOR & Logical Operator Replacement \\
\hline LOI & Logical Operator Insertion \\
\hline LOD & Logical Operator Deletion \\
\hline ASR & Assignment Operator Replacement \\
\hline \hline & Fonte: Elaborada pelo autor.
\end{tabular}

6. identificação dos mutantes equivalentes: os mutantes equivalentes $E Q=\left\{e q_{1} ; e q_{2} ; \ldots\right.$; $\left.e q_{t}\right\}$ foram identificados manualmente. Os mutantes considerados equivalentes são aqueles que possuem o mesmo comportamento visual do programa original de RV.

7. execução do conjunto de dados de teste: a ferramenta Sikuli ${ }^{2}$ (YEH; CHANG; MILLER, 2009) foi utilizada para executar, para cada conjunto de mutantes obtido por cada programa $p_{i}$, um conjunto de dados de teste $T$ gerado pela ferramenta ViReST. Esse

1 Ferramenta de mutação para programas em Java. Essa ferramenta gera automaticamente mutantes para testes de mutações tradicionais e testes de mutação em nível de classe. A MuJava pode testar classes individuais e pacotes de várias classes

2 Sikuli, é uma abordagem visual para pesquisa e automação de interfaces gráficas do usuário usando screenshots. A Sikuli também fornece um script visual para automatizar as interações GUI, usando padrões de captura de tela para direcionar eventos de mouse e teclado. 
processo foi realizado por meio de uma transformação manual dos dados de teste gerados pela ferramenta ViReST em ações correspondentes que existem na Sikuli. Essas ações foram adicionadas manualmente na ferramenta SikuLi por meio de screenshots e, em seguida, foram executadas em cada mutante gerado. Os dados de teste gerados visam verificar se o comportamento visual de um programa mutante corresponde ao comportamento visual do programa original de RV. Se o comportamento visual for diferente do comportamento esperado, então o dado de teste é capaz de identificar o mutante. $\mathrm{Na}$ Figura 24 é apresentado um exemplo dos screenshots de acordo com o dado de teste $T_{1}$ $=1,2,2.1,3,3.1,4,4.1,5,5.1,6,6.2,7$ gerado pela abordagem VR-ReST para o programa Alternate Appearance. Como pode ser visto, as entrada de $T_{1}$ estão relacionadas com as ações realizadas na Sikuli. Por exemplo: 1 = "find" (linha 1), 2 e 2.1 = "click" (linha 2), 3 e 3.1 = "click" (linha 3), 4 e 4.1 = "click" (linha 4), 5 e 5.1 = "click" (linha 5), 6 e $6.2=$ "exists" (linhas 6, 7, 8 e 9) e 7 = "findAll" (linha 10).

Figura 24 - Exemplo da execução de $T_{1}$ para o programa Alternate Appearance usando a ferramenta Sikuli

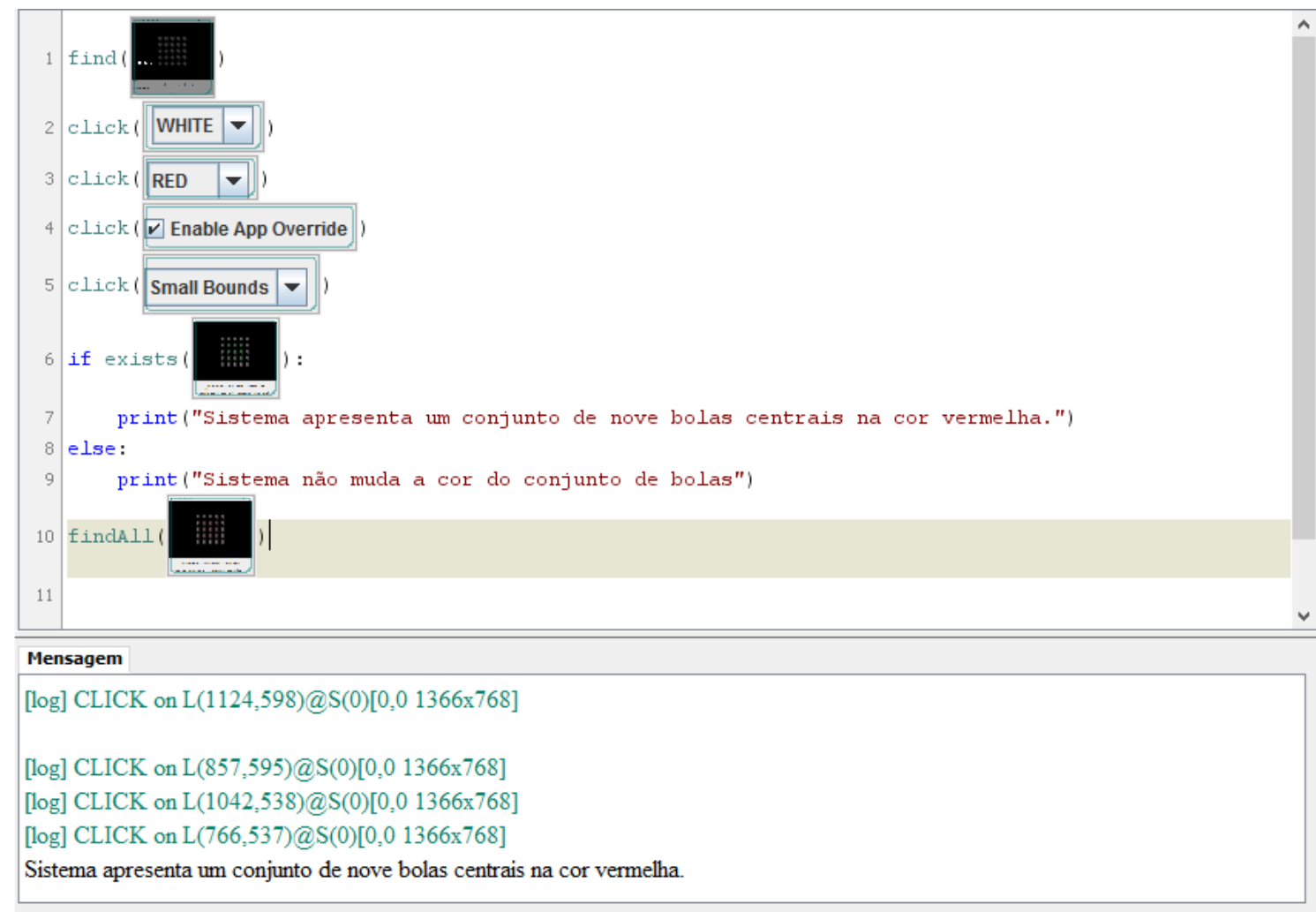

(python) | R: $10 \mid C: 11$

Fonte: Elaborada pelo autor.

8. cálculo do escore de mutação: o $E M$ de um conjunto de teste $T$ indica diretamente sua eficácia na detecção de falhas. O $E M$ foi calculado para cada programa $p_{i}$, conforme apresentado na Tabela 12. 
9. comparação entre a abordagem VR-ReST e o teste aleatório: uma comparação entre a abordagem VR-ReST e o TA foi realizada com a finalidade de avaliar a adequação dos dados de testes gerados. Essa etapa é subdividida em três sub-etapas:

a) uma base de dados $D$ foi criada contendo todas as possíveis entradas $E=\left\{e_{1}, e_{2}, \ldots\right.$, $\left.e_{h}\right\}$. Essas entradas representam as ações de um determinado programa $p_{i}$, correspondendo aos comportamentos dos objetos presentes no programa como, por exemplo, rotacionar, transladar, movimentar, etc.;

b) uma função aleatória foi desenvolvida para gerar um conjunto de dados de teste $T$ a partir de $D$. Para cada programa $p_{i}$, foram utilizados os requisitos especificados $R$. Para cada requisito $r_{i}$ pelo menos uma entrada $e_{i}$ está associada $\left(e_{i} \subseteq r_{i}\right)$. Por exemplo, o requisito "User rotates syringe until Breast”, está associado à entrada rotates gravada em $D$. Assim, cada conjunto de dados de teste $T$ foi gerado por meio da seleção aleatória das entradas $E$ que fazem parte de cada requisito, logo $T=\left\{e_{1} \subseteq\right.$ $\left.r_{1}, \ldots ., e_{h} \subseteq r_{m}\right\}$. Na Tabela 15 é apresentado um exemplo de três requisitos e seus respectivos dados de teste gerados usando o teste aleatório.

Tabela 15 - Exemplo de um conjunto de dados de teste gerados usando a função aleatória

\begin{tabular}{l|l}
\hline \multicolumn{1}{c|}{ Requisitos } & \multicolumn{1}{c}{ Dados de Teste } \\
\hline \hline 1. User selects syringe & DT1: selects, translates, deforms \\
2. User moves syringe until Breast & DT2: selects, translates, rotates \\
3. User rotates syringe until Breast & DT3: selects, moves, rotates \\
\hline
\end{tabular}

Fonte: Elaborada pelo autor.

c) o conjunto de dados de teste gerados pelo teste aleatório foram adicionados na Sikuli e executados em cada mutante gerado.

\subsubsection{Coleta e Análise dos Dados}

As informações dos dois primeiros programas (Bouncing Ball e Alternate Appearance) foram coletadas do site que estavam disponibilizadas. A coleta dos requisitos e a compreensão do funcionamento do programa ViMeT Game foi realizada por meio de uma visita ao LApIS. Ao longo desta visita foram identificadas dificuldades relacionadas à especificação de requisitos e, em relação aos testes, pois os requisitos não são documentados e, geralmente, somente são realizados testes de usabilidade no final do processo de desenvolvimento de aplicações de RV.

\subsection{Análise e Discussão dos Resultados}

Nesta seção são detalhados os resultados alcançados e a análise estatística descritiva para os dois experimentos. 


\subsubsection{Eficácia da BeLaRS para auxiliar na especificação de requisitos}

Na Figura 25 é apresentada uma especificação de requisitos usando a BeLaRS referente à aplicação apresentada no Quadro 1. A especificação usando a linguagem BeLaRS é dividida em duas partes: na primeira (VED) são realizadas a descrição dos objetos e das características do AV, e na segunda (IND) é especificada a interação entre o usuário e o sistema, destacando as transformações e os comportamentos dos objetos.

Figura 25 - Exemplo de uma especificação de requisitos usando a BeLaRS

\begin{tabular}{|l|l|}
\hline \multicolumn{1}{|c|}{ VED } & \multicolumn{1}{c|}{ IND } \\
1. Virtual environment is black & *Basic Flow: \\
2. Virtual environment has punctual light & 1. User selects syringe by mouse $(1.1)$ \\
3. Virtual environment has syringe and brest & 2. User moves syringe until breast $(2.1,2.2)$ \\
4. Syringe is a cylinder & 3. User rotates the syringe \\
5. Syringe is blue & 4. User inserts the syringe on the breast \\
6. Syringe is on the right side & 5. System deforms breast \\
7. Breast is a cube & "Alternative Flow: \\
8. Breast is pink & 1.1 While user not select syringe \\
9. Breast is on the left side & 1.1 .1 System shows message "Select the syringe" \\
& 2.1 lf user not moves syringe until breast \\
& 2.1 .1 System shows message "Move syringe until \\
& breast" \\
& 2.2 Else System changes color syringe to red \\
\hline
\end{tabular}

Fonte: Elaborada pelo autor.

\subsubsection{Conformidade}

Para avaliar a conformidade da abordagem, foram analisadas a simplicidade, a ortogonalidade e a escalabilidade da linguagem BeLaRS. Os resultados são apresentados na Figura 26.

A primeira análise a ser realizada diz respeito à simplicidade da BeLaRS $\left(\mathrm{C}-\mathrm{QP}_{1}\right)$. Cerca de 74\% dos estudantes avaliou a linguagem BeLaRS como "muito" ou "extremamente" simples, o que confirmou a hipótese alternativa $\left(\mathrm{C}-\mathrm{H} 1_{1}\right.$ :A BeLaRS é simples pois utiliza diversos conceitos de RV e auxilia os usuários na realização de seu trabalho), conforme pode ser visto na Figura 26. No entanto, $13 \%$ dos estudantes avaliaram a simplicidade da linguagem BeLaRs como "moderadamente", $10 \%$ como "um pouco" e $3 \%$ como "não um pouco"; esses estudantes - $26 \%$ do total - concluíram que as palavras-chaves não são suficientes para auxiliar na especificação de requisitos, uma vez que elas estão relacionadas apenas aos conceitos de GC. Acredita-se que alguns estudantes não possuem conhecimento suficiente sobre a estrutura do GC, o que justifica essas avaliações.

Grande parte dos estudantes $(71 \%)$ avaliou a linguagem BeLaRS como "muito" e "extremamente" ortogonal, o que confirma a hipótese alternativa $\left(\mathrm{C}-\mathrm{H} 2_{1}\right.$ :A BeLaRS é ortogonal devido a cada palavra-chave representar um conceito específico de RV). Os estudantes forneceram um feedback satisfatório para esta questão, confirmando que as palavras-chaves da BeLaRS 
Figura 26 - Resultados referentes à simplicidade, ortogonalidade e escalabilidade da BeLaRS

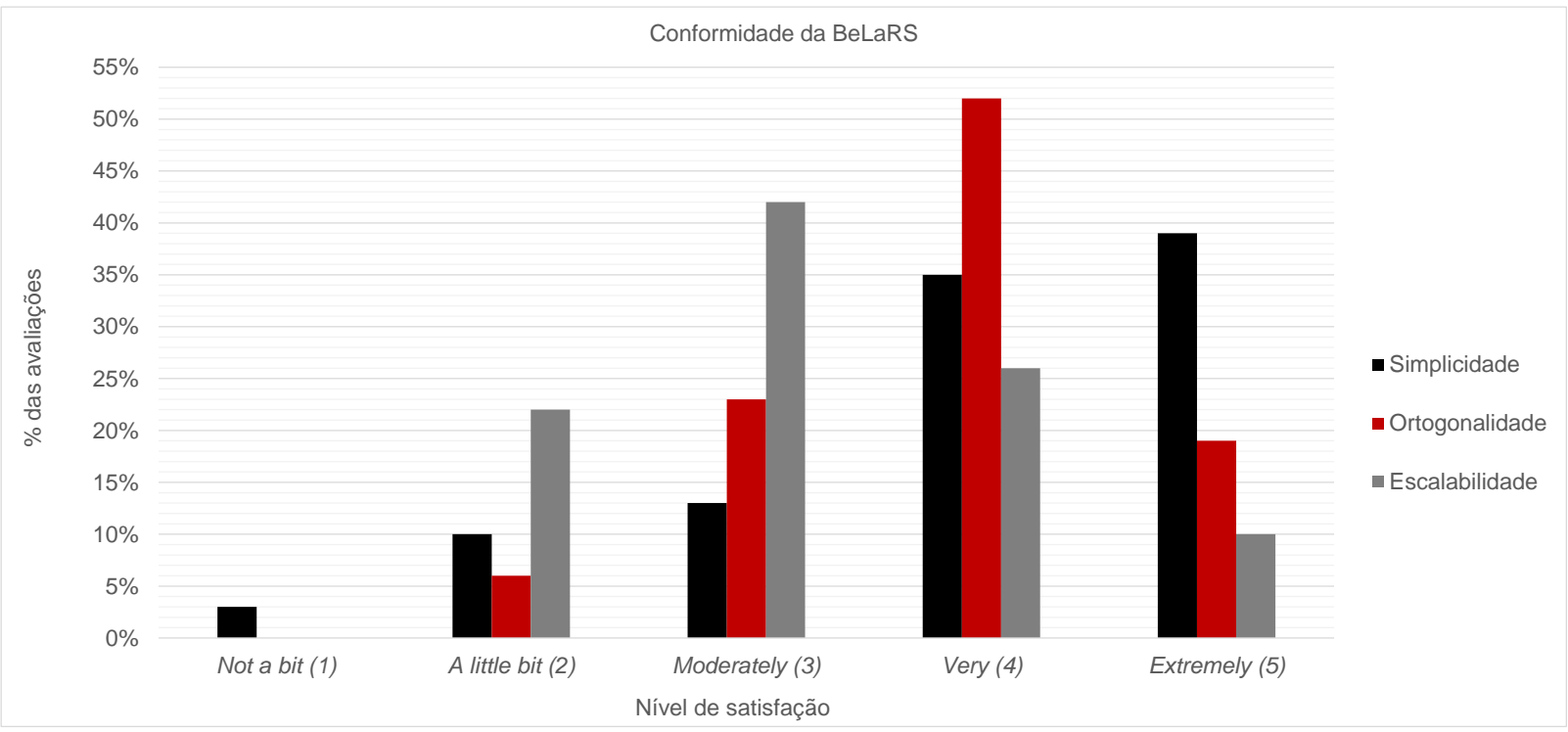

Fonte: Elaborada pelo autor.

representam conceitos distintos na VR. No entanto, ficou claro a partir do feedback de alguns estudantes que uma palavra-chave pode ter conotações diferentes. Assim, algumas palavras-chave adotadas podem representar o mesmo conceito.

Quase metade dos estudantes (42\%) avaliou a linguagem BeLaRS como "moderadamente" escalável, o que confirma a hipótese nula ( $\mathrm{C}-\mathrm{H} 3_{0}$ : A BeLaRS não é escalável devido a não possuir palavras-chaves suficientes para especificar requisitos em larga escala), como pode ser visto na Figura 26. Sete estudantes (22\%) avaliaram a BeLaRS como "pouco" escalável e declararam que algumas regras da BeLaRS precisam ser melhoradas. Apenas $36 \%$ dos estudantes avaliaram a BeLaRS como escalável. Assim, fica nítido que a falta de escalabilidade é devido ao fato de o banco de dados de palavras-chaves ter sido criado apenas para atender as necessidades dos três programas de RV utilizados nesse experimento. Portanto, é necessário considerar diferentes domínios como educação, entretenimento, jogos, entre outros, para que seja possível ampliar a quantidade de palavras-chaves utilizadas na BeLaRS. Essa ampliação pode ser considerada trabalhosa uma vez que é necessário definir palavras-chaves que sejam comuns em diferentes programas do mesmo domínio. Mesmo trabalhosa, é importante salientar que a implementação está preparada para que a ampliação seja realizada.

De acordo com os resultados obtidos, duas hipóteses alternativas das três foram confirmadas . Isto significa que, de acordo com os estudantes, a BeLaRS tem uma sintaxe precisa e compreende um número razoável de palavras-chaves que podem fornecer suporte na especificação de requisitos de aplicações de RV. No entanto, a hipótese alternativa da questão de pesquisa $\left(\mathrm{C}-\mathrm{QP}_{3}\right)$ foi rejeitada, uma vez que a escalabilidade precisa ser melhorada para superar algumas de suas limitações. Acredita-se que a adição de mais palavras-chaves aumentará o 
número de aplicações de RV que poderão utilizar a BeLaRS. Portanto, é importante incluir novas palavras-chaves, principalmente características relacionadas às cores e aos comportamentos, tais como abrir, fechar, andar, correr, etc; para proporcionar uma ampla gama de possibilidades durante a especificação.

\subsubsection{Aceitação e Uso}

A aceitação e o uso da BeLaRS foi avaliada por meio das respostas dos estudantes em relação ao tempo, utilidade, facilidade de especificação e compreensão das regras. Os resultados são apresentados na Figura 27.

Figura 27 - Resultados referentes à aceitação e ao uso da BeLaRS

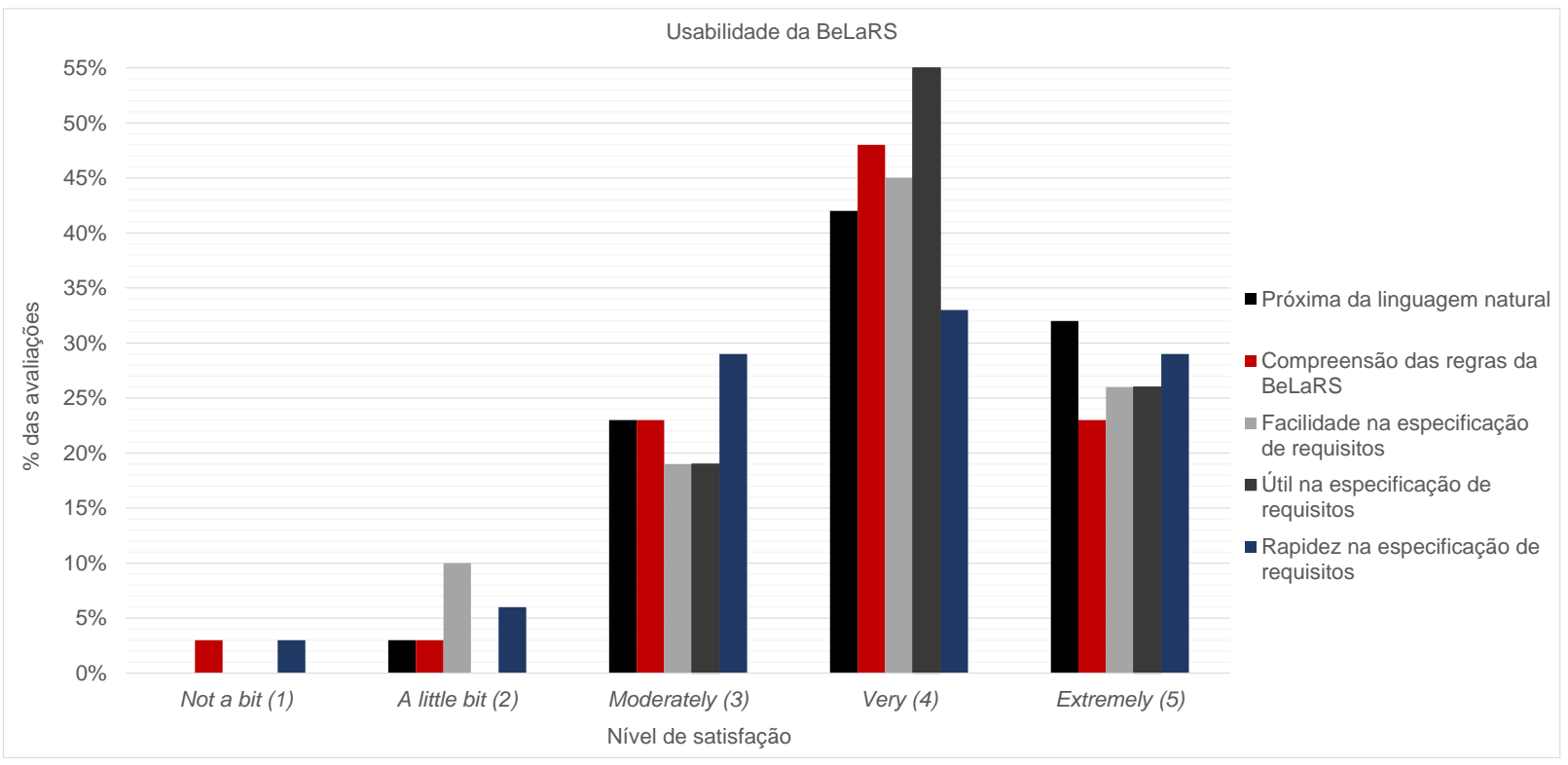

Fonte: Elaborada pelo autor.

A maioria dos estudantes (74\%) avaliou a BeLaRS como próxima da linguagem natural, confirmando a hipótese alternativa (U-H1 $1_{1}$ :A especificação de requisitos usando a BeLaRS é próxima da especificação usando a linguagem natural) da $\mathrm{U}-\mathrm{QP}_{1}$, conforme pode ser visto na Figura 27. No entanto, $23 \%$ dos estudantes avaliaram a BeLaRS como "moderadamente" e apenas 3\% avaliaram como "pouco" próxima da linguagem natural. Os estudantes explicaram que suas avaliações foram atribuídas às regras da BeLaRS, uma vez que essas regras não eram fáceis de serem compreendidas e com pouca utilidade comparada com a linguagem natural. É importante destacar que na tentativa de aproximar ainda mais a especificação de requisitos utilizando a BeLaRS da linguagem natural, é necessário simplificar as regras da BeLaRS, de tal forma que a especificação de requisitos seja realizada mais livremente sem perder a sua formalidade.

Grande parte dos estudantes (71\%) avaliou como "extremamente" e "muito" fácil de compreender as regras da BeLaRS (U-H2 ${ }_{1}$ :As regras da BeLaRS são fácies de serem compreen- 
didas) da U-QP 2 . Somente $3 \%$ avaliaram como "pouco" e "nenhum pouco" fácil de entender as regras BeLaRS. Esse resultado foi devido à falta de clareza na explicação e significado lógico das regras da BeLaRS. Todas as regras foram ilustradas para um único exemplo, limitando assim, a suas compreensões. Além disso, como as regras foram explicadas unicamente por meio de texto, isso pode ter tornado ambíguo o entendimento dos estudantes. Nesse contexto, além das melhorias a serem realizadas na linguagem, em um próximo experimento as regras serão explicadas detalhadamente por meio de diferentes exemplos juntamente com um áudio.

Cerca de $71 \%$ dos estudantes confirmou que é fácil especificar os requisitos usando a BeLaRS, confirmando a hipótese alternativa (U-H3 ${ }_{1}$ : A BeLaRS facilita a especificação de requisitos) da $\mathrm{U}_{-} \mathrm{QP}_{3}$. No entanto, três estudantes (10\%) afirmaram que é apenas "um pouco" fácil especificar requisitos usando BeLaRS. Esta avaliação pode ser devido a alguma incerteza causada pela estrutura de controle e restrições, que são incluídas nas regras, bem como a forma como foram explicadas. O resultado alcançado nesta $Q P$ está diretamente relacionado com o conhecimento/experiência dos estudantes com as áreas de ER e RV, uma vez que os três estudantes que consideraram ser um pouco fácil especificar os requisitos usando a BeLaRS não tinham nenhuma experiência na área de RV. Portanto, há indícios que o grau de conhecimento dos estudantes em RV influenciou diretamente na compreensão e no uso da BeLaRS para especificação de requisitos.

Grande parte dos estudantes (81\%) ratificou que a BeLaRS é útil para especificar os requisitos de aplicações de RV, como pode ser visto na Figura 27. Assim, a hipótese alternativa ( $U-H 4_{1}$ :A BeLaRS é útil na especificação de requisitos de aplicações de RV.) é confirmada. Vale ressaltar a importância da BeLaRS e a assistência que fornece na especificação de requisitos por meio de uma especificação formalizada, contribuindo para reduzir o risco de interpretação incorreta, ambiguidade e possíveis erros.

Para responder a questão $\mathrm{U}-\mathrm{QP}_{5}$ foi computado o tempo que os estudantes realizaram a especificação de requisitos. Esse tempo variou em um intervalo de 10 a 45 minutos. Como pode ser visto na Figura 28, o tempo médio foi de 22,52 minutos. Foi possível observar que seis outliers (E8, E10, E15, E21, E22, E25) tiveram um tempo muito acima ou abaixo da média. Essas diferenças de tempo podem ter sido causadas por variações nas habilidades de cada estudante na área RV e sua capacidade de entender as regras da BeLaRS. Os três estudantes mais rápidos (E10, E15, E21) são especialistas com mais de quatro anos de experiência no desenvolvimento de aplicações RV, enquanto que os mais lentos (E8, E22, E25) não tinham experiência na área RV.

A partir dos resultados obtidos com o estudo de caso, foi possível detectar alguns problemas na BeLaRS que foram melhorados. Dentre tais melhorias realizadas é importante destacar:

- aplicação da teoria da estrutura de constituintes proposta por Chomsky (1956) para reduzir 
Figura 28 - Tempo gasto pelos alunos para esecificar os requisitos usando a BeLaRS

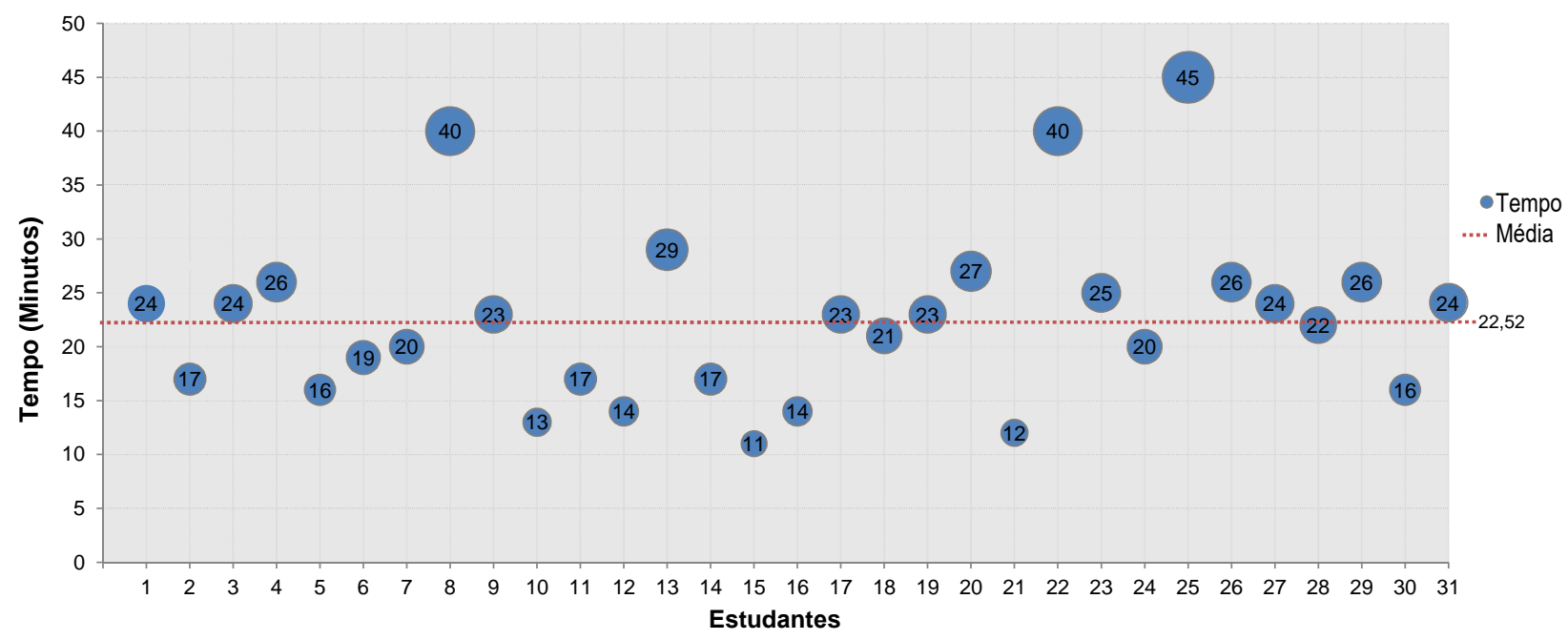

Fonte: Elaborada pelo autor.

a gramática da linguagem por meio do uso de Noun Phrase (NP) e de Verb Phrase (VP), tornando-a mais simples e mais direta para especificar requisitos;

- definição de vários objetos do mesmo tipo usando um "ID" que é representado por um dígito e interação entre objetos do mesmo tipo (um exemplo é mostrado na figura 29). Neste caso o objeto "Pawn1" interage com "Pawn10". Esses objetos são definidos como do mesmo tipo, pois possuem o mesmo prefixo (Pawn) sendo diferenciados pelo sufixo que são representados pelos seus respectivos IDs. Essa definição possibilitou melhorias em relação à escalabilidade, uma vez que com essa nova estrutura é possível especificar a interação entre objetos do mesmo tipo, permitindo que outros tipos de aplicações de RV também sejam especificadas usando a BeLaRS.

- inclusão de comportamentos: moves up, moves down, moves right, moves left, moves out, moves into, moves into, picks, drops. Com a inclusão desses comportamentos foi possível melhorar a ortogonalidade e a escalabilidade, uma vez que com novos comportamentos é possível especificar aplicações de RV de diferentes domínios.

- inclusão de preposições: up to, in, on, between.

Os resultados sugerem que a BeLaRS é uma alternativa eficaz que pode ser utilizada para a especificação de requisitos de aplicações de RV. Um dos principais benefícios da BeLaRS é prover uma especificação semi-formal, garantindo assim, uma especificação mais consistente, inequívoca e completa. Portanto, é fundamental uma especificação mais rigorosa e precisa para realizar testes funcionais eficazes. 
Figura 29 - Definição e interação de objetos do mesmo tipo

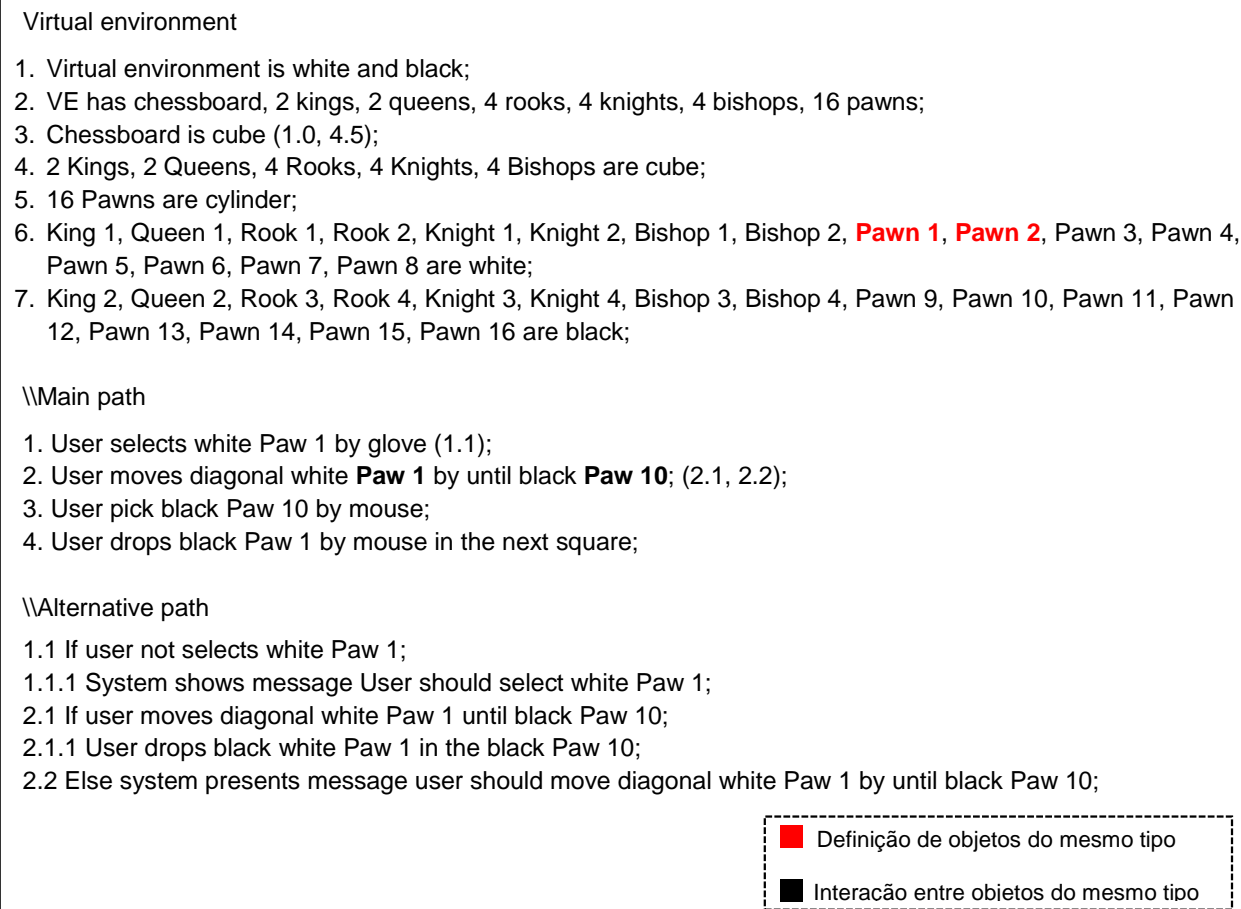

Fonte: Elaborada pelo autor.

\subsubsection{Eficácia da abordagem VR-ReST para auxiliar a geração auto- mática dos testes}

Esta seção analisa os resultados alcançados em relação à eficácia da abordagem VR-ReST para a detecção de falhas, com base nos procedimentos apresentados na Subseção 6.3.5.

\subsubsection{Eficácia da abordagem VR-ReST na detecção de falhas $\left(Q P_{1}\right)$}

Na Tabela 16 são resumidos os resultados obtidos referentes à eficácia da abordagem ViReST para detectar falhas para cada um dos programas de RV $\left(Q P_{1}\right)$. A coluna Programas apresenta o nome dos programas. A coluna Gerados apresenta o número total de mutantes gerados a partir dos operadores usando a ferramenta MuJava. A coluna Mortos mostra a quantidade de mutantes mortos pelos conjuntos de teste gerados. A coluna Equivalentes exibe o número de mutantes equivalentes, ou seja, aqueles mutantes que possuem o mesmo comportamento visual da aplicação original. A coluna Vivos apresenta os mutantes que os dados de testes não foram capazes de matar. Finalmente, a coluna $E M$ fornece a média do escore de mutação.

A Tabela 16 apresenta a média do $E M$ obtida após a aplicação dos quatro critérios $(N C$, $E C, E P C$ e $P P C$ ) na cobertura do GFR gerado a partir da especificação de requisitos de cada programa de RV.

O teste de mutação foi utilizado para validar a eficácia da abordagem. No teste de 
Tabela 16 - Resultados da eficácia da abordagem VR-ReST

\begin{tabular}{c|c|c|c|c||c}
\hline Programas & Gerados & Mortos & Equivalentes & Vivos & EM (\%) \\
\hline \hline Ball & 53 & 35 & 13 & 5 & 88,32 \\
Alternate Appearance & 209 & 137 & 65 & 7 & 95,51 \\
ViMeT Game & 1077 & 432 & 613 & 32 & 93,13 \\
\hline
\end{tabular}

Fonte: Elaborada pelo autor.

mutação, a adequação do conjunto de dados de teste é medida pelo $E M$, ou seja, quanto maior for o número de mutantes mortos, mais adequado é o conjunto de dados de teste e, consequentemente, um maior número de falhas é detectado. Portanto, os resultados indicam que a abordagem VRReST é efetiva para detectar falhas, uma vez que a média do $E M$ atingida, considerando os três programas, foi de $92,32 \%$.

Devido à ausência de estudos nesse escopo para o domínio de RV, um estudo para um domínio similar, que avalia interface gráfica do usuário (do inglês, Graphical User Interface (GUI)) usando teste de mutação foi analisado. Oliveira et al. (2015) realizaram uma análise empírica da eficácia de um conjunto de 18 operadores de mutação (MOs) baseados em GUI. Este estudo revela que os MOs baseados em GUI alcançaram um escore de quase $84 \%$ de eficácia. Portanto, para o domínio de RV, o EM alcançado pela abordagem VR-ReST pode ser considerado um bom resultado, mesmo não havendo trabalhos neste domínio.

É importante destacar que os mutantes equivalentes foram investigados. Os mutantes não mortos foram analisamos manualmente para verificar se eram equivalentes ou mutantes difíceis de matar. Esta análise foi realizada devido ao fato de os mutantes equivalentes demonstrarem uma falsa fraqueza no conjunto de dados do teste. Assim, o EM nunca atingirá 100\%, por isso é necessário analisá-los e removê-los do conjunto de mutantes. De acordo com essa análise, foi possível notar que os mutantes eram realmente equivalentes.

Por fim, foi possível concluir que a abordagem VR-ReST permite identificar falhas durante o processo de desenvolvimento. Dentre tais falhas é possível destacar por exemplo, a movimentação do objeto bola fora da cena do programa Bouncing Ball (ver Figura 30).

Conforme pode ser visto na Figura 30, a Figura 30(a) representa a aplicação original na qual a bola deve se movimentar para cima e para baixo dentro da cena. Por outro lado, a Figura 30(b) representa um exemplo de uma falha detectada, na qual a bola se movimenta de forma errônea saindo da cena delimitada. Esta falha foi detectada por meio de um dado de teste gerado pela ferramenta ViReST, o qual foi aplicado no programa original e no mutante. Esse dado de teste aplicado no mutante visa revelar que o comportamento visual do programa mutante (Figura 30(b)) é diferente do comportamento visual do programa original (Figura 30(a)). Portanto, para este exemplo, o dado de teste foi capaz de detectar o mutante, ou seja, revelar a falha.

Para identificar as falhas em aplicações de RV, comumente são realizados testes de 
Figura 30 - Exemplo de um comportamento correto no programa original (a) e de uma falha detectada no programa mutado (b)

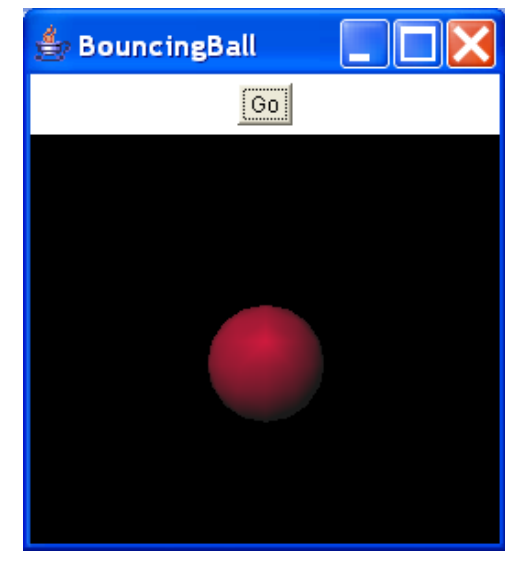

(a) Comportamento correto

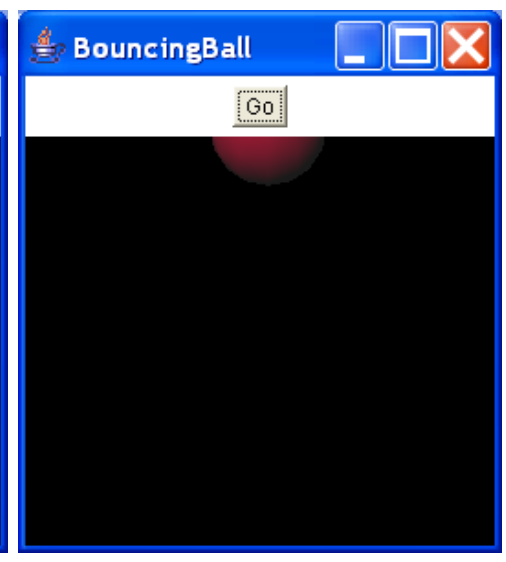

(b) Falha detectada

Fonte: Elaborada pelo autor.

usabilidade no final do processo de desenvolvimento. Como são realizados somente este tipo de teste, as falhas detectadas estão diretamente relacionadas com a percepção do usuário, como, por exemplo, "O uso do óculos estereoscópico foi desconfortável, pois não foi possível visualizar a imagem nitidamente". Nesse contexto, o teste de usabilidade pode não ser capaz de revelar tipos específicos de falhas devido a ser uma técnica centrada no usuário. Por outro lado, com a abordagem proposta é possível gerar dados de teste capazes de verificar se os comportamentos dos programas estão realmente sendo realizados de acordo com requisitos especificados. Portanto, por meio da abordagem VR-ReST é possível detectar falhas durante o processo de desenvolvimento, utilizando como entrada os requisitos especificados e, como saídas produzidas, os comportamentos de cada programa.

\subsubsection{Relação entre a qualidade dos requisitos especificados e a qualidade dos dados de teste gerados $\left(Q P_{2}\right)$}

Outro aspecto importante que foi possível observar é que a qualidade dos requisitos especificados e os dados de teste gerados estão diretamente relacionados $\left(Q P_{2}\right)$. Um bom requisito é aquele que descreve de forma completa e inequivocamente a funcionalidade do programa com todas as suas características. E um bom conjunto de dados de teste é aquele capaz de revelar falhas existentes, isto é, matar todos os mutantes não equivalentes.

Neste contexto, é importante notar que os mutantes vivos, apresentados na Tabela 16, estão diretamente relacionados com a especificação de requisitos, uma vez que os $R T s$ são derivados a partir destes requisitos e os dados de teste $T$ são gerados para cobrir os $R T s$. Independentemente dos critérios utilizados e como a geração dos dados de teste é realizada, seja manualmente ou automaticamente, se um requisito particular $r_{i}$ não fizer parte da especificação, então será impossível produzir um dado de teste $t_{i}$ para cobrir um $r t_{i}$ gerado, uma vez que um $r t_{i}$ 
é derivado a partir da especificação de requisitos.

Na Tabela 17 são apresentados os dados de teste gerados automaticamente pela ferramenta ViReST de acordo com cada critério de teste e o escore obtido a partir dos mutantes gerados apresentados na Tabela 16. Na coluna Programas é apresentado cada programa. A coluna Req. lista o número de requisitos (funcionalidades) especificados de cada programa. A coluna $D T$ revela o número de dados de teste gerados pela abordagem VR-ReST, de acordo com cada critério (NC, EC, EPC, PPC), que foram necessários para matar os mutantes gerados. Finalmente, a coluna $E M$ fornece o escore de mutação de acordo com cada critério de teste.

Tabela 17 - Relação entre a qualidade dos requisitos especificados e a qualidade dos dados de testes gerados pela abordagem VR-ReST

\begin{tabular}{c|c|cccc||cccc}
\hline \multirow{2}{*}{ Programas } & \multirow{2}{*}{ Req. } & \multicolumn{4}{|c|}{ DT } & \multicolumn{4}{c}{ EM (\%) } \\
\cline { 3 - 10 } & & NC & EC & EPC & PPC & NC & EC & EPC & PPC \\
\hline \hline Ball & 11 & 2 & 2 & 3 & 3 & 87,79 & 87,19 & 88,64 & 89,67 \\
Alternate Appearance & 33 & 2 & 2 & 4 & 6 & 95,27 & 94,56 & 95,83 & 96,41 \\
ViMeT Game & 37 & 2 & 3 & 3 & 3 & 92,38 & 92,89 & 93,45 & 93,83 \\
\hline
\end{tabular}

Fonte: Elaborada pelo autor.

Conforme pode ser observado na Tabela 17, utilizando como base o estudo de Oliveira et al. (2015) no qual foi atingido um EM de quase $84 \%$ de eficácia, os resultados são considerados bons, uma vez que todos os EM alcançados pelos três programas são superiores ao EM alcançado neste estudo. O programa Ball alcançou um escore médio de mutação de 88,32\%, o Alternate Appearance de $95,51 \%$ e o ViMeT Game de 93,13\%.

Após os EMs alcançados pelas aplicações, apresentados na Tabela 17, ao analisar manualmente os mutantes remanescentes foi possível observar que os mutantes vivos dependem da qualidade dos dados de teste, os quais estão diretamente relacionados à especificação de requisitos. Para exemplificar essa relação foi realizada uma nova especificação para aplicação Ball, com a finalidade de tentar matar os mutantes vivos identificados. Na Figura 31a e na Figura 31b são apresentadas as duas especificações: especificação original e especificação modificada da aplicação Ball, respectivamente.

Conforme ilustrado na Figura 31b, os requisitos modificados são 2, 2.2, 3.1.1 e 4.1.1. Em ambos os requisitos foram adicionadas características que estão sublinhadas. Estas características representam os comportamentos da bola que são controlados pelo sistema. A ausência dessas características apresentadas na Figura 31a estão diretamente relacionadas aos mutantes vivos.

Uma nova especificação de requisitos para cada aplicação foi realizada na ferramenta ViReST na tentativa de matar os mutantes vivos apresentados na Tabela 17. Após a especificação, novos dados de teste foram obtidos de acordo com cada critério. Os resultados alcançados a partir da nova especificação são apresentados na Tabela 18.

Ao analisar as Tabelas 17 e 18 é possível verificar que para as aplicações Ball e Alternate Appearance somente os dados de teste apresentados na Tabela 17 foram necessários para cobrir 
Figura 31 - Comparação entre as especificações dos requisitos

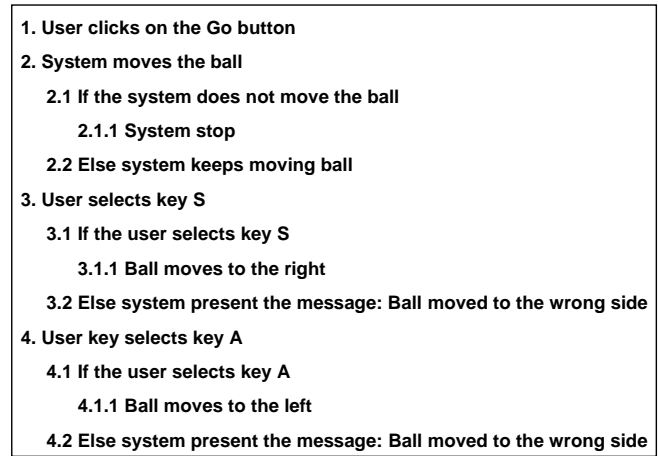

(a) Especificação Original

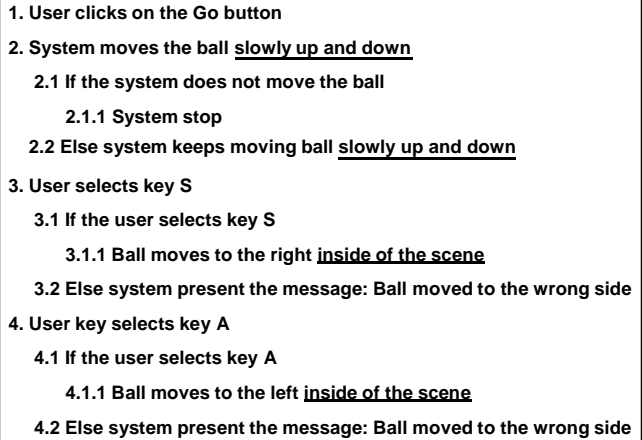

(b) Especificação Modificada

Fonte: Elaborada pelo autor.

Tabela 18 - Relação entre a qualidade dos requisitos especificados e a qualidade dos dados de testes gerados a partir das especificações modificadas

\begin{tabular}{c|c|cccc|cccc}
\hline \multirow{2}{*}{ Prog. } & \multirow{2}{*}{ Req. } & \multicolumn{4}{|c|}{ DT } & \multicolumn{4}{c}{ EM (\%) } \\
\cline { 3 - 10 } & & NC & EC & EPC & PPC & NC & EC & EPC & PPC \\
\hline \hline Ball & 11 & 2 & 2 & 3 & 3 & 100 & 100 & 100 & 100 \\
Alternate Appearance & 33 & 2 & 2 & 4 & 6 & 97,34 & 97,34 & 99,68 & 100 \\
ViMeT Game & 37 & 2 & 3 & 4 & 4 & 97,47 & 97,92 & 98,56 & 98,89 \\
\hline
\end{tabular}

Fonte: Elaborada pelo autor.

os novos requisitos. Por outro lado, para a aplicação ViMeT Game, mais dois dados de teste (um dado de teste para o EPC e um para o PPC) foram necessários para matar 25 dos 32 mutantes vivos. A explicação mais provável para este resultado é: $(i)$ alguns requisitos são cobertos por qualquer dados de teste; e (ii) alguns requisitos são cobertos por dados de testes específicos. Além disso, sete mutantes permaneceram vivos; a razão para isso é que estes mutantes não possuem comportamentos visuais diferentes em relação ao programa original.

A Tabela 19 apresenta informações estatísticas sobre os três programas de RV utilizados nesse experimento. As colunas representam o escore de mutação médio alcançado por cada programa de acordo com os quatro critérios de acordo utilizando a especificação original $(\mathrm{O})$ e a especificação modificada (M).

A partir dos resultados foi possível identificar que o programa Boucing Ball alcançou um escore de mutação médio de 88,32\% usando a especificação Original (O) e 99,75\% usando a especificação Modificada (M); para o programa Alternate Appearance 95,51\% usando especificação (O) e 98,59\% usando a especificação (M); e para o programa ViMeT Game 93,13\% usando especificação (O) e 98,21 \% usando a especificação (M). Por meio dos resultados obtidos, foi possível constatar que com uma especificação mais detalhada e completa é possível gerar dados de teste com mais qualidade o que justifica o aumento do EM para todos os programas, conforme apresentado na Tabela 18. Portanto, tanto a média quanto a mediana dos EM dos programas a 
Tabela 19 - Estatística descritiva sumarizando o EM alcançado por cada programa de RV a partir da especificação (O) e especificação (M)

\begin{tabular}{c|cc|cc|cc}
\cline { 2 - 7 } & \multicolumn{5}{c}{ Programas com Especificação O e M } \\
\cline { 2 - 7 } & EM Ball $(\mathbf{\%})$ & \multicolumn{2}{c}{ EM Alternate (\%) } & \multicolumn{1}{c}{ EM ViMeT(\%) } \\
\cline { 2 - 7 } & $\mathbf{( O )}$ & $\mathbf{( M )}$ & $\mathbf{( O )}$ & $\mathbf{( M )}$ & $\mathbf{( O )}$ & $\mathbf{( M )}$ \\
\hline Mínimo & 87.19 & 99 & 94.56 & 97.34 & 92.38 & 97.47 \\
Máximo & 89.67 & 100 & 96.41 & 100 & 93.83 & 98.89 \\
Média & 88.32 & 99.75 & 95.51 & 98.59 & 93.13 & 98.21 \\
Mediana & 88.21 & 100 & 95.55 & 98.51 & 93.17 & 98.24 \\
Desvio Padrão & 1.07 & 0.50 & 0.78 & 1.44 & 0.63 & 0.64 \\
\hline
\end{tabular}

partir das especificações (M) sugerem que a qualidade dos requisitos especificados influencia na qualidade do conjunto de dados de teste gerado.

A Figura 32 resume os dados da Tabela 19 em gráficos. As linhas grossas são as medianas, de modo que a mediana é o escore de mutação de cada especificação (original (O) e modificada (M)) usando os quatro critérios de teste por programa.

Figura 32 - Comparação entre as especificações dos requisitos

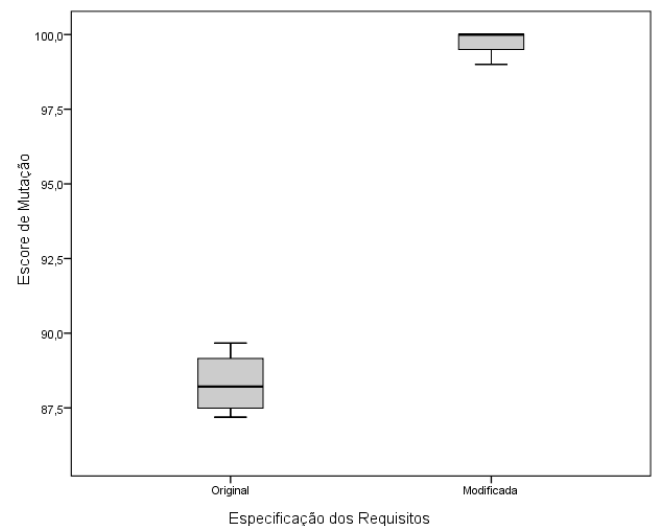

(a) Bouncing Ball

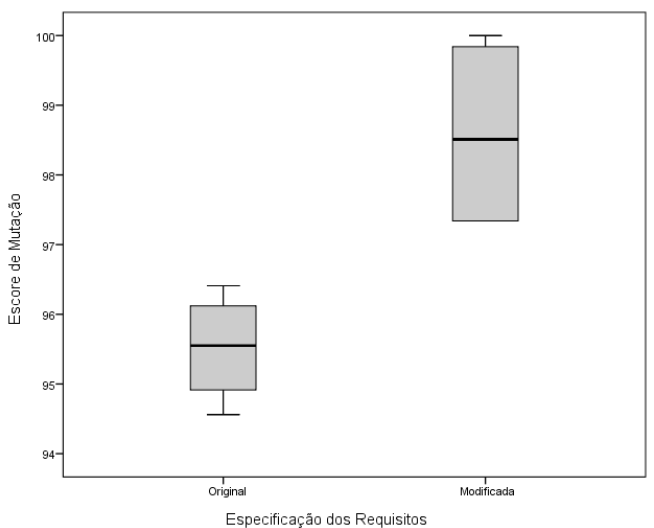

(b) Alternate Appearance

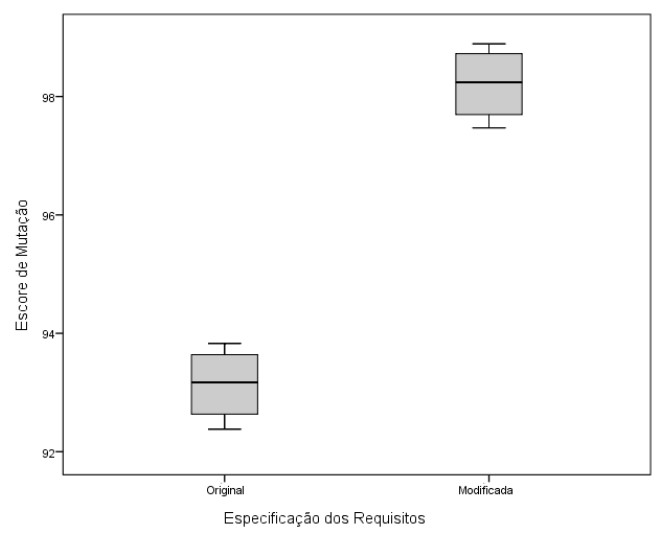

(c) ViMeT Game

Fonte: Elaborada pelo autor. 
Na Figura 32a a mediana do EM usando a especificação (O) é 88,21\% enquanto que com a especificação (M) é 100\%; na Figura 32b a mediana do EM foi de 95,55\% usando (O) e 98,51\% usando $\mathrm{M}$ e, por fim, na Figura 32ca mediana do EM foi de de 93,17\% usando (O) e $98,24 \%$ usando M. As caixas em torno das medianas encerram os percentis 25 (Q1) até 75 (Q3) e as linhas acima e abaixo das caixas representam o intervalo dos dados. Este gráfico sugere que todos os programas que utilizam a especificação $(M)$ têm um EM superior à especificação $(\mathrm{O})$, confirmando a necessidade de especificar os requisitos de uma forma e concisa e completa.

Nesta questão, foi possível notar que a qualidade dos dados de teste gerados depende fortemente de uma especificação de requisitos completa. Para confirmar esta dependência, este experimento foi conduzido em duas partes. Na primeira parte, a especificação de requisitos $(\mathrm{O})$ foi utilizada para gerar os dados de teste e calcular o EM para cada programa. Na segunda parte, os mutantes restantes foram analisados com a finalidade de associar suas falhas aos requisitos especificados. A partir desta análise, foi observado que para algumas falhas não existe um requisito particular na especificação $(\mathrm{O})$. Por exemplo, para a especificação $(\mathrm{O})$ existiam falhas como: (i) a bola se movimentava fora da cena e (ii) a bola se movimenta rápido, as quais não estavam relacionadas a nenhum requisito umas vez que algumas características ("inside of the scene" e "moving ball slowly up and down") não foram especificadas. Na tentativa de detectar essas falhas, essas características foram adicionadas na especificação (M), mais precisamente nos requisitos "2. System moves the ball slowly up and down" e "2.2. Else system keeps moving ball slowly up and down".

Para confirmar que uma especificação de requisitos completa (isto é, aquela que aborda todas as interações e características possíveis do AV e objetos) pode gerar um conjunto de dados de teste de alta qualidade, foram realizadas as seguintes etapas: $(i)$ as características ausentes nos requisitos associados aos mutantes remanescentes foram incluídas; (ii) um novo conjunto de dados de teste foi gerado; e (iii) o EM foi computado.

Portanto, conforme pode ser observado na Figura 31, a partir da inclusão das características ausentes nos requisitos foi possível aumentar o EM em 11,43\% para o programa Bouncing Ball, 3,08\% para Alternate Appearance e 5,08\% para ViMeT Game.

\subsubsection{Eficácia da abordagem VR-ReST comparada com o teste aleatório}

Por fim, na questão $Q P_{3}$ foi realizada uma comparação entre a abordagem VR-ReST e o $T A$ para avaliar a qualidade dos dados de teste gerados e o $E M$ obtido para cada programa. Os dados de teste gerados pela abordagem VR-ReST foram de acordo com um dos quatro critérios definidos, enquanto que com o teste aleatório os dados de teste são selecionados aleatoriamente. Para realizar essa comparação, foram conduzidas duas análises: (i) usando um conjunto de dados de teste com o mesmo tamanho e (ii) usando um conjunto de dados de teste com tamanhos diferentes.

Em primeiro lugar, foi investigado se o teste aleatório é capaz de obter uma cobertura 
semelhante à da abordagem VR-ReST usando o mesmo tamanho de conjunto de dados de teste gerado por esta. Por exemplo, se a abordagem gerou um total de 8 dados de teste (considerando todos os critérios) para matar os mutantes, logo esse mesmo tamanho (8 dados de teste) foi utilizado como o limite de dados de teste a serem gerados pelo teste aleatório, garantindo que o EM alcançado foi obtido em condições semelhantes (mesma quantidade de dados de teste). Essa análise foi realizada para cada programa adotando os dados de teste gerados pela abordagem VR-ReST apresentados na Tabela 18.

Na Tabela 20 são apresentados os resultados referentes à eficácia da abordagem VRReST e o TA usando um conjunto de dados de teste com mesmo tamanho. A primeira coluna lista os nomes dos programas. As quatro colunas seguintes agrupadas em $D T$, representam o conjunto de dados de teste gerados por cada critério de teste (NC, EC, EPC e PPC) apresentados na Tabela 18. A quarta coluna, agrupada em EM VR-ReST (\%) o EM obtido pela VR-ReST. A última coluna apresenta o escore de mutação obtido pelo $T A$ utilizando os mesmos conjuntos de dados de teste listados na coluna DT. Para definir um tamanho exato dos dados de teste e apenas um escore de mutação para cada aplicação, a média dos dados de teste apresentados na coluna $D T$ e do $E M$ apresentado na coluna $E M V R-R e S T$ foi calculada.

Tabela 20 - Comparação entre o EM obtido pela abordagem VR-ReST e pelo teste aleatório com o mesmo tamanho do conjunto de dados de teste

\begin{tabular}{|c|c|c|c|c|c|c|c|c|c|}
\hline \multirow{2}{*}{ Programas } & \multicolumn{4}{|c|}{ DT } & \multicolumn{4}{|c|}{ EM VR-ReST(\%) } & \multirow{2}{*}{ EM TA (\%) } \\
\hline & NC & EC & EPC & PPC & NC & EC & EPC & PPC & \\
\hline Bouncing Ball & 2 & 2 & 3 & 3 & 100 & 100 & 100 & 100 & 78.79 \\
\hline Alternate Appearance & 2 & 2 & 4 & 6 & 97.34 & 97.34 & 99.68 & 100 & 77.76 \\
\hline ViMeT Game & 2 & 3 & 4 & 4 & 97.47 & 97.92 & 98.56 & 98.89 & 82.70 \\
\hline
\end{tabular}

Nos três programas foi possível observar que com o mesmo tamanho do conjunto de dados de teste apresentado na coluna $D T$, a abordagem VR-ReST obteve melhores escores de mutação do que o TA. Os escores de mutação mais baixos obtidos pela abordagem VR-ReST foram a partir dos dados de teste gerados de acordo com os critérios de teste $\mathrm{NC}$ e EC, uma vez que os dados de teste gerados por NC não alcançam todos os nós e EC não atingem todas as arestas no GFR. Por outro lado, usando o teste aleatório, a aplicação Alternate Appearance obteve o menor escore de mutação de 77,76\% e a aplicação ViMeT Game obteve o maior score de mutação de $82,70 \%$. Portanto, estes resultados sugerem que o teste aleatório alcança um EM mais baixo ao utilizar um conjunto de dados de teste limitado.

Finalmente, a abordagem VR-ReST foi comparada com o TA em termos do tamanho e da adequação do conjunto de dados do teste. Essa análise consistiu na avaliação do número dos dados de teste gerados necessários por cada abordagem para matar os mutantes.

A Figura 33 resume o número de dados de teste gerados pela abordagem VR-ReST de acordo com cada critério e pelo TA. O programa Alternate Appearance obteve o maior número de dados de teste para todos os critérios: 2 dados de teste para NC, 2 para EC, 4 para EPC e 6 
para PPC (Figura 33b). Por outro lado, a aplicação Bouncing Ball obteve o menor número de dados de teste gerados, sendo 2 dados de teste para NC, 2 para EC, 3 de EPC e 3 for PPC (Figura 33a). Para todos os programas, de acordo com os resultados obtidos, o critério PPC gerou mais dados de teste do que os demais critérios: PPC gerou em torno de 21,43\% mais dados de teste do que EPC e 50\% mais dados de teste do que EC e 57,15\% a mais do que NC. Em contrapartida, esse mesmo critério (PPC) alcançou os melhores EM. Apesar do PPC ter gerado mais dados de teste em relação aos demais critérios, em média o PPC cobriu cerca de de 99,41\% dos RTs, garantindo uma melhor cobertura em relação aos demais critérios de teste.

Figura 33 - Comparação do número de dados de teste gerados entre a abordagem VR-ReST e o teste aleatório

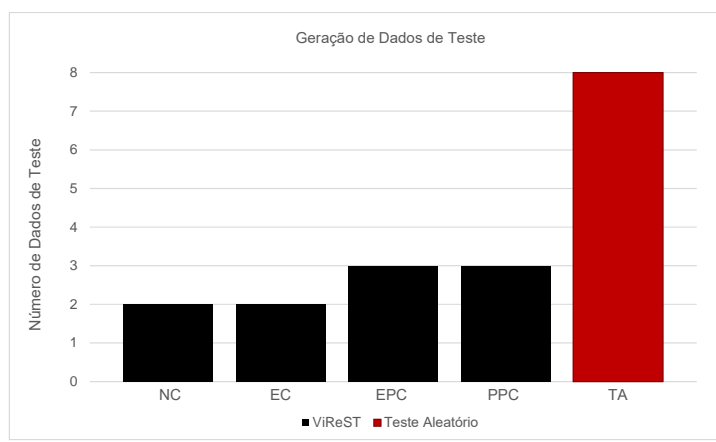

(a) Quantidade de dados de teste gerados por cada abordagem para o programa Bouncing Ball

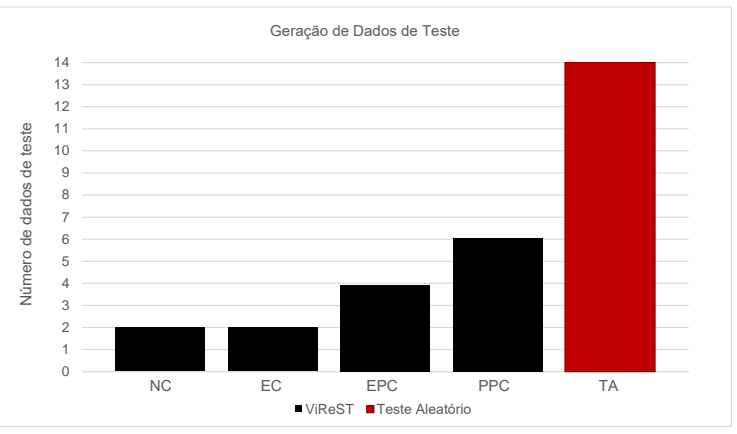

(b) Quantidade de dados de teste gerados por cada abordagem para o programa Alternate Appearance

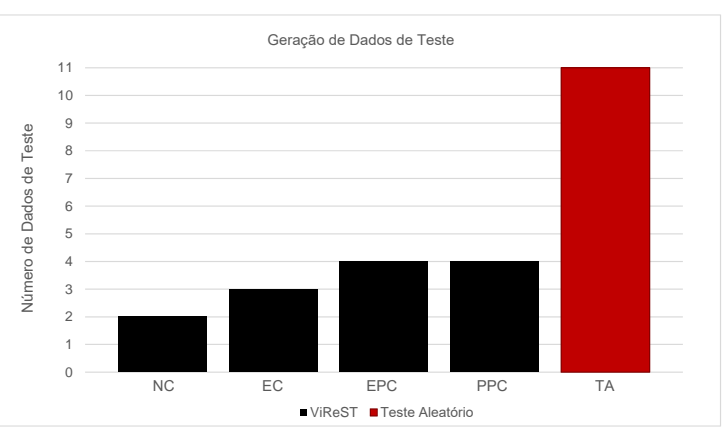

(c) Quantidade de dados de teste gerados por cada abordagem para o programa ViMeT Game

Fonte: Elaborada pelo autor.

De acordo com os resultados apresentados na Figura 33, a geração de dados de teste usando a abordagem VR-ReST é mais eficiente do que o $T A$, uma vez que a utilização de critérios de teste garante dados de teste com maior qualidade. Além disso, a abordagem VR-ReST gerou menos dados de teste adequados para todos os critérios, ou seja, gerou um número menor de dados capazes de matar mutantes não equivalentes.

Na Figura 34 é sumarizado o escore de mutação obtido a partir dos dados gerados pela abordagem VR-ReST e pelo $T A$. Os dados de teste gerados pela abordagem VR-ReST foram apresentados na coluna DT da Tabela 18 e pelo $T A$ foram apresentados na Figura 33. 
Figura 34 - Comparação do escore de mutação obtido pela ferramenta ViReST e Teste Aleatório

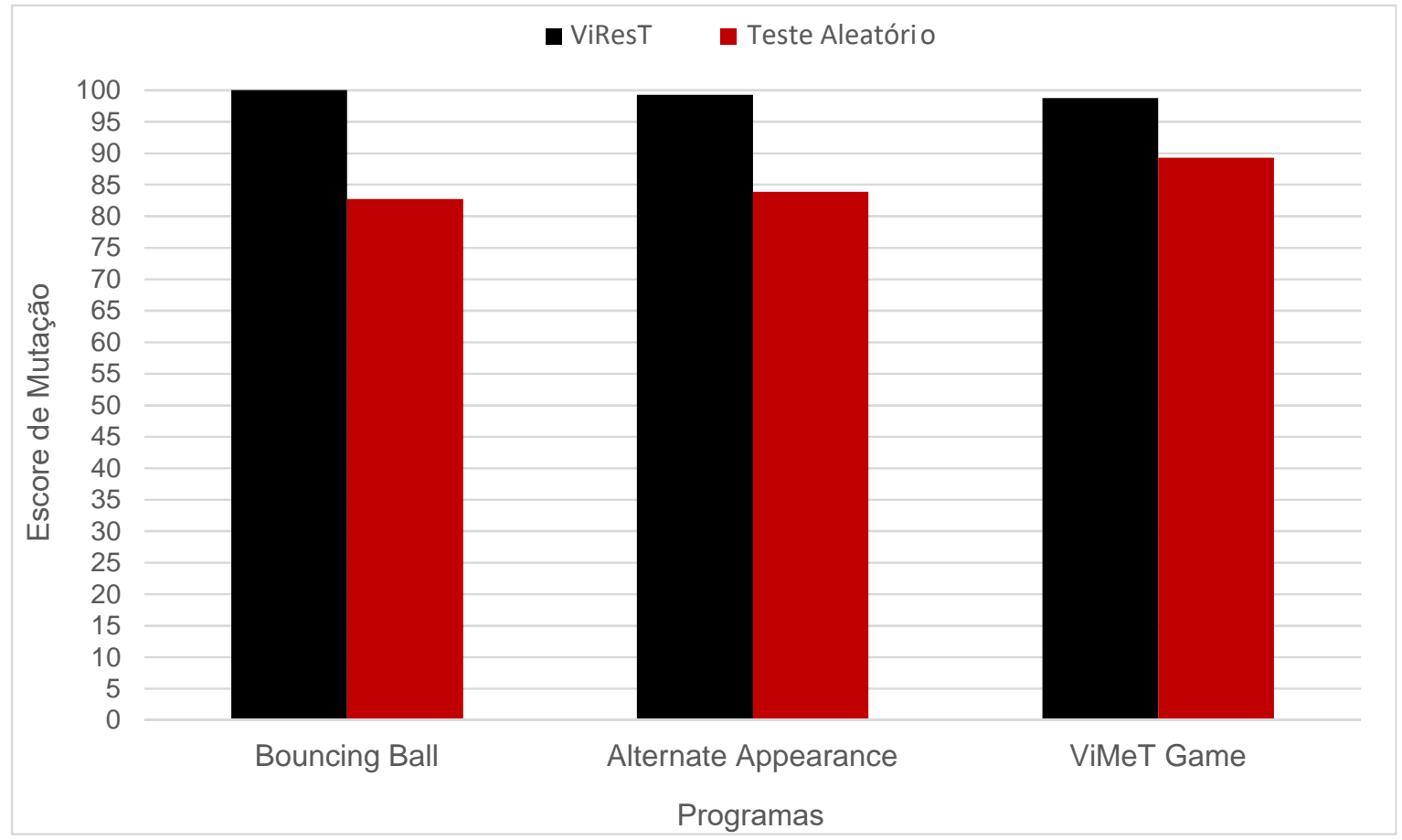

Fonte: Elaborada pelo autor.

De acordo com os dados apresentados na Figura 34 foi possível observar que o TA obteve um aumento no escore de mutação uma vez que produziu mais dados de teste necessários para cobrir os RTs. Para o programa Alternate Appearance, o TA gerou 14 dados de teste e obteve um $E M$ de $84,21 \%$ e a abordagem VR-ReST obteve um EM de 98,52\%. Para o programa ViMeT Game o TA gerou 11 dados de teste e alcançou um EM de 89,22\%. Por outro lado, a abordagem VR-ReST alcançou um EM de 98,21\%. Finalmente, para o programa Bouncing Ball, o TA gerou 8 dados de teste e obteve um $E M$ de $83,49 \%$. A abordagem VR-ReST gerou um conjunto de dados de teste capazes de matar $100 \%$ dos mutantes aplicando todos os critérios de teste.

Na maioria dos casos, a geração de dados de teste usando $T A$ é demorada e sem garantia de produzir um conjunto de dados de teste que possa cobrir alguns tipos de requisitos, especialmente para grandes programas. Portanto, analisando todos os programas pertencentes a diferentes domínios de RV, os resultados indicam que os dados de teste gerados pela abordagem VR-ReST são mais adequados do que os dados gerados pelo $T A$, uma vez que este teste não alcançou $100 \%$ no $E M$, enquanto que abordagem VR-ReST atingiu escores de mutação de $98 \%$ a $100 \%$.

Portanto, a partir da análise dos resultados, conclui-se que a abordagem VR-ReST pode ser vista como uma alternativa para auxiliar a fase de teste no processo de desenvolvimento de aplicações VR. Os benefícios do uso da abordagem VR-ReST incluem quatro critérios de teste que podem cobrir diferentes RTs, o que significa que o conjunto de dados de teste gerado por meio da abordagem pode ajudar a detectar diversos tipos de falhas. 


\subsection{Ameaças à Validade}

Nesta seção são detalhadas as possíveis ameaças à validade que podem afetar os valores e as conclusões dos estudos empíricos conduzidos.

As ameaças à validade externa estão relacionadas à generalização dos resultados. A representatividade dos programas é um problema que geralmente prejudica as pesquisas, pois não existem teorias que garantam que um determinado conjunto de programas selecionados seja uma amostra representativa para a condução dos estudos empíricos. Com a finalidade de minimizar esse problema, foram utilizados três programas pertencentes a diferentes domínios e com tamanhos diferentes, sendo dois amplamente utilizados no domínio de RV e um que representa uma aplicação real. No entanto, não é possível afirmar que os resultados podem ser generalizados para todas as aplicações de RV que utilizam o conceito de GC. Nesse contexto, replicações futuras são necessárias para corroborar os resultados obtidos.

As ameaças à validade por construção estão preocupadas com a relação entre a teoria e o que é observado. No desenvolvimento da abordagem proposta bem como na análise dos programas de RV, possíveis equívocos podem ter sido cometidos. Para mitigar esse risco foram realizados diversos testes entre os módulos de requisitos e teste durante o período de desenvolvimento a fim de assegurar que durante a condução do estudo de caso e do experimento a ferramenta tivesse êxito na sua execução. Com relação à ferramenta MuJava para a geração dos mutantes, a mesma tem sido amplamente utilizada por diversos estudos, assim podendo ser desconsiderada essa ameaça.

Por fim as ameças à validade interna caracterizam o grau de confiabilidade entre os resultados esperados e os resultados obtidos. Todas as variáveis em ambos estudos empíricos foram controladas para mitigar possíveis ameaças. Além disso, para a ampliar a confiabilidade dos resultados, os dados obtidos foram analisados com auxílio de análise descritiva para assegurar que os resultados apresentados por meio de tabelas e gráficos sejam realmente coerentes e interpretados de forma apropriada.

\subsection{Considerações Finais}

Neste Capítulo foram apresentados dois estudos experimentais conduzidos: um estudo de caso exploratório e um experimento controlado. O estudo de caso foi realizado para investigar a conformidade e aceitação e uso da linguagem BeLaRS para auxiliar a especificação de requisitos. O experimento controlado foi conduzido para verificar a eficácia da abordagem VR-ReST na realização do teste funcional em aplicações de RV.

De acordo com os resultados obtidos por meio dos estudos empíricos, pode-se concluir que o uso de uma linguagem semi-formal e dos critérios de teste, pode de fato, beneficiar a realização de testes durante o processo de desenvolvimento de uma aplicação de RV. Os 
estudos comprovaram que em três programas a utilização da abordagem VR-ReST, inserida na ferramenta ViReST, de fato auxilia a especificação de requisitos e a realização de testes funcionais em aplicações de RV.

Os resultados do estudo de caso confirmam que a linguagem foi considerada simples e útil para 74\% dos estudantes que participaram do experimento. Quanto ao experimento que avaliou a eficácia da abordagem VR-ReST, os resultados indicam que a qualidade dos dados de teste gerados está diretamente relacionada à qualidade dos requisitos especificados uma vez que, ao melhorar a especificação, os novos dados de teste gerados para todos os critérios obtiveram um aumento no escore de mutação médio de 11,68\% para o programa Ball, 3,08\% para o programa Alternate Appearance e 5,08\% para o programa ViMeT Game em relação ao EM alcançado previamente conforme apresentado na Tabela 17. Ainda é importante destacar que os resultados obtidos sugerem que a abordagem VR-ReST é mais eficaz em relação ao $T A$, pois com os dados de teste gerados é possível alcançar um $E M$ de $98,33 \%$, enquanto que, com mesmo tamanho do conjunto de dados de teste o TA obteve um EM de 79,75\%. 
CAPÍTULO

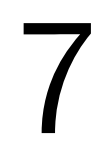

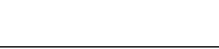

\section{CONSIDERAÇÕES FINAIS}

Com a finalidade de verificar a hipótese estabelecida no Capítulo 1 - "É possível gerar dados de teste automatizados a partir de uma especificação de requisitos semi-formal para realizar o teste funcional em aplicações de Realidade Virtual que utilizam conceitos de Grafo de Cena.”, esta pesquisa almejou buscar soluções para auxiliar o testador na realização do teste funcional por meio da especificação de requisitos e da geração de dados de teste no escopo de aplicações de RV.

Nesse contexto, foi definida uma abordagem com o foco na formalização da especificação de requisitos e na geração dos testes, bem como um apoio ferramental que permite executar de forma automatizada ambas as atividades. A abordagem é composta por três etapas sequenciais: (i) o primeiro envolve informações sobre a aplicação, os usuários e os requisitos são especificados por meio do modelo ViReS; (ii) o segundo consiste no mapeamento do requisitos utilizando a BeLaRS para para obter uma especificação formal desses requisitos; e o (iii) o terceiro compreende a derivação dos RTs e a geração dos dados de teste, com base nos quatro dos critérios de teste definidos, que são aplicados nos RTs para verificar sua cobertura.

Além disso, um apoio computacional, denominado ViReST, também foi desenvolvido para auxiliar o testador durante a atividade de teste. Esse apoio computacional é uma ferramenta, a qual foi dividida em dois principais componentes: $(i)$ o primeiro engloba uma estrutura para especificação de requisitos utilizando a BeLaRS para especificar características do AV e dos objetos, bem como as interações entre o usuário e o sistema; (ii) o segundo consiste em um apoio para a execução dos testes funcionais, incluindo a geração dos RTs e a geração dos dados de teste.

Como parte da pesquisa, um estudo de caso e um experimento foram conduzidos com o objetivo de avaliar as vantagens de utilizar a abordagem apresentada. Os resultados alcançados a partir do estudo de caso realizado com a BeLaRS mostraram que a linguagem é viável e eficaz para realizar uma especificação de requisitos semi-formal de aplicações de RV, como 
forma de auxiliar os projetistas a obterem uma especificação de requisitos mais concisa, livre de ambiguidades e completa e terem documentado os requisitos das aplicações a serem desenvolvidas.

Os dados obtidos por meio do experimento mostraram que a abordagem VR-ReST é eficaz para auxiliar o testador na realização do teste funcional, uma vez que os dados de teste são gerados de forma automática a partir da especificação especicação previamente realizada pela própria abordagem. Adicionalmente, com base nos critérios de cobertura NC, EC, EPC e PPC, os dados se mostraram capazes de cobrir diferentes requisitos de teste, ou seja, detectar diferentes tipos de falhas. Portanto, a partir dos resultados apresentados, a hipótese foi confirmada e o objetivo foi alcançado.

Outra contribuição relevante deste trabalho a ser destacada é o modelo ViReS que fornece meios para apoiar a especificação de requisitos sobre as características e as interações no AV. O modelo oferece como suporte um guia de especificação de requisitos (ver Apêndice A), no qual é possível documentar todas as informações e requisitos necessários para o desenvolvimento de aplicações de RV com a finalidade de facilitar a identificação de futuras possíveis mudanças a serem realizadas nessas aplicações.

\subsection{Contribuições}

Para identificar as contribuições inéditas da presente tese, foi realizada uma extensa revisão da literatura sobre o tema durante o desenvolvimento dessa pesquisa. Diversos trabalhos, conforme apresentado no Capítulo 4 propuseram modelos, metodologias ou abordagens para auxiliar somente uma das fases do processo de ER no domínio de RV. Alguns trabalhos identificados no contexto de teste de software versam a utilização do ambiente de RV para ensinar e/ou executar teste de software. Poucos trabalhos apresentam contribuições da atividade de teste de software para RV.

Dentre os trabalhos que abordam contribuições da atividade de teste de software para RV, Bezerra, Delamaro e Nunes (2011) foram os pioneiros em explorar a definição de cinco critérios de teste estruturais para aplicações de RV baseadas em GC. Os critérios foram criados com base na estrutura do GC com a finalidade de verificar os nós que representam os objetos virtuais na cena e apontar se, durante a realização de um teste, não forem executadas transformações definidas por meio das especificação de determinados objetos (representados por nós).

Nesse contexto, uma vez que tem-se um domínio pouco explorado e com possibilidade de contribuições inéditas tanto para a área de teste de software quanto para a área de RV, a principal contribuição desta pesquisa é fornecer para o domínio de RV uma abordagem teórica e prática para formalizar a especificação de requisitos e a automatizar a geração de testes funcionais em aplicações de RV que utilizam conceito de GC. Destacam-se as seguintes contribuições específicas: 
1. Desenvolvimento de um modelo para orientar a especificação de requisitos: foi proposto um modelo, chamado Virtual Requirement Specification (ViReS), para auxiliar o processo de levantamento, especificação e validação de requisitos de aplicações de RV que utilizam o conceito de GC. Esse modelo é composto por quatro fases (descrição geral, elicitação, especificação e validação) que são baseadas no modelo incremental e nas principais características extraídas de cada metodologia selecionada, conforme apresentado na Subseção 6.2.2.2. O objetivo desse modelo é fornecer meios para apoiar a criação do AV de acordo com as suas necessidades, incluindo as interações. Assim, é possível concluir que o modelo ViReS auxilia o projetista na criação de aplicações de RV a partir dos requisitos especificados. Pretende-se que o modelo seja utilizado por outros pesquisadores para prover o reúso e melhorias no contexto da especificação de requisitos de aplicações de RV;

2. Desenvolvimento de uma linguagem semi-formal: foi desenvolvida uma linguagem específica chamada Behavior Language Requirement Specification (BeLaRS) que facilita a elaboração de uma especificação semi-formal dos requisitos para auxiliar o teste funcional no domínio de RV. A BeLaRS foi desenvolvida com base em uma Linguagem Natural Controlada (LNC) (do inglês, Control Natural Language - CNL) (HEITMEYER; BHARADWAJ, 2000), em descrições de casos de uso (COCKBURN, 2001), na teoria da estrutura de constituintes (CHOMSKY, 1956) e nos conceitos de GC. O objetivo é assegurar uma especificação mais formal, precisa, sem ambiguidade e mais próximo do nível de compreensão do usuário.

3. Definição dos critérios de testes para geração dos dados: os critérios utilizados para auxiliar o teste funcional são: (i) Node Coverage (NC); (ii) Edge Coverage (EC); (iii) EdgePair Coverage (EPC); e (iv) Prime Path Coverage (PPC). Esses critérios são selecionados para garantir a qualidade dos dados de testes gerados e a cobertura dos Requisitos de Teste (RTs) produzidos.

4. Apoio Computacional: o apoio computacional apresentado no Capítulo 5 foi desenvolvido para automatizar a atividade de especificação e geração dos dados de teste em aplicações de RV. Para auxiliar o projetista, os requisitos relativos às interações do sistema e do usuário e às características dos objetos podem ser especificados de forma padronizada utilizando a linguagem BeLaRS no componente de requisitos. A partir dos requisitos validados, os mesmo são convertidos no Grafo de Fluxo de Requisitos (GFR) no componente de teste, o qual foi adaptado a partir do Grafo de Fluxo de Controle (GFC). A partir do GFR, os RTs são derivados usando um algoritmo de busca em profundidade de acordo com um dos quatro critérios apresentados anteriormente. O processo de geração do GFR é composto de três etapas: ( $i$ ) especificação dos requisitos; (ii) associação dos requisitos aos nós; e (iii) geração do GFR. Além disso, esse componente permite também, gerar dados 
de teste percorrendo o GFR a partir do vértice inicial até o vértice final para verificar a cobertura dos RTs.

5. Realização de estudos experimentais: dois estudos empíricos foram conduzidos, sendo um estudo de caso e um experimento. O estudo de caso exploratório visa verificar a conformidade e usabilidade da linguagem BeLaRS; e o experimento controlado tem com objetivo avaliar a eficácia da ferramenta ViReST na realização do teste funcional em aplicações de RV. No estudo de caso foram consideradas três métricas para avaliar a conformidade: "simplicidade", "ortogonalidade" e "escalabilidade", enquanto que a usabilidade foi avaliada por meio da "facilidade de uso". O experimento avaliou a "eficácia" da ferramenta em relação à qualidade dos dados de teste gerados para a detecção de falhas em aplicações de RV. Os resultados mostraram que para todas as métricas, exceto "escalabilidade", que a linguagem auxilia a especificação de aplicações de RV e que a ferramenta ViReST é eficaz na realização de testes funcionais uma vez que permite localizar erros que o testador não seria capaz de identificar utilizando testes ad-hoc ou que somente poderiam ser detectados na fase final do desenvolvimento.

\subsection{Limitações}

A prova de conceito descrita nesta pesquisa reforça a hipótese que a utilização de atividades de teste automatizadas são fundamentais para que as aplicações de RV alcancem um nível de confiança e qualidade, contudo, existem algumas limitações:

- o modelo ViReS visa orientar a especificação de requisitos de aplicações de RV, fornecendo meios para apoiar a criação do AV de acordo com as suas necessidades, incluindo as interações. No entanto, como o modelo ViReS é baseado nos conceitos de GC, pode-se apenas especificar requisitos que representem características do AV e dos objetos contidas no GC;

- a abordagem VR-ReST provê uma linguagem (BeLaRS) para auxiliar a especificação de requisitos. Essa linguagem aumenta o nível de abstração do processo de especificação, escondendo determinadas complexidades. O uso dessa linguagem guia o projetista durante a especificação de uma determina cena, norteando quais informações sobre o AV, os objetos e as interações devem ser especificadas. No entanto, para ser realizada essa especificação, é necessário compreender as regras da BeLaRS; baseadas na descrição de casos;

- a ferramenta ViReST contém um componente que auxilia a realização da geração automática dos testes baseados nos critérios de teste previamente definidos. No entanto, a criação ou avaliação de conjuntos de dados de teste no escopo de aplicações de RV continua sendo responsabilidade do testador. 


\subsection{Sugestões de Trabalhos Futuros}

Com base em todo o trabalho realizado foi possível perceber que a área de RV não tem um processo de desenvolvimento consolidado, uma vez que, em geral, os desenvolvedores da área não costumam formalizar a especificação de requisitos e os testes de usabilidade somente são realizados no final do desenvolvimento da aplicações de RV. Nesse contexto, a definição e a automatização de critérios de teste é uma área relativamente nova no domínio de RV. Esta tese considera a geração automática de testes funcionais para aplicações de RV que usam o conceito de GC. Assim, o trabalho desenvolvido nesta tese deve ser ajustado e melhorado com base na experiência substancial de aplicações práticas para obter relevância tanto na academia quanto na indústria. Com base no MS conduzido e apresentado no Capítulo 4 e na pesquisa apresentada nesta tese, há muitas pesquisas que podem ser realizadas no futuro pelo autor e por outros pesquisadores dos grupos de pesquisa em engenharia de software do ICMC e do LApIS.

Uma dessas pesquisas seria realizar mais estudos de caso utilizando diferentes aplicações de RV, visando comprovar se os mesmos resultados sobre a conformidade e usabilidade da linguagem BeLaRS, ou resultados semelhantes, serão obtidos.

No contexto do modelo ViReS, também seria importante aplicar estudos de caso envolvendo uma população para conceber novas especificações para verificar se o mesmo pode ser utilizado para registrar informações de forma eficiente referente à aplicação a ser desenvolvida.

Para análise dos dados qualitativos obtidos por meio do estudo de caso seria importante considerar uso da metodologia grounded theory para análise qualitativa (GLASER; STRAUSS, 2009).

Outro ponto importante a ser considerar é a análise de outras linguagens utilizadas em ER que poderiam contribuir para a melhoria da BeLaRS. Por fim, outro trabalho futuro seria implementar algum mecanismo de suporte à evolução da linguagem BeLaRS. Isso se mostra necessário quando novas aplicações muito específicas ou que não são baseadas no conceito de GC precisam ser desenvolvidas. 



\section{REFERÊNCIAS}

ALIPIO, F. Integração da captura de movimentos (MOCAP) com a realidade virtual imersiva. 2010. Disponível em: <http://realidadevirtualemocap.wikispaces.com/>. Acesso em: 18/12/2016. Citado na página 54.

ALLEN, J. Natural Language Understanding. $2^{\text {nd }}$. ed. Redwood City, CA, USA: BenjaminCummings Publishing, 1995. Citado nas páginas 85, 89 e 90.

ALSHAHWAN N.AND HARMAN, M. Automated web application testing using search based software engineering. In: Proceedings of the 26th IEEE/ACM International Conference on Automated Software Engineering (ASE). [S.1.]: IEEE, 2011. p. 3-12. Citado na página 31.

AMMANN, P.; OFFUTT, J. Introduction to software testing. $1^{\text {st }}$. ed. New York, NY, USA: Cambridge University Press, 2008. 344 p. Citado nas páginas 46 e 49.

ANDREWS, A.; BOUKHRIS, S.; ELAKEILI, S. Fail-safe testing of web applications. In: Proceedings of the 23rd Australian Software Engineering Conference (ASWEC). [S.1.]: IEEE, 2014. p. 200-209. Citado na página 31.

BAL, M.; MANESH, H. F.; HASHEMIPOUR, M. Virtual-reality-based information requirements analysis tool for cim system implementation: a case study in die-casting industry. International Journal of Computer Integrated Manufacturing, Taylor \& Francis, Inc., Bristol, PA, USA, v. 21, n. 3, p. 231-244, 2008. ISSN 0951-192X. Citado nas páginas 69, 70, 71 e 166.

BAR-ZEEV, A. Scene graphs - past, present and future. 2007. Disponível em: <http://www. realityprime.com/articles/scenegraphs-past-present-and-future>. Acessado em: 07/01/2016. Citado na página 57.

BARBOSA, E. F.; CHAIM, M. L.; VINCENZI, A. M. R.; DELAMARO, M. E.; JINO, M.; MALDONADO, J. C. Introdução ao teste de software. In: DELAMARO, M. E.; MALDONADO, J. C.; JINO, M. (Ed.). $1^{\text {st }}$. ed. Norwell, MA, USA: Rio de Janeiro, RJ, Brasil, 2007. cap. Teste Estrutural, p. 47-74. ISBN 0-7923-7323-5. Citado na página 49.

BARDIN, S.; CHEBARO, O.; DELAHAYE, M.; KOSMATOV, N. An all-in-one toolkit for automated white-box testing. In: Proceedings of the International Conference on Tests and Proofs. [S.1.]: Springer, 2015. Citado na página 31.

BARDIN, S.; DELAHAYE, M.; DAVID, R.; KOSMATOV, N.; PAPADAKIS, M.; TRAON, Y. L.; MARION, J.-Y. Sound and quasi-complete detection of infeasible test requirements. In: Proceedings of the 8th IEEE International Conference on Software Testing, Verification and Validation (ICST). [S.1.]: IEEE, 2015. p. 1-10. Citado na página 31.

BASILI, V.; WEISS, D. A methodology for collecting valid software engineering data. IEEE Transactions on Software Engineering, v. 10, n. 6, p. 728-738, 1986. Citado na página 106. 
BENNES, L.; BAZZARO, F.; SAGOT, J. Virtual reality as a support tool for ergonomic-style convergence: multidisciplinary interaction design methodology and case study. In: Proceedings of the Virtual Reality International Conference (VRIC). Laval, França: ACM, 2012. v. 24, p. 1-10. ISBN 978-1-4503-1243-1. Citado nas páginas 72, 73 e 166.

BERTOLINO, A. Software testing research: Achievements, challenges, dreams. In: Proceedings of the Workshop on the Future of Software Engineering (FOSE). Minneapolis, MN, USA: IEEE-CS Press, 2007. p. 85-103. Citado na página 31.

BEZERRA, A.; DELAMARO, M. E.; NUNES, F. L. S. Automated testing of virtual reality application interfaces. In: Proceedings of the Symposium on Virtual and Augmented Reality. [S.1.]: IEEE, 2011. (SVR '11), p. 56-65. Citado nas páginas 34, 39, 74, 78, 130, 166 e 170.

BIERBAUM, A.; HARTLING, P.; CRUZ-NEIRA, C. Automated testing of virtual reality application interfaces. In: Proceedings of the Workshop on Virtual Environments. [S.1.]: ACM, 2003. (EGVE '03), p. 107-114. Citado nas páginas 34, 74, 76, 166 e 170.

BIRTHELMER, H.; SOETEBIER, I.; SAHM, J. Efficient representation of triangle meshes for simultaneous modification and rendering. In: Proceedings of the 3rd International Conference on Computational Science (ICCS). Melbourne, Australia: Springer-Verlag, 2003. p. 925-934. ISBN 3-540-40194-6. Citado na página 56.

BOUKHRIS, S.; ANDREWS, A.; ALHADDAD, A.; DEWRI, R. A case study of black box fail-safe testing in web applications. Journal of Systems and Software, 2016. Citado na página 31.

BOWMAN, D. A.; KRUIJJF, E.; LAVIOLA, J. J.; POUPYREV, I. 3D User Interfaces: Theory and Practice. $1^{\text {st }}$. ed. [S.1.]: Addison Wesley, 2004. 512 p. Citado nas páginas 55, 81 e 84.

BRERETON, P.; KITCHENHAM, B. A.; BUDGEN, D.; TURNER, M.; KHALIL, M. Lessons from applying the systematic literature review process within the software engineering domain. Systems and Software, New York, NY, USA, v. 80, n. 4, p. 571-583, 2007. Citado nas páginas 64 e 158.

BUDD, T. A. Mutation analysis: Ideas, example, problems and prospects. In: . [S.1.]: NorthHoland Publishing Company, 1981. cap. Computer Program Testing. Citado na página 50.

CACCIABUE, P. C. Guide to Applying Human Factors Methods. [S.1.]: Springer-Verlag, 2004. 700 p. Citado na página 70.

CALLAGHAN, M.; HIRSCHMüLLER, H. 3-D visualisation of design patterns and Java programs in computer science education. SIGCSE Bull, ACM, New York, NY, USA, v. 30, n. 3, p. 37-40, 1998. ISSN 0097-8418. Citado nas páginas 73, 166 e 167.

CHATTERJEE, R.; JOHARI, K. A prolific approach for automated generation of test cases from informal requirement. SIGSOFT Softw. Eng. Notes, v. 35, n. 5, p. 1-11, 2010. Citado na página 34.

CHELIMSKY, D.; ASTELS, D.; HELMKAMP, B.; NORTH, D.; DENNIS, Z.; HELLESOY, A. The RSpec BOOK: Behaviour Driven Development with RSpec, Cucumber, and Friends. $1^{\text {st }}$. ed. [S.1.]: Pragmatic BOOKshelf, 2010. Citado na página 37. 
CHEN, C. J.; LAU, S. Y.; CHUAH, K. M.; TEH, C. S. Group usability testing of virtual realitybased learning environments: A modified approach. Procedia - Social and Behavioral Sciences, v. 97, p. 691-699, 2013. Citado nas páginas 34, 74, 75, 78 e 166.

CHEN, L.; LI, Q. Automated test case generation from use case: A model based approach. In: IEEE INTERNATIONAL CONFERENCE ON COMPUTER SCIENCE AND INFORMATION TECHNOLOGY (ICCSIT), 3. Chengdu, China, 2010. p. 372-377. Citado na página 34.

CHI, E. Prefuse - Information Vizualization Toolkit. 2007. Disponível em: <http://prefuse. org >. Acesso em: 01/01/2017. Citado na página 90.

CHOMSKY, N. Three models for the description of language. RE Transactions on Information Theory, v. 2, n. 3, p. 113-124, 1956. Citado nas páginas 37, 86, 115 e 131.

COCKBURN, A. Writing Effecive Use Cases. $3^{\text {rd }}$. ed. [S.1.]: Addison-Wesley, 2001. Citado nas páginas 37,83 e 131 .

COREMAN, T. H.; LEISERSON, C. E.; RIVEST, R. L.; STEIN, C. Introduction to Algorithm. $3^{\text {rd }}$. ed. [S.1.]: The MIT Press, 2009. Citado na página 91.

COSTA, M. G. Estratégia de automação em testes: requisitos, arquitetura e acompanhamento de sua implantação. Tese (Dissertação de Mestrado) - Universidade Estadual de Campinas (UNICAMP), Campinas, SP, Brasil, Fevereiro 2004. Citado na página 31.

CRYSTAL, D. Dictionary of Linguistics and Phonetics. $6^{\text {th }}$. ed. [S.1.]: Wiley-Blackwell, 2008. Citado na página 86.

CYBULSKI, J. L.; PARKER, C.; SEGRAVE, S. Using constructivist experiential simulations in re education. In: Proceedings of the Australian Workshop on Requirements Engineering (AWER). Adelaide, Australia: [s.n.], 2006. p. 1-10. Citado nas páginas 69, 71, 166 e 167.

DAMASCENO, E.; JR, J. B. D.; LOPES, L. F. B. Aplicação da técnica de redesenho de ambientes 3d por meio de engenharia semiótica. In: Proceedings of the Workshop de Realidade Virtual e Aumentada (WRVA). Santos, SP, Brasil: [s.n.], 2009. p. 1-12. Citado nas páginas 69, 70, 71, 166,167 e 170.

DAMASCENO, E.; OLIVEIRA, D. C. Análise swot das metodologias de sistemas de realidade virtual. In: Proceedings of the Workshop de Realidade Virtual e Aumentada (WRVA). Santos, SP, Brasil: [s.n.], 2009. p. 1-12. Citado nas páginas 69, 70, 71, 166, 167 e 170.

DAVIS, F. D.; BAGOZZI, R. P.; WARSHAW, P. R. User acceptance of computer technology: A comparison of two theoretical models. Manage. Sci., v. 35, n. 8, p. 982-1003, ago. 1989. Citado na página 101.

DELAMARO, M. E. Introdução ao teste de software: técnicas e ferramentas - Conceitos básicos. 2012. Disponível em: <http://disciplinas.stoa.usp.br/course/view.php?id=35>. Acesso em: 28/12/2016. Citado na página 47.

DELAMARO, M. E.; MALDONADO, J. C.; JINO, M. Introdução ao teste de software. In: DELAMARO, M. E.; MALDONADO, J. C.; JINO, M. (Ed.). $1^{\text {st }}$. ed. Rio de Janeiro, RJ, Brasil: Elsivier Editora Ltda, 2007. cap. Conceitos Básicos, p. 1-7. Citado na página 50. 
DELAMARO, M. E.; NARDI, P. A.; LEMOS, O. A. L.; SPOTO, E. S.; MALDONADO, J. C.; MASIERO, P. C.; VICENZI, A. M. R. Static analysis of java bytecode for domain-specific software testing. In: Proceedings of the XXI Simpósio Brasileiro de Engenharia de Software (SBES). João Pessoa-PB: [s.n.], 2007. v. 1, p. 325-341. Citado nas páginas 46 e 47.

DELAMARO, M. E.; NUNES, F. L. S.; ANDRADE, M. S. Avaliação de sistemas de auxílio ao diagnóstico: utilização de medidas de cobertura de código para aperfeiçoar a geração de curvas ROC. In: Proceedings of the VI Workshop de Informática Médica. Vitória, ES, Brasil: [s.n.], 2006. v. 1, p. 118-124. Citado na página 39.

DELAMARO, M. E.; PEZZè, M.; VINCENZI, A. M. R.; MALDONADO, J. C. Mutant operators for testing concurrent Java programs. In: Proceedings of the XV Simpósio Brasileiro de Engenharia de Software (SBES). Rio de Janeiro, RJ, Brasil: [s.n.], 2001. p. 272-285. Citado na página 31 .

DEMILLO, R. A. Mutation Analysis as a Tool for Software Quality Assurance. [S.1.]: School of Information and Computer Science, Georgia Institute of Technology, 1980. 7 p. Citado nas páginas 47 e 51.

DEMILLO, R. A.; LIPTON, R. J.; SAYWARD, F. G. Hints on test data selection: Help for the practicing programmer. Computer, IEEE Computer Society Press, Los Alamitos, CA, USA, v. 11, n. 4, p. 34-43, 1978. Citado nas páginas 50 e 104.

DÍAZ, I.; LOSAVIO, F.; MATTEO, A.; PASTOR, O. A specification pattern for use cases. Information Managment, v. 41, n. 8, p. 961-975, 2004. Citado na página 37.

FABBRI, S. C. P. F.; VINCENZI, A. M. R.; MALDONADO, J. C. Introdução ao teste de software. In: DELAMARO, M. E.; MALDONADO, J. C.; JINO, M. (Ed.). $1^{\text {st }}$. ed. [S.1.]: Rio de Janeiro, RJ, Brasil, 2007. cap. Teste Funcional, p. 9-24. ISBN 0-7923-7323-5. Citado na página 48.

FERREIRA, A. G. Uma arquitetura para visualização distribuída de ambientes virtuais. Tese (Dissertação de Mestrado) — Pontifícia Universidade Católica do Rio de Janeiro (PUC/RJ), Rio de Janeiro, RJ, Brasil, Dezembro 1999. Citado nas páginas 57 e 58.

FILHO, W. P. P. Engenharia de Software: Fundamentos, Métodos e Padrões. $2^{\text {nd }}$. ed. [S.1.]: LCT, 2003. Citado na página 42.

FILLMORE, C. J. Universals in Linguistic Theory. New York, NY, USA: Holt, Rinehart and Wilson, 1968. Citado nas páginas 85 e 89.

FLORCZYK, M.; WINIECKI, W. The Parametric Method for Functional Testing of Virtual Instruments. In: Proceedings of the 3rd Intelligent Data Acquisition and Advanced Computing Systems: Technology and Applications (IDAACS). Sofia, Bulgaria: IEEE, 2005. p. 310-315. Citado nas páginas 74, 76 e 166.

FOWLER, M. Dsl Bliki. 2009. Disponível em: <http://martinfowler.com/bliki/dsl.html>. Acessado em: 13/11/2016. Citado na página 45.

FRANKL, P. G.; WEYUKER, E. J. Testing software to detect and reduce risk. Systems and Software, Elsevier Science Inc., New York, NY, USA, v. 53, n. 3, p. 275-286, 2000. Citado na página 47. 
GAONA, P. A. G.; MONCUNILL, D. M.; GORDILLO, K.; CRESPO, R. G. Applying the scr requirements method to the light control case study. Journal IEEE Latin America Transactions, v. 14, n. 4, p. 2915-2920, 2016. Citado na página 32.

GLASER, B. G.; STRAUSS, A. L. The Discovery of Grounded Theory: Strategies for Qualitative Research. $1^{\text {st }}$. ed. [S.1.]: Aldine Transaction, 2009. 282 p. Citado na página 133.

GONCALVES, V. M.; NUNES, F. L. S.; DELAMARO, M. E.; OLIVEIRA, R. A. P. Avaliação de Funções de Similaridade em um Framework de Teste para Programas com Saídas Gráficas. In: Proceedings of the XXXVII Conferencia Latinoamericana de Informática (CLEI). Quito, Equador: [s.n.], 2011. v. 1, p. 1-15. Citado na página 38.

GOURAUD, H. Continuous Shading of Curved Surfaces. IEEE Transactions on Computers, IEEE, Washington, DC, USA, v. 20, n. 6, p. 623-629, 1971. Citado na página 58.

GREINER, J.; OESTERLEIN, T.; LENIS, G.; DöSSEL, O. Virtual-reality based visualization of cardiac arrhythmias on mobile devices. In: Proceedings of the Computing in Cardiology Conference (CinC). [S.1.]: IEEE, 2016. p. 1081-1084. Citado na página 32.

GUO, T.; ZHOU, X.; ZHU, G. Application of CBR in VR-based test and simulation system. In: Proceedings of the International Conference on Machine Learning and Cybernetics. Xi-an, China: IEEE, 2003. p. 2337-2340. Citado nas páginas 74, 76 e 166.

HAMLET, R. G. Testing programs with the aid of a compiler. IEEE Trans. Software Eng., v. 3, n. 4, p. 279-290, 1977. Citado na página 104.

HEITMEYER, C.; BHARADWAJ, R. Applying the scr requirements method to the light control case study. Journal of Universal Computer Science, v. 6, n. 7, p. 650-678, 2000. Citado nas páginas 83,85 e 131 .

INITION. Haptic Device. 2013. Disponível em: <http://inition.co.uk/3D-Technologies/ sensable-phantom-omni>. Acesso em: 05/01/2017. Citado na página 55.

JACOBSON, I. Object oriented development in an industrial environment. In: Proceedings of the Conference on Object-oriented Programming Systems, Languages and Applications. [S.1.]: ACM, 1987. (OOPSLA '87), p. 183-191. ISBN 0-89791-247-0. Citado na página 44.

JIMÉNEZ-DÍAZ, G.; GóMEZ-ALBARRáN, M.; GONZáLEZ-CALERO, P. A. Role-Play Virtual Environments: Recreational Learning of Software Design. In: Proceedings of the 3rd European conference on Technology Enhanced Learning: Times of Convergence: Technologies Across Learning Contexts (EC-TEL). Maastricht, The Netherlands: Springer-Verlag, 2008. p. 27-32. ISBN 978-3-540-87604-5. Citado nas páginas 72, 73 e 166.

JINO, M.; MALDONADO, J. C.; DELAMARO, M. E. Introducao ao teste de software. In: DELAMARO, M. E.; MALDONADO, J. C.; JINO, M. (Ed.). $2^{\text {nd }}$. ed. [S.1.]: Elsivier Editora Ltda, 2016. cap. Conceitos Básicos, p. 1-7. Citado na página 32.

KIM, G. J.; KANG, K. C.; KIM, H.; LEE, J. Software engineering of virtual worlds. In: Proceedings of the Symposium on Virtual reality Software and Technology (VRST). Taipei, Taiwan: ACM, 1999. p. 131-138. ISBN 1-58113-019-8. Citado nas páginas 34, 69, 70, 71 e 166. 
KIM, H. S. S. W. Y.; KIM, R. Y. C. A study on test case generation based on state diagram in modeling and simulation environment*. In: . Springer Berlin Heidelberg: [s.n.], 2011. cap. Advanced Communication and Networking, p. 298-305. Citado nas páginas 74, 75, 76, 77 e 166.

KIM., T. Theoretical analysis of the physiologic mechanism for visual comfort in $3 \mathrm{~d}$ virtual reality. In: Proceedings of the IEEE International Conference on Consumer Electronics (ICCE). [S.1.]: IEEE, 2017. p. 302-305. Citado na página 32.

KINTIS, M. P. M.; MALEVRIS, N. Employing second order mutation for isolating first order equivalent mutants. Software Testing, Verification and Reliability Journal (STVR), v. 25, n. 5-7, p. 508-535, 2015. Citado na página 31.

KIRNER, C.; SISCOUTTO, R. Realidade Virtual e Aumentada: Conceitos, Projeto e Aplicações. [S.1.: s.n.], 2007. 300 p. Citado nas páginas 32, 33, 53, 54 e 55.

KIRNER, T.; MARTIN, V. A model of software development process for virtual environments. In: Proceedings of IEEE Symposium on Application-Specific Systems and Software Engineering and Tecnology (ASSET). [S.1.]: IEEE Computer Society, 1999. p. 155-161. Citado nas páginas 34, 72, 81, 84, 166 e 170.

Contribution to the requirements engineering of virtual environments. In: Proceedings of Workshop em Engenharia de Requisitos (WER). [S.1.: s.n.], 2007. p. 142-157. Citado nas páginas 69, 70, 71, 84, 166, 167 e 169.

KITCHENHAM, B.; BUDGEN, D.; BRERETON, P. Evidence-Based Software Engineering and Systematic Reviews. [S.1.]: Chapman and HallCRC, 2015. 433 p. Citado na página 63.

KITCHENHAM, B.; PRETORIUS, R.; BUDGEN, D.; BRERETON, P.; TURNER, M.; NIAZI, M.; LINKMAN, S. Systematic literature reviews in software engineering - a tertiary study. Inf. Softw. Technol., Butterworth-Heinemann, Newton, MA, USA, p. 792-805, 2010. Citado nas páginas $63,64,77,155,156$ e 160.

KOWALCZYK, E.; MEMON, A. Extending manual gui testing beyond defects by building mental models of software behavior. In: Proceedings of the 30th International Conference on Automated Software Engineering Workshop. [S.1.]: IEEE Computer Society, 2015. (ASEW '15), p. 35-41. Citado na página 32.

KUUTTI, K.; BATTARBEE, K.; SäDE, S.; MATTELMäKI, T.; KEINONEN, T.; TEIRIKKO, T.; TORNBERG, A. Virtual Prototypes in Usability Testing. In: Proceedings of the 34th Annual Hawaii International Conference on System Sciences (HICSS). Maui, Hawaii, USA: IEEE, 2001. p. 5029-5036. ISBN 0-7695-0981-9. Citado nas páginas 74, 76 e 166.

LARMAN, C. Utilizando UML e Padrões:Uma Introdução à Análise e ao Projeto Orientados a Objetos e ao Desenvolvimento Iterativo. $3^{\text {rd }}$. ed. [S.1.]: Artmed, 2007. Citado na página 45 .

LIKERT, R. A technique for the measurement of attitudes. Journal Archives of Psychology, v. 22, n. 140, p. 1-55, 1932. Citado na página 103.

LIMA, J. C. B. Fast Game Language: Uma DSL (linguagem de domínio específico) para criação rápida de jogos. Tese (Mestrado Profissional em Engenharia de Software) - Centro de Estudos e Sistemas Avançados do Recife (CESAR), Recife, PE, Brasil, 2012. Citado na página 45. 
LIU, A.; TENDICK, F.; CLEARY, K.; KAUFMANN, C. A Survey of Surgical Simulation: Application, Technology and Education. Presence: Teleoperators and Virtual Environments, MIT Press, Cambridge, MA, USA, v. 12, n. 6, p. 599-614, 2003. ISSN 1054-7460. Citado na página 59.

MA, Y.-S.; OFFUTT, J.; KWON, Y. R. Mujava: An automated class mutation system: Research articles. Softw. Test. Verif. Reliab., John Wiley and Sons Ltd., Chichester, UK, v. 15, n. 2, p. 97-133, jun. 2005. Citado na página 109.

MACHADO, F. N. R. Análise e gestão de requisitos de software: onde nascem os sistemas. $2^{\text {nd }}$. ed. [S.1.]: Érica,, 2014. Citado na página 43.

MALDONADO, J. C. Critérios Potenciais Usos: Uma Contribuição ao Teste Estrutural de Software. Tese (Tese de Doutorado) — Universidade de Campinas (UNICAMP), Campinas, SP, Brasil, July 1991. Citado nas páginas 31, 45 e 48.

MALETIC, J. I.; LEIGH, J.; MARCUS, A.; DUNLAP, G. Visualizing Object Oriented Software in Virtual Reality. In: Proceedings of the 9th International Workshop on Program Comprehension (IWPC). [S.1.]: IEEE, 2001. p. 103-112. Citado nas páginas 72, 73, 166, 167 e 170 .

MANSSOUR, I. H. Introdução à Java 3D. In: Proceedings of the Simpósio Brasileiro de Computação Gráfica e Processamento de Imagens (SIBGRAPI). São Carlos, SP, Brasil: [s.n.], 2003. p. 72-96. Citado na página 58.

MARCO, I. Dispositivos informáticos utilizados na realidade virtual. 2012. Disponível em: < http://api12dmi.blogspot.com.br/2012/09/dispositivos-informaticos-utilizados-na.html>. Acesso em: 15/01/2017. Citado na página 55.

MARCOZZI, M.; DELAHAYE, M.; BARDIN, S.; KOSMATOV, N.; PREVOSTO, V. Generic and effective specification of structural test objectives. In: Proceedings of the 10th IEEE International Conference on Software Testing, Verification and Validation (ICST). [S.1.]: IEEE, 2017. p. 436-441. Citado na página 31.

MARILILI. Realidade Virtual Não Imersiva. 2011. Disponível em: < http://aplicinfb.blogspot. com.br/2011/01/realidade-virtual-nao-imersiva.html>. Acesso em: 18/012/2016. Citado na página 54.

MARZANO, A.; FRIEL, I.; ERKOYUNCU, J. A.; COURT, S. Design of a virtual reality framework for maintainability and assemblability test of complex systems. Procedia CIRP, v. 37, p. 242-247, 2015. Citado na página 34.

MATOS, E. C. B. de. Beta: uma ferramenta para geração de testes de unidade a partir de especificações B. Dissertação (Mestrado) - Universidade Federal do Rio Grande do Norte, Rio Grande Norte - Natal, 2012. Citado na página 34.

MATTIOLI, F. E. R.; JúNIOR, E. A. L.; CARDOSO, A.; ALVES, N. M. M. Uma Proposta para o Desenvolvimento Ágil de Ambientes Virtuais. In: Proceedings of the VI Workshop de Realidade Virtual e Aumentada (WRA). Santos, SP, Brasil: [s.n.], 2009. p. 296-300. Citado nas páginas 72, 73, 166, 167 e 170.

MICROSOFT. Windows. 2017. Disponível em: <https://www.microsoft.com/pt-br/>. Acesso em: 01/03/2017. Citado na página 57. 
MOAZZEN, S. M. A.; AHMADI, A. 3d simulation of tennis game using learning algorithms by application of virtual reality. In: Proceedings of the Iranian Conference on Electrical Engineering (ICEE). [S.1.]: IEEE, 2017. p. 1527-1531. Citado na página 32.

MONTEIRO, E. F. S.; ZANCHET, D. J. Realidade Virtual e a Medicina. Scientific Electronic Library Online, Acta Cirúrgica Brasileira, São Paulo, SP, Brasil, v. 18, n. 5, p. 489-490, 2003. Citado nas páginas 54 e 55.

MYERS, G. J.; SANDLER, C.; BADGETT, T. The Art of Software Testing. $2^{\text {nd }}$. ed. [S.1.]: Wiley Publishing, 2004. 224 p. Citado nas páginas 46 e 49.

The Art of Software Testing. $3^{r d}$. ed. [S.1.]: Wiley Publishing, 2011. 240 p. Citado nas páginas 46, 48 e 49.

NAKAMOTO, P. T. Estratégia de Especificação de Requisitos de Usabilidade para Sistemas de Realidade Virtual. Tese (Qualificação de Doutorado) — Universidade Federal de Uberlândia, Uberlândia, MG, Brasil, 2011. Citado nas páginas 81 e 84.

NEUBAUER, B. J.; HARRIS, J. D. Immersive visual modeling: potential use of virtual reality in teaching software design. Computing Sciences in Colleges, Consortium for Computing Sciences in Colleges, USA, v. 18, n. 6, p. 142-150, 2003. ISSN 1937-4771. Citado nas páginas $72,73,166$ e 170 .

NUNES, C. M. Uma Linguagem de Domínio Específico para a Framework i*. Tese (Dissertação de Mestrado) - Universidade Nova de Lisboa, Lisboa, Portugal, 2009. Citado na página 45 .

NUNES, F. L. S.; OLIVEIRA, A. C. M. T. G.; ROSSATO, D. J.; MACHADO, M. I. C. ViMeTWizard: Uma ferramenta para instanciação de um framework de Realidade Virtual para treinamento médico. In: Proceedings of the XXXIII Conferência Latino Americana de Informática (CLEI). San José, Costa Rica: [s.n.], 2007. v. 1, p. 1-8. Citado na página 60.

NUSEIBEH, B.; EASTERBOOK, S. Requirements engineering: A roadmap. In: Proceedings of the 22nd International Conference on Software Engineering (ICSE). Limerick, Ireland: ACM, 2000. p. 37-45. ISBN 1-58113-253-0. Citado na página 41.

OLIVEIRA, A. C. M. T. G.; NUNES, F. L. S. Building a open source framework for virtual medical training. Digital Imaging, v. 23, p. 706-720, 2010. Citado nas páginas 37, 59, 75 e 103.

OLIVEIRA, A. R. D. Uma Linguagem de Domínio Específico para AORE. Tese (Dissertação de Mestrado) - Universidade Nova de Lisboa, Lisboa, Portugal, julho 2010. Citado na página 45 .

OLIVEIRA, R. A. P.; ALEGROTH, E.; GAO, Z.; MEMON, A. Definition and evaluation of mutation operators for gui-level mutation analysis. In: Proceedings of 8th International Conference on Software Testing, Verification and Validation Workshops. [S.1.]: IEEE, 2015. (ICSTW'15), p. 1-10. Citado nas páginas 118 e 120.

PAN, K.; WU, X.; XIE, T. Guided test generation for database applications via synthesized database interactions. ACM Trans. Softw. Eng. Methodol., ACM, v. 23, n. 2, p. 1-27, abr. 2014. Citado na página 32. 
PARR, T. The Definitive ANTLR Reference: Building Domain-Specific Languages. [S.1.]: Pragmatic Bookshelf, 2007. 376 p. Citado nas páginas 45 e 94.

PATIL, M. Embedded software product verification validation using virtual reality [vil]. In: Proceedings of the International Transportation Electrification Conference (ITEC). [S.1.]: IEEE, 2015. p. 1-5. Citado nas páginas 74, 75 e 166.

PELLENS, B.; TROYER, O. D.; KLEINERMANN, F. Codepa: A conceptual design pattern approach to model behavior for $\mathrm{x} 3 \mathrm{~d}$ worlds. In: Proceedings of the 13th International Symposium on 3D Web Technology (Web3D). [S.1.]: ACM, 2008. p. 91-99. Citado nas páginas 34, 81 e 84 .

PETERSEN, K.; VAKKALANKA, S.; KUZNIARZ, L. Guidelines for conducting systematic mapping studies in software engineering: An update. Information and Software Technology, p. $1-18,2015$. Citado nas páginas 155 e 156.

PHONG, B. Illumination for computer generated pictures. Magazine Communications da ACM, ACM, New York, NY, USA, v. 18, n. 6, p. 311-317, 1975. ISSN 0001-0782. Citado na página 58.

PINTO, S.; SANTOS, P. M. D.; COSTA, P.; JANSEN, P.; COSTA, D.; PAIVA, A.; PARENTE, M. P. L.; JORGE, R. M. N. Application of virtual reality techniques to a birth simulation. In: Proceedings of the 14th Experiment International Conference (exp.at'17). [S.1.]: IEEE, 2017. p. 125-126. Citado na página 32.

POLLOCK, G. M. Dynamic visualization techniques for high consequence software. In: Proceedings of the Aerospace Conference (AERO). [S.1.]: IEEE, 1998. v. 4, p. 277-296. Citado nas páginas $69,70,71,166$ e 170.

POULIN, P.; FOURNIER, A. A Model for Anisotropic Reflection. In: Proceedings of the 17th Annual Conference on Computer Graphics and Interactive Techniques (SIGGRAPH). Dallas, TX, USA: ACM, 1990. p. 273-282. ISBN 0-89791-344-2. Citado na página 58.

PRESSMAN, R. S. Software engineering: A practitioner's approach. $8^{\text {th }}$. ed. [S.1.]: McGrawHill, 2016. 976 p. Citado nas páginas 41, 42 e 44.

RAMAKRISHNAN, S. LIGHTVIEWS - Visual Interactive Internet Environment for Learning OO Software Testing. In: Proceedings of the 22nd International Conference on Software Engineering (ICSE). Limerick, Ireland: ACM, 2000. p. 692-695. ISBN 1-58113-206-9. Citado nas páginas 74, 76 e 166.

RODRIGUÉZ, G.; SORIA, A.; CAMPO, M. Teaching Scrum to Software Engineering Students with Virtual Reality Support. Lecture Notes in Computer Science, Springer-Verlag, v. 7547, p. 140-150, 2004. Citado nas páginas 72, 73 e 166.

ROEHL, B. Some Thoughts on Behavior in VR Systems. 1995. Disponível em: <http://ece. uwaterloo.ca/ broehl/behav.html>. Acessado em: 12/11/2016. Citado na página 58.

ROGSTAD, E.; BRIAND, L. Cost-effective strategies for the regression testing of database applications: Case study and lessons learned. Journal of Systems and Software, v. 113, p. 257-274, 2016. ISSN 0164-1212. Citado na página 32.

ROPER, M. Software Testing. [S.1.]: McGraw-Hill Book Ltd., 1994. 192 p. Citado na página 48. 
RUSSELL, S.; CREIGHTON, O. Virtual World Tools for Requirements Engineering. In: Proceedings of the 4th International Workshop on Multimedia and Enjoyable Requirements Engineering (MERE). Sydney, Australia: IEEE, 2011. p. 17-20. Citado nas páginas 69, 71, 166 e 170.

RUTHENBECK, G. S.; CARNEY, A. S.; REYNOLDS, K. J. Detail preserving anatomical markers in a virtual reality nasendoscopy simulation. In: Proceedings of the 3rd International Conference on Innovative Computing Technology (INTECH'13). [S.1.]: IEEE, 2013. p. 184188. Citado na página 32.

SALEM, W. Combining vr technology and human factors methods for supporting risk analysis. In: Proceedings of the 3rd International Conference on Information and Communication Technologies: From Theory to Applications (ICTTA). Umayyad Palace, Damascus, Syria: IEEE, 2008. p. 1-6. Citado nas páginas 69, 70, 71 e 166.

SANTOS, A. C. C. dos; DELAMARO, M. E.; NUNES, F. L. S. The relationship between requirements engineering and virtual reality systems: A systematic literature review. In: Proceedings of the Symposium on Virtual and Augmented Reality. [S.1.]: IEEE, 2013. (SVR '13), p. 53-62. Citado nas páginas 63 e 72.

SCAIFE, M.; ROGERS, Y. Informing the design of a virtual environment to support learning in children. Int. J. Hum.-Comput. Stud., Academic Press, Inc., Duluth, MN, USA, v. 55, n. 2, p. 115-143, ago. 2001. Citado nas páginas 34, 81 e 84.

Design of a virtual reality system for affect analysis in facial expressions (vr-saafe); application to schizophrenia. IEEE Transactions on Neural Systems and Rehabilitation Engineering, IEEE, v. 25, n. 5, p. 739-749, 2017. Citado na página 32.

SCHERP, A. Software Development Process Model and Methodology for Virtual Laboratories. 2002. Disponível em: <http://www.offis.de/indexe.htm>. Acesso em: 22/12/2016. Citado na página 70.

SELMAN, D. Java 3D Programming. $1^{\text {st }}$. ed. [S.1.]: The MIT Press, 2002. Citado na página 107.

SEO, J.; KIM, G. J. Design for presence: A structured approach to virtual reality system design. JOURNAL Teleoperators and Virtual Environments, v. 11, p. 378-403, 2002. Citado nas páginas $34,70,81$ e 84 .

SHREINER, D. Opengl(r) programming guide: The offcial guide to learning opengl. $7^{\text {th }}$. ed. [S.1.]: Addison-Wesley Professional, 2009. 936 p. Citado na página 56.

SOMÉ, S. S.; CHENG, X. An approach for supporting system-level test scenarios generation from textual use cases. In: PROCEEDINGS OF THE ACM SYMPOSIUM ON APPLIED COMPUTING, 23. CFortaleza, Ceara, Brazil, 2008. p. 724-729. Citado na página 34.

SOMMERVILLE, I. Software Engineering. 10 ${ }^{\text {th }}$. ed. [S.1.]: Pearson Addison-Wesley, 2016. 816 p. Citado nas páginas 42, 43, 44, 81, 82 e 84.

SOUZA, F. M. Geração de Casos de Teste a partir de Especificações B. Dissertação (Mestrado) - Universidade Federal do Rio Grande do Norte, Rio Grande Norte - Natal, 2009. Citado na página 34 . 
STANNEY, K. M.; MOLLAGHASEMI, M.; REEVES, L.; BREAUX, R.; GRAEBER, D. A. Usability engineering of virtual environments (ves): Identifying multiple criteria that drive effective ve system design. Int. J. Hum.-Comput. Stud., Academic Press, Inc., Duluth, MN, USA, v. 58, n. 4, p. 447-481, 2003. Citado nas páginas 34, 81 e 84.

STUART, R. Design of Virtual Environments. New York, NY, USA: McGraw-Hill, 1996. Citado na página 84.

SUTCLIFFE, A.; GAULT, B. The ISRE method for analyzing system requirements with virtual prototypes: Regular papers. Systems Engineering, John Wiley \& Sons, Chichester, UK, v. 7, n. 2, p. 123-143, 2004. ISSN 1098-1241. Citado nas páginas 69, 70, 71 e 166.

TANRIVERDI, V.; JACOB, R. J. K. VRID: A Design Model and Methodology for Developing Virtual Reality Interfaces. In: Proceedings of the Symposium on Virtual Reality Software and Technology (VRST). Baniff, Alberta, Canada: ACM, 2001. p. 175-182. ISBN 1-58113427-4. Citado nas páginas 34, 72, 81, 84, 166 e 170.

TORENS, C.; EBRECHT, L. RemoteTest: A Framework for Testing Distributed Systems. In: Proceedings of the 5th International Conference on Software Engineering Advances (ICSEA). Nice, France: IEEE, 2010. p. 441-446. ISBN 978-0-7695-4144-0. Citado nas páginas 74, 76 e 166.

TORI, R.; KIRNER, C.; SISCOUTTO, R. Fundamentos e Tecnologia de Realidade Virtual e Aumentada. Belém/PA: VIII Symposium on Virtual Reality, 2006. 412 p. Citado nas páginas 54 e 81 .

TORRES, R. S.; BISCARO, H. H.; ARAUJO, L. V. de; NUNES, F. L. S. Vimetgame: A serious game for virtual medical training of breast biopsy. SBC Journal on 3D Interactive Systems, v. 3, n. 3, p. 12-22, 2012. Citado na página 107.

TREVISAN, D. G.; COSTA, R. M. E. M. da; RIEDER, R.; PINHO, M. S. Tendências e Técnicas em Realidade Virtual e Aumentada. [S.1.]: Canal 6 Projetos Editoriais, 2014. Citado nas páginas 32 e 53.

VALENTE, L. Representação de Cenas Tridimensionais: Grafo de Cenas. 2004. Disponível em: <http://icad.puc-rio.br/ lvalente/docs/2004_SceneGraph.pdf>. Acesso em: 21/01/2017. Citado na página 58.

VEGA, K.; FUKS, H.; CARVALHO, G. Training in requirements by collaboration: Branching stories in second life. Simpósio Brasilerio de Sistemas Colaborativos, IEEE, Fortaleza, CE, Brasil, p. 116-122, 2009. Citado nas páginas 69, 71, 166 e 169.

VINCE, J. Introduction to Virtual Reality. ${ }^{\text {st }}$. ed. [S.1.]: Springer-Verlag, 2004. 163 p. Citado na página 54.

WALSH, A. E. Understanding scene graphs. Dr Dobb's, p. 1-38, 2002. Citado na página 56.

WINTER, V.; DESOVSKI, D.; CUKIC, B. Virtual Environment Modeling for Requirements Validation of High Consequence Systems. In: Proceedings of the 5th International Symposium on Requirements Engineering (RE). Toronto, Canada: IEEE, 2001. p. 23-30. Citado nas páginas 69, 70, 71, 166 e 170.

WIRFS-BROCK, R. J.; MCKEAN, A. Object Design: Roles, Responsibilities, and Collaborations. [S.1.]: Addison Wesley Professional, 2002. 416 p. Citado na página 73. 
WOHLIN, C.; RUNESON, P.; HöST, M.; OHLSSON, M. C.; REGNELL, B.; WESSLÉN, A. Experimentation in Software Engineering: An Introduction. ${ }^{\text {st }}$. ed. [S.1.]: Springer-Verlag Berlin Heidelberg, 2012. Citado nas páginas 77, 99 e 106.

WOO, M.; NEIDER, J.; DAVIS, T.; SHREINER, D. OpenGL, Programming Guide. $3^{r d}$. ed. [S.l.: s.n.], 1999. Citado nas páginas 33 e 57.

XIAO, G.; SOUTHEY, F.; HOLTE, R. C.; WILKINSON, D. Software Testing by Active Learning for Commercial Games. In: Proceedings of the 20th National Conference on Artificial intelligence (AAAI). Pittsburgh, Pennsylvania: AAAI Press, 2005. p. 898-903. ISBN 1-57735-236-X. Citado nas páginas 74, 76, 77, 78 e 166.

YEH, T.; CHANG, T.-H.; MILLER, R. C. Sikuli: Using gui screenshots for search and automation. In: Proceedings of the 22Nd Annual ACM Symposium on User Interface Software and Technology (UIST '09). New York, NY, USA: ACM, 2009. p. 183-192. Citado na página 109.

Advances in automated model-based system testing of software applications with a $\{\mathrm{GUI}\}$ frontend. In: ZELKOWITZ, M. V. (Ed.). Advances in Computers. [S.1.]: Elsevier, 2010, (Advances in Computers, v. 80). p. 121-162. Citado na página 32.

ZHU, H. A formal analysis of the subsume between software test adequacy criteria. IEEE Transactions on Software Engineering, v. 22, n. 4, p. 248-255, 1996. Citado na página 47.

ZOFKA, M. R.; KLEMM, S.; KUHNT F. SCHAMM, T.; ZOLLNER, J. M. Testing and validating high level components for automated driving: Simulation framework for traffic scenarios. In: Proceedings of the IV Intelligent Vehicles Symposium. [S.1.]: IEE, 2008. p. 144-150. Citado na página 34. 
APÊNDICE

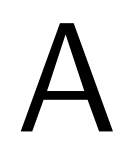

GUIA PARA ESPECIFICAÇÃO DE REQUISITOS DE APLICAÇÕES DE RV 


\section{<Nome da aplicação>}

\section{Especificação de Requisitos}

Data:<dia Mês, ano>

Versão: <Version XX.YY>

Responsável:<Identificação>

$<$ CIDADE $>$, <ESTADO > 


\section{Histórico de revisões}

\begin{tabular}{|c|c|c|c|}
\hline $\begin{array}{c}\text { Versão } \\
\text { (XX.YY) }\end{array}$ & $\begin{array}{c}\text { Data } \\
\text { (DD/MMM/YYYY) }\end{array}$ & Autor & Descrição \\
\hline & & & \\
\hline & & & \\
\hline & & & \\
\hline & & & \\
\hline
\end{tabular}




\section{Índice}

1. DESCRIÇÃO GERAL........................................................... 4

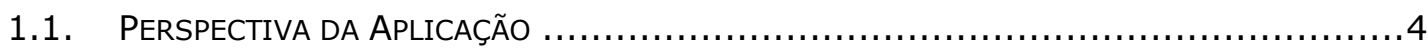

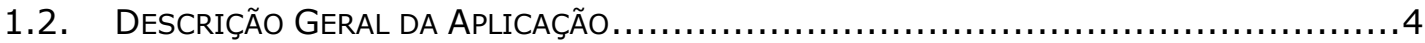

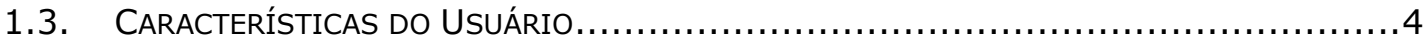

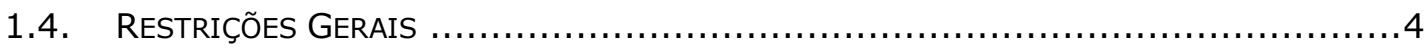

2. DEFINIÇÃO DAS PROPRIEDADES DOS OBJETOS E DO AMBIENTE

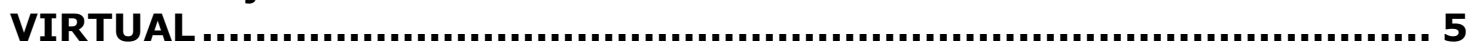

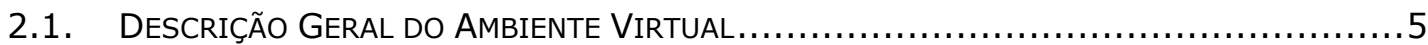

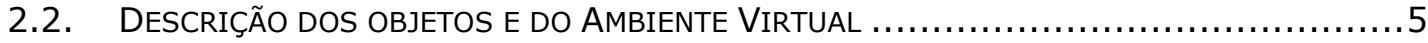

2.3. DESCRIÇÃO DAS AÇÕES QUE OCORREM NO AMBIENTE VIRTUAL............................ 5

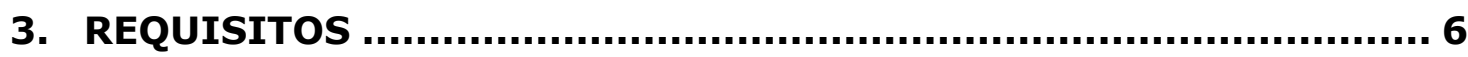

3.1. Requisitos SObre A DescriçÃo do Ambiente Virtual (VED) ......................

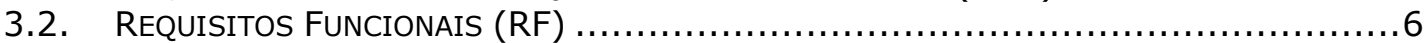

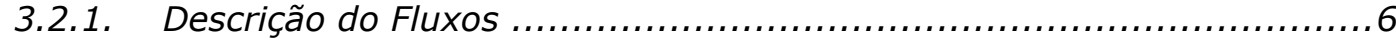

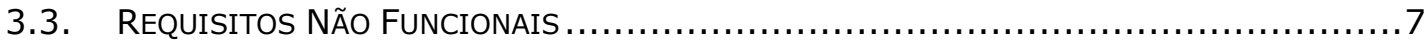




\section{Descrição Geral}

\subsection{Perspectiva da Aplicação}

Descreve-se aqui, os problemas enfrentados atualmente, qual a necessidade de implementar a aplicação e qual o público alvo do sistema.

\subsection{Descrição Geral da Aplicação}

Identificam-se aqui as principais funções que o produto desempenhará, descrevendo de forma sintética o objetivo de cada uma.

\subsection{Características do Usuário}

Descrevem-se aqui as principais características dos grupos de usuários, frequência de uso, nível de instrução e grau de conhecimento e/ou experiência do usuário com a tecnologia de Realidade Virtual (RV).

\subsection{Restrições Gerais}

Descrevem-se aqui aspectos técnicos e gerenciais que possam limitar as opções dos desenvolvedores, tais como restrições legais.

\begin{tabular}{|l|l|}
\hline ID & Descrição \\
\hline [REST01] & \\
\hline [REST02] & \\
\hline
\end{tabular}




\section{Definição das Propriedades dos objetos e do Ambiente Virtual}

\subsection{Descrição Geral do Ambiente Virtual}

Identificam-se aqui as principais características em relação ao Ambiente Virtual (AV) como a quantidade de cenas, se o AV é do tipo imersivo ou não-imersivo bem como os dispositivos a serem utilizados (convencionais ou não-convencionais).

2.2. Descrição dos objetos e do Ambiente Virtual

Identificam-se aqui os objetos e suas propriedades como geometria, aparência; localização dos objetos na cena e a aparência do AV.

2.3. Descrição das ações que ocorrem no Ambiente Virtual

Identificam-se aqui as principais transformações e comportamentos dos objetos. 


\subsection{Requisitos sobre a Descrição do Ambiente Virtual (VED)}

São descritos os requisitos que constituem o VED. Nessa descrição estão inclusas as características do AV, identificação dos objetos presentes na cena, geometria, aparência e localização dos objetos na cena.

\begin{tabular}{|l|l|l|}
\hline ID & Requisito & Descrição \\
\hline [VED01] & & \\
& & \\
\hline [VED02] & & \\
& & \\
\hline
\end{tabular}

\subsection{Requisitos Funcionais (RF)}

São descritos os requisitos funcionais do sistema a ser implementado. Esses requisitos referem-se às descrições das interações (IND) que estão relacionados à interação do usuário, as transformações e ao comportamento dos objetos.

\begin{tabular}{|l|l|l|l|}
\hline ID & Requisito & Descrição & Cena \\
\hline$[$ RF01] & & & \\
\hline$[$ RF02] & & & \\
\hline & & & \\
\hline & & & \\
\hline & & & \\
\hline & & & \\
\hline
\end{tabular}

\subsubsection{Descrição do Fluxos}

- Descrição dos requisitos no fluxo principal na forma de uma sequência de passo; 
- Descrição dos fluxos alternativos usando as estruturas de controle (if, else, while, for, case)

\subsection{Requisitos Não Funcionais}

Descreve-se aqui os requisitos não-funcionais do sistema. Esses requisitos referemse às descrições das interações (IND) que estão relacionadas às restrições relacionadas à resposta do sistema aos comandos do usuário e à renderização de imagens.

\begin{tabular}{|l|l|}
\hline ID & Descrição \\
\hline$[$ RNF01] & \\
\hline$[$ RNF02] & \\
\hline
\end{tabular}


APÊNDICE

B

(1)

\section{MAPEAMENTO SISTEMÁTICO}

Neste Apêndice é detalhado o protocolo do MS apresentado no Capítulo 4.

Um MS, de forma mais abrangente, consiste em uma forma de avaliar e interpretar todas as pesquisas disponíveis, referentes a uma determinada questão de pesquisa, tema, área ou fenômeno de interesse. O MS tem como objetivo apresentar uma avaliação justa de um tema de pesquisa, usando uma metodologia confiável e rigorosa (KITCHENHAM et al., 2010; PETERSEN; VAKKALANKA; KUZNIARZ, 2015). Portanto, de acordo com Kitchenham et al. (2010), um MS implica na forma mais adequada para se identificar, avaliar e interpretar, de uma forma geral, evidências de uma área de pesquisa para um determinado tema. Além do MS, outra técnica denominada de Revisão Sistemática (RS) (do inglês, Systematic Literature Review - SLR) também tem sido bastante utilizada pelos pesquisadores com a finalidade de sintetizar evidências.

Portanto, um MS fornece subsídios para que novas atividades de pesquisa acerca de um determinado tema sejam explorada O MS foi conduzido de acordo com o processo proposto por Kitchenham et al. (2010), que é composto por três fases: Planejamento, Execução e Análise de Resultados (Figura 35).

Figura 35 - Fases do MS

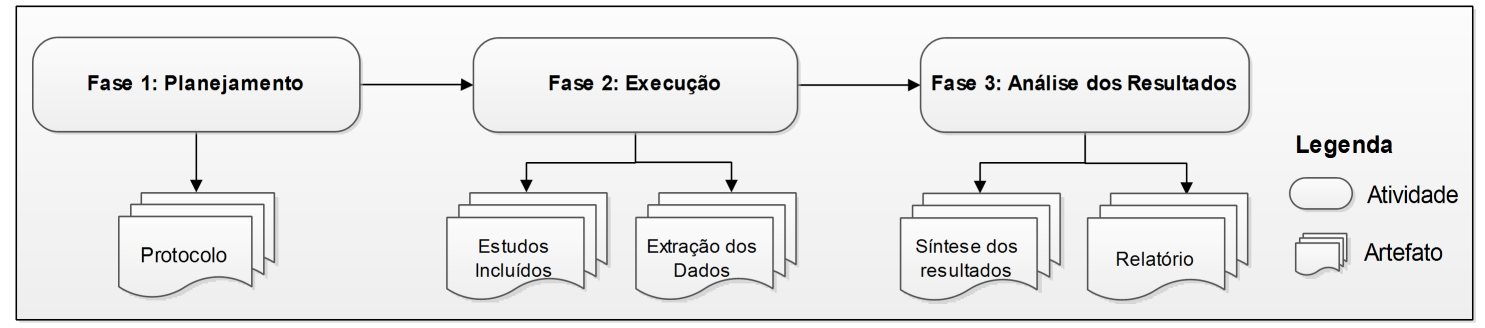

Fonte: Elaborada pelo autor.

$\mathrm{Na}$ fase de planejamento a principal tarefa a ser realizada é a concepção de um protocolo 
detalhado que descreva o processo e os métodos que serão aplicados no MS (PETERSEN; VAKKALANKA; KUZNIARZ, 2015). O protocolo consiste em determinar os dados iniciais que guiarão todo o MS, como os objetivos, as questões de pesquisa, as bases de dados consultadas, as palavras-chaves para busca, os critérios de inclusão e exclusão, extração e síntese dos dados dos estudos.

Durante a fase de ехесис̧ão, as buscas nas bases de dados são realizadas utilizando as palavras-chaves pré-definidas. Em seguida, os estudos são selecionados de acordo com os critérios de inclusão e exclusão definidos na fase de planejamento. O resultado de cada busca é registrado em um formulário, no qual são armazenadas a data de busca, a fonte, a palavra-chave, o título, o ano, o tipo de publicação e o(s) autor(es) de cada estudo selecionado.

A fase de análise dos resultados inicia com a organização dos estudos incluídos. Nessa fase, cada estudo é lido e em um formulário de extração de dados as informações relevantes devem ser registradas pelos pesquisadores. Após a extração dos dados são realizadas a síntese e a análise dos resultados e uma conclusão sobre a pesquisa realizada.

\section{B.1 Fase 1: Planejamento}

Nesta fase, o protocolo é um artefato fundamental no MS que descreve o processo e os métodos que serão adotados. Nesse protocolo são especificadas as questões de pesquisa (QPs), as bases de dados consultadas, as strings de busca, os critérios de inclusão e exclusão, bem como a forma que será realizada a extração dos dados.

\section{B.1.1 Questões de Pesquisa}

A questão de pesquisa deve representar o propósito do MS. Segundo Kitchenham et al. (2010), as QPs devem ser estruturadas e analisadas utilizando a técnica Population, Intervention, Comparison e Outcomes (PICO). Neste MS foram considerados os seguintes termos:

- População: representa uma área de pesquisa específica. No contexto desse MS, a população é ER para $\mathrm{QP}_{1}$, projeto de software para $\mathrm{QP}_{2}$ e teste de software para $\mathrm{QP}_{3}$;

- Intervenção: está relacionada à metodologia de software, ferramenta, tecnologia ou procedimento. No contexto desse MS, a intervenção é metodologia, método, ferramenta ou modelo para $\mathrm{QP}_{1}$ e $\mathrm{QP}_{2}$ e, os tipos de teste de software aplicados no domínio de $\mathrm{RV}$ para para $\mathrm{QP}_{3}$;

- Comparação: não é aplicada no contexto desse MS;

- Resultados: espera-se como resultados uma visão dos estudos primários que descrevem o uso de metodologia, método, ferramenta ou modelo de ER e projeto de software e, os tipos de teste de software realizados no domínio de RV. 
Portanto, para identificar as principais evidências disponíveis na literatura referentes à utilização das áreas de ER, projeto de software e teste de software para sistemas de RV e contribuições de RV para essas áreas foram definidas três questões de pesquisa, com duas sub-questões cada.

- $\mathbf{Q P} \mathbf{P}_{1}$ :Quais são as evidências existentes da relação entre ER e RV?

- QP1 1 : Quais são as evidências existentes referentes à utilização de técnicas de ER para sistemas de RV?

- QP1 2 : Quais são as evidências existentes referentes às contribuições da utilização de RV para o processo de ER?

- $\mathbf{Q P} \mathbf{P}_{2}$ :Quais são as evidências existentes da relação entre projeto de software e RV?

- QP2 1 : Quais são as evidências existentes referentes à utilização de estratégias de projeto de software para sistemas de RV?

- QP2 2 : Quais são as evidências existentes referentes às contribuições da utilização de RV para projeto de software?

- $\mathbf{Q P}_{3}$ : Quais são as evidências existentes da relação entre Teste de Software e RV?

- QP3 1 : Quais são as evidências existentes referentes à utilização de teste de software para sistemas de RV?

- $\mathbf{Q P 3}_{2}$ : Quais são as evidências existentes referentes às contribuições da utilização de RV para Teste de Software?

\section{B.1.2 Estratégia de Busca}

Para estabelecer a estratégia de busca dos estudos foram definidas a string e as fontes de busca a serem utilizadas, pois as evidências materializam-se em estudos publicados e recuperados de algumas fontes de busca selecionadas. Essa recuperação se dá por meio de uma string de busca que sumariza os temas a serem pesquisados.

A string de busca foi definida baseada em quatro fases: ( $i$ ) identificação dos principais termos considerando as questões de pesquisa; (ii) identificação dos sinônimos baseados em estudos relevantes; (iii) utilização do operador booleano "OR" entre os sinônimos identificados e; (iv) utilização do operador booleano "AND” para conectar os principais termos (Figura 36). Diversas combinações dos sinônimos identificados foram testados e uma avaliação preliminar dos resultados apoiou a definição da string.

Após a criação da string, o próximo passo consiste em definir em quais fontes de busca a string criada deve ser aplicada. A seleção das fontes foi realizada em conjunto com um 
Figura 36 - Strings de busca definidas

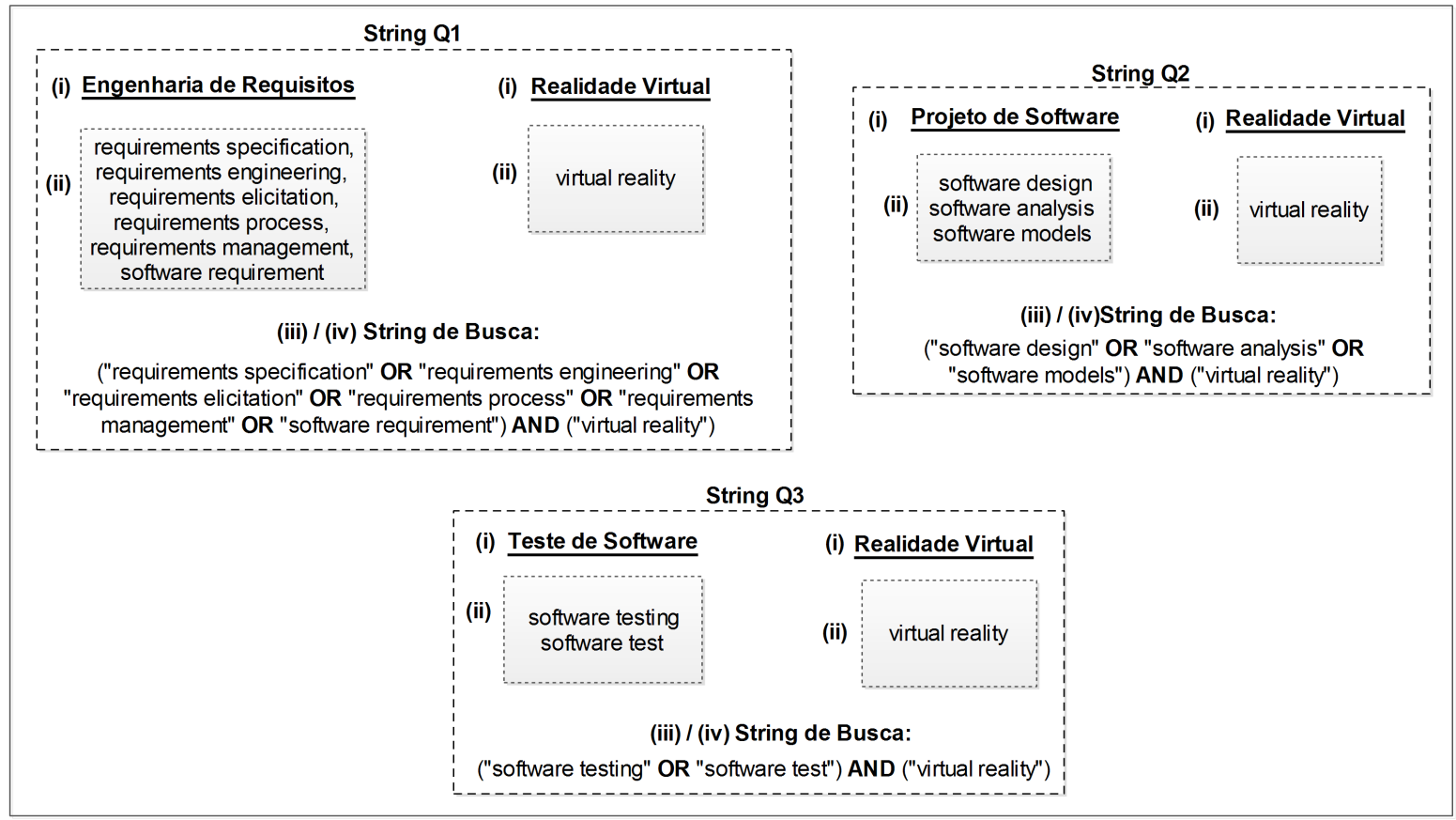

Fonte: Elaborada pelo autor.

especialista da área, a fim de garantir uma maior cobertura de estudos relevantes. Para assegurar a inclusão de todos os estudos relevantes foram realizadas pesquisas automática, manual e por meio de referências. Na Tabela 21 são apresentadas as fontes de buscas automáticas utilizadas nesta RS com base na seleção realizada por Brereton et al. (2007).

Tabela 21 - Fontes de busca automática

\begin{tabular}{c|c}
\hline Fontes de Busca & Endereço Eletrônico \\
\hline \hline IEEE Xplore & www.ieeexplore.com.br \\
ACM Digital Library & www.portal.acm.org \\
Compendex & www.engineeringvillage.com \\
Science Direct & www.sciencedirect.com \\
Scopus & www.scopus.com \\
Springer & www.springerlink.com \\
\hline
\end{tabular}

Fonte: Elaborada pelo autor.

A busca manual foi realizada em cinco eventos relevantes das áreas de ER, projeto de software, teste de software e RV, sendo analisado o título de todos os artigos publicados e em caso de dúvidas, foi realizada a leitura do resumo, cujos artigos não foram incluídos nas bases mencionadas. Outros eventos importantes da área já se encontram indexados nas fontes de busca automáticas anteriormente citadas. Na Tabela 22 são apresentadas as fontes de busca manual.

A lista de controle foi definida juntamente com especialista das áreas de ES e RV, relatando alguns dos principais trabalhos já conhecidos que devem constar na lista de estudos 
Tabela 22 - Fontes de busca manual

\begin{tabular}{c}
\hline Eventos \\
\hline \hline Workshop de Engenharia de Requisitos - WER \\
Australian Workshop on Requirements Engineering - AWRE \\
Workshop on Systematic and Automated Software Testing - SAST \\
Symposium on Virtual and Augmented Reality - SVR \\
Workshop de Realidade Virtual e Aumentada - WRVA \\
\hline
\end{tabular}

Fonte: Elaborada pelo autor.

selecionados. Essa lista é exibido no Quadro 2.

Quadro 2 - Lista de Controle

Bezerra, A.; Delamaro, M. E.; Nunes, F. L. S. Definition of test criteria
based on the Scene Graph for VR applications. Proceedings of the XIII
Symposium on Virtual Reality (SRV), Uberlândia, MG, Brasil: IEEE
Computer Society, 2011, p. 56-65. Bezerra11
Kirner, T. G.; Martins, V. F. Contribution to the Requirements Engi-
neering of Virtual Environments. Proceedings of the 10th Workshop
de Engenharia de Requisitos (WER), Toronto, Canada, 2007, p. 1-11.
Kirner07
Kirner, T. G.; Martins, V. F. A Model of Software Development Process
for Virtual Environments: Definition and a Case Study. Proceedings of
the Symposium on Application - Specific Systems and Software Engi-
neering and Technology (ASSET), Richardson, Texas: IEEE Computer
Society, 1999, p. 155-161.
Damasceno, E.; Oliveira, D. C. Análise swot das metodologias de sis-
temas de realidade virtual. Proceedings of the Workshop de Realidade
Virtual e Aumentada (WRVA), Santos, SP, Brasil, 2009, p. 1-12.

Fonte: Elaborada pelo autor.

\section{B.1.3 Critério de Seleção dos Estudos}

Os critérios de inclusão e exclusão apoiam a seleção de estudos relevantes e que apropriadamente auxiliam no esclarecimento das questões de pesquisa propostas. A inclusão de um estudo foi determinada pela relevância, análise do título, resumo, introdução e conclusão. Para cada questão de pesquisa foram identificados critérios de inclusão diferentes e os mesmos critérios de exclusão se mantiveram para todas as questões. No contexto dessa RS, os estudos foram examinados de acordo com os seguintes critérios:

\section{- Critérios de Inclusão:}

- $\mathrm{CI}_{1}$ : estudos primários que apresentam a utilização de técnicas de ER e a utilização de um tipo de teste de software para o domínio de RV; 
Tabela 23 - Critérios de qualidade

\begin{tabular}{c|l}
\hline ID & Critérios de Qualidade \\
\hline \hline $\mathrm{CQ}_{1}$ & A proposta do estudo foi descrita de forma clara e adequada? \\
$\mathrm{CQ}_{2}$ & Existe uma descrição clara dos métodos utilizados? \\
$\mathrm{CQ}_{3}$ & No estudo fica claro o ambiente virtual utilizado? \\
$\mathrm{CQ}_{4}$ & A proposta do estudo foi avaliada/validada? \\
$\mathrm{CQ}_{5}$ & Os resultados foram reportados de forma clara? \\
\hline
\end{tabular}

Fonte: Elaborada pelo autor.

- $\mathrm{CI}_{2}$ : estudos primários que apresentam evidências das contribuições de RV para o processo de ER e a atividade teste de software.

\section{- Critérios de Exclusão:}

- $\mathrm{CE}_{1}$ : estudos primários que mencionam as técnicas de ER e o tipo de teste de software apenas no abstract;

- $\mathrm{CE}_{2}$ : estudos primários introdutórios para livros;

- $\mathrm{CE}_{3}$ : estudos primários com texto e conteúdo incompletos;

- $\mathrm{CE}_{4}$ : Estudo primário que não sejam full paper ou short paper (pôsteres, tutorais, relatório técnicos, teses e dissertações).

- $\mathrm{CE}_{5}$ : estudos primários que não estejam escritos em inglês ou português.

\section{B.1.4 Avaliação da Qualidade}

Com a finalidade de analisar a qualidade dos estudos incluídos foi desenvolvida uma lista com cinco critérios de qualidade que foi aplicada em todos os estudos incluídos. A lista com os critérios foi adaptada a partir dos critérios de qualidade genéricos criados por Kitchenham et al. (2010).

Para cada critério da lista a seguinte escala foi aplicada: $\operatorname{Sim}(S)=1$ ponto; Não $(N)=0$ ponto; Parcialmente $(\mathrm{P})=0.5$ ponto. $\mathrm{O}$ índice da qualidade final foi calculado pelo somatório das pontuações dos critérios da lista variando entre: 0-1.0 (muito ruim); 1.5-2.0 (ruim); 2.5-3.0 (bom); 3.5-4.0 (muito bom) e 4.5-5.0 (excelente). Vale ressaltar que avaliação da qualidade não foi utilizada como critério de exclusão dos estudos. Na Tabela 23 são apresentados os Critérios de Qualidade (CQ) aplicados em todas as sub-questões.

\section{B.1.5 Extração e Síntese dos Resultados}

A extração e síntese dos resultados foram realizadas inicialmente por meio da leitura do título e resumo, seguida pela introdução e conclusão e por fim leitura na íntegra dos estudos. 
Para apoiar a extração e o registro dos dados e posterior análise, detalhes de todos os estudos foram armazenados usando o software JabRef ${ }^{1}$, gerenciador open source de referência bibliográfica. Na JabRef foi utilizado o recurso disponível de "exportação". Esse recurso foi utilizado em diversas bases de dados eletrônicas para exportar automaticamente os detalhes referentes a cada estudo primário selecionado e excluído, tais como: título, autor(es), resumo, palavras-chave, ano de publicação, país da instituição e bases de dados.

Conforme os dados dos estudos foram extraídos e sintetizados, foi realizada uma análise detalhada dos estudos, classificando-os em quatro categorias: $\mathrm{C}_{1}-$ Metodologia; $\mathrm{C}_{2}-\mathrm{Ferramentas}$; $\mathrm{C}_{3}$-Educação e; $\mathrm{C}_{4}$-Contribuições para ES ou RV. Cada estudo primário pode estar relacionado a uma ou mais categorias. A seguir é realizada uma breve descrição de cada categoria:

- $\mathbf{C}_{1}$-Metodologia: compreende métodos, técnicas, abordagens, metodologias e modelos;

- $\mathbf{C}_{2}$-Ferramentas: aborda protótipos, frameworks, sistemas e ferramentas desenvolvidas;

- $\mathbf{C}_{3}$-Educação: trata de abordagens e jogos voltados para aprendizagem de ER, projeto de software e teste de software utilizando o domínio de RV e vice-versa; e

- $\mathbf{C}_{4}$-Contribuições para ES ou RV: trata de aplicações e contribuições de ER, projeto de software e teste de software para sistemas de RV e vice-versa.

As categorias foram definidas baseadas nos objetivos de cada estudo incluído para facilitar a compreensão dos resultados. Na Figura 37 é ilustrada a criação da categoria " $\mathrm{C}_{2}-$ Ferramentas", por exemplo, sendo associados sinônimos baseados nos objetivos identificados nos estudos.

Figura 37 - Criação das categorias

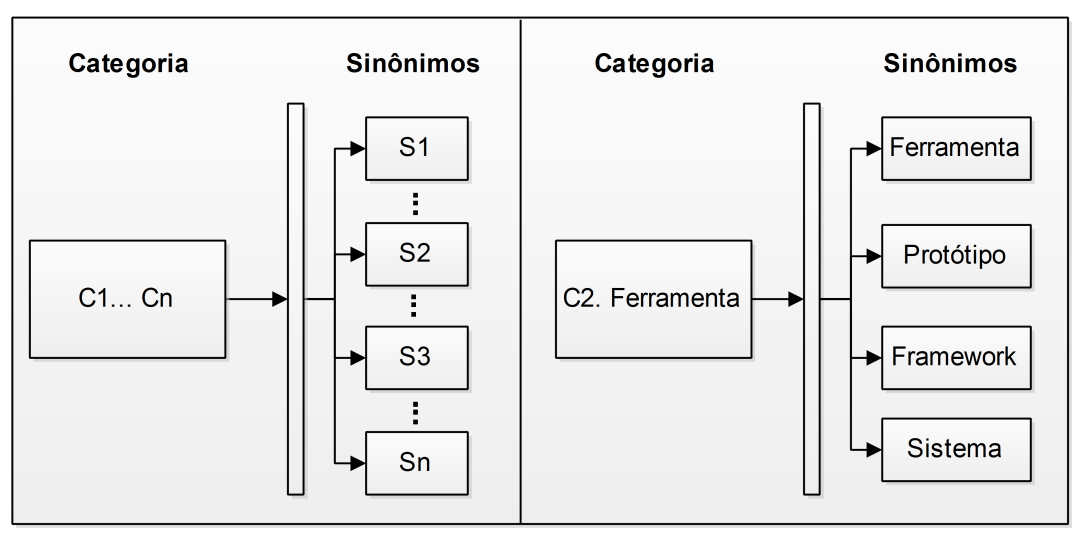

Fonte: Elaborada pelo autor.

Para auxiliar a extração de dados a serem coletados para cada estudo primário, um formulário foi criado abordando os seguintes aspectos: $(i)$ dados relevantes sobre ER e teste 
Tabela 24 - Anos consultados nas fontes de busca manual

\begin{tabular}{c|c|c}
\hline Questões & Fonte de Busca Manual & Anos Consultados \\
\hline \hline $\mathrm{QP}_{1}$ & WER & 1998 a 2012 \\
& AWRE & 2003,2006 e 2009 \\
\hline $\mathrm{QP}_{2}$ & SAST & 2007 a 2016 \\
\hline $\mathrm{QP}_{1}, \mathrm{QP}_{2} \mathrm{e}_{3}$ & SVR & $2001,2002,2004$ e 2006 a 2016 \\
& WRVA & 2006 a 2012,2013 a 2016 \\
\hline
\end{tabular}

de software, (ii) a data da extração do dado, (iii) o título do estudo primário, (iv) os autores do estudo primário, (v) o veículo de publicação e (vi) um resumo destacando as principais contribuições do estudo primário para posteriormente realizar a classificação. Durante o processo de extração, informações sobre cada estudo primário foram independentemente coletadas por todos os pesquisados que participaram do MS.

\section{B.2 Fase 2: Condução}

Inicialmente a string de busca (Figura 36) foi aplicada nas fontes de busca automática (Tabela 21) com o objetivo de identificar os estudos relevantes. Para complementar os estudos identificados na busca automática foi realizada a busca manual (Tabela 22) de acordo com o planejamento apresentado na Seção B.1.

A busca manual foi realizada nas fontes apresentadas na Tabela 22. No entanto, para algumas conferências somente em determinados anos os estudos estavam disponíveis. Na Tabela 24 são ilustrados os anos consultados de acordo com as suas respectivas fontes e questão de pesquisa.

O processo de seleção dos estudos são detalhados e ilustrados de acordo com cada questão de pesquisa. É importante destacar que a primeira execução desse MS foi realizada em 2013; posteriormente foi conduzido novamente em novembro de 2016 com o objetivo de atualizá-lo. No total foram incluídos 32 estudos, sendo 25 estudos por meio da busca automática, 5 estudos por meio da busca manual e 2 estudos por meio de referência.

Na Figura 38 é apresentado o processo de seleção dos estudos primários da questão $\mathrm{QP}_{1}$. Para responder a $\mathrm{QP}_{1}$, no passo 1 , foram identificados 615 estudos na IEEE, 81 na $A C M, 466$ na Compendex, 67 na ScienceDirect, 338 na Scopus e 103 na SpringerLink. A partir dos 1670 estudos retornados das fontes de busca, os estudos repetidos foram identificados e excluídos, os títulos e resumos dos estudos restantes (894) foram lidos e neles aplicados os critérios de inclusão e exclusão (Passo 2). No passo 3 foram lidas a introdução, a conclusão e aplicados os critérios de inclusão e exclusão nos 85 estudos que passaram pelo filtro do passo anterior, restando 9 estudos incluídos. No passo 4, dos 9 estudos lidos na íntegra, 8 estudos foram incluídos. No passo 5 foram selecionados 4 estudos por meio da busca manual. Por fim, no passo 6 nenhum estudo foi incluído por meio de referências, totalizando 12 estudos previamente selecionados. 
Figura 38 - Processo de seleção dos estudos primários da $\mathrm{QP}_{1}$

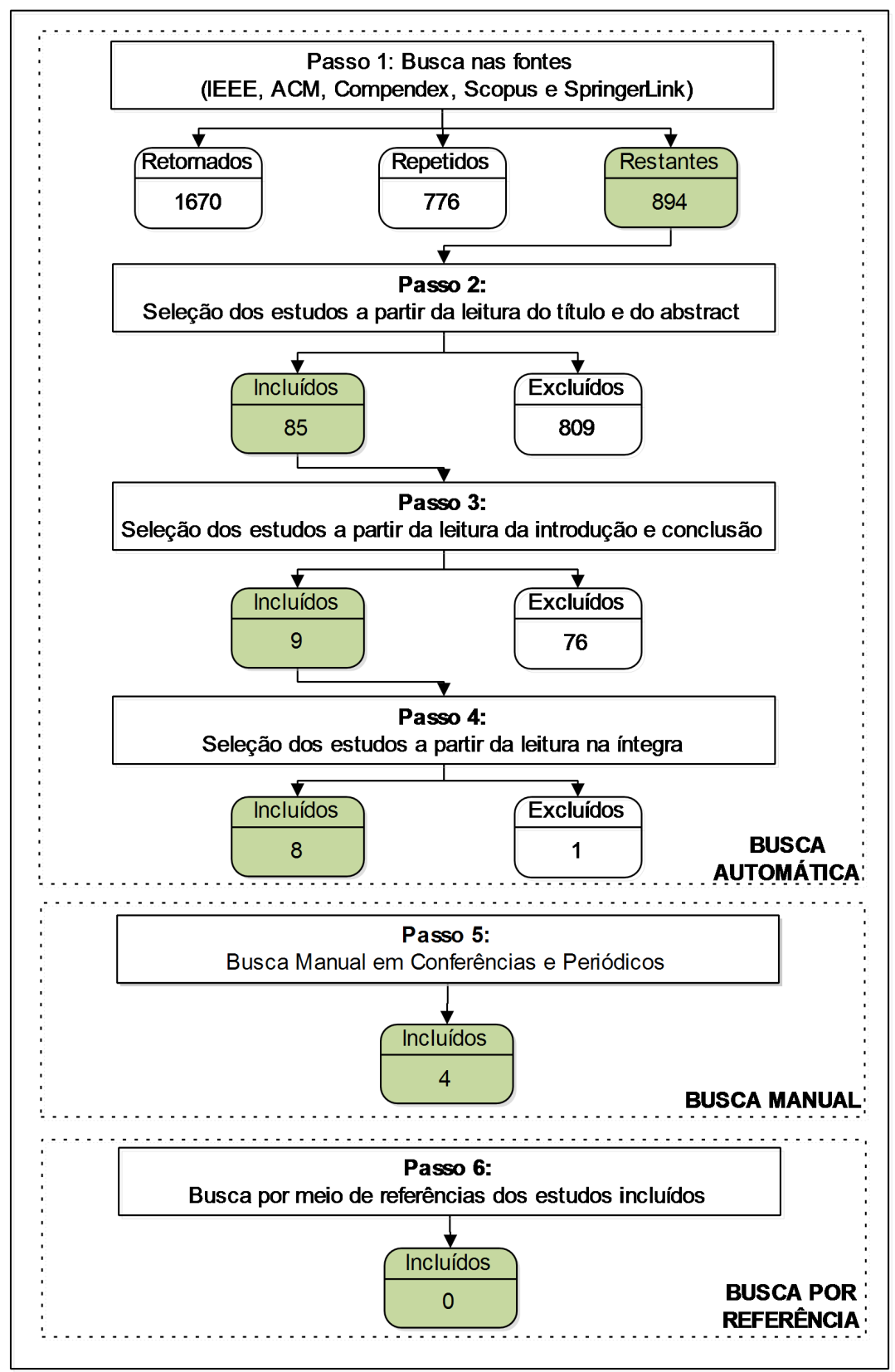

Fonte: Elaborada pelo autor.

Os passos do processo de seleção relacionados à $\mathrm{QP}_{2}$ são apresentados na Figura 39. No passo 1, foram identificados 181 estudos na IEEE, 158 na ACM, 264 na Compendex, 90 na ScienceDirect, 79 na Scopus e 193 na SpringerLink. A partir dos 965 estudos retornados das fontes de busca, os estudos repetidos foram identificados e excluídos, os títulos e resumos dos estudos restantes (889) foram lidos e neles aplicados os critérios de inclusão e exclusão (Passo 2). No passo 3 foram lidas a introdução, a conclusão e aplicados os critérios de inclusão e exclusão nos 71 estudos que passaram pelo filtro do passo anterior, restando 22 estudos incluídos. No passo 4, dos 22 estudos lidos na íntegra, somente 6 estudos foram incluídos. No passo 5 
Figura 39 - Processo de seleção dos estudos primários da $\mathrm{QP}_{2}$

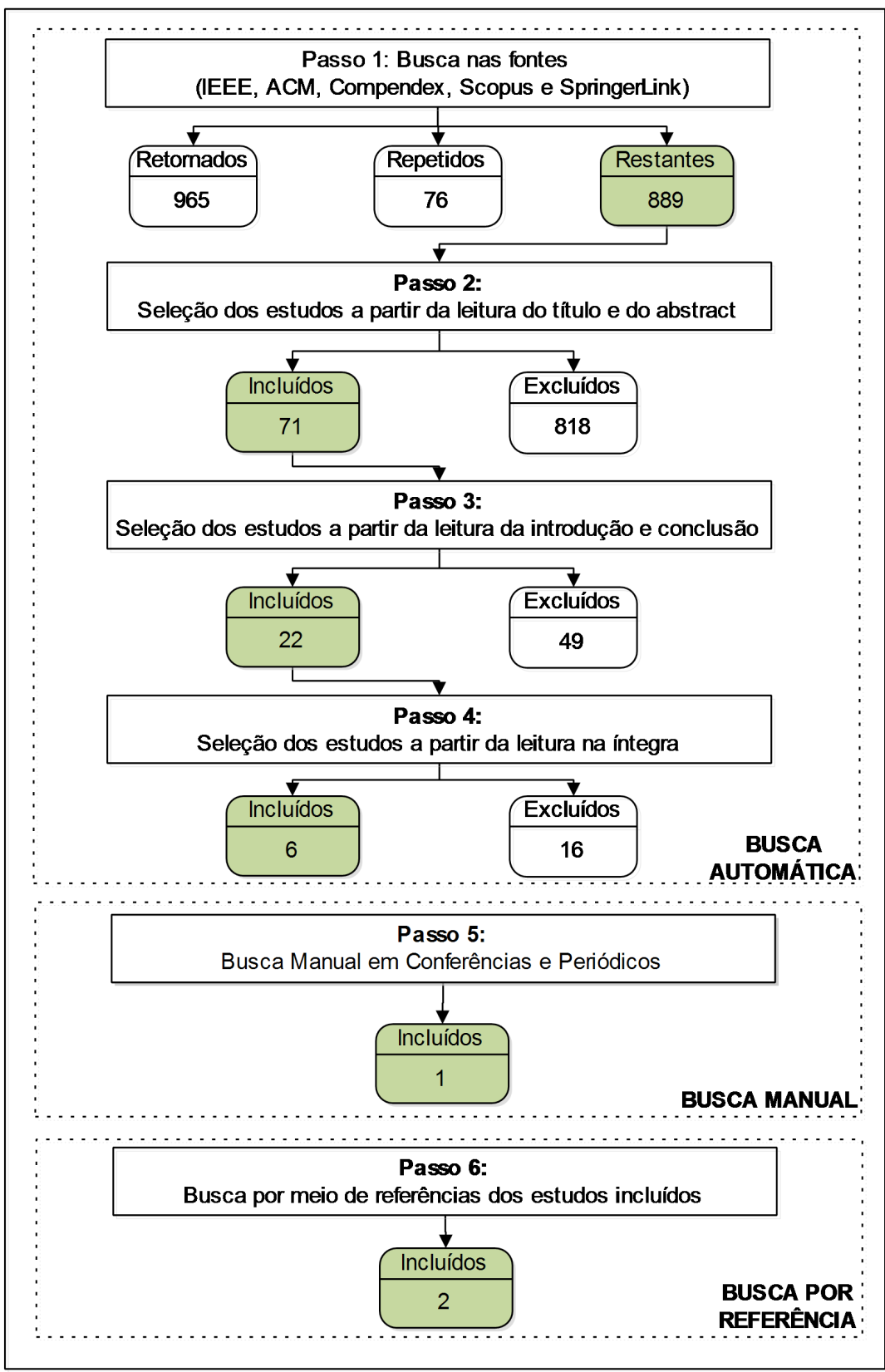

Fonte: Elaborada pelo autor.

foi selecionado 1 estudo por meio da busca manual. Por fim, no passo 6 foram selecionados 2 estudos por meio de referências dos 7 estudos selecionados nos passos anteriores, totalizando 9 estudos.

Para finalizar, na Figura 40 são apresentados os passos do processo de seleção relacionados a $\mathrm{QP}_{3}$. No passo 1, foram identificados 146 estudos na IEEE, 50 na ACM, 121 na Compendex, 32 na ScienceDirect, 123 na Scopuse 74 na SpringerLink. A partir dos 546 estudos retornados das fontes de busca, os estudos repetidos foram identificados e excluídos, os títulos e resumos dos estudos restantes (425) foram lidos e neles aplicados os critérios de inclusão e exclusão 
(Passo 2). No passo 3 foram lidas a introdução, a conclusão e aplicados os critérios de inclusão e exclusão nos 29 estudos que passaram pelo filtro do passo anterior, restando 12 estudos incluídos. No passo 4, dos 15 estudos lidos na íntegra, 11 estudos foram incluídos. No passo 5 nenhum estudo foi incluído por meio da busca manual. Por fim, no passo 6 nenhum estudo foi incluído por meio de referências, totalizando 11 estudos.

Figura 40 - Processo de seleção dos estudos da questão $\mathrm{QP}_{3}$

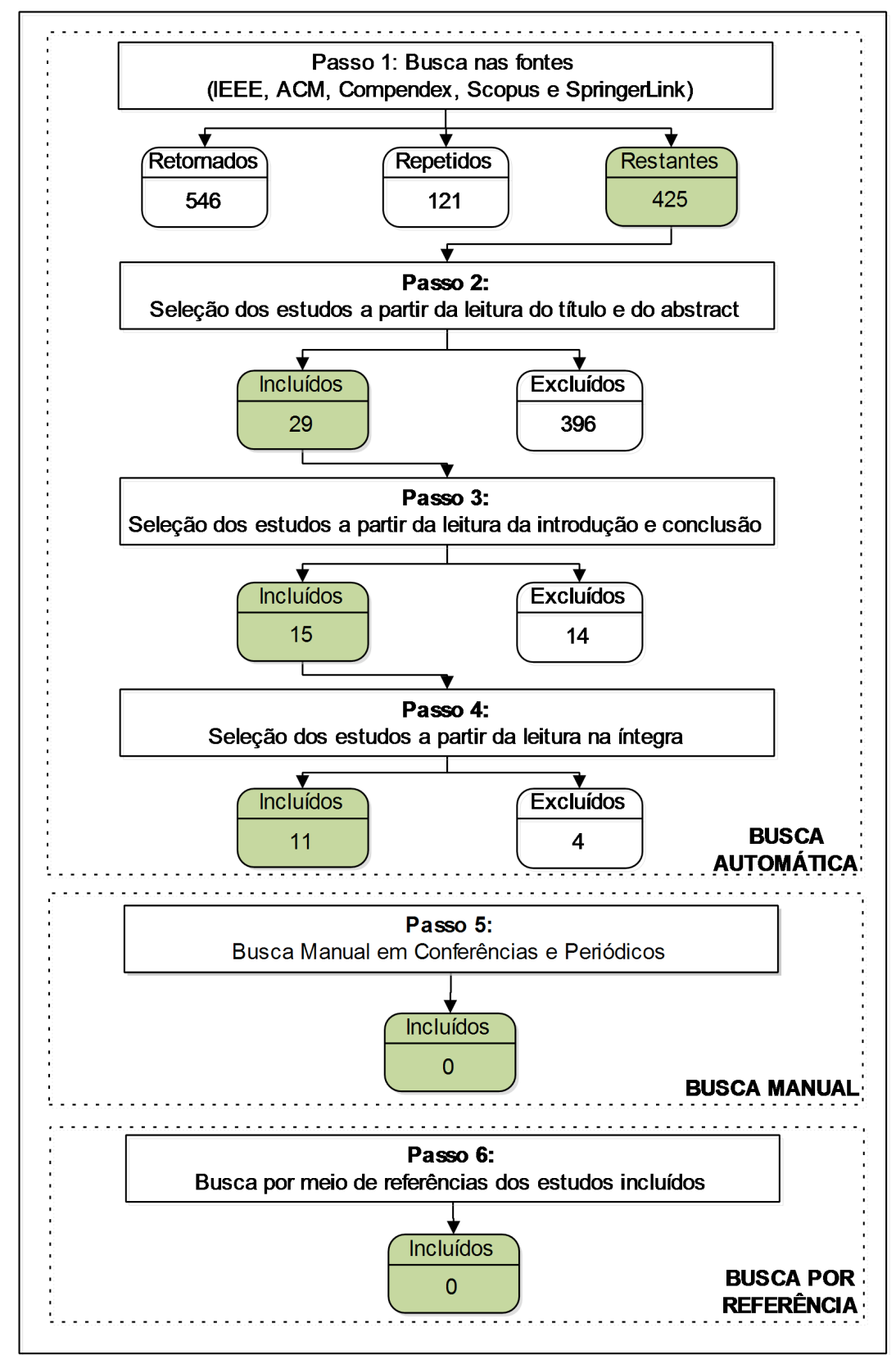

Fonte: Elaborada pelo autor. 


\section{B.3 Fase 3: Síntese e Análise dos Resultados}

Os 32 estudos discutem a utilização de ER, projeto de software e teste de Software para sistemas de RV e a utilização de tecnologias de RV para essas áreas. Antes de apresentar os resultados e a análise de cada questão de pesquisa uma breve descrição das características gerais dos estudos é realizada. Na Tabela 25 são apresentadas a classificação dos estudos de acordo com as suas categorias, a validação dos estudos (se os autores conduziram alguma forma de avaliação nos seus trabalhos) e a forma como foram selecionados.

Tabela 25 - Visão geral dos estudos incluídos de acordo com as suas respectivas categorias

\begin{tabular}{|c|c|c|c|}
\hline \multicolumn{4}{|l|}{$\mathrm{QP}_{1}$} \\
\hline Categoria & Estudo & Validação & Seleção \\
\hline $\mathrm{C}_{1}$ & $\begin{array}{l}\text { (DAMASCENO; JR; LOPES, 2009) } \\
\text { (SUTCLIFFE; GAULT, 2004) } \\
\text { (WINTER; DESOVSKI; CUKIC, 2001) }\end{array}$ & $\begin{array}{l}\text { Sim } \\
\text { Sim } \\
\text { Sim }\end{array}$ & $\begin{array}{l}\text { Manual } \\
\text { Scopus } \\
\text { IEEE }\end{array}$ \\
\hline $\mathrm{C}_{2}$ & (POLLOCK, 1998) & Não & IEEE \\
\hline $\mathrm{C}_{3}$ & $\begin{array}{l}\text { (VEGA; FUKS; CARVALHO, 2009) } \\
\text { (CYBULSKI; PARKER; SEGRAVE, 2006) }\end{array}$ & $\begin{array}{l}\text { Não } \\
\text { Sim }\end{array}$ & $\begin{array}{c}\text { IEEE } \\
\text { Manual }\end{array}$ \\
\hline $\mathrm{C}_{4}$ & $\begin{array}{l}\text { (RUSSELL; CREIGHTON, 2011) } \\
\text { (DAMASCENO; OLIVEIRA, 2009) } \\
\text { (SALEM, 2008) } \\
\text { (KIRNER; MARTIN, 2007) }\end{array}$ & $\begin{array}{l}\text { Não } \\
\text { Não } \\
\text { Sim } \\
\text { Não }\end{array}$ & $\begin{array}{l}\text { Compendex } \\
\text { Manual } \\
\text { IEEE } \\
\text { Manual }\end{array}$ \\
\hline $\mathrm{C}_{1}$ e $\mathrm{C}_{2}$ & $\begin{array}{l}\text { (BAL; MANESH; HASHEMIPOUR, 2008) } \\
\text { (KIM et al., 1999) }\end{array}$ & $\begin{array}{l}\text { Sim } \\
\text { Não }\end{array}$ & $\begin{array}{l}\text { Compendex } \\
\text { ACM }\end{array}$ \\
\hline \multicolumn{4}{|l|}{$\mathrm{QP}_{2}$} \\
\hline Categoria & Estudo & Validação & Seleção \\
\hline $\mathrm{C}_{1}$ & $\begin{array}{l}\text { (BENNES; BAZZARO; SAGOT, 2012) } \\
\text { (TANRIVERDI; JACOB, 2001) }\end{array}$ & $\begin{array}{l}\text { Sim } \\
\text { Não }\end{array}$ & $\begin{array}{l}\mathrm{ACM} \\
\mathrm{ACM}\end{array}$ \\
\hline $\mathrm{C}_{2}$ & (MALETIC et al., 2001) & Sim & Referência \\
\hline $\mathrm{C}_{1}$ e $\mathrm{C}_{3}$ & $\begin{array}{l}\text { (JIMÉNEZ-DÍAZ; GóMEZ-ALBARRáN; } \\
\text { GONZáLEZ-CALERO, 2008) }\end{array}$ & Não & Compendex \\
\hline $\mathrm{C}_{1}$ e $\mathrm{C}_{4}$ & $\begin{array}{l}\text { (MATTIOLI et al., 2009) } \\
\text { (KIRNER; MARTIN, 1999) }\end{array}$ & $\begin{array}{l}\text { Não } \\
\text { Sim }\end{array}$ & $\begin{array}{l}\text { Manual } \\
\text { IEEE }\end{array}$ \\
\hline $\mathrm{C}_{2}$ e $\mathrm{C}_{3}$ & $\begin{array}{l}\text { (RODRIGUÉZ; SORIA; CAMPO, 2004) } \\
\text { (NEUBAUER; HARRIS, 2003) } \\
\text { (CALLAGHAN; HIRSCHMüLLER, 1998) }\end{array}$ & $\begin{array}{l}\text { Sim } \\
\text { Não } \\
\text { Não }\end{array}$ & $\begin{array}{l}\text { Compendex } \\
\text { ACM } \\
\text { Referência }\end{array}$ \\
\hline \multicolumn{4}{|l|}{$\mathrm{QP}_{3}$} \\
\hline Categoria & Estudo & Validação & Seleção \\
\hline $\mathrm{C}_{1}$ & $\begin{array}{l}\text { (KIM; KIM, 2011) } \\
\text { (FLORCZYK; WINIECKI, 2005) } \\
\text { (PATIL, 2015) }\end{array}$ & $\begin{array}{l}\text { Sim } \\
\text { Não } \\
\text { Não }\end{array}$ & $\begin{array}{l}\text { Compendex } \\
\text { Compendex } \\
\text { IEEE }\end{array}$ \\
\hline $\mathrm{C}_{2}$ & $\begin{array}{l}\text { (TORENS; EBRECHT, 2010) } \\
\text { (GUO; ZHOU; ZHU, 2003) } \\
\text { (KUUTTI et al., 2001) } \\
\text { (BIERBAUM; HARTLING; CRUZ-NEIRA, } \\
\text { 2003) }\end{array}$ & $\begin{array}{l}\text { Não } \\
\text { Não } \\
\text { Sim } \\
\text { Não }\end{array}$ & $\begin{array}{l}\text { IEEE } \\
\text { IEEE } \\
\text { IEEE } \\
\text { IEEE }\end{array}$ \\
\hline $\mathrm{C}_{3}$ & (XIAO et al., 2005) & Sim & Scopus \\
\hline $\mathrm{C}_{4}$ & (BEZERRA; DELAMARO; NUNES, 2011) & Sim & IEEE \\
\hline $\mathrm{C}_{1}$ e $\mathrm{C}_{2}$ & (CHEN et al., 2013) & Não & IEEE \\
\hline $\mathrm{C}_{2}$ e $\mathrm{C}_{3}$ & (RAMAKRISHNAN, 2000) & Sim & Scopus \\
\hline
\end{tabular}

Fonte: Elaborada pelo autor. 
Na Figura 41 é apresentado o resultado obtido ao final desse processo, isto é, a quantidade de estudos incluídos em cada base de acordo com as suas respectivas questões de pesquisa.

Figura 41 - Estudos incluídos por base utilizando busca automática

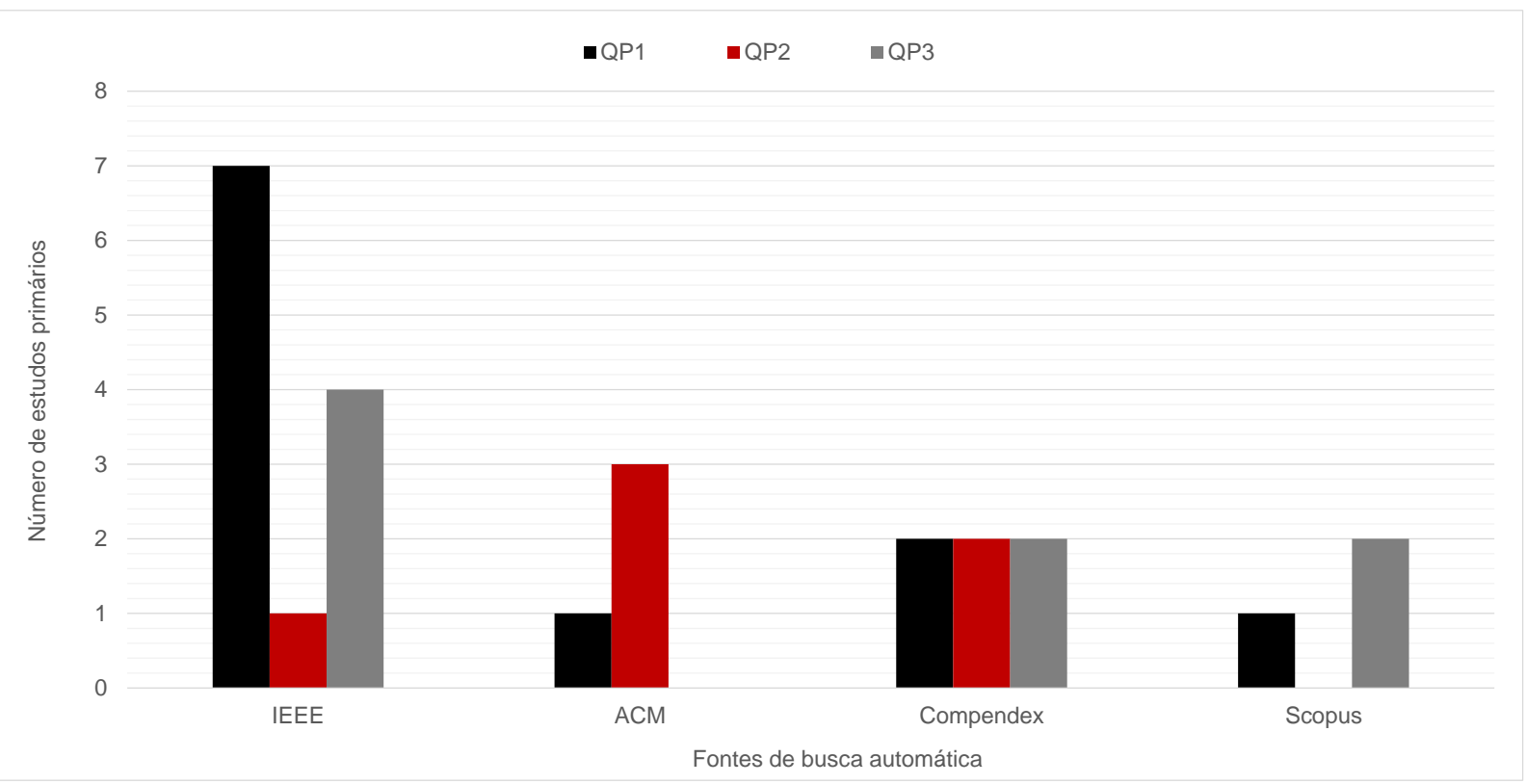

Fonte: Elaborada pelo autor.

A base de dados eletrônica IEEE obteve mais estudos selecionados, totalizando 12. Em seguida, foram selecionados seis estudos do Compendex, quatro estudos da $A C M$ e três estudos do Scopus. As demais bases de dados (Sciencee SpringerLink) não tiveram nenhum estudo incluído.

Com a busca manual realizada em cinco eventos, foram incluídos três estudos ((DAMASCENO; OLIVEIRA, 2009), (DAMASCENO; JR; LOPES, 2009) e (MATTIOLI et al., 2009)) do Workshop de Realidade Virtual e Aumentada (WRVA), um estudo ((KIRNER; MARTIN, 2007)) do Workshop de Engenharia de Requisitos (WER) e um estudo ((CYBULSKI; PARKER; SEGRAVE, 2006)) do Australian Workshop on Requirements Engineering (AWRE). É importante destacar que dois estudos ((MALETIC et al., 2001) e (CALLAGHAN; HIRSCHMüLLER, 1998)) foram incluídos por meio de referências.

Após efetuar as buscas e a análise, foi possível constatar que poucos estudos apresentam a relação entre ES e RV, ou seja, a utilização de ES para sistemas de RV (11 estudos) e as contribuições de RV para ES (21 estudos), conforme é ilustrado na Figura 42.

Os estudos são apresentados em vários tipos de publicação, como: conferências, periódicos, workshops e simpósios. Neste MS os estudos identificados foram organizados de acordo com os seus respectivos tipos de publicação. Na Figura 43 são apresentados os tipos de publicação identificados em cada questão de pesquisa. Em geral, considerando as três questões de pesquisa, o tipo de publicação mais comum foi em conferências com 50\% (16/32) e o menos comum foi 
Figura 42 - Relação entre as áreas de ES e RV

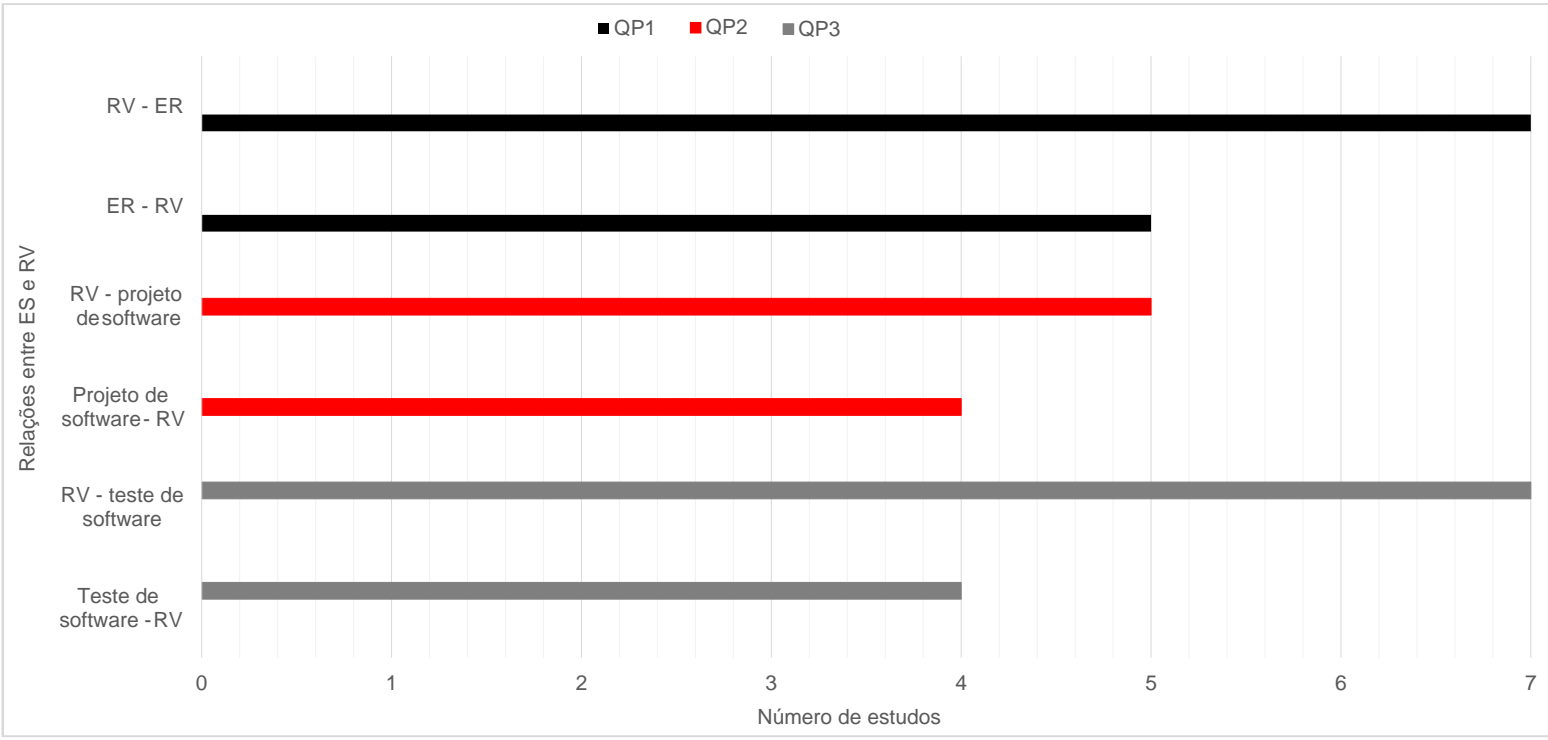

Fonte: Elaborada pelo autor.

em simpósio com 9,37\% (3/32).

Figura 43 - Tipos de publicação de acordo com cada QP

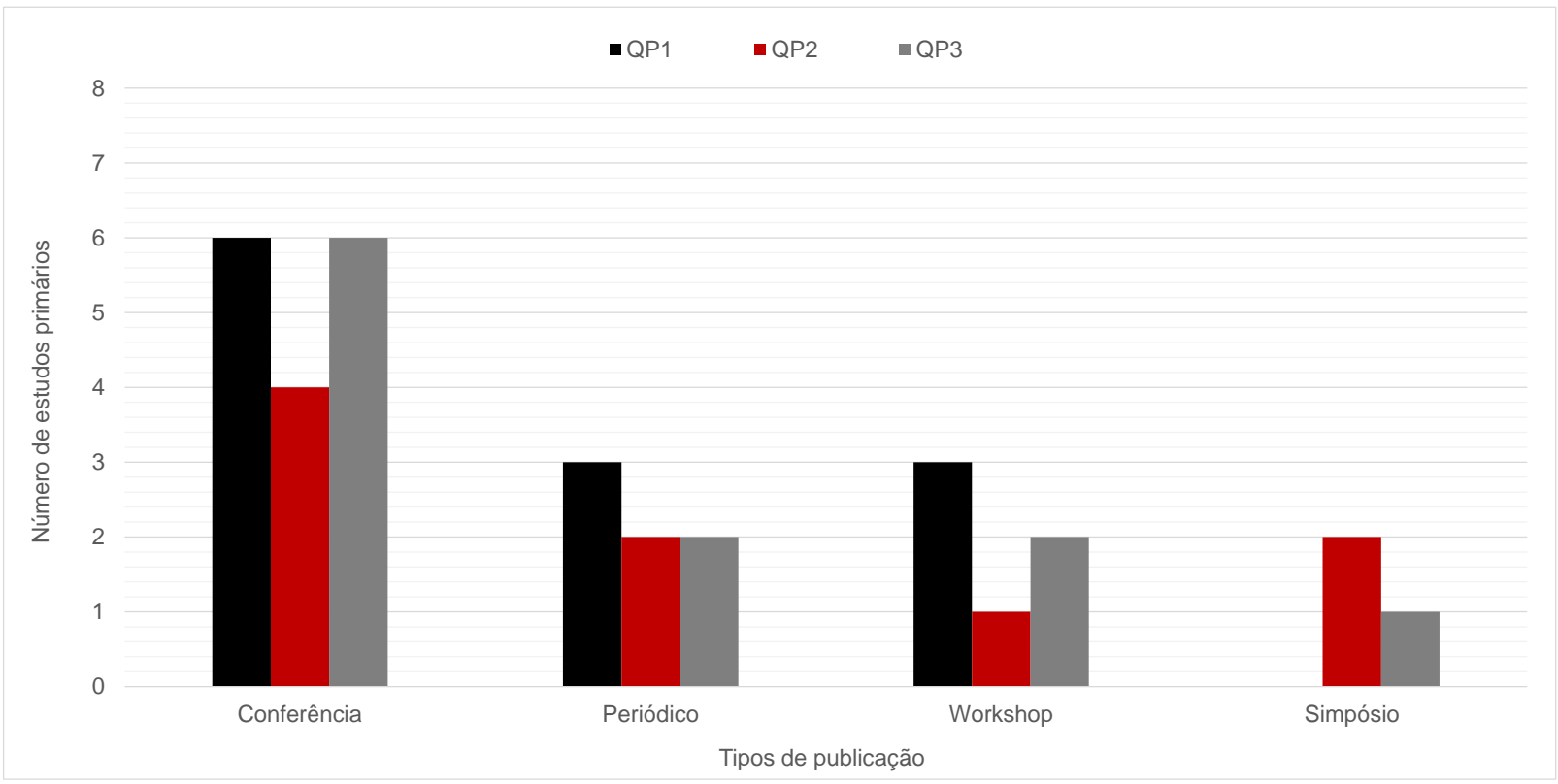

Fonte: Elaborada pelo autor.

É importante salientar que, considerando o contexto pesquisado, a aplicabilidade de ER, Projeto de Software e Teste de Software para o desenvolvimento de sistemas de RV, bem como a utilização de RV para essas áreas de ES somente começaram a ser investigadas a partir de 1998. Nesse período a quantidade de pesquisas variou significativamente; em 2002 nenhuma pesquisa 
foi realizada, enquanto que, nos últimos cinco anos foram realizadas somente sete pesquisas, evidenciando a necessidade de exploração da relação dessas áreas (Figura 44).

Figura 44 - Estudos primários publicados por ano de acordo com as QPs

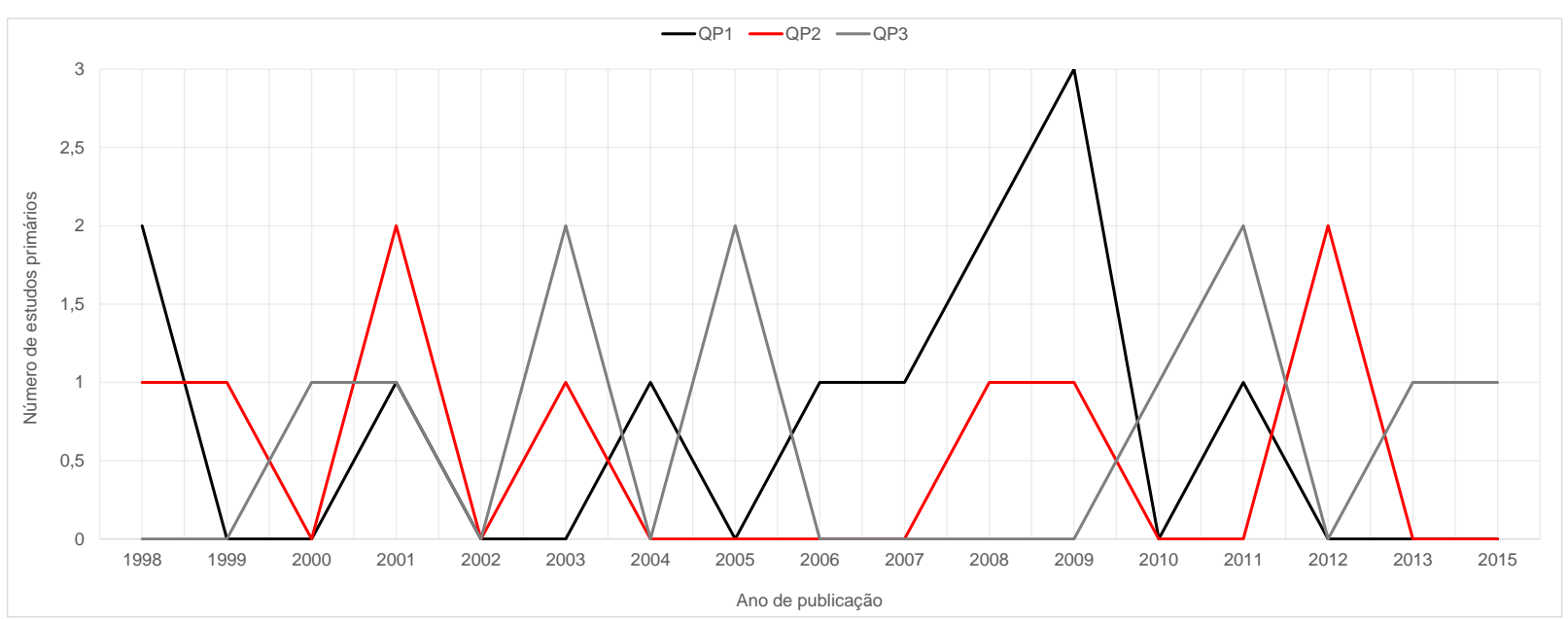

Fonte: Elaborada pelo autor.

Neste MS foram incluídos estudos de 17 países diferentes, conforme pode ser visto na Figura 45. A classificação dos países foi baseada no país de origem dos autores. Caso o estudo tenha diversos autores de países distintos, um ponto para cada país foi atribuído.

Figura 45 - Estudos primários por país de acordo com as QPs

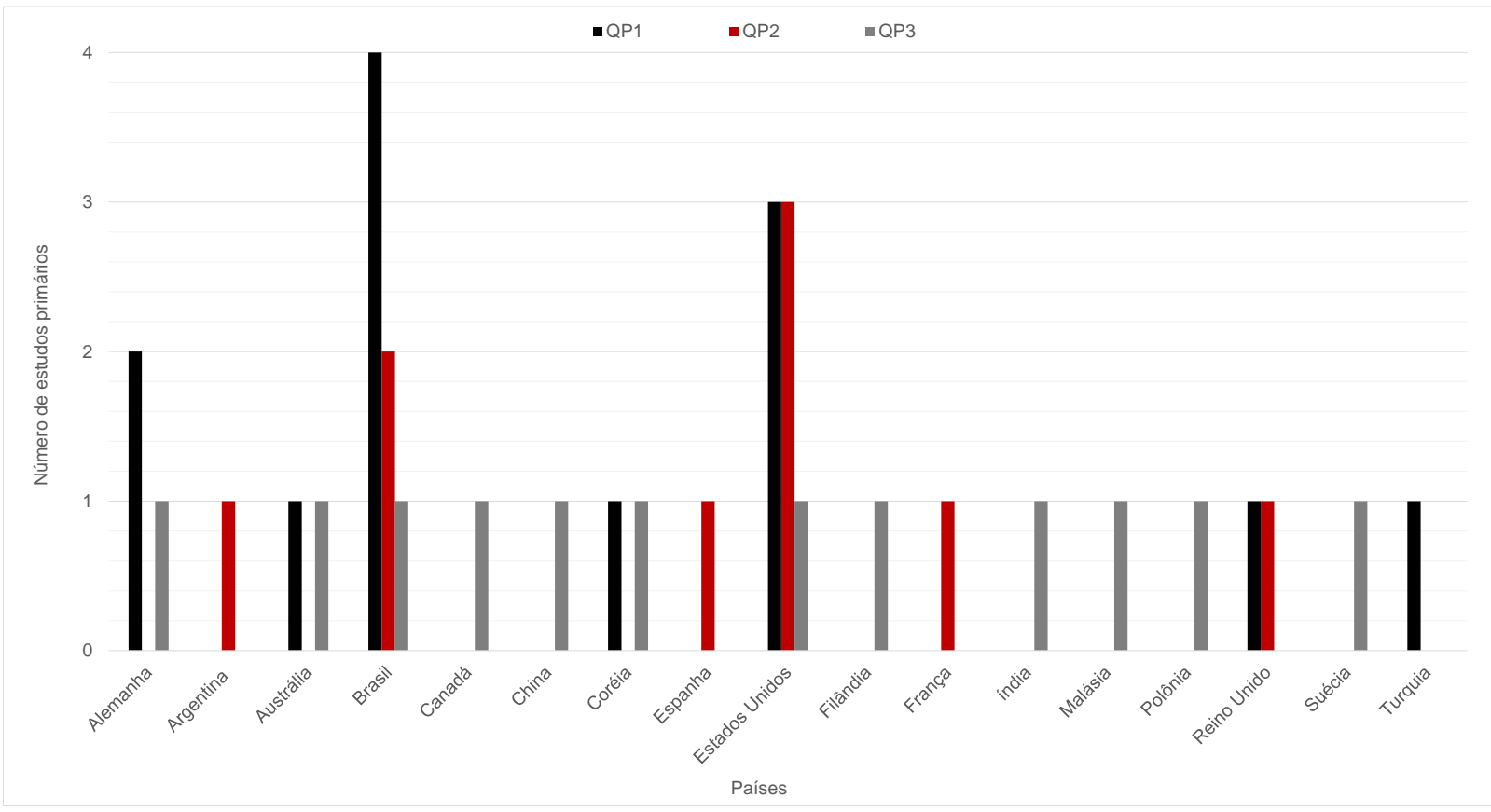

Fonte: Elaborada pelo autor.

Dos 17 países, os que mais têm realizado pesquisas nesta área são o Brasil com sete estudos ((VEGA; FUKS; CARVALHO, 2009), (KIRNER; MARTIN, 2007), (DAMASCENO; 
OLIVEIRA, 2009), (DAMASCENO; JR; LOPES, 2009), (KIRNER; MARTIN, 1999), (MATTIOLI et al., 2009) e (BEZERRA; DELAMARO; NUNES, 2011)) e os Estados Unidos também com sete estudos ((WINTER; DESOVSKI; CUKIC, 2001), (POLLOCK, 1998), (RUSSELL; CREIGHTON, 2011), (NEUBAUER; HARRIS, 2003), (TANRIVERDI; JACOB, 2001), (MALETIC et al., 2001) e (BIERBAUM; HARTLING; CRUZ-NEIRA, 2003)).

Adicionalmente, foi observada que a colaboração internacional entre os pesquisadores é pouco explorada, pois somente 2 estudos dos 32 tiveram a colaboração entre dois países, enquanto que 26 estudos tiveram colaborações de pesquisadores de um único país; e somente 4 estudos tinham somente um pesquisador envolvido. É importante ressaltar que o Brasil apresentou um significativo número de evidências em função da busca manual ter considerado conferências brasileiras, visto que, em uma análise exploratória anterior (busca automática) já haviam sido identificados estudos de interesse em conferências e periódicos relevantes. Os estudos primários incluídos em cada QP foram discutidos no Capítulo 4. 
APÊNDICE

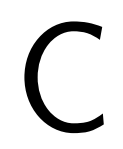

QUESTIONÁRIO APLICADO PARA AVALIAÇÃO DA BELARS 


\section{Evaluation Behavior based Language for Requirements Specification (BeLaRS)}

We are conducting this survey in order to get your evaluation about our proposed language for requirement specification of Virtual Reality applications.

Each question this survey must be evaluated according to the following criterias:

$1=$ Not a bit $\quad 2=$ A little bit $\quad 3=$ Moderately $\quad 4=$ Very $\quad 5=$ Extremely

The survey would not take more than 10 minutes of your valuable time.

Thank you for participating in the survey. Please be assured that your responses of the questions below will be kept confidential.

* Required

\section{User Information}

1. What is your education level? *

Check all that apply.

Undergraduate

Master's in progress

Master's completed

Doctorate in progress

Doctorate completed

Other:

2. What is your experience with Virtual Reality? *

Check all that apply.

None

$\square$ Novice

$\square$ Intermediate

$\square$ Expert

3. How long time do you have experience in Virtual Reality? *

Check all that apply.

$\square$ None
$\square \quad<=1$ year
$\square 2$ to 4 years
$\square 4$ to 6 years
$\square>6$ years




\section{Evaluation Questions}

Each question this survey must be evaluated according to the following criterias:

$$
1=\text { Not a bit } \quad 2=\text { A little bit } \quad 3=\text { Moderately } \quad 4=\text { Very } \quad 5=\text { Extremely }
$$

1. How clearly is defined and explained the BeLaRS purpose?*

Mark only one oval.

$\begin{array}{llllll}1 & 2 & 3 & 4 & 5 & \\ \text { Not a bit clearly } & \longrightarrow & & \end{array}$

2. How near is the BeLaRS to natural language? *

Mark only one oval.

Not a bit near $\square \longrightarrow \square$ Extremely near

3. How is the orthogonality of BeLaRS language? *

* Orthogonality: each construct in the language is used to represent exactly one distinct concept in the domain.

Mark only one oval.

$\begin{array}{llllll}1 & 2 & 3 & 4 & 5 & \\ \text { Not a bit orthogonal } & \square & & \end{array}$

4. How is the conformity of the BeLaRS language? *

* Confirmity: the language constructs must correspond to important domain concepts.

Mark only one oval.

Not a bit conformity $\square \longrightarrow \square_{\text {Extreme conformity }}$

5. How is the scalability of the BeLaRS language? *

* Scalability: the language provides constructs to help manage large-scale descriptions.

Mark only one oval.

$\begin{array}{llllll}1 & 2 & 3 & 4 & 5 & \\ \text { Not a bit scalable } & \square & & \end{array}$

6. How is the simplicity of BeLaRS language? *

* Simplicity: the language should be as simple as possible in order to express the concepts of interest and to support its users and stakeholders in their preferred ways of working.

Mark only one oval.

Not a bit simple $\square \longrightarrow{ }_{\text {Extremely simple }}^{1}$


7. How is the usability of the BeLaRS language? *

* Usability: includes requirements such as space economy, accessibility, understandability characteristics that are desirable, and which may be partly covered by the core requirements. Mark only one oval.

Not a bit useful $\square \longrightarrow \square$ Extremely useful

8. How useful the BeLaRS can be for users without technical expertise of Virtual Reality? * Mark only one oval.

$\begin{array}{lllll}1 & 2 & 3 & 4 & \\ \text { Not a bit useful } & \end{array}$

9. How clear, concise and informative are the rules presented in the document available? * Mark only one oval.

$\begin{array}{lllll}1 & 2 & 3 & 4 & 5\end{array}$

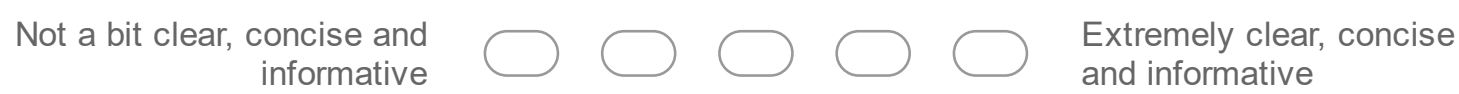

10. How easy is understanding of the BeLaRS rules? *

Mark only one oval.

Not a bit easy

11. How enough are the keywords defined to specify requirements of Virtual Reality applications?* Mark only one oval.

Not a bit enough

12. If in the previous question you have checked the option in which "the keywords are not a bit enough", then write down which keywords we should add in BeLaRS. 
13. How helpful are the items defined in Tables 1, 2, 3, 4, 5 and 6 for the requirements specification? *

Mark only one oval.

$\begin{array}{llllll}1 & 2 & 3 & 4 & 5 & \\ \text { Not a bit helpful } & \square & \square & \square & & \end{array}$

14. How useful are the control structures to specify alternative paths? * Mark only one oval.

$\begin{array}{lllll}1 & 2 & 3 & 4 & 5 \\ \text { Not a bit useful } & \square & \end{array}$

15. How helpful was the BeLaRS for requirements specification of Virtual Reality applications? * Mark only one oval.

$\begin{array}{llllll}1 & 2 & 3 & 4 & 5 & \\ \text { Not a bit helpful } & \square & \square & \square & \end{array}$

16. How easy was to writen the requirements using BeLaRS? * Mark only one oval.

$\begin{array}{llllll}1 & 2 & 3 & 4 & 5 & \\ \text { Not a bit easy } \square & \square & & \end{array}$

17. How useful was the rules provided to use of the BeLaRS?* Mark only one oval.

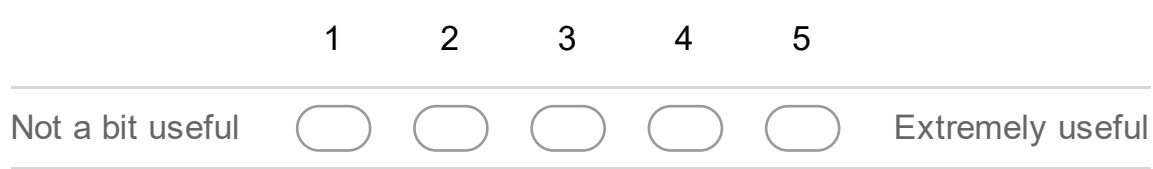

18. How quick was the requirements specification using the BeLaRS? * Mark only one oval.

Not a bit quick $\square \longrightarrow \square$ Extremely quick

19. What suggestions do you have regarding the BeLaRS? 
20. What other suggestions do you have? 
APÊNDICE

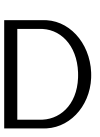

EXPLICAÇÕES E EXEMPLOS DAS REGRAS DA BELARS DISPONIBILIZADAS AOS ESTUDANTES 


\section{Requirements Specification for Virtual Reality Applications}

Este estudo de caso faz parte de uma tese de doutorado que visa a realizar testes funcionais para aplicações de Realidade Virtual (RV) usando Grafo de Cena (GC) a partir das especificações de requisitos. Os principais aspectos que podem ser representados na estrutura do GC são: geometria, aparência, transformação, comportamento, iluminação, som e câmera.

Nós desenvolvemos uma linguagem chamada Behavior based Language for Requirement Specification (BeLaRS), a fim de padronizar a especificação de requisitos para facilitar a realização dos testes funcionais. A BeLaRS é baseada na especificação usando caso de uso e Behavior Drive Development (BDD).

O objetivo desse estudo de caso é avaliar a usabilidade, simplicidade, conformidade, escalabilidade e ortogonalidade da linguagem proposta, por meio de uma especificação de requisitos para uma aplicação gerada pelo Framework Virtual Medical Training (ViMeT) que visa a simular exames de biópsia (ver Figura 1). Assim, para condução desse estudo de caso as seguintes atividades deverão ser realizadas:

1. Analisar este documento para ver um exemplo de uma especificação de requisitos usando a BeLaRS;

2. Consultar neste documento as regras, as palavras-chaves e a explicação do uso da BeLaRS para o exemplo descrito a seguir, a fim de ajudar a especificação de requisitos que será realizada para a Figura 1;

3. Preencher o horário de início (seção 1) e término (seção 5) conforme apresentado no exemplo;

4. Realizar a especificação de requisitos para aplicação gerada pelo ViMeT no formulário disponibilizado no link (http://goo.gl/forms/Guv9PkaJwR) e submetê-la;

5. Preencher o questionário disponibilizado no link (http://goo.gl/forms/x7X0ao2Nux) para avaliar a BeLaRS.

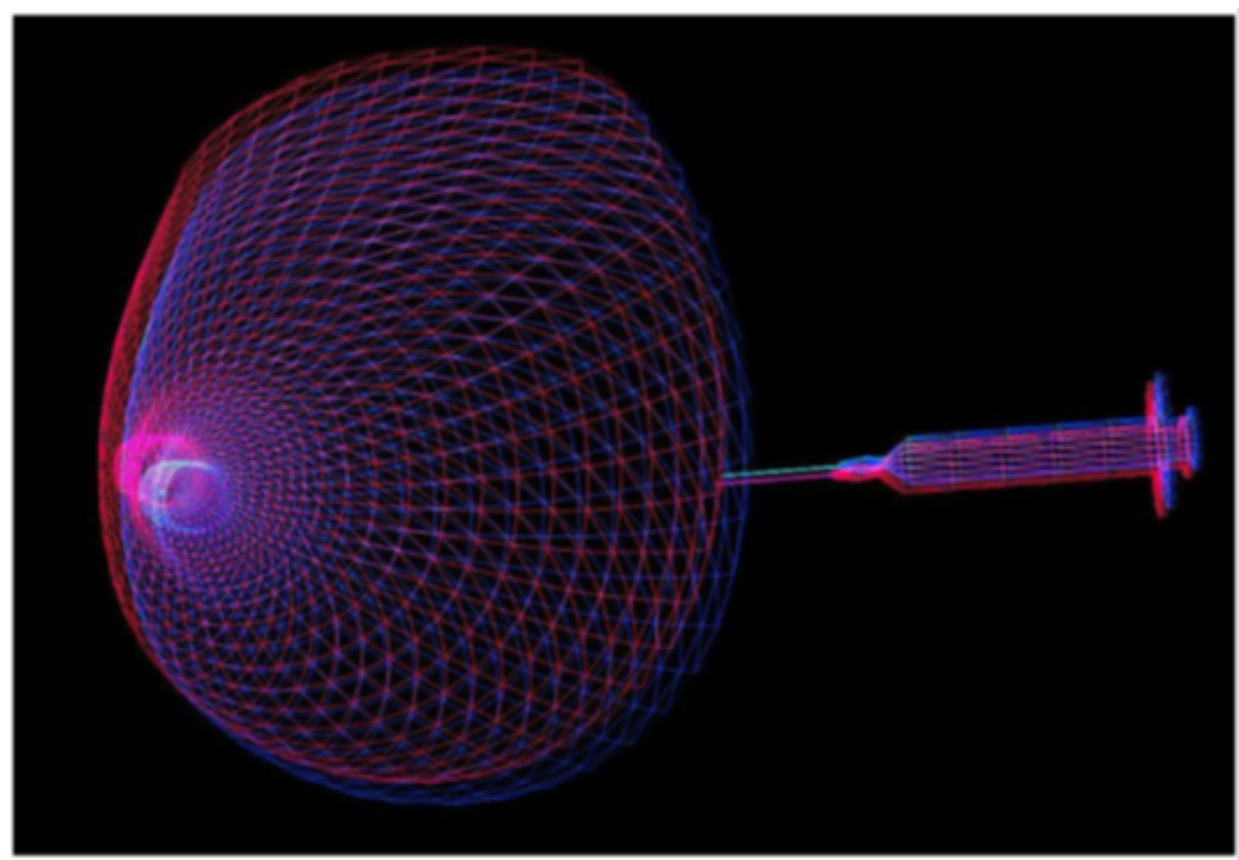

Figura 1. Aplicação gerada pelo ViMeT 


\title{
Requirements Specification for Virtual Reality Applications
}

A seguir será apresentado um exemplo que foi especificado utilizando a BeLaRS. Ao longo do exemplo serão apresentadas as regras e a explicação sobre o uso da BeLaRS.

\begin{abstract}
Exemplo: Acertar a bola com o bastão
O ambiente virtual tem cor azul e luz ambiente. O ambiente virtual é composto por dois objetos: bola e bastão. A bola é representada pela esfera com dimensões $(1.0,4,5)$. O bastão é representado pelo cilindro. A bola tem cor amarela e o bastão cor marrom. A bola está no canto inferior direito e o bastão está localizado no canto superior esquerdo do ambiente virtual.

O usuário deve selecionar o bastão usando o mouse. Enquanto o usuário não selecionar o bastão, o sistema deve apresentar uma mensagem indicando que o usuário deve selecionar bastão. Em seguida, o bastão deve ser movimentado pelo usuário até a bola. Se o bastão não for movimentado pelo usuário até a bola, o sistema deve apresentar uma mensagem indicando que o usuário deve movimentar o bastão. Senão, se o bastão for movimentado, então a bola deve mudar a cor para branca e o usuário deve ir para o próximo passo. Depois, o usuário deve rotacionar o bastão. Em seguida, o usuário deve acertar o bastão na bola e finalmente a bola deve ser trasladada pelo sistema.
\end{abstract}

A especificação do exemplo usando a BeLaRS é apresentada e explicada a seguir. A especificação é dividida em duas etapas: Virtual Environment Descriptions (VED) e Interaction Descriptions (IND) apresentadas nas seções 3 e 4 respectivamente.

\section{Initial Time}

Primeiramente deve ser inserida a hora em que a especificação está sendo iniciada.

Please, fill out the time that the requirement specification is starting up

10:05

Example: 11:00 AM

\section{General Descriptions}

Em seguida, deve ser inserida as descrições gerais sobre a aplicação que será especificada.

Application Name:

Baseball game

Scenario Number:

01

Scenario Description:

Acertar a bola com o bastão 


\section{Virtual Environment Descriptions (VED)}

Consiste na especificação das características do ambiente virtual (luz, som, aparência e definição dos objetos) e das características dos objetos (luz, som, aparência, geometria).

- Tabela 1 são apresentadas as palavras-chaves para descrição do Ambiente Virtual;

- Tabela 2 são apresentadas como as palavras-chaves foram utilizadas para a especificação de requisitos do exemplo usando BeLaRS (coluna 2);

- Palavra que estiver sublinhada é opcional.

- Os nomes dos objetos devem iniciar com letra maiúscula.

\section{Tabela 1. Palavras-chaves do VED}

\begin{tabular}{|c|c|c|}
\hline $\begin{array}{l}\text { REQUIREMENTS } \\
\text { COMPOSITION }\end{array}$ & ITEMS & KEYWORDS \\
\hline \multirow[b]{2}{*}{ Subject } & VE & Virtual environment \\
\hline & object name & $\begin{array}{l}\text { Objects names that compose the virtual environment ( start with upper } \\
\text { case) }\end{array}$ \\
\hline \multirow[b]{2}{*}{ Verb } & $\begin{array}{l}\text { geometry object } \\
\text { description / object } \\
\text { position }\end{array}$ & is, are \\
\hline & $\begin{array}{c}\text { virtual environment } \\
\text { description / } \\
\text { objects definitions / } \\
\text { appearance object }\end{array}$ & has, have \\
\hline \multirow{8}{*}{ Predicate } & geometry & $\begin{array}{l}\text { (Point, line, vector, vertex, polygon, triangle, sphere, cone, cube, cylinder, } \\
\text { box, curves, surfaces) parameter }\end{array}$ \\
\hline & position & $\begin{array}{l}\text { (upper right corner, upper left corner, lower right corner, lower left corner, } \\
\text { inside left, inside right, centre, right side, left side, underside, upper, top } \\
\text { center, bottom center) parameter }\end{array}$ \\
\hline & appearance & (Color name color, transparency, texture or brightness) parameter \\
\hline & color_name & $\begin{array}{l}\text { white, black, red, blue, yellow, green, orange, purple, pink, gray, silver, } \\
\text { brown, gold, lime, violet, magenta, beige }\end{array}$ \\
\hline & light & (ambient, directional, reflective or punctual) light \\
\hline & sound & (background, point, soundscape) sound \\
\hline & object name & Objects names in the Virtual environment ( start with upper case) \\
\hline & parameter & $(\mathrm{x}, \mathrm{x}, \mathrm{x} . \mathrm{x})-\mathrm{x}$ is a digit. Can be an int or a float \\
\hline
\end{tabular}

\section{Tabela 2. Explicação do uso das Palavras-chaves no VED}

\begin{tabular}{|c|c|c|}
\hline $\begin{array}{l}\text { Requirements of the } \\
\text { Scenario Example }\end{array}$ & $\begin{array}{c}\text { Requirements specified by } \\
\text { BeLaRS }\end{array}$ & Items \\
\hline $\begin{array}{l}\text { 1. O ambiente virtual tem cor } \\
\text { azul e luz ambiente. }\end{array}$ & $\begin{array}{l}\text { 1.Virtual environment has blue } \\
\text { color, ambient light }\end{array}$ & $\begin{array}{l}- \text { VE }+ \text { virtual environment description + } \\
\text { color_name }+ \text { appearance + light }\end{array}$ \\
\hline $\begin{array}{l}\text { 2. O ambiente virtual é } \\
\text { composto por dois objetos: bola } \\
\text { e bastão. }\end{array}$ & $\begin{array}{l}\text { 2. Virtual environment has Ball, } \\
\text { Bat }\end{array}$ & - VE + objects definitions + object name \\
\hline $\begin{array}{l}\text { 3. A bola é representada pela } \\
\text { esfera com dimensões }(1.0 \text {, } \\
4,5) \text {. }\end{array}$ & 3. Ball is sphere $(1.0,45)$ & $\begin{array}{l}- \text { Object name }+ \text { geometry object } \\
\text { description }+ \text { geometry }+ \text { parameter }\end{array}$ \\
\hline $\begin{array}{l}\text { 4. O bastão é representado pelo } \\
\text { cilindro. }\end{array}$ & 4. Bat is cylinder. & $\begin{array}{lrl}- & \text { Object name }+ & \text { geometry object } \\
\text { description }+ \text { geometry } & & \end{array}$ \\
\hline 5. A bola tem cor amarela & 5. Ball has yellow color & - Object name + appearance object + \\
\hline 6. O bastão tem cor marrom. & 6. Bat has brown color & color name + appearance \\
\hline $\begin{array}{l}\text { 7. A bola está no canto inferior } \\
\text { direito do ambiente virtual. }\end{array}$ & 7. Ball is lower right corner & - Object name + object position + \\
\hline $\begin{array}{l}\text { 8. O bastão está localizado no } \\
\text { canto superior esquerdo. }\end{array}$ & 8. Bat is upper left corner & position \\
\hline
\end{tabular}




\section{Interaction Description (IND)}

Consiste nas ações realizadas pelo usuário e nas respostas do sistema mediante a essas ações. A descrição das interações é composta pelo Main Path e o Alternative Path.

- Tabela 3 são apresentadas as palavras-chaves para descrição do Main Path;

- Tabela 4 são apresentadas como as palavras-chaves foram utilizadas para a especificação de requisitos do exemplo no Main Path usando BeLaRS (coluna 2);

- Tabela 5 são apresentadas as palavras-chaves para descrição do Alternative Path;

- Tabela 6 são apresentadas como as palavras-chaves foram utilizadas para a especificação de requisitos do exemplo no Alternative Path (coluna 2);

- Palavras que estiverem sublinhadas são opcionais.

- Os nomes dos objetos devem iniciar com letra maiúscula.

\section{Main Path}

Representa o fluxo normal das interações, ou seja, todas as ações que devem ser realizadas no Ambiente Virtual.

- Os requisitos que possuírem um Alternative Path são indicados por meio de dígitos (por exemplo, 1.1).

- O mesmo requisito pode ter mais de um Alternative Path.

Tabela 3. Palavras-chaves Main Path

\begin{tabular}{|c|c|c|}
\hline $\begin{array}{l}\text { REQUIREMENTS } \\
\text { COMPOSITION }\end{array}$ & ITEMS & KEYWORDS \\
\hline \multirow{2}{*}{ Subject } & user & User, user \\
\hline & entity & Application, System, application, system \\
\hline \multirow[t]{2}{*}{ Verb } & should + behavior & $\begin{array}{l}\text { select, click, insert, move, move up, move down, move right, move left, } \\
\text { move out, move into, move diagonal, pick, drop, deform, detect collision, } \\
\text { navigate, manipulate, release, open, hit, close, change, make, do, go }\end{array}$ \\
\hline & should + transformation & rotate, translate, scale \\
\hline \multirow{7}{*}{ Predicate } & appearance & (color name color, transparency, texture or brightness) parameter \\
\hline & color_name & $\begin{array}{l}\text { white, black, red, blue, yellow, green, orange, purple, pink, gray, silver, } \\
\text { brown, gold, lime, violet, magenta, beige }\end{array}$ \\
\hline & restriction & preposition + device, preposition + object name, preposition + color name \\
\hline & preposition & by, in, until, into, to, for, on the \\
\hline & device & gloves, head mounted displays, HMD, joystick, haptic, mouse, keyboard \\
\hline & object name & start with upper case \\
\hline & parameter & $(\mathrm{x}, \mathrm{x}, \mathrm{x} . \mathrm{x})-\mathrm{x}$ is a digit and can be a int or float \\
\hline Alternative Path & alternative path & $(x . x)-x$ is a digit \\
\hline
\end{tabular}

\section{Tabela 4. Explicação do uso das palavras-chaves no Main Path}

\begin{tabular}{|c|c|c|}
\hline $\begin{array}{l}\text { Requirements of the } \\
\text { Scenario Example }\end{array}$ & $\begin{array}{c}\text { Requirements specified by } \\
\text { BeLaRS }\end{array}$ & Items \\
\hline $\begin{array}{l}\text { 1. O usuário deve selecionar o } \\
\text { bastão usando o mouse. }\end{array}$ & $\begin{array}{l}\text { 1. User should select Bat by } \\
\text { mouse (1.1) }\end{array}$ & $\begin{array}{l}\text { - User + should behavior }+ \text { object name }+ \\
\text { preposition }+ \text { device }+ \text { alternative path }\end{array}$ \\
\hline $\begin{array}{l}\text { 2. Em seguida, o bastão deve } \\
\text { ser movimentado pelo usuário } \\
\text { até a bola. }\end{array}$ & $\begin{array}{l}\text { 2. User should move Bat until } \\
\text { Ball } \underline{(2.1,2.2)}\end{array}$ & $\begin{array}{l}\text { - User + should behavior + object name + } \\
\text { preposition }+ \text { object name }+ \text { alternative path }\end{array}$ \\
\hline $\begin{array}{l}\text { 3. Depois, o usuário deve } \\
\text { rotacionar o bastão. }\end{array}$ & 3. User should rotate Bat & $\begin{array}{l}\text { - User + should transformation + object } \\
\text { name }\end{array}$ \\
\hline $\begin{array}{l}\text { 4. Em seguida, o usuário deve } \\
\text { acertar o bastão na bola. }\end{array}$ & $\begin{array}{l}\text { 4. User should hit Bat on the } \\
\text { Ball }\end{array}$ & $\begin{array}{l}\text { - User + should behavior + object name + } \\
\text { preposition + object name }\end{array}$ \\
\hline $\begin{array}{l}\text { 5. Finalmente a bola deve ser } \\
\text { trasladada pelo Sistema. }\end{array}$ & 5. System should translate Ball & - System + should behavior + object name \\
\hline
\end{tabular}




\section{Alternative Path}

Representam fluxos condicionais que podem acontecer para um determinado requisito apresentado no Main Path.

- No Alternative Path são utilizadas as seguintes estruturas de controle:If/Else, While, For, Switch (Case).

- Para cada estrutura de controle existem instruções a serem seguidas que também são representadas por dígitos (por exemplo,1.1.1).

\section{Tabela 5. Palavras-chaves Alternative Path}

\begin{tabular}{|c|c|c|}
\hline $\begin{array}{l}\text { REQUIREMENTS } \\
\text { COMPOSITION }\end{array}$ & ITEMS & KEYWORDS \\
\hline $\begin{array}{l}\text { Control } \\
\text { Structures }\end{array}$ & cs & If/Else, While For, Switch (Case) \\
\hline \multirow{2}{*}{ Paths } & alternative path & $(\mathrm{x} . \mathrm{x})-\mathrm{x}$ is a digit \\
\hline & path & $(\mathrm{X} . \mathrm{X} . \mathrm{X})-\mathrm{X}$ is a digit \\
\hline \multirow{2}{*}{ Subject } & user & User, user \\
\hline & entity & Application, System, application, system \\
\hline \multirow[t]{2}{*}{ Verb } & not + behavior & $\begin{array}{l}\text { selects, clicks, inserts, moves, moves up, moves down, moves right, } \\
\text { moves left, moves out, moves into, moves diagonal, picks, drops, } \\
\text { deforms, detects collision, navigates, manipulates, releases, opens, hits, } \\
\text { closes, changes, makes, does, shows, presents, goes }\end{array}$ \\
\hline & not + transformation & rotates, translates, scales \\
\hline \multirow{7}{*}{ Predicate } & restriction & preposition + device, preposition + object name, preposition + color name \\
\hline & object name & start with upper case \\
\hline & appearance & (color name color, transparency, texture or brightness) parameter \\
\hline & color_name & $\begin{array}{l}\text { white, black, red, blue, yellow, green, orange, purple, pink, gray, silver, } \\
\text { brown, gold, lime, violet, magenta, beige }\end{array}$ \\
\hline & preposition & by, in, until, into, to, for, on the \\
\hline & device & gloves, head mounted displays, HMD, joysticks, haptics, mouse, keyboard \\
\hline & complement & text free \\
\hline
\end{tabular}

\section{Tabela 6. Explicação do uso das palavras-chaves no Alternative Path}

\begin{tabular}{|c|c|c|}
\hline $\begin{array}{l}\text { Requirements of the Scenario } \\
\text { Example }\end{array}$ & $\begin{array}{c}\text { Requirements specified by } \\
\text { BeLaRS }\end{array}$ & Items \\
\hline $\begin{array}{l}\text { 1.1Enquanto } 0 \text { usuário não } \\
\text { selecionar o bastão, }\end{array}$ & $\begin{array}{l}1.1 \text { While user not selects } \\
\text { Bat by mouse, }\end{array}$ & $\begin{array}{l}\text { - alternative path }+ \text { structures }+ \text { user }+ \text { not } \\
\text { behavior }+ \text { object name }+ \text { preposition }+ \text { device }\end{array}$ \\
\hline $\begin{array}{l}1.1 .1 \quad 0 \quad \text { sistema r deve } \\
\text { apresentar uma mensagem } \\
\text { indicando que } 0 \text { usuário deve } \\
\text { selecionar bastão. }\end{array}$ & $\begin{array}{l}\text { 1.1.1 System shows } \\
\text { message "User should select } \\
\text { Bat". }\end{array}$ & - path + system + behavior + complemtent \\
\hline $\begin{array}{l}2.1 \text { Se o bastão não for } \\
\text { movimentado pelo usuário até a } \\
\text { bola, }\end{array}$ & $\begin{array}{l}2.1 \text { If user not moves Bat } \\
\text { until Ball, }\end{array}$ & $\begin{array}{l}\text { - alternative path }+ \text { structures }+ \text { user }+ \text { not } \\
\text { behavior }+ \text { object name }+ \text { preposition }+ \text { object } \\
\text { name }\end{array}$ \\
\hline \begin{tabular}{l}
\multicolumn{1}{c}{$2.1 .1 \quad 0 \quad$ sistema $r$ deve } \\
apresentar uma mensagem \\
indicando que 0 usuário deve \\
movimentar o bastão.
\end{tabular} & $\begin{array}{l}2.1 .1 \text { System presents } \\
\text { message User should moves } \\
\text { Bat. }\end{array}$ & - path + system + behavior + complemtent \\
\hline $\begin{array}{l}\text { 2.2. Senão, se o bastão for } \\
\text { movimentado, então a bola deve } \\
\text { mudar a cor para branco, }\end{array}$ & $\begin{array}{l}2.2 \text { Else system changes } \\
\text { color Ball for white, }\end{array}$ & $\begin{array}{l}\text { - alternative path }+ \text { structures }+ \text { system + } \\
\text { behavior }+ \text { appearance }+ \text { object name }+ \\
\text { preposition }+ \text { color name }\end{array}$ \\
\hline $\begin{array}{l}2.2 .1 \mathrm{O} \text { usuário deve ir para o } \\
\text { próximo passo. }\end{array}$ & 2.2.1 User goes to step 3 . & - path + user + behavior + complemtent \\
\hline
\end{tabular}

\section{Final Time}

Finalmente deve ser inserida a hora em que a especificação foi finalizada.

\section{Please, fill out the time that the requirement specification is finished}

$10: 35$

Example: 11:00 AM 